\title{
What are
E-ssential skills?
}

A multimethod approach to 21st-century digital skills within the creative industries

Ester van Laar 


\section{What are E-ssential skills?}

A multimethod approach to 21st-century digital skills within the creative industries 
What are E-ssential skills?

A multimethod approach to 21st-century digital skills within the creative industries

\section{DISSERTATION}

to obtain

the degree of doctor at the University of Twente, on the authority of the rector magnificus, prof. dr. T. T. M. Palstra,

on account of the decision of the graduation committee to be publicly defended

on Friday November 1, 2019, at 12:45

Cover design: Roy Ensink

Printed by: Ipskamp Printing, proefschriften.net

Lay-out: Anouk Westerdijk, persoonlijkproefschrift.n

ISBN: $\quad$ 978-90-365-4867-0

DOI: $\quad 10.3990 / 1.9789036548670$

(C) 2019 Ester van Laar, The Netherlands.

All rights reserved. No parts of this thesis may be reproduced, stored in a retrieval system or transmitted in any form or by any means without permission of the author. by Ester van Laar

born on September 11, 1993

in Apeldoorn, the Netherlands 
This dissertation has been approved by:

Promotor: Prof. dr. ing. A. J. A. M. van Deursen

Promotor: Prof. dr. J. A. G. M. van Dijk

Co-promotor: Prof. dr. J. de Haan
Graduation Committee

Chairman: Prof. dr. T. A. J. Toonen

Promotors: $\quad$ Prof. dr. ing. A. J. A. M. van Deursen Prof. dr. J. A. G. M. van Dijk

Co-promotor: Prof. dr. J. de Haan

Members:

Prof. dr. L. d'Haenens

Prof. dr. J. M. Voogt

Prof. dr. T. Bondarouk

Prof. dr. A. J. M. de Jong 


\section{TABLE OF CONTENTS}

\begin{tabular}{|c|c|c|}
\hline \multirow[t]{9}{*}{ Chapter 1.} & General introduction & 11 \\
\hline & 1.1 Introducing 21 st-century digital skills & 12 \\
\hline & 1.2 Changing nature of work in the digital era & 15 \\
\hline & 1.3 Digital skills as key assets of human capital & 17 \\
\hline & 1.4 Problem definition and research objectives & 19 \\
\hline & 1.5 The creative industries as a case study & 20 \\
\hline & 1.6 Research questions & 21 \\
\hline & 1.7 Research approach and methods & 24 \\
\hline & 1.8 Research outline & 27 \\
\hline \multirow[t]{9}{*}{ Chapter 2.} & $\begin{array}{l}\text { The relation between } 21 \text { st-century skills and digital skills: A } \\
\text { systematic literature review }\end{array}$ & 31 \\
\hline & 2.1 Introduction & 32 \\
\hline & 2.2 Theoretical background & 33 \\
\hline & 2.3 Method & 36 \\
\hline & 2.4 Results & 40 \\
\hline & 2.5 Discussion & 48 \\
\hline & 2.6 Conclusion & 51 \\
\hline & Appendix 2.A References included studies & 53 \\
\hline & $\begin{array}{l}\text { Appendix } 2 . B \text { Included studies with skill dimensions and main } \\
\text { concept }\end{array}$ & 59 \\
\hline \multirow[t]{8}{*}{ Chapter 3.} & $\begin{array}{l}\text { 21st-century digital skills for the creative industries workforce: } \\
\text { Perspectives from industry experts }\end{array}$ & 65 \\
\hline & 3.1 Introduction & 66 \\
\hline & $\begin{array}{l}\text { 3.2 Theoretical background: } 21 \text { st-century digital skills within the } \\
\text { creative industries }\end{array}$ & 67 \\
\hline & 3.3 Method & 69 \\
\hline & 3.4 Results & 72 \\
\hline & 3.5 Discussion & 77 \\
\hline & 3.6 Conclusion & 80 \\
\hline & Appendix 3.A Interview and coding scheme & 82 \\
\hline
\end{tabular}




\begin{tabular}{|c|c|c|}
\hline \multirow[t]{9}{*}{ Chapter 4.} & $\begin{array}{l}21 \text { st-century digital skills instrument aimed at working } \\
\text { professionals: Conceptual development and empirical } \\
\text { validation }\end{array}$ & 93 \\
\hline & 4.1 Introduction & 94 \\
\hline & 4.2 Initial instrument development & 95 \\
\hline & 4.3 Pilot survey results & 100 \\
\hline & 4.4 Full survey results & 102 \\
\hline & 4.5 Discussion & 109 \\
\hline & 4.6 Conclusion & 111 \\
\hline & Appendix 4.A Items per skill after the cognitive interviews & 113 \\
\hline & Appendix 4.B Items per skill after the pilot test & 119 \\
\hline \multirow[t]{6}{*}{ Chapter 5.} & $\begin{array}{l}\text { The sequential and conditional nature of } 21 \text { st-century digital } \\
\text { skills }\end{array}$ & 125 \\
\hline & $\begin{array}{l}5.1 \text { Theoretical framework: relations among } 21 \text { st-century digital } \\
\text { skills }\end{array}$ & 126 \\
\hline & 5.2 Method & 132 \\
\hline & 5.3 Results & 138 \\
\hline & 5.4 Discussion & 143 \\
\hline & 5.5 Conclusion & 145 \\
\hline \multirow[t]{10}{*}{ Chapter 6.} & $\begin{array}{l}\text { Determinants of } 21 \text { st-century skills and digital skills for } \\
\text { workers: A systematic literature review }\end{array}$ & 147 \\
\hline & 6.1 Introduction & 148 \\
\hline & 6.2 Theoretical background & 148 \\
\hline & 6.3 Method & 154 \\
\hline & 6.4 Results & 157 \\
\hline & 6.5 Discussion & 163 \\
\hline & Appendix 6.A References included studies & 168 \\
\hline & Appendix 6.B Significant individual determinants categorized & 180 \\
\hline & Appendix 6.C Significant determinants of 21st-century skills & 183 \\
\hline & $\begin{array}{l}\text { Appendix 6.D Significant determinants of } 21 \text { st-century digital } \\
\text { skills }\end{array}$ & 189 \\
\hline \multirow[t]{3}{*}{ Chapter 7.} & $\begin{array}{l}\text { Determinants of } 21 \text { st-century digital skill levels: A large-scale } \\
\text { survey among working professionals }\end{array}$ & 195 \\
\hline & 7.1 Introduction & 196 \\
\hline & $\begin{array}{l}7.2 \text { Theoretical framework: determinants of } 21 \text { st-century digital } \\
\text { skills }\end{array}$ & 197 \\
\hline
\end{tabular}

\begin{tabular}{|c|c|c|}
\hline & 7.3 Method & 201 \\
\hline & 7.4 Results & 203 \\
\hline & 7.5 Discussion & 209 \\
\hline & 7.6 Conclusion & 212 \\
\hline & Appendix 7.A The 21 st-century digital skills measures & 213 \\
\hline & Appendix 7.B The independent measures & 217 \\
\hline \multirow[t]{9}{*}{ Chapter 8.} & $\begin{array}{l}\text { Measuring the levels of } 21 \text { st-century digital skills among } \\
\text { working professionals: A performance-based approach }\end{array}$ & 221 \\
\hline & 8.1 Introduction & 222 \\
\hline & 8.2 Theoretical background & 223 \\
\hline & 8.3 Method & 228 \\
\hline & 8.4 Results & 231 \\
\hline & 8.5 Discussion & 236 \\
\hline & 8.6 Conclusion & 239 \\
\hline & Appendix 8.A Assignments & 241 \\
\hline & Appendix 8.B Coding scheme & 244 \\
\hline \multirow[t]{7}{*}{ Chapter 9.} & $\begin{array}{l}\text { Developing policy aimed at } 21 \text { st-century digital skills for the } \\
\text { creative industries: An interview study with managing directors }\end{array}$ & 247 \\
\hline & 9.1 Introduction & 248 \\
\hline & 9.2 Method & 249 \\
\hline & 9.3 Results & 252 \\
\hline & 9.4 Discussion & 265 \\
\hline & 9.5 Conclusion & 271 \\
\hline & Appendix 9.A Interview and coding scheme & 272 \\
\hline \multirow[t]{9}{*}{ Chapter 10.} & General discussion & 279 \\
\hline & 10.1 Main findings & 280 \\
\hline & 10.2 Theoretical and methodological implications & 291 \\
\hline & 10.3 Practical implications & 294 \\
\hline & 10.4 Limitations and future research directions & 298 \\
\hline & References & 303 \\
\hline & Summary & 335 \\
\hline & Samenvatting (Summary in Dutch) & 341 \\
\hline & Dankwoord (Acknowledgement in Dutch) & 349 \\
\hline
\end{tabular}




\section{CHAPTER 1}

\section{GENERAL INTRODUCTION}

Advances in automation and information and communication technology (ICT) have increased the need to understand which skills are necessary for a global competitive workforce. The Organisation for Economic Co-operation and Development (OECD) (2017) considers it imperative to ensure that all workers are "equipped with the right type of skills to successfully navigate through an ever-changing, technology-rich work environment, and give all workers the opportunity to continuously maintain their skills, upskill and/or reskill throughout their working lives" (p. 2). The digitalization of the economy has changed the skills needed by workers; thus, the crucial question is as follows: what are the skills they must acquire? The concern is that people will enter the workforce without the skills that are most valued by employers. 


\subsection{INTRODUCING 21ST-CENTURY DIGITAL SKILLS}

The concept of '21st-century skills' has become popular in the development of education-related policy; it is a term that has been used to indicate a set of skills that workers need to develop to be prepared for and succeed in the labor market (Greiff, Niepel, \& Wüstenberg, 2015; Griffin \& Care, 2012). The educational system is expected to provide students with the skill requirements of the labor market (Fonesca, 2010). Nevertheless, there is a comprehensive concern regarding the 'skills mismatch' between education and work (Dede, 2010; Soulé \& Warrick, 2015). Furthermore, the adaptability and employability of the existing workforce have become an important issue. The research highlights the desirability of maintaining and improving the skills of existing employees rather than relying on the skills provided by younger people entering the workforce (Davies, Hanley, Jenkins, \& Chan, 2017; Midtsundstad, 2019). Continued training and development is considered to be a main pathway to update the skills of the workforce.

The notion of 21st-century skills, specifically, those skills that are recognized as prerequisites for success in the workplace, has been widely discussed in both the academic and practitioner literature. The concept of 21st-century skills is one that has drawn broad attention to emphasize the skills needed to integrate, synthesize and creatively apply content knowledge in novel situations (Binkley et al., 2012; Selwyn, 2015). Since the early 2000s, a number of initiatives have proposed and outlined frameworks for 21 st-century skills. One of the earliest examples is the Metiri group's enGauge 21st Century Skills Framework (2003). This framework identifies the following four skills areas that students need to survive and thrive in a rapidly changing digital world: digital-age literacy, inventive thinking, effective communication, and high productivity. Another and better known example is the Partnership for 21st Century Skills (P21) (2007), initiated by a consortium of business leaders, educators and policy makers. They categorize these skills as follows: learning skills (creativity and innovation; critical thinking and problem solving; communication and collaboration), literacy skills (information literacy; media literacy; ICT literacy) and life skills (flexibility and adaptability; initiative and self-direction; social and cross-cultural skills; productivity and accountability; leadership and responsibility). Similarly, the Assessment and Teaching of 21st Century Skills project (ATC21S) (2012) is an example of an international, multistakeholder partnership among academics, governments and industry members (Binkley et al., 2012). The stated goal of this international collaboration is to "change the way students are taught in the classroom, to make their education relevant for the 21st century and beyond" (Suto, 2013, p. 2). The creators of the ATC21S organize skills, knowledge and attitudes into four categories: ways of thinking (creativity and innovation critical thinking, problem solving and decision making; learning to learn and metacognition), ways of working (communication; collaboration), tools for working (information literacy; ICT literacy) and living in the world (citizenship; life and career; personal and social responsibility). There are several other examples that show which 21 st-century skills should be considered. However, the exact nature of the skills conceptualizations is often not sufficiently defined. While a broad range of skills are identified, the underlying skill dimensions remain unclear. As a result, "it is unclear what precisely phrases such as 21 st century knowledge, 21st century skills, and 21st century learning mean" (Kereluik, Mishra, Fahnoe, \& Terry, 2013, p. 127). Given that these concepts are ill-defined, it has become increasingly difficult to determine what should be expected from workers.

A related issue is the ongoing controversy on whether the term 21 st-century skills reflects new rather than long known skills relevant to the needs of the current economy. The various sets of skills represented under the umbrella of '21st-century skills' have been valuable for many centuries. Instead, what is 'new' or specific to this century is the implications of technological advancements (Kereluik et al., 2013). The concept of 21st-century skills in itself might not be new; however, the content of such skills is profoundly different in technologyrich environments. The term 21 st-century skills was first used to list a broad and generic skill set required for workers to thrive in the current labor market. In more recent years, the included skills are often related to digital media and technology. For example, collaboration can be considered in terms of enduring human skills that bear specific importance in the digital context. Workers must be able to collaborate in environments that are mediated by technology to share information and make decisions across business and national boundaries. The focus on the role of ICT with regard to skills is new and has altered their meaning and relevance (Binkley et al., 2012; Voogt, Erstad, Dede, \& Mishra, 2013). An increasingly technology-rich society requires individuals to acquire a new set of skills related to the use of ICT or digital technologies. To date, the role of ICT with regard to skills has mostly been covered in terms of concepts such as 'digital skills'. Digital skills have been identified as being crucial for the social inclusion and professional development of individuals (e.g., Mossberger Tolbert, \& Stansbury, 2003; Van Dijk, 2005; Warschauer, 2003). Nevertheless, 
21st-century skills and digital skills have been two largely separate research areas.

The research on digital skills forms part of a wider debate about the defining and understanding of the skills that are required to participate fully in the digital age (Helsper \& Eynon, 2013). Various terms have been used to designate the ability to operate and use digital technology including digital competence (e.g., Ferrari, 2012; Ilomäki, Paavola, Lakkala, \& Kantosalo, 2016), digital literacy (e.g., Bawden, 2008; Eshet-Alkalai \& Amichai-Hamburger, 2004), digital skills (e.g., Gui \& Argentin, 2011; Zhong, 2011), Internet skills (e.g., Litt, 2013; Van Deursen \& Van Dijk, 2010) and media literacy (e.g., Buckingham, 2007; Livingstone, 2004). Although these concepts are often used synonymously, they are distinct in meaning. One of the most frequently used terms is digital literacy. Gilster (1997) first defined the term digital literacy with an emphasis on information retrieval and information management rather than technical competence as a core skill. He defined it as "the ability to understand and use information in multiple formats from a wide variety of sources when it is presented via computers" (p. 1). In fact, the term literacy is used with all types of adjectives including ICT literacy, computer literacy, information literacy and media literacy. Media literacy, for instance, is concerned with the ability to manage digital information in a variety of media. Digital competence emphasizes the type of attitudes, knowledge and skills that are required when using digital technology in one's personal and social life as well as at work (Hatlevik \& Christophersen, 2013). The concept covers technical know-how and skills as well as aspects such as confidence and critical thinking. Digital competence is a broad term compared to the concept of digital skills. 'Digital skills' is the most specific term because it focuses on action and not on knowledge and its application (Van Dijk, 2019). In light of the rapid and continual development of digital technology, the concept not only comprises basic technical skills but also the creation and understanding of content. In this dissertation, the term digital skills is preferred as it emphasizes the capacity to put one's abilities into action and to act consciously and effectively with a purpose (Ferrari, 2013; GallardoEchenique, De Oliveira, Marqués-Molias, \& Esteve-Mon, 2015; Janssen et al., 2013). People's abilities become actions when they are "inclined to apply them, and see that this might be an appropriate occasion" (Carr, McChesney, Cowie, Miles-Kingston, \& Sands, 2010, p. 215). Although the term digital skills is preferred, an extended and explicit perspective on digital skills as a broader concept is still lacking. The term digital skills is often used to emphasize a more technical context.

The content and the scope of digital skills must be changed to fully capture the impact of new technology in society (Ilomäki et al., 2016). As a result, in this dissertation, the term 21st-century digital skills is taken as point of departure as a broader concept that covers and integrates digital skills. This concept emerges from the 21st-century skills frameworks supported by the evidence showing that labor markets value not only technical skills but also contentrelated or higher-order skills, especially in the context of ICT use (Claro et al., 2012). This dissertation aims to obtain an understanding of digital skills in the broader context posed by 21 st-century skills studies. The digital aspect is often seen as a discrete skill - ICT literacy is among the skills that appear in nearly every set of 21 st-century skills. The impact of ICT on human skills should be integrated into the broad spectrum of skills. The overarching aim of the studies presented in this dissertation is to improve our scientific understanding of 21stcentury digital skills in the workplace. To do so, we will use quantitative and qualitative research methods.

This introduction begins with the changes in the nature of work that explain the need to rethink the types of skills that are required for participation in the labor market (1.2). Thereafter, the role of digital skills as important assets of human capital is discussed (1.3). In what follows, the focus is on the study details, including problem definition and research objectives (1.4); the use of creative industries as a case study (1.5); research questions (1.6); and research approach and methods (1.7). The introduction concludes with an outline of the research presented in this dissertation (1.8).

\subsection{CHANGING NATURE OF WORK IN THE DIGITAL ERA}

Digital technologies' significant impact on the labor market is primarily the result of the complementing or substituting of workers. A few decades ago, Reich (1992) reflected on changes in the nature of work by focusing on the implications of ICT with regard to the types of jobs demanded by society. $\mathrm{He}$ mentioned that many of the jobs for routine production workers would probably disappear because of the potential of ICT to take over such recurring tasks. At the same time, he predicted an increasing need for in-person service workers or 'mind workers'. Similarly, Levy and Murnane (2004) argued that rule-based tasks, computers are an easy substitute; however, computers cannot easily . 
replace humans in tasks that require expert thinking or complex communication. Castells (1996) made an even stronger argument; he stated that "for the first time in human history, the human mind is a direct productive force, not just a decisive element in the production system" (p. 32). When examining the tasks that people perform in their daily workplaces, the number of jobs that primarily consist of repetitive and routine work is declining (Autor, Levy, \& Murnane, 2003). This trend is accompanied by a corresponding increase in interactive and nonroutine cognitive tasks. Drucker (1969), who coined the term 'knowledge society,' argued that in the future, knowledge would be the primary production resource. The emphasis would be on knowledge workers and their ability to create, share and apply knowledge (Drucker, 1993; Florida \& Goodnight, 2005).

The above predictions fit with our current understanding of work. Contemporary societies have shifted from an economy based on commodities and manual labor to one based on knowledge and highly qualified human capital (Carleton, 2011; Jara et al., 2015). In the workplace, computers and robots now also perform routine or repetitive cognitive tasks. The availability of big data has made an increasing number of complex tasks automatable (Frey \& Berger, 2014). The literature has investigated the sector of jobs that are at the highest risk of being substituted by 'machines' (Autor, 2015; Berger \& Frey, 2015; Frey \& Osborne, 2017). In particular, the risk of automatization phasingout jobs is high in terms of transportation and logistics as well as production, office and administrative work. Although some jobs may be lost, automatization also creates new job opportunities - who will manufacture and monitor the robots? (Picatoste, Pérez-Ortiz, \& Ruesga-Benito, 2018). A stronger emphasis is placed on jobs that require skills that are less susceptible to computerization such as problem solving, creativity and socio-emotional skills (Frey \& Osborne, 2017). Many jobs that require social interaction (e.g., management, education or healthcare) or creative skills (e.g., science or engineering) are less likely to suffer from job losses (Berger \& Frey, 2015). The term 21st-century digital skills reflects the important dimensions of human skills in the digital context that are necessary for individual employability. The skills being rewarded in the labor market are a combination of technical and human heuristics; this combination is different from the primary focus on narrower technical skills, which was a prevailing paradigm in the past. Thus, automation changes the way in which work is conducted by eliminating some jobs while creating new jobs and reshaping the skills that are required for others.
The application of new technologies is also changing the content of jobs that are not susceptible to technology substitution. The acquisition of $21 \mathrm{st}$ century digital skills is vital to keep pace with technological developments. With the ubiquity of digital technology, work is increasingly performed in changing contexts by team members who are globally dispersed with a common goal of carrying out interdependent tasks (Bosch-Sijtsema, Ruohomäki, \& Vartiainen, 2009; Lin, 2010). Knowledge workers usually do not perform only individual tasks, but they work in multidisciplinary teams on complex and situation-specific tasks (Bosch-Sijtsema, Fruchter, Vartiainen, \& Ruohomäki, 2011). Such teams often work in a project-based organizational setting, which implies that team members can simultaneously work on multiple projects with different team members. Each team member must not only passively retrieve content but, more importantly, actively contribute valuable content such as knowledge that is useful for others to solve work-related problems or develop new ideas (Rode, 2016). The employment relationship has shifted from lifetime employment in a single organization to portfolio work (Kefela, 2010). In terms of power relationships, teamwork and horizontal relationships have replaced highly hierarchical and vertical work relationships (Fonesca, 2010). The content of work has become relatively more flexible, complex and situation-specific, which has raised the expectations of individual workers' skill levels. The issue lies in the complexity of what is required to prepare individuals for digital-age work.

\subsection{DIGITAL SKILLS AS KEY ASSETS OF HUMAN CAPITAL}

Despite the fact that technological advancements have resulted in fundamental changes within the workplace, the human capital that resides within the workforce drives organizations' competitiveness and innovation capacity (Carleton, 2011; Picatoste et al., 2018). The rapid rate of change and increasing complexity of contemporary society demands a versatile and highly knowledgeable human capital base (Kefela, 2010). No longer is it possible to keep up with all the knowledge in a field; therefore, employers are more preoccupied with workers' abilities to continuously learn for the purpose of creating a flexible and adaptable workforce (Anderson, 2008; Plomp, 2013). In other words, workers must be responsive to change and be ready to obtain a variety of skills or adopt new ways of working. In the contemporary workplace, ideally, workers will be in charge of their own learning, empowering them to take an active rather than a passive role in acquiring new knowledge and 
skills (Thoman \& Jolls, 2004). In addition, the pervasiveness of ICT and the widespread access to digital information have led to increasing expectations for lifelong learning (Head, Van Hoeck, \& Garson, 2015). Learning itself is increasingly mediated and being redefined by technology (Littlejohn, Beetham, \& McGill, 2012, p. 547). Consequently, today's workforce must be equipped with a set of digital skills that are transferable and flexible to be able to compete in changing labor markets. As the problems that must be solved are becoming more complex, workers must constantly build new knowledge, requiring the updating of expertise and continuous learning (David \& Foray, 2002; Littlejohn et al., 2012). In the contemporary work context, knowledge, especially in the technical areas, rapidly becomes outdated, which demonstrates the need for continual online learning.

The future of employment has become increasingly insecure due to technological advances and the obsolescence of acquired skills. In terms of employability, low-qualified workers in particular occupy a vulnerable position in the labor market (Kyndt, Govaerts, Keunen, \& Dochy, 2013). Their work is under pressure because of the decrease in routinized manual labor and the devaluation of educational degrees (Illeris, 2006; Kyndt, Govaerts, Dochy, \& Baert, 2011). The elimination of jobs is more likely to affect low-skilled workers than high-skilled workers (Arntz, Gregory, \& Zierahn, 2016; Falk \& Biagi, 2017). Although digita skills are learned abilities that can be improved through education and training, the prior research has shown that low-qualified workers participate much less in formal learning activities (Boeren, Nicaise, \& Baert, 2010; Van Deursen \& Van Dijk, 2014). The main argument is that skilled (i.e., educated) workers are more capable of learning how to use new technologies and that they are more flexible with respect to their job assignment (Evangelista, Guerrieri, \& Meliciani, 2014). Although digital skills are viewed as an important component of human capital, individuals differ in the extent to which they possess the digital skills required to benefit from and participate in the knowledge society. All workers have the opportunity to become online creators of knowledge; however, some individuals more than others possess the skills that are required to produce and distribute self-created content online (Gretter \& Yadav, 2016; Jenkins, Purushotma, Weigel, Clinton, \& Robison, 2009). As new digital technologies emerge, and thereby the need for digital skills continues to evolve, the key challenge is to ensure that the population at large can attain and maintain a reasonable skill level (Leahy \& Dolan, 2010). Employability increasingly depends upon an individual's level of digital skills (Garrido, Sullivan, \& Gordon, 2012).
Consequently, emphasis should be placed on the acquisition and maintenance of workers' digital skills in response to the changing labor market.

\subsection{PROBLEM DEFINITION AND RESEARCH OBJECTIVES}

ICT has had a profound impact on the labor market, and it has caused a change in the set of skills that are required from workers. Employers have become more demanding in terms of the level and variety of digital skills they require from their workers. The problem is that there is still limited operational knowledge about the types of 21st-century digital skills that workers must learn in the workplace. Because the concept of 21st-century skills is a response to the knowledge society, and digital media and technologies are an important driver 21 st-century skills must integrate the digital aspect. To determine whether workers possess the skills that are needed, the meaning of 21 st-century digital skills and their underlying skill dimensions should be uncovered. To promote employability and to obtain a better position with regard to global competitive challenges, organizations must gain insight into the actual levels of 21st-century digital skills among their workers. To potentially improve workers' skill levels, a distinctive operational definition for each skill is required to guide future measurements. A solid foundation for direct practical application of 21stcentury digital skills should include an operational 21st-century digital skills framework, actual measured skill levels, and an understanding of how such skills can be acquired in relation to the working environment. Therefore, this dissertation seeks to determine how to ensure that workers possess the 21stcentury digital skills that meet the requirements and expectations of the current workplace. This dissertation is focused on identifying how to define, measure and develop working professionals' 21 st-century digital skills. The dissertation has multiple scientific and practical objectives.

Scientific objectives:

1) To clarify the concepts of 21 st-century skills, digital skills, and their combination

2) To create an operational 21st-century digital skills framework aimed at knowledge workers

3) To test the level of 21st-century digital skills in a particular knowledgeintensive sector

4) To determine the role of personal labor conditions on the level of 21stcentury digital skills 
Practical objectives:

1) To explore the role of human work, including potential employment, in the 21st-century

2) To define policy recommendations on how to strengthen workers' 21 stcentury digital skills

As will be discussed in more detail in the next section, the creative industries are used as a case study, particularly given the knowledge intensity of the work in this sector.

\subsection{THE CREATIVE INDUSTRIES AS A CASE STUDY}

This dissertation presents insights from the highly knowledge-intensive and innovative sector of the creative industries. Innovation, especially in the creative industries, relies on workers and their ability to generate knowledge to solve problems and innovate in organizations. The creative industries are those in which human capital is the crucial factor for success and where new ideas and approaches flourish (Piergiovanni, Carree, \& Santarelli, 2012). Although contested, in general, the creative industries include traditional or core performing arts (e.g., arts/crafts, fashion, literature, music, and theatre) as well as those that are typically more commercially oriented such as advertising, design, media, software development and gaming (Flew \& Cunningham, 2010). They have in common that individual workers' creativity, skills and talent are their most important assets (Mietzner \& Kamprath, 2013). The sector is characterized by a highly educated labor force (Florida, 2002; Hennekam \& Bennett, 2017). Another common feature is the distinctive profile shared by workers in such industries. The sector is typically composed of a relatively large number of self-employed and freelance workers (Trip \& Romein, 2014). Work is often freelance or performed on a short-term contractual basis, as creative businesses constantly form and re-form value chains to create new products and services (Bridgstock, 2011). The products and services of the creative industries are highly dependent on technology-intensive developments (Mangematin, Sapsed, \& Schüßler, 2014). At the same time, the creative industries also serve as innovation drivers for new technologies and for economic growth across other industries (Caves, 2000; Müller, Rammer, \& Trüby, 2009). The strong economic position of the creative industries, together with the potential for further economic growth, led the Dutch government to name the creative industries a 'top sector'. They exemplify the increasing demand for highly skilled knowledge workers whose job is to produce intellectual capital. The primary focus is on understanding skill development practices in this dynamic and fast-changing sector. The sample consists of working professionals who are involved in the creative process from the initial analysis of the problem to the introduction of a product, process or service in the market. The included job functions range from strategists, business developers and designers to software engineers and marketers.

\subsection{RESEARCH QUESTIONS}

A plethora of concepts have been used to underscore the need to use a variety of digital technologies. While several current frameworks tend to focus on technical operations, many are moving in a direction where they take into account higher-order thinking or learning skills that are in line with the 21stcentury skills perspective (Claro et al., 2012). Despite the widely shared sense that digital skills are essential for successful participation in the workforce and society at large, there seems to be no agreement on the specific set of skills (Ananiadou \& Claro, 2009; De Haan \& Sonck, 2012; Van Dijk \& Van Deursen, 2014). To date, 21 st-century skills and digital skills have been two largely separate research areas. Because of ICTs impact on human skills, it is necessary to integrate these areas. Furthermore, a great amount of the research explores the sets of skills that are considered to be important and seeks to determine how such skills should be defined (Helsper \& Eynon, 2013). However, the lack of theoretical justification has resulted in definitions that ignore the full range of skills and focus only on some limited conceptualizations (Ilomäki et al., 2016). Researchers have often used similar labels to refer to different skills, or vice versa. In addition, the skills described lack a precise operational definition that is required to determine what should be expected from workers (Voogt \& Pareja Roblin, 2012). As a result, what it means to be digitally skilled in more practical terms is less evident (Janssen et al., 2013). A first step of this effort is to provide conceptual clarity - in other words, an operational definition that provides concrete terms to help inform measurement efforts. It can be argued that there is a need to converge broad conceptual and narrow operational definitions as well as digital and higher-order thinking or learning skills (AlaMutka, 2011; Ferrari, Punie, \& Redecker, 2012). Moreover, to determine whether the described 21 st-century digital skills are suitable for the workplace, they 
must be tested for applicability and completeness in reference to the labor market. It is apparent that there is still a need to clearly define the types of skills that knowledge workers need in the current workplace. Although a number of frameworks and taxonomies have been developed, none captures a broad range of skills while providing a theoretical rationale for defining the dimensions and linking them to the work context. Thus, the first two research questions of this dissertation are as follows:

RQ1: What is the relation between 21st-century skills and digital skills?

RQ2: How can the 21st-century digital skills that are aimed at knowledge workers be conceptualized and operationalized?

Following the issue of definition is the question of measurement. An instrument that can measure a broad range of 21st-century digital skil dimensions that is applicable to working professionals has yet to be developed. Currently, many scientific studies have considered digital skills from an educational perspective, focusing predominantly on the assessment of pupils or students (Litt, 2013). Moreover, in most existing digital skills measurements, people are presented with a list of skills, and they are asked to evaluate how well they perform those skills (Van Deursen, Van Dijk, \& Peters, 2012). However, this subjective rating has significant validity problems (Hargittai, 2005; Merritt, Smith, \& Renzo, 2005) as they depend on the individual's ability to judge their own skill level (Aesaert, Van Nijlen, Vanderlinde, \& Van Braak, 2014). People tend to rate their own skill levels higher (e.g., Hargittai, 2002; Talja, 2005; Van Deursen \& Van Dijk, 2010). Moreover, the measurement of skills is often simplified and includes only a few items or one single measure for a combination of skills. There is a shortage of reliable instruments that can measure the broad range of digital skills that are in line with the 21st-century skills perspective. Additionally, the empirical data that are required to determine how 21st-century digital skills can be effectively and accurately measured are lacking. Therefore, the third research question is as follows:

RQ3: Which measures are reliable to quantify 21st-century digital skill levels among knowledge workers?

To design interventions that result in skill improvements, is it is important to understand how 21st-century digital skills interrelate. However, most skills frameworks do not rank or prioritize the skills that they propose; to date, the interrelationships among such skills have rarely been systematically investigated.
For example, Bloom's taxonomy (1956) from lower-order to higher-order thinking - knowledge, comprehension, application, analysis, synthesis and evaluation - is theory-driven; however, it has not to our knowledge been empirically tested. Most of the prior research has neither conceptually specified nor empirically tested how different skills relate to each other. This gap in the research raises the fourth research question:

RQ4: What is the relation among various 21st-century digital skills?

To promote employability, it is essential to gain more insight into the skill levels among working professionals. Often, the focus is restricted to the technical use of ICT (Van Deursen, Helsper, \& Eynon, 2016). In particular, skills such as digital problem solving, communication and collaboration are not equally covered by the research (Siddiq, Hatlevik, Olsen, Throndsen, \& Scherer, 2016). To accurately measure the level of a wider range of 21 st-century digital skills, objective measurements are needed. The indirect nature of self-reported surveys does not always represent people's actual performance levels. Ideally, skill measurements should provide the opportunity to directly perform a skill. Direct observation is considered to be the most reliable and valid method (Eshet-Alkalai \& Amichai-Hamburger, 2004; Hargittai, 2002). Nevertheless, this type of measurement is rarely applied as its cost is a strong limitation for data gathering. The available performance tests often focus on specific educational settings among pupils and students (e.g., Aesaert \& Van Braak, 2015; Siddiq, Gochyyev, \& Wilson, 2017). There has been a lack in scientific studies that specifically examine the actual level of digital skills possessed by working professionals. Furthermore, because the administration of performance-based tasks takes time, the number of skills included in the measurements is limited (Aesaert et al., 2014). The studies among the general population have shown that the levels of digital skills leave room for improvement (Van Deursen \& Van Dijk, 2011a). However, it is not known whether the same patterns of results also apply to professionals who work in highly knowledge-intensive sectors. This gap in the research raises the fifth research question:

RQ5: What is the level of 21st-century digital skills among the professionals working within the creative industries?

For research and practical purposes, it is essential to identify the factors that determine skill levels. Despite the near consensus that there is a rising demand for 21st-century digital skills, the research often fails to examine a broad 
range of skills and focuses on a relatively limited set of determinants, mostly sociodemographic and socioeconomic factors (Hargittai, 2010; Scheerder, Van Deursen, \& Van Dijk, 2017). Furthermore, the lack of consensus on what constitutes the measurable dimensions of each skill has particularly hampered recent measurement attempts (Van Deursen, Van Dijk, \& Peters, 2011). In the current contribution, several 21st-century digital skills will be measured separately. As such, the specific determinants for each skill can be uncovered. Examining determinants per skill helps to explain the performance differences for each skill and, as such, contributes to the strengthening of the workforce. Thus, the sixth research question to be answered is as follows:

RQ6: Which determinants, at the level of the individual worker, contribute to the level of 21st-century digital skills among the professionals working within the creative industries?

Answering the prior research questions will result in determining which 21st-century digital skills need the most attention and which personal labor conditions support the required improvements. However, important questions with regard to how the development of 21 st-century digital skills can be supported and under what conditions remain unanswered (Littlejohn et al., 2012; Matzat \& Sadowski, 2012). As such, it is important to investigate the sort of practices deployed by organizations and individual workers with the purpose of identifying current shortfalls and policy development. Multiple stakeholders (e.g., education, industry, and individual workers) have a responsibility to fulfill the demands of the labor market. Therefore, a multistakeholder approach to skill development policy will be used. The seventh and final research question to be answered is as follows:

RQ7: How can policy be developed to strengthen workers' levels of 21st century digital skills?

\subsection{RESEARCH APPROACH AND METHODS}

The research questions that are addressed in this dissertation demand a multimethod approach. The first research question - which examines the relation between 21st-century skills and digital skills - is approached by conducting a systematic literature review. A systematic literature review is conducted to analyze the content of a range of concepts associated with 21 st-century skills, digital skills, and their combination. The concept of 21 st-century digital skills is one that is multidimensional and emerges from several backgrounds. Researchers have often ignored the existing definitions of skills, and they have not systematically built on the previous efforts provided by others. The scattered research efforts across several areas and publications must be collected to show the potential synergies. This review, in combination with interviews, is also used to address the second research question - which conceptualizes and operationalizes 21 st-century digital skills aimed at knowledge workers. A systematic literature review is conducted to analyze various definitions and the connection points between the available conceptualizations and operationalizations. The review method provides a means by which to identify, evaluate and synthesize the relevant academic literature concerning 21st-century digital skills. Moreover, the interview method is used to test the relevance of the developed 21st-century digital skills framework in reference to the labor market. The theoretical framework is linked to practice; industry experts are first asked which skills are viewed as relevant for the workforce and thereafter they are confronted with the skills that have been identified in the academic literature. In this way, the interviews are used to validate the identified skills from the systematic literature review. This qualitative method allows managers and senior executives working within the creative industries to express their individual perceptions and thereby provides an in-depth understanding of 21stcentury digital skills.

The third research question - which develops reliable measures to quantify the levels of 21st-century digital skills among working professionals - is approached by conducting cognitive interviews and surveys (both pilots and full surveys). Although the developed 21st-century digital skills framework covers meaningful conceptualizations of digital skills, the operationalization of these skills is not fully developed. Nonetheless, this framework contains the operational components that guided the development of this instrument. A pool of items is generated based on a thorough literature review. Subsequently, cognitive interviews are conducted to review the items. After the revision of the items, a survey pilot and full survey among a large sample of professionals working within the creative industries are conducted to empirically validate the instrument. To overcome issues of self-evaluation, the survey questions measured the frequency of various skill-related actions by using the Internet. This survey instrument extends the conventional and superficial notion of measuring digital skills by proposing a separate set of items per skill. The focus is on factually asking how often people perform a certain digital skill proficiency 
at work. The development and initial validation of a quantitative measurement instrument on 21st-century digital skills is described.

The survey instrument provides a means by which to address the fourth research question - which examines the relation among various 21 st-century digital skills. As it is not expected that all these skills develop independently, a survey is used to test the sequence of 21 st-century digital skills. Based on theory-driven hypotheses for expected relations among 21 st-century digital skills, a conceptual model is proposed and empirically tested. The sequence of 21st-century digital skills highlights another potential barrier to skill development in addition to the factors that influence differences in workers' skill levels. The design of skill interventions is difficult without an understanding of the other skills that are required to perform well on a specific skill.

The fifth and sixth research questions - which test the level of 21st-century digital skills and determine the roles of individual labor conditions in terms of skill levels - are addressed by conducting a systematic literature review and administrating a survey instrument combined with a performance test to professionals working within the creative industries. The systematic literature review accounts for a state-of-the-art overview of the empirical studies on the determinants that are relevant to each type of skill. The previous systematic literature review serves as a starting point as the identified essential skills provide directions for subsequent search actions. The insights from the current systematic literature review are used to operationalize a set of determinants in a survey instrument. The emphasis is on those determinants that can be influenced by the users of the technologies themselves as well as by policy makers, educators and managers in organizations. Although the developed survey instrument is an indirect measure of workers' performance levels, the survey method allows the researcher to present a large number of questions on a wide range of skills and determinants in a relatively short time frame. In this way, the effect of potential determinants on 21st-century digital skills can be quantified. Moving beyond single-skill measures toward multidimensional measurements, it is possible to identify which skills are influenced by specific determinants and which are not. Furthermore, it becomes possible to determine if there are differences in the degree and type of influence of each factor. An extensive overview of the differences in digital skill levels for motivational, personal and social determinants is presented.

Although surveys are useful to conduct on large samples and for crosscomparisons, self-reported results are less appropriate for measuring people's actual performance levels. Testing the level of 21st-century digital skills is, therefore, also addressed by conducting a performance test in which professionals working within the creative industries must perform tasks online while being observed by the researcher. An objective test is preferable over a self-reported survey from the perspective of validity. This type of measurement means that the assessment is based on the analysis of working professionals' directly demonstrated performance. Thus, it measures individuals' actual skills and does not rely on their own judgment. To provide a detailed analysis of the skill levels, an authentic performance test with a refined set of indices per skill is developed. The possibility of measuring a broad range of skills that are actually performed by professionals working within the creative industries is further investigated. The performance-based method is a means by which to expose detailed skill indices to provide a deeper analysis of working professionals levels of digital skills. Performance tests prove to be well-suited to provide a realistic view of digital skill levels. However, this method also poses challenges because their time-consuming and labor-intensive nature make such studies difficult to conduct on a large scale.

The seventh research question - which investigates how to develop policy to strengthen workers' levels of 21st-century digital skills - is addressed by conducting an interview study. The interview method provides rich exploratory data to investigate how 21st-century digital skills are nurtured and developed in an organizational context. By interviewing the top-level management of organizations within the creative industries, we aim to understand the experiences and practices around 21st-century digital skills development. In the final study of this dissertation, the results of our previously conducted studies are discussed as well as the organization's own policy in this area. Insights from the top-level management are put forward in practical policy recommendations for how workers can acquire, learn and develop 21st-century digital skills that enable them to flourish.

\subsection{RESEARCH OUTLINE}

Following the objectives and research questions, the following research is outlined.

In Chapter 2, a systematic literature review is presented to synthesize the existing knowledge of 21 st-century digital skills. First, this review exposes the relation between the concepts of 21 st-century skills and digital skills

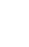


(RQ1). Second, this review provides a framework of 21 st-century digital skills with conceptual dimensions and key operational components aimed at the knowledge worker (RQ2).

Chapter 3 describes a qualitative interview study to investigate perceptions from managers and senior executives working within the creative industries with regard to 21st-century digital skills (RQ2). The developed framework brought forward by the systematic literature review in Chapter 2 serves as input for the in-depth interviews. Industry experts' views on the previously cited 21st-century digital skills and the extent to which skill development receives attention in the current organizational practices are discussed.

Chapter 4 describes the development of a measurement instrument on 21stcentury digital skills (RQ3). A three-fold approach is followed to refine and test the validity of the findings: (1) cognitive interviews, (2) a pilot survey, and (3) a full survey. The result is a theoretically and empirically validated instrument that measures the following 21st-century digital skills: information management, communication, collaboration, critical-thinking, creativity, and problem-solving skills.

In Chapter 5, the survey instrument is used to empirically test the relation among various 21 st-century digital skills (RQ4). The results confirm the sequence of the skills under investigation.

Chapter 6 presents a systematic literature review conducted to provide a comprehensive overview of the empirical studies measuring skill determinants at the level of the individual worker (RQ6). In addition, the results show the differences between 21st-century skills and digital skills studies with respect to the investigated determinant groups and the corresponding skills.

Chapter 7 examines the levels of 21st-century digital skills and the potential determinants that contribute to the level of these skills (RQ5, RQ6). The individual determinants are identified from the systematic literature review and operationalized in terms of survey items. The large-scale survey among professionals working within the creative industries shows that each skill is explained by a different set of determinants, thereby requiring unique approaches for skill development.

Chapter 8 is about measuring the actual levels of 21 st-century digital skills by means of a performance test (RO5). Authentic tasks are developed and used to directly measure a refined set of indices per skill among a subsample of the participants from the survey.
Chapter 9 provides a qualitative interview study to discuss the findings with the top-level management of organizations within the creative industries. The emphasis is on the type of policy recommendations that should be considered with respect to skill development (RQ7). A multistakeholder approach to the development of policy around 21st-century digital skills is taken.

In Chapter 10, the theoretical and practical contributions are discussed. Lastly, this chapter reflects upon the limitations of the dissertation and proposes directions for future research. 


\section{CHAPTER 2}

THE RELATION BETWEEN 21ST-CENTURY SKILLS AND DIGITAL SKILLS: A SYSTEMATIC LITERATURE REVIEW

Innovation starts with people, making the human capital within the workforce decisive for economic development. In a fast-changing knowledge economy, 21 st-century digital skills drive organizations' competitiveness and innovation capacity. Although such skills are seen as crucial, the digital aspect integrated with 21 st-century skills is not yet sufficiently defined. The main objectives of this chapter are: (1) to examine the relation between 21st-century skills and digital skills and (2) to provide a conceptual framework of 21 st-century digital skills and key operational components aimed at the knowledge worker. A systematic literature review was conducted to synthesize the relevant academic literature concerned with 21st-century digital skills. In total, 1592 different articles were screened from which 75 articles met the predefined inclusion criteria. The results show that 21 st-century skills are broader than digital skills - the list of skills mentioned is far more extensive. In addition, in contrast to digital skills, 21st-century skills are not necessarily underpinned by ICT. Furthermore this review identifies seven core skills: technical, information management, communication, collaboration, creativity, critical thinking, and problem solving Five contextual skills are also identified: ethical awareness, cultural awareness, flexibility, self-direction, and lifelong learning.

1 Van Laar, E., Van Deursen, A. J. A. M., Van Dijk, J. A. G. M., \& De Haan, J. (2017). The relation between 21st-century skills and digital skills: A systematic literature review. Computers in Human Behavior, 72, 577-588. doi:10.1016/j.chb.2017.03.010. 


\subsection{INTRODUCTION}

Although ICTs are a foundation for innovation, in themselves they do not create a knowledge-based economy. Innovation starts with people, making the human capital within the workforce decisive (Anderson, 2008; Kefela, 2010; Lanvin \& Kralik, 2009; Lanvin \& Passman, 2008). The current workplace requires highly skilled workers because they are faced with increasingly complex and interactive tasks. Such workers are expected to efficiently select knowledge from the amount of information available and effectively apply this knowledge, both in their professional and personal lives. Employees not only need excellent technical preparation; they also need sufficient skills to adapt to the changing requirements of the job (Ahmad, Karim, Din, \& Albakri, 2013; Carnevale \& Smith, 2013). Knowledge has become vital in the 21st century and people need to acquire so-called 21st-century skills to succeed in the labor market. In general, 21st-century skills include collaboration, communication, digital literacy, citizenship, problem solving, critical thinking, creativity and productivity (Voogt \& Pareja Roblin, 2012; also see Chapter 1). These skills are labeled 21stcentury skills to indicate that they are considered to be more relevant to the current economic and social developments than to those of the past century, characterized as an industrial mode of production. The growing impact of globalization and the knowledge society have led many to argue that $21 \mathrm{st}$ century skills are essential to be successful in the workplace and that ICT is central to their development (Lewin \& McNicol, 2015). The development of the global knowledge society and the rapid integration of ICT make it imperative to also acquire digital skills necessary for employment and participation in society. In this respect, the concept of '21st-century digital skills' is introduced in the previous chapter. The 21st-century digital skills are critical for both people and organizations for keeping up with developments and innovating products and services.

Although 21st-century skills and digital skills are both seen as crucial, the relation between the concepts is not yet sufficiently defined. Importantly, these skills go beyond the mere technical definitions as, for instance, terms such as 'digital skills' or 'ICT skills' often carry. How someone thinks, solves problems and learns has a greater impact on a person's ability to function in a technologically rich society than just being knowledgeable about specific software (e.g., Ahmad et al., 2013; Claro et al., 2012; Eshet-Alkalai, 2004). In line with Claro et al. (2012), we consider 21st-century digital skills as: (1) the mastery of ICT applications to solve cognitive tasks at work; (2) skills that are not technology-driven, as they do not refer to the use of any particular software program; (3) skills that support higher-order thinking processes; and (4) skills related to cognitive processes favoring employees' continuous learning.

The current chapter has three objectives. The first objective is to identify the concepts being used to describe the skills that are required in a digital environment, go beyond mere technical use, and focus on 21 st-century digital skills. The next section inventories the various concepts that are used to define the human attributes associated with ICT use. The following research question is addressed:

Which concepts are being used to describe the skills that are required in a digital environment, go beyond mere technical use, and focus on 21st-century digital skills?

The second objective is to define the relation between 21 st-century skills and digital skills. In addition, the third objective is to provide a framework of 21st-century digital skills with a conceptual definition and key operational components aimed at knowledge workers. A systematic literature review is conducted to synthesize the relevant academic literature concerned with 21stcentury digital skills. The objectives are approached by addressing the following research questions:

- Which selection is being made to synthesize the relevant literature concerned with 21st-century digital skills?

Which concepts are being used?

What is the particular field of study?

Which research methods are being used?

Which skills are mentioned as being essential for the workforce?

How are the skills mentioned conceptualized?

- How are the skills mentioned operationalized?

\subsection{THEORETICAL BACKGROUND}

This section identifies various conceptualizations that describe the skills that are required in a digital environment and indicates the extent to which the identified concepts integrate the digital aspect with 21st-century skills. To find the most suitable concepts to guide our systematic literature review, a distinction is made between: (1) technological skills concepts, (2) 21st-century skills concepts, and (3) 21st-century digital skills concepts. 


\subsubsection{Technological skills concepts}

Various terms are used to define the human attributes associated with ICT use. With the spread of digital technologies, terms such as IT, ICT and computer literacy have become prevalent (Bawden, 2008). The technology plays a dominant role in defining the skills that are considered important. In most cases, the concepts consist of a domain part (e.g., computer, ICT, Internet, multimedia) in combination with a specific knowledge perspective (e.g., competence, literacy, skills) (Hatlevik, Ottestad, \& Throndsen, 2015). These concepts primarily indicate a basic set of skills in using computers or Internet technology; for example, turning off the computer, opening a folder and saving a file. They do not go far enough to explain the skills an individual must possess to exploit the full potential of ICT. However, those technical skills are a driving force behind the need for 21st-century skills and required for the acquisition of 21 st-century digital skills.

\subsubsection{1st-century skills concepts}

'Digital competence' has become a key concept in the discussion of the types of skills that citizens must have in the knowledge society. Although the term encompasses 'digital', the digital aspect is often seen as a discrete skill - implying that the 21st-century skills are not necessarily underpinned by ICT. Digital competence covers information management, collaboration, communication and sharing, creation of content and knowledge, ethics and responsibility, evaluation and problem solving, and technical operations (Ferrari, 2012). Similar aspects are put forward in '21st-century skills' definitions. The promise of 21 st-century learning is that digital technologies will transform traditional learning and mobilize those skills that are necessary in an emerging digital environment. A detailed conceptual framework is taken from the Partnership for 21st Century (P21). The P21 (2008) lists three types of skills: learning skills (creativity and innovation; critical thinking and problem solving; communication and collaboration), literacy skills (information literacy; media literacy; ICT literacy) and life skills (flexibility and adaptability; initiative and self-direction; social and cross-cultural skills; productivity and accountability; leadership and responsibility). Other groups and organizations have proposed similar frameworks. The Assessing and Teaching of 21st Century Skills (ATC21S), for instance, used an expert group to define key 21st-century skills (Binkley et al., 2012). They categorized 21st-century skills as follows: ways of thinking (creativity and innovation; critical thinking, problem solving and decision making; learning to learn and metacognition), ways of working (communication; collaboration) tools for working (information literacy; ICT literacy) and living in the world (life and career; personal and social responsibility). The main focus is on the teaching and learning practices to ensure students' mastery of 21 st-century skills in the classroom as preparation for working life (Leahy \& Dolan, 2010).

\subsubsection{1st-century digital skills concepts}

Only a few approaches provide an integration of 'digital' and 21st-century skills. First, 'digital literacy', introduced by Gilster (1997), is considered as the ability to understand and to use information from a variety of digital sources. Digital literacy is distinguished from the more limited technical skills view of digital literacy by explicitly stating that "digital literacy is about mastering ideas, not keystrokes" (p. 1-2). Thus, digital literacy must be more than the ability to use digital sources effectively. Eshet-Alkalai (2004) published a conceptual model of survival skills for digital literacy, involving more than the ability to use software or operate a digital device; it includes cognitive and social-emotional skills to perform tasks and solve problems in digital environments. $\mathrm{Ng}$ (2012) distinguished three intersecting dimensions that are the technical, cognitive and social-emotional dimensions of digital literacy. Overall, digital literacy is presented as a mindset that enables users to perform intuitively in digital environments, and to both easily and effectively access the wide range of knowledge embedded in such environments (Martin, 2008). Moreover, Van Deursen and Van Dijk (2010) proposed a range of 'digital skills' conceptualizations, accounting for technical or media aspects (medium-related skills) and substantial or content aspects (content-related skills). Specifically, the focus is on operational, formal, information, communication, content-creation and strategic skills (Van Deursen, Helsper, \& Eynon, 2016). That proposed definition avoids a technologically deterministic viewpoint by accounting for technical aspects and the aspects related to the content provided by the Internet. Finally, the concept of 'e-skills' focuses on the question of what an organization should do with ICT. Mitrovic (2010) defined e-skills as "the ability to develop and use ICT to adequately participate in an environment increasingly dominated by access to electronically-enabled information, and a well-developed ability to synthesize this information into effective and relevant knowledge" (p. 2).

To conclude, despite the lack consistency in the terms used, many concepts have been put forward in response to the skills that are required in the new 
social and technological environments. In our systematic literature review the focus is on the skills that are required in a digital environment, go beyond mere technical use, and focus on 21 st-century digital skills. Therefore, we take into account: digital competence, digital literacy, digital skills, e-skills, 21st-century (learning or thinking) skills, and 21st-century competence.

\subsection{METHOD}

\subsubsection{Systematic literature review}

A systematic literature review is a review of "a clearly formulated question that uses systematic and explicit methods to identify, select and critically appraise relevant research and to collect and analyze data from the studies that are included in the review" (Moher, Liberati, Tetzlaff, \& Altman, 2009, p. 264). This method was chosen because it helps to synthesize academic literature in an accurate and reliable manner. In our case, we looked systematically at articles that categorize 21 st-century digital skills. The systematic literature review was conducted in accordance with the Preferred Reporting Items for Systematic Reviews and Meta-Analyses (PRISMA) approach (Moher et al., 2015). The PRISMA approach entails an evidence-based checklist of 27 items and a fourphase flow diagram. The checklist items were included if there was evidence that not reporting the item was associated with increased risk of bias, or where it was clear that information was necessary to appraise the reliability of a review (Liberati et al., 2009). The PRISMA approach is not intended to be a quality assessment tool but the aim is to ensure clarity and transparency when reporting systematic literature reviews. The PRISMA checklist of 27 items and four-phase flow diagram were used to report our results.

\subsubsection{Search terms}

The search action was conducted using the Scopus, Web of Science and PsycINFO databases, which are three well-established databases in the social sciences. The search action included 21 st-century digital skills related terms in agreement with terms for the operationalization. For each construct, we used several keywords to ensure a broad coverage of studies. Each database has its own indexing terms, therefore; individual proximity operators were used. As a result, the following Boolean search action was conducted:

("21st-century competenc*" OR "21st-century (NEAR/2) skills" OR "twentyfirst century (NEAR/2) skills" OR 21st-century learning skills OR twenty- first century learning skills OR 21st-century thinking skills OR twenty-first century thinking skills OR "digital competenc*" OR "digital (NEAR/2) skills" OR "digital literacy" OR "e-skills") AND (defin* OR frame* OR measur* OR model OR review)

\subsubsection{Selection criteria}

A number of criteria were specified to select the most relevant studies. In all three databases, the limitations of document type (peer-reviewed article), language (English) and time period (2000-2016) were added. To be included, articles had to fulfill the four criteria defined below.

1) Focus on 21 st-century skill dimensions or a related term. The technical aspect may be discussed in addition to the 21st-century skill dimensions. A precondition because a limited number of research studies focuses on 21st-century digital skills.

2) Include conceptualizations or an actual measurement of 21st-century (digital) skills or a related term. This criterion was used to create a $21 \mathrm{st}$ century digital skills framework based on the academic literature.

3) Mention the term in context of workforce preparation. A precondition because the main aim of this study is to propose a framework relevant to the current workforce.

4) Be published in a peer-reviewed journal. This latter criterion was used since such journals are considered to be the most reliable source of scientific information.

\subsubsection{Study selection}

The study selection was made in three steps. First, the titles of all retrieved articles were screened for eligibility for the above-mentioned inclusion criteria. Second, the abstracts of all initially relevant articles were screened for eligibility by applying uniform criteria. Finally, the full text of all remaining publications was checked. All articles deemed relevant were coded in terms of the following: the names of the authors, the publication date, the journal name, the aims, the method, the skills mentioned, the definition and operationalization of skills, and the results and conclusion. Coding of the articles was done to ensure all articles that fulfilled the four criteria were selected. Based on this document, we extracted of all selected articles information about the study field, the study type, the main concept, the list of skills, and if the skills were conceptualized or operationalized. Data extraction is part of the content-analysis process to 
make an overview of the characteristics of all articles that were included in our research. The final part of the content-analysis process consisted of looking at how the skills were conceptualized and operationalized to not only list the skills but to also provide them with a conceptual definition and operationa components.

\subsubsection{PRISMA flowchart}

Given the restrictions of document type, language and time period, 2,148 articles were identified from the databases. Out of the 2,148, 556 were duplicates which means 1,592 different articles were screened. After title and abstract screening, 255 were read in full text from which 75 articles met all four inclusion criteria. Appendix 2.A presents the references of the included studies. Figure 2.1 presents the flowchart for the selection of the included studies. Additional records were not identified through other sources because the references of the included articles did not contribute to the received information. There were six reasons for excluding a full-text screening: (1) not containing a 21st-century (digital) skills operationalization; (2) only focused on the technical aspect; (3) not mentioned in the context of workforce preparation; (4) not a peer-reviewed journal article; (5) no full-text available online; and (6) a duplicate first author. If there were several suitable articles with the same first author, we selected the most recent available article.

\subsubsection{Selection bias}

To assess quality of the study, a sample of the articles was independently coded by a second coder. Publication bias in a systematic literature review occurs mostly during the selection process and a transparent selection process is necessary to minimize such bias (Moher et al., 2015). The Scopus database was chosen to execute the search action because this is the largest abstract and citation database of peer-reviewed literature. A second coder performed the search action and followed the study selection steps of title, abstract and full-text evaluation according to a predefined instruction. Based on the eligibility criteria, the second coder decided whether or not to closely examine an article. If the article was read in full text and not selected, the reason for not including the article was provided. Cohen's kappa coefficient is a statistic which measures interrater agreement. In the first round of coding with $25 \%$ of the articles derived from the search action in Scopus ( $n=192)$, the inter-rater reliability was not good among the coders; therefore, a second round of coding with $15 \%$ of the articles $(n=114)$ was performed. Between the two code rounds, the criteria were specified to clarify the ambiguity. After the specification of the criteria, the inter-rater reliability in the second round for 120 selected articles was .70 which shows good agreement between the two coders.

To ensure the validity of the coding and to avoid researcher bias in coding the study characteristics, we also conducted a coding session for the main findings of the systematic literature review. A second coder randomly selected $20 \%$ of the 75 included articles and wrote down the skills mentioned. Thereafter all the skills had to be coded based on our skills framework and we used a separate code for the skills that were not mentioned in the framework. A Cohen's kappa of .82 was achieved, denoting good agreement between the two coders. After the coding sessions, all disagreements were resolved through discussion to reach consensus.

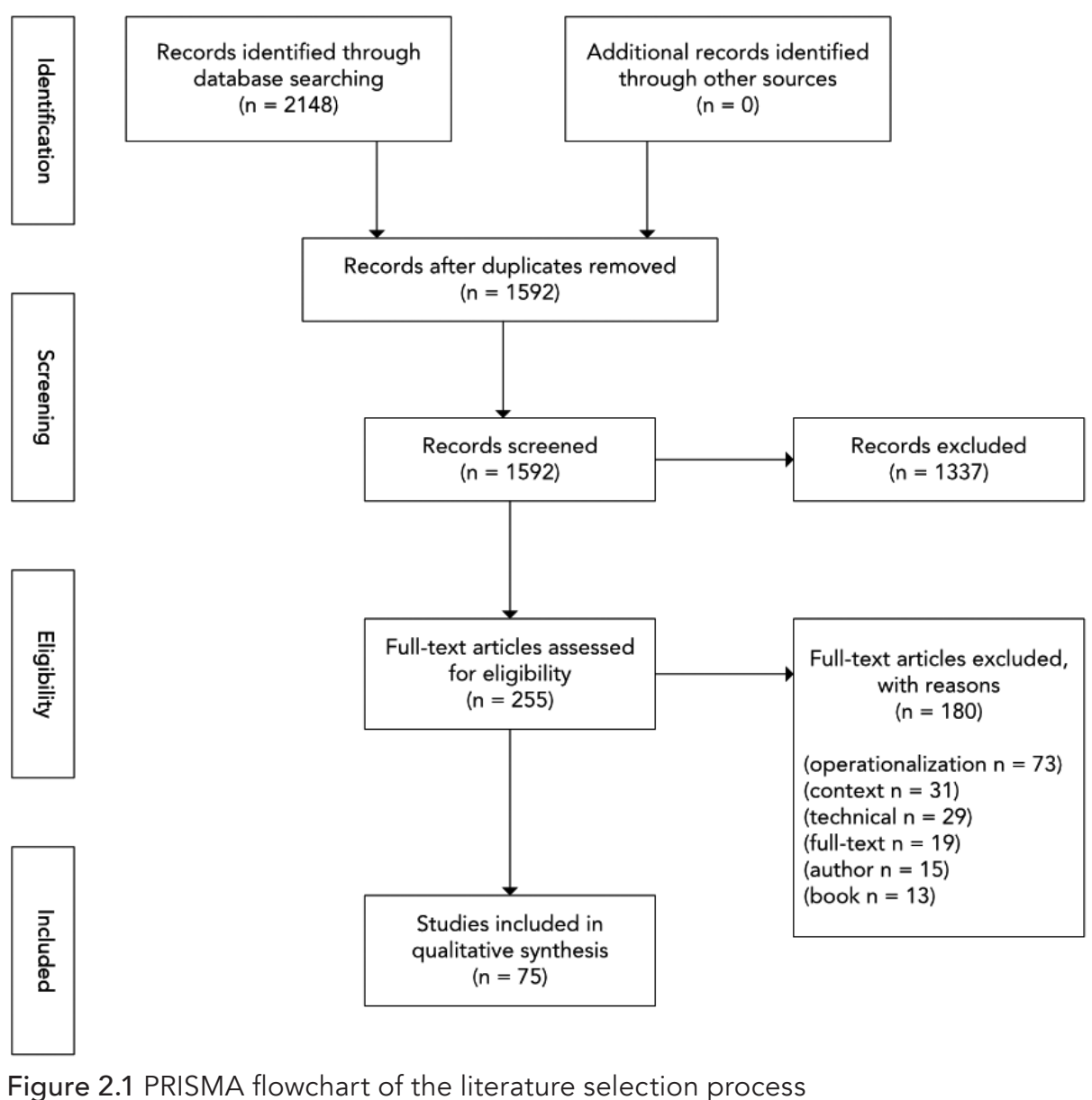

Figure 2.1 PRISMA flowchart of the literature selection process 


\subsection{RESULTS}

2.4.1 Content analysis

Overall, the articles were diverse in scope, addressed various 21st-century skil dimensions, utilized a range of theoretical models, and adopted a variety of methodological approaches. Appendix 2.B provides an overview of the skills mentioned and the main concept used in the included articles.

\section{Study type and field}

Table 2.1 provides an overview of the various study types. To clarify, a review must cover all of the scientific literature in a field that is defined by the author while a theoretical analysis only includes references to those works that are necessary for the analysis. The results indicate that surveys were the most commonly employed type of study $(n=22)$ followed by theoretical studies $(n=14)$ and performance tests $(n=12)$. Although there were performance assessments included ( $n=12$ ), five focused on one particular skill, problem solving, and referred to the MicroDYN approach proposed by Greiff, Wüstenberg, and Funke (2012). A limited number of studies used large-scale performance tests in which the participants were asked to complete assignments. Most studies did not determine participants' exact skill levels but relied on self-assessments. In total 35 studies (survey, mixed method, case study, Delphi study, and experiment) relied on self-assessment in comparison with 12 performance test studies.

Table 2.1 Study type included articles $(n=75)$

\begin{tabular}{|c|c|c|c|c|c|c|}
\hline & & $\begin{array}{l}\text { Operational } \\
\text { Single skill }\end{array}$ & $\begin{array}{l}\text { Operational } \\
\text { Multiple } \\
\text { skills }\end{array}$ & $\begin{array}{l}\text { Conceptual } \\
\text { Single skill }\end{array}$ & $\begin{array}{l}\text { Conceptual } \\
\text { Multiple } \\
\text { skills }\end{array}$ & $\mathrm{n}$ \\
\hline \multirow[t]{11}{*}{ Study type } & Case study & 1 & 2 & & & 3 \\
\hline & Comparative analysis & & & & 3 & 3 \\
\hline & Content analysis & & & & 1 & 1 \\
\hline & Delphi study & & 1 & & 1 & 2 \\
\hline & Experiment & 1 & & & & 1 \\
\hline & Mixed method & & 7 & & & 7 \\
\hline & Performance test & 7 & 5 & & & 12 \\
\hline & Review & & & 4 & 6 & 10 \\
\hline & Survey & 6 & 14 & & 2 & 22 \\
\hline & Theoretical & & & 6 & 8 & 14 \\
\hline & Total & 15 & 29 & 10 & 21 & 75 \\
\hline
\end{tabular}

Table 2.2 on the next page provides an overview of the various study fields. For the categorization of studies fields, Scopus journal classification of subject categories was used. In the case of multiple categories, the most convenient field was chosen. Based on the categorization, it became clear that Education is the most prevalent study field $(n=27)$. In addition, there are many studies referring to the educational field; for instance, Computer Science and Education $(n=17)$ and Engineering and Education $(n=4)$

Overview concepts

Table 2.3 shows an overview of the concepts used in the articles. Remarkably, e-skills was never mentioned as a key concept. Clearly, most articles referred to 21 st-century skills $(n=35)$. These articles focus on teaching and learning practices to ensure students mastery of 21 st-century skills in the classroom as preparation for working life. As a consequence, students were the main participant group and not the working population.

\begin{tabular}{ll} 
Table 2.3 Concepts used included articles $(\mathrm{n}=75)$ \\
\hline Term & $\mathrm{n}$ \\
\hline 21st-century (or twenty-first) skills & 35 \\
Digital literacy & 8 \\
Digital skills & 5 \\
21st-century (or twenty-first) learning skills & 5 \\
Digital competence & 5 \\
Information literacy & 5 \\
21st-century (or twenty-first) competence & 3 \\
21st-century (or twenty-first) thinking skills & 3 \\
Transversal (or transferable) skills & 2 \\
21st-century ICT literacy & 1 \\
21st-century ICT skills & 1 \\
New media literacy & 1 \\
Multiliteracy & 1 \\
\hline
\end{tabular}




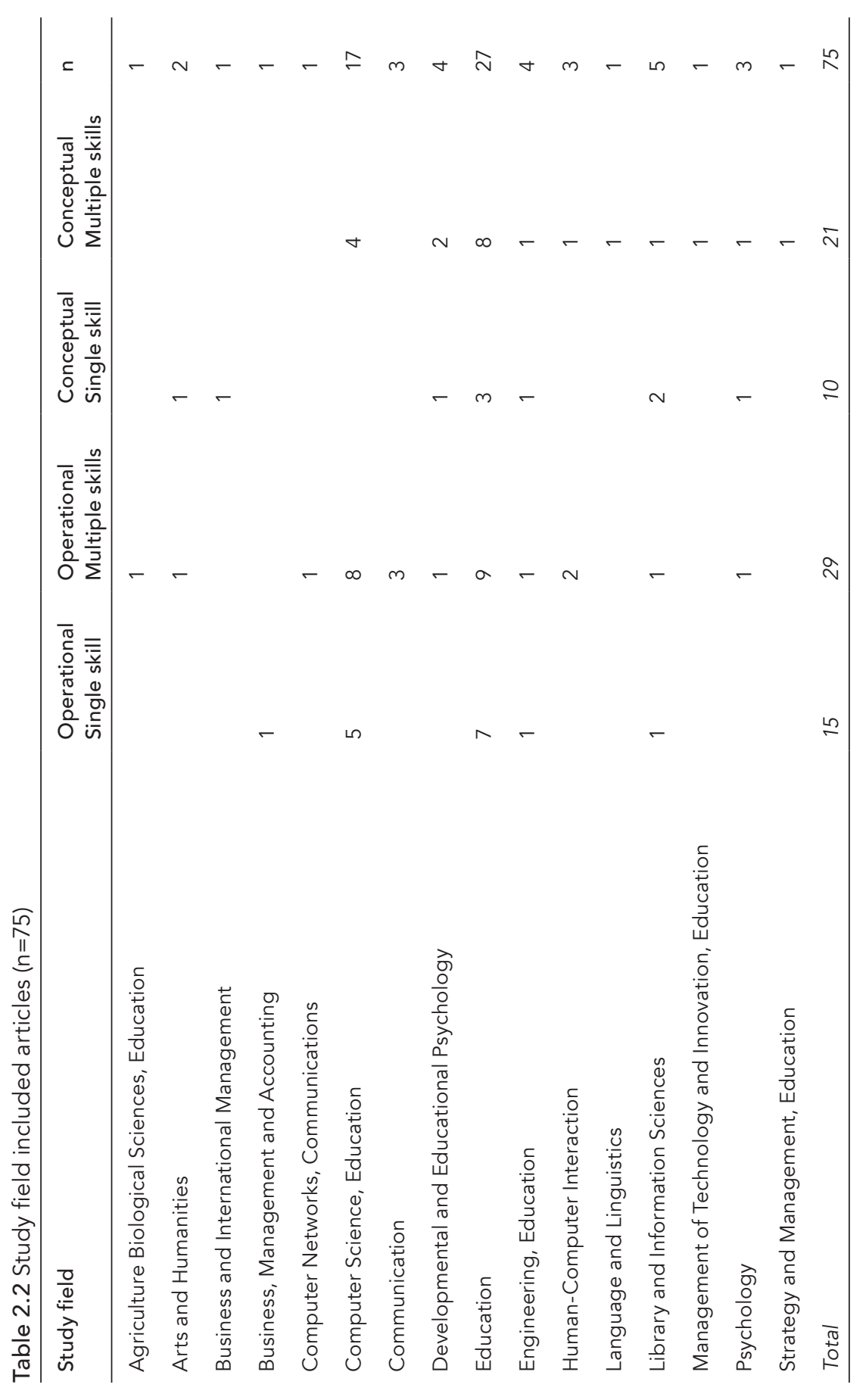

21st-century skill dimensions

Table 2.4 shows the number of articles that addressed the various $21 \mathrm{st}$ century skill dimensions. In total, 75 articles were included from which $10 \%$, seven articles, must mention a skill to be included in the framework. The most frequently reported skills were information management $(n=31)$, critical thinking $(n=30)$, creativity $(n=29)$, problem solving $(n=24)$, collaboration $(n=24)$ and communication $(n=22)$. Furthermore, a distinction was made between articles that only conceptualize skills and articles that attempt to measure such skills. Critical thinking $(n=18)$, information management $(n=16)$, technical $(n=12)$ and problem solving $(n=11)$ were the most thoroughly examined skills. Overall, $21^{\text {st }}$-centuy skills or digital competence refer to an extensive list of skills on conceptual level while digital skills or digital literacy often refer to a limited number of skills on operational level.

Table 2.4 Skills mentioned included articles $(n=75)$

\begin{tabular}{llll}
\hline & Operational & Conceptual & $\mathrm{n}$ \\
\hline Information management & 16 & 15 & 31 \\
Critical thinking & 18 & 12 & 30 \\
Creativity & 12 & 17 & 29 \\
Problem solving & 11 & 13 & 24 \\
Collaboration & 11 & 13 & 24 \\
Communication & 11 & 11 & 22 \\
Technical & 12 & 6 & 18 \\
Self-direction & 6 & 10 & 16 \\
Lifelong learning & 4 & 6 & 10 \\
Ethical awareness & 5 & 4 & 9 \\
Cultural awareness & 2 & 7 & 9 \\
Flexibility & 2 & 6 & 8 \\
\hline
\end{tabular}

Relation between 21st-century skills and digital skills

The concepts of 21st-century skills and digital competence both emphasize a broad spectrum of skills. Beyond skills, knowledge and attitude are viewed as essential to thrive in the knowledge society. The list of skills mentioned is extensive; however, both concepts do not integrate the digital aspect. The digital aspect is often seen as a discrete skill - implying that 21 st-century skills 
are not necessarily underpinned by ICT. Furthermore, many 21st-century skills categorizations and conceptualizations are given but only a few frameworks are available to provide operational components. In addition, if an operationalization is provided, the focus is often on one particular skill. The main difference with digital skills or digital literacy is that these concepts do provide the 21st-century digital skills integration. Although the skills mentioned are moving toward the knowledge-related skills, they do not cover a broad spectrum of 21stcentury skills. However, the skills mentioned are more thoroughly measured in comparison with 21st-century skills or digital competence. Overall, the focus is on knowledge- or content-related skills. In addition, the research tends to focus on citizens or students instead of skills required for the workforce.

2.4.2 Conceptual 21st-century digital skills framework

The concept of 21 st-century digital skills is introduced to combine the more vague but broader set of 21 st-century skills with the more operationalized but limited set of digital skills. 21st-century skills and digital skills are both seen as crucial, but the combination is not yet sufficiently defined. To conceptualize the 21 st-century digital skill dimensions, we took into account the descriptions that are available in the included articles. For each included article, we listed the skills conceptualizations and operational components. Based on the results, a distinction is made between the core skills (Table 2.5) and the contextual skills (Table 2.6). The core skills are fundamental for performing tasks that are necessary in a broad range of occupations. Contextual skills are those skills that are required to take advantage of the core skills and, therefore, must be connected to such core skills. For each skill, a conceptual definition with key operational components is provided. It must be noted that the digital aspect for the contextual skills - cultural awareness, flexibility and self-direction - was added by the researcher. There was no article available that made a connection toward the digital aspect.
Table 2.5 Framework with core 21st-century digital skills

\begin{tabular}{ll}
\hline $\begin{array}{l}\text { 21st-century digital } \\
\text { skill dimensions }\end{array}$ & Conceptual definition with operational components \\
\hline Technical & The skills to use (mobile) devices and applications to accomplish practical \\
& tasks and recognize specific online environments to navigate and \\
& maintain orientation. \\
& Key components (e.g., Ng, 2012; Van Deursen et al., 2016): \\
& - ICT knowledge: understand the characteristics of (mobile) devices or \\
& applications. \\
& - ICT usage: operate basic (mobile) application operations and access \\
& resources for everyday use. \\
& - Navigation: avoid losing orientation when navigating online. \\
\hline Information & The skills to use ICT to efficiently search, select and organize information \\
management & to make informed decisions about the most suitable sources of \\
& information for a given task. \\
& Key components (e.g., Ahmad et al., 2016; Snow \& Katz, 2009): \\
& - Define: use ICT to formulate a research statement to facilitate the \\
& search for information. \\
& - Access: use ICT to find and retrieve information from a variety of online \\
& sources. \\
& - Evaluate: use ICT to judge the usefulness and sufficiency of information \\
& for a specific purpose. \\
& - Manage: use ICT to organize information to be able to find it later. \\
\hline Che skills to use ICT to transmit information to others, ensuring that the \\
meaning is expressed effectively. \\
Key components (e.g., Claro et al., 2012; Siddiq, Scherer, \& Tondeur, \\
2016): \\
- Transmitting information: use ICT to communicate information and \\
ideas effectively to multiple audiences using a variety of media and \\
online formats.
\end{tabular}


21st-century digital Conceptual definition with operational components

\section{skill dimensions}

Critical thinking The skills to use ICT to make informed judgements and choices about obtained information and communication using reflective reasoning and sufficient evidence to support the claims.

Key components (e.g., Greene, Yu, \& Copeland, 2014; Lee et al., 2016): Clarification: use ICT to ask and answer questions of clarification related to the problem.

- Assessment: use ICT to judge the suitability of a source for a given problem.

Justification: use ICT to invoke arguments for claims based upon their consistency with other knowledge claims (e.g., personal, memory, testimony, coherence, rationality, replication).

Linking ideas. use ICT to link facts, ideas and notions.

Novelty: use ICT to suggest new ideas for discussion.

Problem solving The skills to use ICT to cognitively process and understand a problem situation in combination with the active use of knowledge to find a solution to a problem.

Key components (e.g., Greiff et al., 2013; Scherer \& Gustafsson, 2015):

Knowledge acquisition: use ICT to acquire implicit and/or explicit knowledge about the problem.

Knowledge application: use ICT to apply implicit and/or explicit knowledge about the problem to find a solution.

\section{1st-century digital Conceptual definition with operational componen}

skill dimensions

Ethical awareness The skills to behave in a socially responsible way, demonstrating The skills to behave in a socially responsible way, demonstrating
awareness and knowledge of legal and ethical aspects when using ICT. Key components (e.g., Claro et al., 2012; Janssen et al., 2013):

Key components (e.g., Claro et al., 2012; Janssen et al., 2013):
- ICT responsible use: decide about the legal, ethical and cultural limits of personally and socially responsible use of ICT by understanding potential risks that exist on the Internet when using ICT.

ICT social impact: understand, analyze and evaluate the impact of ICT in social, economic and cultural contexts when using ICT.

Cultural awareness The skills to show cultural understanding and respect other cultures when

using ICT.
Key components (e.g., Yang et al., 2014; Young, 2015):

Key components (e.g., Yang et al., 2014, Young, 2015): Cross-cultural communication: attitudes toward online communication
and collaboration experiences with people from different cultures and collaboration experiences with people from different cultures when using ICT.

Flexibility The skills to adapt one's thinking, attitude or behavior to changing ICT environments.

Key components (e. Anderman, Sinatra, \& Gray, 2012; Osman, Hamid \& Hassan, 2009):

Adapting to frequent and uncertain situations: attitude toward modify one's thinking, attitudes or behaviors to be better suited to current o future ICT environments.

Self-direction The skills to set goals and manage progression toward reaching those goals in order to assess one's own progress when using ICT.

Key components (e.g., Holt \& Brockett, 2012; Quieng, Lim, \& Lucas, 2015): - Goal setting: state learning or time goals when using ICT.

Control: willingness of individuals to take control of their own learning when using ICT.

Initiative: proactively take steps toward decisions and actions when using ICT.

Monitor progress: assess whether previously set goals have been met when using ICT.

Lifelong learning The skills to constantly explore new opportunities when using ICT that can be integrated into an environment to continually improve one's capabilities.

Key components (e.g., Chai et al., 2015; Uzunboylu \& Hürsen, 2011): Knowledge creation efficacy: use ICT to create useful knowledge individually. 


\subsection{DISCUSSION}

2.5.1 Main findings

The first objective of this study was to identify the concepts being used to describe the skills that are required in a digital environment, go beyond mere technical use, and focus on 21 st-century digital skills. The theoretical framework identified various concepts: 21st-century (learning or thinking) skills, digital competence, digital literacy, digital skills, and e-skills. Clearly, concepts are moving in a direction where they consider knowledge- or content-related skills. Although the importance of 21st-century skills and digital skills has been well established, the relation between both concepts was not yet sufficiently defined. The second objective was to define the relation between two main concepts: 21 st-century skills and digital skills. In addition, the third objective was to provide a framework of 21st-century digital skills with a conceptual definition and key operational components aimed at knowledge workers. All three objectives were approached by systematically synthesizing the relevant academic literature concerned with 21 st-century digital skills. Several research questions were addressed about the concept and method used, the study field, the skills mentioned, and how the skills were conceptualized or operationalized. A systematic literature review methodology was followed to address transparency and replicability (Jesson, Matheson, \& Lacey, 2011). The systematic literature review identified 75 articles that met the predefined inclusion criteria.

Based on the characteristics of the 75 included articles, the results show that 21 st-century skills are broader than digital skills. The idea of 21 st-century skills goes beyond skills - knowledge and attitude are viewed as essential to thrive in the knowledge society. Besides, the 21 st-century skills are not necessarily underpinned by ICT while digital skills or literacy do provide such integration. Furthermore, many 21st-century skills categorizations are given but only a few frameworks are available to provide operational components. The digital skills mentioned are more thoroughly measured in comparison with 21st-century skills. Both concepts tend to focus on citizens' or students' levels of skills and not on skills for the workforce. However, they did help to establish a conceptual 21st-century digital skills framework with key operational components aimed at knowledge workers as presented in Tables 2.5 and 2.6. To create this framework, this study systematically identified key 21 st-century skill or digital skill dimensions by evaluating articles that aim to define or measure them. This has resulted in a framework of seven core skills (technical, information management, communication, collaboration, creativity, critical thinking, and problem solving) and five contextual skills (ethical awareness, cultural awareness, flexibility, self-direction, and lifelong learning). In a global knowledge economy, those skills to a great extent determine organizations' competitiveness and capacity to drive innovation. Given the rapid rate of change and influence of technology, employees need to develop 21st-century digital skills to cope and thrive in this changing society. The 21st-century digital skills were viewed as essential, but they were not yet ultimately covered by the published research. Therefore, this study has taken a first step toward closing this research gap. Although this study has extended our understanding and categorization of 21 st-century digital skills, it also contains points for discussion.

\subsubsection{Limitations}

The systematic literature review was limited by focusing on the literature from the past sixteen years and specifically focusing only on peer-reviewed articles to ground our understanding of 21st-century digital skills in research evidence. Consequently, this review might have excluded relevant articles published before the year 2000 and relevant books or conference papers. Furthermore, a limited number of articles were available about 21st-century digital skills that are conceptualized or measured in reference to the labor market. As such, the criterion was that articles must mention the skills as preparation for work. This means that the educational context was not necessarily excluded. The articles that discussed the skills only in the classroom, often primary education, were excluded - an article must make the connection to those skills beyond the classroom. It is expected that many of the ideas discussed in the educational context will also be relevant to understanding 21st-century digital skills for work. However, the dynamic changes in the types of jobs demanded by the knowledge society pose serious challenges to educational systems, as they are currently asked to prepare young people for jobs that may not yet exist (Voogt, Erstad, Dede, \& Mishra, 2013). In addition, the research also states that there is a mismatch between the qualifications of graduates and the skills demanded by jobs (Cobo, 2013; Soulé \& Warrick, 2015).

Several limitations must be noted concerning the process of creating our skills framework. First, the digital aspect was not ultimately covered by the included studies. The concept of 21st-century skills was the most popular. In addition, the articles that do integrate the digital aspect do not yet cover a broad range of 21 st-century skills. As a result, it was difficult to conceptualize 
the digital aspect for all twelve skills. In particular for the contextual skills, we used the conceptual definitions provided by the literature and added the digital aspect ourselves. Furthermore, for 21st-century digital skills to be included in the framework they must be mentioned by at least seven articles. This rule has resulted, for instance, in the fact that entrepreneurial skills were excluded because they were just five times mentioned. Entrepreneurial skills could be of relevance for the workforce context; it emphasizes a person's innovation capacity and ability to perceive new opportunities to commercialize. Moreover, lifelong learning was more than seven times recognized as an important 21stcentury digital skill. However, lifelong learning could also be perceived as an approach instead of a skill. "Lifelong learning is a continuous, voluntary, and self-motivated act to expand one's own knowledge" (Kaur \& Beri, 2016, p. 1365) It is considered to be a mindset meaning that learning - gaining new skills and new knowledge - is a lifetime opportunity and achievement. Thus, it could be questioned if lifelong learning is a 21st-century digital skill.

\subsubsection{Future research directions}

Our inclusion criteria identified 75 articles that provided conceptualizations or measurement of 21 st-century digital skills, suggesting that concerns about the lack of empirical evidence in this area are starting to be addressed. A few dimensions - technical, information management, critical thinking and problem solving - were studied in more detail. The majority of measurements examined components such as ICT usage (technical), define, access, manage and evaluate digital information (information management), justification (critical thinking) and the active use of knowledge to find a solution (problem solving). Although 21stcentury skills have been widely recognized, the main emphasis in assessment is still on the functional skills such as technical knowledge and usage (Ahonen \& Kinnunen, 2015). Ahonen and Kinnunen (2015) revealed that students rated social skills and collaboration as the most important competences needed in the future. Our systematic literature review shows a lack of extensive tests targeting students' soft skills, understood to be behavioral and other nontechnical skills (Cobo, 2013). One conceivable explanation for why some skills are measured more frequently than others is that soft skills are regarded as hard to observe, quantify or measure (Cobo, 2013; Silva, 2009). Another explanation is that the list of 21st-century skills is extensive, and it is therefore impossible to develop one test that covers all such skills (Aesaert \& Van Braak, 2015). Many 21st-century skills categorizations are given to an extended range of terms; however, only a few frameworks are available to provide operational components. Because of the limited amount of research in this area, it was difficult to establish operational components for each skill. This lack of research also means that potentially there are more operational components and future research could further elaborate on our skills framework.

Another future research direction is that the majority of measurement tools available target secondary students, pointing to the lack of tests targeting employees, and thus motivating the development of tests for these groups of participants. Besides, a considerable proportion of the measures developed for gauging participants' skills are based on self-reports in which they are asked to evaluate how well they perform on certain skill-related tasks (Aesaert, Van Nijlen, Vanderlinde, \& Van Braak, 2014). Such indirect measures have been recognized as challenging as they only provide rough proxies for actual skil levels. The increasing attention given to 21 st-century skills has also resulted in an increasing interest in whether and how to include the assessment of these skills in large-scale tests. Assessments allow us to determine to what extent employees have obtained the 21 st-century digital skills that are required to enable them to be productive members of an information-rich and technologybased society (Ahmad et al., 2013). If the argument of the centrality of 21stcentury digital skills for employability is accepted, then data should become available about the actual skill levels within the workforce. Performance tests could be a suitable measurement method for future research. They provide a more realistic view of employees' skill levels as a variety of skill indices can be extracted based on directly demonstrated performance. Given that a tradition of measuring the various aspects of 21 st-century digital skills has not yet been established, it may be useful to carry out smaller in-depth qualitative studies before launching large-scale quantitative assessments. This recommendation is addressed in Chapter 3, because here we report the results of an in-depth qualitative interview study concerning the meaning of 21 st-century digital skills within the creative industries.

\subsection{CONCLUSION}

The premise of this study was that to meet the current demands of the workforce, it is necessary to propose a new conceptual framework that includes 21st-century digital skills. This chapter searched for the digital equivalent of 21 st-century skills. Both 21 st-century skills and digital skills studies emphasize 
content-related skills, but the integration is not yet sufficiently defined. The vision of 21st-century digital skills is that those skills are required to participate in the knowledge-based workforce and to put employees in charge of their own learning. The essence is what employees can do with knowledge to support 21st-century skills and take full advantage of ICT. Defining 21st-century digital skills as precisely as possible is an essential first step to identify, and possibly quantify, current and expected needs.

\section{APPENDIX 2.A REFERENCES INCLUDED STUDIES}

Aharony, N., \& Bronstein, J. (2013). Academic librarians' perceptions on information literacy: The Israeli perspective. Portal, 14(1), 103-119. doi:10.1353/pla.2013.0040.

Ahmad, M., Badusah, J., Mansor, A. Z, Karim, A. A, Khalid, F, Daud, M. Y, Din, R. \& Zulkefle, D. F. (2016). The application of 21st century ICT literacy model among teacher trainees. Turkish Online Journal of Educational Technology, 15(3), 151-161.

Ahonen, A. K., \& Kinnunen, P. (2015). How do students value the importance of twentyfirst century skills? Scandinavian Journal of Educational Research, 59(4), 1-18. doi:10.1080/00313831.2014.904423

Alozie, N. M., Grueber, D. J., \& Dereski, M. O. (2012). Promoting 21st-century skills in the science classroom by adapting cookbook lab activities: The case of DNA extraction of wheat germ. American Biology Teacher, 74(7), 485-489. doi:10.1525/ abt.2012.74.7.10.

Anderman, E. M., Sinatra, G. M., \& Gray, D. L. (2012). The challenges of teaching and learning about science in the twenty-first century: Exploring the abilities and constraints of adolescent learners. Studies in Science Education, 48(1), 89-117. doi:10.1080/03057267.2012.655038.

Barak, M. (2017). Science teacher education in the twenty-first century: A pedagogical framework for technology-integrated social constructivism. Research in Science Education, 47(2), 283-303. doi:10.1007/s11165-015-9501-y.

Barbot, B., Besançon, M., \& Lubart, T. (2015). Creative potential in educational settings: Its nature, measure and nurture. Education 3-13, 43(4), 371-381. doi:10.1080/0300 4279.2015.1020643

Boyaci, Ş. D. B., \& Atalay, N. (2016). A scale development for 21 st century skills of primary school students: A validity and reliability study. International Journal of Instruction 9(1), 133-148.

Calvani, A., Fini, A., Ranieri, M., \& Picci, P. (2012). Are young generations in secondary school digitally competent? A study on Italian teenagers. Computers \& Education 58(2), 797-807. doi:10.1016/j.compedu.2011.10.004

Care, E., Scoular, C., \& Griffin, P. (2016). Assessment of collaborative problem solving in education environments. Applied Measurement in Education, 29(4), 250-264. doi:10.1080/08957347.2016.1209204.

Caviglia, F., \& Delfino, M. (2015). Foundational skills and dispositions for learning: An experience with information problem solving on the web. Technology, Pedagogy and Education, 25(4), 1-26. doi:10.1080/1475939X.2015.1080756.

Chai, C. S., Deng, F., Tsai, P. S., Koh, J. H. L., \& Tsai, C. C. (2015). Assessing multidimensional students' perceptions of twenty-first-century learning practices. Asia Pacific Education Review, 16(3), 389-398. doi:10.1007/s12564-015-9379-4.

Choi, K., Lee, H., Shin, N., Kim, S.-W., \& Krajcik, J. (2011). Re-conceptualization of scientific literacy in South Korea for the 21st century. Journal of Research in Science Teaching, 48(6), 670-697. doi:10.1002/tea.20424. 
Choy, D., Deng, F., Chai, C. S., Koh, H. L. J., \& Tsai, P. S. (2016). Singapore primary and secondary students' motivated approaches for learning: A validation study. Learning and Individual Differences, 45, 282-290. doi:10.1016/j.lindif.2015.11.019.

Claro, M., Preiss, D. D., San Martín, E., Jara, I., Hinostroza, J. E., Valenzuela, S., Cortes, F., \& Nussbaum, M. (2012). Assessment of 21st century ICT skills in Chile: Test design and results from high school level students. Computers \& Education, 59(3), 1042 1053. doi:10.1016/j.compedu.2012.04.004.

Cobo, C. (2013). Mechanisms to identify and study the demand for innovation skills in world-reowned organizations. On the Horizon, 21(2), 96-106. doi:10.1108/10748121311322996.

De Bie, H., Wilhelm, P., \& Van der Meij, H. (2015). The Halpern Critical Thinking Assessment (HCTA): Toward a Dutch appraisal of critical thinking. Thinking Skills and Creativity, 17, 33-44. doi:10.1016/j.tsc.2015.04.001.

DiCerbo, K. E. (2014). Game-based assessment of persistence. Journal of Educational Technology \& Society, 17(1), 17-28.

Donovan, L., Green, T. D., \& Mason, C. (2014). Examining the 21st century classroom: Developing an innovation configuration map. Journal of Educational Computing Research, 50(2), 161-178. doi:10.2190/EC.50.2.a.

Dwyer, C. P., Hogan, M. J., \& Stewart, I. (2014). An integrated critical thinking framework for the 21st century. Thinking Skills and Creativity, 12, 43-52. doi:10.1016/j. tsc.2013.12.004

Eisenderg, M. B. (2011). Develop and deliver essential information literacy programs Journal of the Korean Library and Information Science Society, 45(2), 5-21. doi:10.4275/KSLIS.2011.45.2.005.

Eshet-Alkalai, Y., \& Chajut, E. (2009). Changes over time in digital literacy. CyberPsychology \& Behavior, 12(6), 713-715. doi:10.1089/cpb.2008.0264.

Gerber, S., \& Scott, L. (2011). Gamers and gaming context: Relationships to critical thinking. British Journal of Educational Technology, 42(5), 842-849. doi:10.1111/ j.1467-8535.2010.01106.x.

Gobert, J. D., Kim, Y. J., Sao Pedro, M. A., Kennedy, M., \& Betts, C. G. (2015). Using educational data mining to assess students' skills at designing and conducting experiments within a complex systems microworld. Thinking Skills and Creativity, 18, 81-90. doi:10.1016/j.tsc.2015.04.008.

Greene, J. A., Yu, S. B., \& Copeland, D. Z. (2014). Measuring critical components of digital literacy and their relationships with learning. Computers \& Education, 76 55-69. doi:10.1016/j.compedu.2014.03.008.

Greiff, S., Wüstenberg, S., Holt, D. V., Goldhammer, F., \& Funke, J. (2013). Computerbased assessment of complex problem solving: Concept, implementation and application. Educational Technology Research \& Development, 61(3), 407-421. doi:10.1007/s11423-013-9301-x.

Gui, M., \& Argentin, G. (2011). Digital skills of Internet natives: Different forms of digital literacy in a random sample of northern Italian high school students. New Media \& Society, 13(6), 963-980. doi:10.1177/14614448810389751
Hatlevik, O. E., Gudmundsdóttir, G. B., \& Loi, M. (2015). Examining factors predicting students' digital competence. Journal of Information Technology Education, 14, 123-137.

Helsper, E. J., \& Eynon, R. (2013). Distinct skill pathways to digital engagement. European Journal of Communication, 28(6), 696-713. doi:10.1177/0267323113499113.

Herde, C. N. Wüstenberg, S. \& Greiff, S. (2016). Assessment of complex problem solving: What we know and what we don't know. Applied Measurement in Education, 29(4), 265-277. doi:1080/08957347.2016.1209208.

Heye, D. (2006). Creativity and innovation: Two key characteristics of the successfu 21st century information professional. Business Information Review, 23(4), 252-257. doi:10.1177/0266382106072255.

Hinrichsen, J., \& Coombs, A. (2013). The five resources of critical digital literacy: A framework for curriculum integration. Research in Learning Technology, 21, 1-16. doi:10.3402/rlt.v21.21334

Holt, L., \& Brockett, R. G. (2012). Self-direction and factors influencing technology use: Examining the relationships for the 21st century workplace. Computers in Human Behavior, 28(6), 2075-2082. doi:10.1016/j.chb.2012.06.011.

Ibrahim, M. L., \& Jimoh, A. O. (2013). Sustainable teacher education in Nigeria through information literacy in the 21st century. Mediterranean Journal of Social Sciences, 4(12), 75-80. doi:10.5901/mjss.2013.v4n12p75.

Jang, H. (2015). Identifying 21st century STEM competencies using workplace data. Journal of Science Education \& Technology, 25(2), 1-18. doi:10.1007/s10956-015 9593-1.

Janssen, J., Stoyanov, S., Ferrari, A., Punie, Y., Pannekeet, K., \& Sloep, P. (2013). Experts' views on digital competence: Commonalities and differences. Computers \& Education, 68, 473-481. doi:10.1016/j.compedu.2013.06.008.

Jara, I., Claro, M., Hinostroza, J. E., San Martín, E., Rodríguez, P., Cabello, T., Ibieta, A., Labbé, C. (2015). Understanding factors related to Chilean students' digital skills: A mixed methods analysis. Computers \& Education, 88, 387-398. doi:10.1016/j. compedu.2015.07.016.

Järvelä, S. (2015). How research on self-regulated learning can advance computer supported collaborative learning. Journal for the Study of Education and Development, 38(2), 279-294. doi:10.1080/02103702.2015.1016747.

Kingsley, T. L., \& Grabner-Hagen, M. M. (2015). Gamification: Questing to integrate content knowledge, literacy and 21st-century learning. Journal of Adolescent \& Adult Literacy, 59(1), 51-61. doi:10.1002/jaal.426.

Lee, C. S., \& Kolodner, J. L. (2011). Scaffolding students' development of creative design skills: A curriculum reference model. Journal of Educational Technology \& Society, 14(1), 3-15.

Lee, H., Parsons, D., Kwon, G., Kim, J., Petrova, K., Jeong, E., \& Ryu, H. (2016). Cooperation begins: Encouraging critical thinking skills through cooperative reciprocity using a mobile learning game. Computers \& Education, 97, 97-115. doi:10.1016/j.compedu.2016.03.006. 
Levinsen, K. T. (2011). Fluidity in the networked society: Self-initiated learning as a digital literacy competence. Electronic Journal of E-Learning, 9(1), 52-62.

Lloyd, A. (2011). Trapped between a rock and a hard place: What counts as information literacy in the workplace and how is it conceptualized? Library Trends, 60(2), 277 296. doi:10.1353/lib.2011.0046.

Lombardi, A. R., Kowitt, J. S., \& Staples, F. E. (2015). Correlates of critical thinking and college and career readiness for students with and without disabilities. Career Development and Transition for Exceptional Individuals, 38(3), 142-151. doi:10.1177/2165143414534888.

Mainert, J., Kretzschmar, A., Neubert, J. C., \& Greiff, S. (2015). Linking complex problem solving and general mental ability to career advancement: Does a transversal skil reveal incremental predictive validity? International Journal of Lifelong Education 34(4), 393-411. doi:10.1080/02601370.2015.106002.

McNicol, S. (2015). Modelling information literacy for classrooms of the future. Journal of Librarianship and Information Science, 47(4), 303-313. doi:10.1177/0961000614526612.

Mengual-Andrés, S., Roig-Vila, R., \& Mira, J. B. (2016). Delphi study for the design and validation of a questionnaire about digital competences in higher education. International Journal of Educational Technology in Higher Education, 13(1), 1-11. doi:10.1186/s41239-016-0009-y.

Mohammadyari, S., \& Singh, H. (2015). Understanding the effect of e-learning on individual performance: The role of digital literacy. Computers \& Education, 82, 11-25. doi:10.1016/j.compedu.2014.10.025.

Monge, R., \& Frisicaro-Pawlowski, E. (2014). Redefining information literacy to prepare students for the 21st century workforce. Innovative Higher Education, 39(1), 59-73. doi:10.1007/s1075501392605

Ng, W. (2012). Can we teach digital natives digital literacy? Computers \& Education 59(3), 1065-1078. doi:10.1016/j.compedu.2012.04.016.

Niepel, C., Mustafić, M., Greiff, S., \& Roberts, R. D. (2015). The dark side of creativity revisited: Is students' creativity associated with subsequent decreases in thei ethical decision making? Thinking Skills and Creativity, 18, 43-52. doi:10.1016/j. tsc.2015.04.005

Obschonka, M., Hakkarainen, K., Lonka, K., \& Salmela-Aro, K. (2017). Entrepreneurship as a twenty-first century skill: Entrepreneurial alertness and intention in the transition to adulthood. Small Business Economics, 48(3), 1-15. doi:10.1007/s11187-016-9798-6.

Osman, K., Hamid, S. H. A., \& Hassan, A. (2009). Standard setting: Inserting domain of the 21 st century thinking skills into the existing science curriculum in Malaysia. Procedia - Social and Behavioral Sciences, 1(1), 2573-2577. doi:10.1016/j.sbspro.2009.01.454.

Quieng, M. C., Lim, P. P., \& Lucas, M. R. D. (2015). 21st Century-based soft skills: Spotlight on non-cognitive skills in a cognitive-laden dentistry program. European Journal of Contemporary Education, 11(1), 72-81. doi:10.13187/ejced.2015.11.72.

Ras, E., Krkovic, K., Greiff, S., Tobias, E., \& Maquil, V. (2014). Moving towards the assessment of collaborative problem-solving skills with a tangible user interface. Turkish Online Journal of Educational Technology, 13(4), 95-104.
Razzouk, R., \& Shute, V. (2012). What is design thinking and why is it important? Review of Educational Research, 82(3), 330-348. doi:10.3102/0034654312457429.

Redecker, C., \& Johannessen, O. (2013). Changing assessment: Towards a new assessment paradigm using ICT. European Journal of Education, 48(1), 79-96. doi:10.1111/ejed.12018.

Romero, M., Usart, M. \& Ott, M. (2015). Can serious games contribute to developing and sustaining 21st century skills? Games and Culture, 10(2), 148-177. doi:10.1177/1555412014548919

Salas-Pilco, S. Z. (2013). Evolution of the framework for 21st century competencies. Knowledge Management \& E-Learning, 5(1), 10-24.

Scherer, R., \& Gustafsson, J. E. (2015). The relations among openness, perseverance and performance in creative problem solving: A substantive-methodological approach. Thinking Skills and Creativity, 18, 4-17. doi:10.1016/j.tsc.2015.04.004.

Siddiq, F., Scherer, R., \& Tondeur, J. (2016). Teachers' emphasis on developing students' digital information and communication skills (TEDDICS): A new construct in 21st century education. Computers \& Education, 92-93, 1-14. doi:10.1016/j. compedu.2015.10.006.

Smith, A. M. J., \& Paton, R. A. (2014). Embedding enterprise education: A service based transferable skills framework. International Journal of Management Education, 12(3), 550-560. doi:10.1016/j.ijme.2014.02.002.

Snow, E., \& Katz, I. R. (2009). Using cognitive interviews to validate an interpretive argument for the ETS iSkills ${ }^{\mathrm{TM}}$ assessment. Communications in Information Literacy, 3(2), 99-127. doi:10.15760/comminfolit.2010.3.2.75.

Soh, T. M. T., Osman, K., \& Arsad, N. M. (2012). M-21CSI: A validated 21st century skills instrument for secondary science students. Asian Social Science, 8(16), 38-44. doi:10.5539/ass.v8n16p38.

Somerville, M. M. Smith, G. W. \& Macklin, A. S. (2008). The ETS iSkillsTM Assessment: A digital age tool. Electronic Library, 26(2), 158-171. doi:10.1108/02640470810864064.

Soulé, H., \& Warrick, T. (2015). Defining 21st century readiness for all students: What we know and how to get there. Psychology of Aesthetics, Creativity, and the Arts, 9(2), 178-186. doi:10.1037/aca0000017.

Thoman, E., \& Jolls, T. (2004). Media literacy: A national priority for a changing world. American Behavioral Scientist, 48(1), 18-29. doi:10.1177/0002764204267246.

Uzunboylu, H., \& Hürsen, C. (2011). Lifelong learning competence scale (Lllcs): The study of validity and reliability. Hacettepe Egitim Dergisi, 41, 449-460.

Van Deursen, A. J. A. M., Helsper, E. J., \& Eynon, R. (2016). Development and validation of the Internet Skills Scale (ISS). Information, Communication \& Society, 19(6), 804 823. doi:10.1080/1369118X.2015.1078834.

Voogt, J. M., \& Pareja Roblin, N. (2012). A comparative analysis of internationa frameworks for 21st century competences: Implications for national curriculum policies. Journal of Curriculum Studies, 44(3), 299-321. doi:10.1080/00220272.20 12.668938 . 
Westby, C. (2010). Multiliteracies: The changing world of communication. Topics in Language Disorders, 30(1), 64-71. doi:10.1097/TLD.0b013e3181d0a0ab.

Woods-Groves, S. (2015). The human behavior rating scale-brief: A tool to measure 21st century skills of k-12 learners. Psychological Reports, 116(3), 769-796. doi:10.2466/03.11.PR0.116k29w0

Wüstenberg, S., Stadler, M., Hautamäki, J., \& Greiff, S. (2014). The role of strategy knowledge for the application of strategies in complex problem-solving tasks. Technology, Knowledge and Learning, 19(1-2), 127-146. doi:10.1007/s10758-0149222-8.

Yang, J., Huiju, Y., Chen, S.-J., \& Huang, R. (2014). Strategies for smooth and effective cross-cultural online collaborative learning. Journal of Educational Technology \& Society, 17(3), 208-221.

Young, J. A. (2015). Assessing new media literacies in social work education: The development and validation of a comprehensive assessment instrument. Journa of Technology in Human Services, 33(1), 72-86. doi:10.1080/15228835.2014.998577.
APPENDIX 2.B INCLUDED STUDIES WITH SKILL DIMENSIONS AND

\section{MAIN CONCEPT}

\begin{tabular}{|c|c|c|}
\hline Author/Year & 21st-century (digital) skill dimensions & Main concept \\
\hline $\begin{array}{l}\text { Aharony and } \\
\text { Bronstein (2013) }\end{array}$ & Information literacy & $\begin{array}{l}\text { Information } \\
\text { literacy }\end{array}$ \\
\hline $\begin{array}{l}\text { Ahmad et al. } \\
\text { (2016) }\end{array}$ & $\begin{array}{l}\text { Defining, accessing, evaluating, managing, integrating, } \\
\text { creating, communicating }\end{array}$ & $\begin{array}{l}\text { 21st-century } \\
\text { ICT literacy }\end{array}$ \\
\hline $\begin{array}{l}\text { Ahonen and } \\
\text { Kinnunen (2015) }\end{array}$ & $\begin{array}{l}\text { Collaboration, problem solving, creativity, communication, } \\
\text { critical thinking, information literacy, technical proficiency, } \\
\text { citizenship, independent Initiative, work skills, cultural } \\
\text { awareness, social responsibility, learning skills and lifelong } \\
\text { learning, ecological awareness }\end{array}$ & $\begin{array}{l}\text { Twenty-first } \\
\text { century skills }\end{array}$ \\
\hline $\begin{array}{l}\text { Alozie, Grueber, } \\
\text { and Dereski (2012) }\end{array}$ & $\begin{array}{l}\text { Adaptability, complex communication/social skills, } \\
\text { non- routine problem solving, self-management/self- } \\
\text { development, systems thinking }\end{array}$ & $\begin{array}{l}\text { 21st-century } \\
\text { skills }\end{array}$ \\
\hline $\begin{array}{l}\text { Anderman, } \\
\text { Sinatra, and Gray } \\
\text { (2012) }\end{array}$ & $\begin{array}{l}\text { Adaptability, complex communication/social skills, } \\
\text { nonroutine problem solving skills, self-management/self- } \\
\text { development, systems thinking }\end{array}$ & $\begin{array}{l}\text { Twenty-first } \\
\text { century skills }\end{array}$ \\
\hline Barak (2016) & $\begin{array}{l}\text { Adapting to frequent changes and uncertain situations, } \\
\text { collaborating and communicating in decentralized } \\
\text { environments, generating data and managing } \\
\text { information, releasing control by encouraging exploration }\end{array}$ & $\begin{array}{l}\text { Twenty-first } \\
\text { century } \\
\text { competence }\end{array}$ \\
\hline $\begin{array}{l}\text { Barbot, Besançon, } \\
\text { and Lubart (2015) }\end{array}$ & Creativity & $\begin{array}{l}\text { Twenty-first } \\
\text { century skills }\end{array}$ \\
\hline $\begin{array}{l}\text { Boyaci and Atalay } \\
\text { (2016) }\end{array}$ & $\begin{array}{l}\text { Creativity and innovation, critical thinking and problem } \\
\text { solving, cooperation, communication }\end{array}$ & $\begin{array}{l}\text { 21st-century } \\
\text { learning skills }\end{array}$ \\
\hline $\begin{array}{l}\text { Calvani et al. } \\
\text { (2012) }\end{array}$ & $\begin{array}{l}\text { ICT knowledge: visual literacy, trouble shooting, } \\
\text { understanding technological concepts; Higher-order } \\
\text { cognitive skills: organizing and connecting textual and } \\
\text { visual data, organizing structured data, information } \\
\text { research; Ethical knowledge: staying safe online, respect } \\
\text { on the net, understanding social and technological } \\
\text { inequality }\end{array}$ & $\begin{array}{l}\text { Digital } \\
\text { competence }\end{array}$ \\
\hline $\begin{array}{l}\text { Care, Scoular, and } \\
\text { Griffin (2016) }\end{array}$ & Collaborative problem solving & $\begin{array}{l}21 \text { st-century } \\
\text { skills }\end{array}$ \\
\hline $\begin{array}{l}\text { Caviglia and } \\
\text { Delfino (2016) }\end{array}$ & Information problem solving & Digital literacy \\
\hline Chai et al. (2015) & $\begin{array}{l}\text { Self-directed learning, collaborative learning, meaningful } \\
\text { learning with technology, critical thinking, creative } \\
\text { thinking, authentic problem solving, knowledge creation } \\
\text { efficacy }\end{array}$ & $\begin{array}{l}\text { Twenty-first } \\
\text { century } \\
\text { learning skills }\end{array}$ \\
\hline
\end{tabular}


Appendix 2.B Continued

\begin{tabular}{|c|c|c|}
\hline Author/Year & 21st-century (digital) skill dimensions & Main concept \\
\hline Choi et al. (2011) & $\begin{array}{l}\text { Communication, collaboration, systematic thinking, use } \\
\text { of evidence to support claims, information management, } \\
\text { self-directed planning, monitoring, evaluation }\end{array}$ & $\begin{array}{l}\text { Twenty-first } \\
\text { century } \\
\text { thinking skills }\end{array}$ \\
\hline Choy et al. (2016) & Self-directed learning, collaborative learning & $\begin{array}{l}\text { 21st-century } \\
\text { skills }\end{array}$ \\
\hline Claro et al. (2012) & $\begin{array}{l}\text { ICT fluency/skill in sourcing for information, ICT } \\
\text { skills in processing information, ICT skills in effective } \\
\text { communication, ICT skills in collaboration and virtual } \\
\text { interactions, ICT responsible use, ICT social impact }\end{array}$ & $\begin{array}{l}\text { 21st-century } \\
\text { ICT skills }\end{array}$ \\
\hline Cobo (2013) & $\begin{array}{l}\text { Collaboration, critical thinking, contextual learning, } \\
\text { searching, synthesizing and disseminating information, } \\
\text { communication, self-direction, creativity }\end{array}$ & $\begin{array}{l}21 \text { st-century } \\
\text { skills }\end{array}$ \\
\hline $\begin{array}{l}\text { De Bie, Wilhelm, } \\
\text { and Van der Meij } \\
\text { (2015) }\end{array}$ & Critical thinking & $\begin{array}{l}\text { 21st-century } \\
\text { skills }\end{array}$ \\
\hline DiCierbo (2014) & Task persistence & $\begin{array}{l}\text { 21st-century } \\
\text { skills }\end{array}$ \\
\hline $\begin{array}{l}\text { Donovan, Green, } \\
\text { and Mason (2014) }\end{array}$ & $\begin{array}{l}\text { Creativity and innovation, critical thinking and problem } \\
\text { solving, communication, collaboration }\end{array}$ & $\begin{array}{l}21 \text { st-century } \\
\text { skills }\end{array}$ \\
\hline $\begin{array}{l}\text { Dwyer, Hogan, } \\
\text { and Stewart (2014) }\end{array}$ & Critical thinking & $\begin{array}{l}21 \text { st-century } \\
\text { thinking skills }\end{array}$ \\
\hline Eisenderg (2011) & Information literacy & $\begin{array}{l}21 \text { st-century } \\
\text { skills }\end{array}$ \\
\hline $\begin{array}{l}\text { Eshet-Alkali and } \\
\text { Chajut (2009) }\end{array}$ & $\begin{array}{l}\text { Photo-visual literacy, reproduction literacy, branching } \\
\text { literacy, information literacy, socio-emotional literacy }\end{array}$ & Digital literacy \\
\hline $\begin{array}{l}\text { Gerber and Scott } \\
\text { (2011) }\end{array}$ & Critical thinking & $\begin{array}{l}\text { 21st-century } \\
\text { skills }\end{array}$ \\
\hline $\begin{array}{l}\text { Gobert et al. } \\
\text { (2015) }\end{array}$ & $\begin{array}{l}\text { Critical thinking, nonroutine problem solving, systems- } \\
\text { thinking }\end{array}$ & $\begin{array}{l}\text { 21st-century } \\
\text { skills }\end{array}$ \\
\hline $\begin{array}{l}\text { Greene, Yu, and } \\
\text { Copeland (2014) }\end{array}$ & Self-regulated learning skills, epistemic cognition & Digital literacy \\
\hline Greiff et al. (2013) & Complex problem solving & $\begin{array}{l}\text { Transversal } \\
\text { skills }\end{array}$ \\
\hline $\begin{array}{l}\text { Gui and Argentin } \\
\text { (2011) }\end{array}$ & Theoretical, operational, evaluation & Digital skills \\
\hline $\begin{array}{l}\text { Hatlevik, } \\
\text { Gudmundsdóttir, } \\
\text { and Loi (2015) }\end{array}$ & $\begin{array}{l}\text { Retrieve and handle digital information, create and } \\
\text { process digital information, digital judgement, digital } \\
\text { communication }\end{array}$ & $\begin{array}{l}\text { Digital } \\
\text { competence }\end{array}$ \\
\hline $\begin{array}{l}\text { Helsper and Eynon } \\
\text { (2013) }\end{array}$ & Technical, social, creative, critical & Digital skills \\
\hline
\end{tabular}

Appendix 2.B Continued

\begin{tabular}{|c|c|c|}
\hline Author/Year & 21st-century (digital) skill dimensions & Main concept \\
\hline $\begin{array}{l}\text { Herde, } \\
\text { Wüstenberg, and } \\
\text { Greiff (2016) }\end{array}$ & Complex problem solving & $\begin{array}{l}\text { 21st-century } \\
\text { skills }\end{array}$ \\
\hline Heye (2006) & Creativity and innovation & $\begin{array}{l}\text { 21st-century } \\
\text { skills }\end{array}$ \\
\hline $\begin{array}{l}\text { Hinrichsen and } \\
\text { Coombs (2013) }\end{array}$ & Decoding, meaning making, using, analyzing, personal & Digital literacy \\
\hline $\begin{array}{l}\text { Holt and Brockett } \\
\text { (2012) }\end{array}$ & Self-direction, technology use & $\begin{array}{l}21 \text { st-century } \\
\text { skills }\end{array}$ \\
\hline $\begin{array}{l}\text { Ibrahim and Jimoh } \\
\text { (2013) }\end{array}$ & Information literacy & $\begin{array}{l}\text { Information } \\
\text { literacy }\end{array}$ \\
\hline Jang (2015) & $\begin{array}{l}\text { Problem solving, social communication, technology and } \\
\text { engineering, systems thinking, time management }\end{array}$ & $\begin{array}{l}\text { 21st-century } \\
\text { skills }\end{array}$ \\
\hline $\begin{array}{l}\text { Janssen et al. } \\
\text { (2013) }\end{array}$ & $\begin{array}{l}\text { General knowledge and functional skills, use in } \\
\text { everyday life, specialized and advanced competence } \\
\text { for work and creative expression, technology mediated } \\
\text { communication and collaboration, information processing } \\
\text { and management, privacy and security, legal and } \\
\text { ethical aspects, balanced attitude toward technology, } \\
\text { understanding and awareness of role of ICT in society, } \\
\text { learning about and with digital technologies, informed } \\
\text { decisions on appropriate digital technologies, seamless } \\
\text { use demonstrating self-efficacy }\end{array}$ & $\begin{array}{l}\text { Digital } \\
\text { competence }\end{array}$ \\
\hline Jara et al. (2013) & Information, communication, ethics and social impact & Digital skills \\
\hline Järvelä (2015) & $\begin{array}{l}\text { Computer-supported collaborative learning, self- } \\
\text { regulated learning }\end{array}$ & $\begin{array}{l}\text { Twenty-first } \\
\text { century skills }\end{array}$ \\
\hline $\begin{array}{l}\text { Kingsley and } \\
\text { Grabner-Hagen } \\
\text { (2015) }\end{array}$ & $\begin{array}{l}\text { Creativity and innovation, critical thinking and problem } \\
\text { solving, communication, collaboration }\end{array}$ & $\begin{array}{l}\text { 21st-century } \\
\text { learning skills }\end{array}$ \\
\hline $\begin{array}{l}\text { Lee and Kolodner } \\
\text { (2011) }\end{array}$ & Creative design & $\begin{array}{l}\text { Twenty-first } \\
\text { century skills }\end{array}$ \\
\hline Lee et al. (2016) & Critical thinking & $\begin{array}{l}\text { 21st-century } \\
\text { learning skills }\end{array}$ \\
\hline Levinsen (2011) & Lifelong learning & Digital literacy \\
\hline Lloyd (2011) & Information literacy & $\begin{array}{l}\text { Information } \\
\text { literacy }\end{array}$ \\
\hline $\begin{array}{l}\text { Lombardi, Kowitt, } \\
\text { and Staples (2014) }\end{array}$ & Critical thinking & $\begin{array}{l}21 \text { st-century } \\
\text { skills }\end{array}$ \\
\hline $\begin{array}{l}\text { Mainert et al. } \\
\text { (2015) }\end{array}$ & Complex problem solving & $\begin{array}{l}\text { Twenty-first } \\
\text { century skills }\end{array}$ \\
\hline
\end{tabular}


Appendix 2.B Continued

\begin{tabular}{|c|c|c|}
\hline Author/Year & 21st-century (digital) skill dimensions & Main concept \\
\hline McNicol (2014) & $\begin{array}{l}\text { Design and creation, information gathering, collaboration, } \\
\text { flexibility }\end{array}$ & $\begin{array}{l}\text { Information } \\
\text { literacy }\end{array}$ \\
\hline $\begin{array}{l}\text { Mengual-Andrés, } \\
\text { Roig-Vila, and Mira } \\
\text { (2016) }\end{array}$ & $\begin{array}{l}\text { Technological literacy, information access and use, } \\
\text { communication and collaboration, digital citizenship, } \\
\text { creativity and innovation }\end{array}$ & $\begin{array}{l}\text { Digital } \\
\text { competence }\end{array}$ \\
\hline $\begin{array}{l}\text { Mohammadyari } \\
\text { and Singh (2015) }\end{array}$ & $\begin{array}{l}\text { Operate different types of computers and access } \\
\text { resources, search, find and evaluate information } \\
\text { effectively, use technological tools to accomplish tasks, } \\
\text { solve problems, act appropriately in online communities, } \\
\text { keep oneself away from harm in digital environments }\end{array}$ & Digital literacy \\
\hline $\begin{array}{l}\text { Monge and } \\
\text { Frisicaro- } \\
\text { Pawlowski (2014) }\end{array}$ & Facility in managing information, sensitivity, versatility & $\begin{array}{l}\text { Information } \\
\text { literacy }\end{array}$ \\
\hline $\mathrm{Ng}(2012)$ & Technical, cognitive, social-emotional & Digital literacy \\
\hline Niepel et al. (2015) & Creativity, ethical decision making & $\begin{array}{l}\text { 21st-century } \\
\text { skills }\end{array}$ \\
\hline $\begin{array}{l}\text { Obschonka et al. } \\
\text { (2017) }\end{array}$ & Entrepreneurship & $\begin{array}{l}21 \text { st-century } \\
\text { skills }\end{array}$ \\
\hline $\begin{array}{l}\text { Osman, Hamid, } \\
\text { and Hassan (2009) }\end{array}$ & $\begin{array}{l}\text { Adaptability and managing complexity, self-direction, } \\
\text { curiosity, creativity, risk taking, higher-order thinking and } \\
\text { sound reasoning }\end{array}$ & $\begin{array}{l}\text { 21st-century } \\
\text { thinking skills }\end{array}$ \\
\hline $\begin{array}{l}\text { Quieng, Lim, and } \\
\text { Lucas (2015) }\end{array}$ & $\begin{array}{l}\text { Communication, collaboration and relationships, critical } \\
\text { thinking and decision making, self-direction and initiative }\end{array}$ & $\begin{array}{l}21 \text { st-century } \\
\text { skills }\end{array}$ \\
\hline Ras et al. (2014) & Collaborative problem solving & $\begin{array}{l}\text { 21st-century } \\
\text { skills }\end{array}$ \\
\hline $\begin{array}{l}\text { Razzouk and Shute } \\
\text { (2012) }\end{array}$ & Design thinking & $\begin{array}{l}\text { 21st-century } \\
\text { skills }\end{array}$ \\
\hline $\begin{array}{l}\text { Redecker and } \\
\text { Johannessen } \\
\text { (2013) }\end{array}$ & $\begin{array}{l}\text { Problem solving, reflection, creativity, critical } \\
\text { thinking, learning to learn, risk-taking, collaboration, } \\
\text { entrepreneurship }\end{array}$ & $\begin{array}{l}\text { 21st-century } \\
\text { skills }\end{array}$ \\
\hline $\begin{array}{l}\text { Romero, Usart, } \\
\text { and Ott (2015) }\end{array}$ & $\begin{array}{l}\text { Collaboration, communication, ICT literacy, social } \\
\text { and cultural citizenship, creativity, critical thinking, } \\
\text { problem solving, productivity, learning to learn, self- } \\
\text { direction, flexibility and adaptability, risk taking, conflict } \\
\text { management, initiative and entrepreneurship }\end{array}$ & $\begin{array}{l}\text { 21st-century } \\
\text { skills }\end{array}$ \\
\hline Salas-Pilco (2013) & $\begin{array}{l}\text { Communication and collaboration, citizenship and social } \\
\text { responsibility, information and research, digital literacy, } \\
\text { creativity and innovation, critical thinking and decision } \\
\text { making, sociocultural sensitivity and awareness, autonomy } \\
\text { and leadership, learning to learn and metacognition, } \\
\text { productivity, entrepreneurship, life and career, math and } \\
\text { science }\end{array}$ & $\begin{array}{l}\text { 21st-century } \\
\text { competence }\end{array}$ \\
\hline
\end{tabular}

Appendix 2.B Continued

\begin{tabular}{|c|c|c|}
\hline Author/Year & 21st-century (digital) skill dimensions & Main concept \\
\hline $\begin{array}{l}\text { Scherer and } \\
\text { Gustafsson (2015) }\end{array}$ & Creative problem solving & $\begin{array}{l}21 \text { st-century } \\
\text { skills }\end{array}$ \\
\hline $\begin{array}{l}\text { Siddiq, Scherer, } \\
\text { and Tondeur } \\
\text { (2016) }\end{array}$ & $\begin{array}{l}\text { Accessing, evaluating, sharing and communicating digital } \\
\text { information }\end{array}$ & Digital skills \\
\hline $\begin{array}{l}\text { Smith and Paton } \\
\text { (2014) }\end{array}$ & Information usage, self, communication & $\begin{array}{l}\text { Transferable } \\
\text { skills }\end{array}$ \\
\hline $\begin{array}{l}\text { Snow and Katz } \\
\text { (2009) }\end{array}$ & $\begin{array}{l}\text { Define, access, evaluate, manage, integrate, create, } \\
\text { communicate }\end{array}$ & $\begin{array}{l}\text { 21st-century } \\
\text { skills }\end{array}$ \\
\hline $\begin{array}{l}\text { Soh, Osman, and } \\
\text { Arsad (2012) }\end{array}$ & $\begin{array}{l}\text { Digital age literacy, inventive thinking, effective } \\
\text { communication, high productivity, spiritual value }\end{array}$ & $\begin{array}{l}21 \text { st-century } \\
\text { skills }\end{array}$ \\
\hline $\begin{array}{l}\text { Somerville, Smith, } \\
\text { and Macklin (2008) }\end{array}$ & $\begin{array}{l}\text { Define, access, evaluate, manage, integrate, create, } \\
\text { communicate }\end{array}$ & $\begin{array}{l}21 \text { st-century } \\
\text { skills }\end{array}$ \\
\hline $\begin{array}{l}\text { Soulé and Warrick } \\
\text { (2015) }\end{array}$ & Creativity, communication, collaboration, critical thinking & $\begin{array}{l}\text { 21st-century } \\
\text { learning skills }\end{array}$ \\
\hline $\begin{array}{l}\text { Thoman and Jolls } \\
\text { (2004) }\end{array}$ & Media literacy & $\begin{array}{l}21 \text { st-century } \\
\text { skills }\end{array}$ \\
\hline $\begin{array}{l}\text { Uzunboylu and } \\
\text { Hürsen (2011) }\end{array}$ & $\begin{array}{l}\text { Self-management, learning how to learn, initiative } \\
\text { and entrepreneur, acquiring information, digital } \\
\text { competencies, decision-taking }\end{array}$ & $\begin{array}{l}\text { Digital } \\
\text { competence }\end{array}$ \\
\hline $\begin{array}{l}\text { Van Deursen, } \\
\text { Helsper, and } \\
\text { Eynon (2016) }\end{array}$ & $\begin{array}{l}\text { Operational, information navigation, social, creative, } \\
\text { mobile }\end{array}$ & Digital skills \\
\hline $\begin{array}{l}\text { Voogt and Pareja } \\
\text { Roblin (2012) }\end{array}$ & $\begin{array}{l}\text { Collaboration, communication, ICT literacy, social/cultural } \\
\text { skills, citizenship, creativity, critical thinking, problem } \\
\text { solving, productivity }\end{array}$ & $\begin{array}{l}\text { 21st-century } \\
\text { competence }\end{array}$ \\
\hline Westby (2009) & $\begin{array}{l}\text { Visual literacy, computer literacy, media literacies/ } \\
\text { technology literacy, cultural literacy }\end{array}$ & Multiliteracy \\
\hline $\begin{array}{l}\text { Woods-Groves } \\
\text { (2015) }\end{array}$ & $\begin{array}{l}\text { Persistence, curiosity, externalizing affect, internalizing } \\
\text { affect, cognition }\end{array}$ & $\begin{array}{l}\text { 21st-century } \\
\text { skills }\end{array}$ \\
\hline $\begin{array}{l}\text { Wüstenberg et al. } \\
\text { (2014) }\end{array}$ & Complex problem solving & $\begin{array}{l}\text { Twenty-first } \\
\text { century skills }\end{array}$ \\
\hline Yang et al. (2014) & Collaboration, cultural awareness & $\begin{array}{l}\text { 21st-century } \\
\text { skills }\end{array}$ \\
\hline
\end{tabular}




\section{CHAPTER 3}

\section{ST-CENTURY DIGITAL SKILLS FOR THE CREATIVE INDUSTRIES WORKFORCE: PERSPECTIVES FROM INDUSTRY EXPERTS}

The creative industries workforce requires employees that use ICT applications to solve knowledge-related tasks at work. The aim of this chapter is twofold: (1) to see if the 21 st-century digital skills as defined in the previous chapter are applicable to the creative industries workforce and (2) to investigate the extent to which skill development receives attention in the current organizational practices. In-depth interviews were conducted with a sample of 24 managers and senior executives of creative organizations based in the Netherlands. As a guideline for the interviews, we used the 21 st-century digital skills framework. The interview results support the importance of 21st-century digital skills. Nevertheless, there seems to be insufficient attention to the levels of these skills; they play a minor role during the application and evaluation procedures. Often, it is assumed that existing digital skills are sufficient. Managers are encouraged to develop requirements necessary for future employees as well as measurements to ensure current employees skill levels. The developed framework might be used as a management tool for indicating skills that need to be assessed among professionals working within the creative industries. ${ }^{2}$

2 Van Laar, E., Van Deursen, A. J. A. M., van Dijk, J. A. G. M., \& De Haan, J. (2019). Twenty-first century digital skills for the creative industries workforce: Perspectives from industry experts. First Monday, 24(1). doi:10.5210/fm.v24i1.9476. 


\subsection{INTRODUCTION}

By improving access to services, enhancing connectivity, and changing the ways in which people communicate, interact and engage with one another, ICTs have become a central contributor to social transformation. ICT furthermore supports economic growth by generating business and employment opportunities. In this respect, human capital is a critical asset, as employees create a strong base for innovative and competitive power. The ability to manage human capital and its conversion into useful 'products' is considered the most critical management skill, providing the ultimate in competitive edge (More, 1999). The human capita that resides within the workforce influences the various innovative capabilities of organizations (Santos-Rodrigues, Dorrego, \& Jardon, 2010; Singh, 2012). ICT use by organizations increases revenue growth, workplace productivity and competitiveness while fostering innovation and employment throughout the economy. As a result, digital skills are not only vital to participating in the knowledge society (Van Deursen \& Van Dijk, 2011a), they have also become a key element for facilitating employment opportunities (Gómez, Tobarra, \& López, 2014). The rapid integration of new ICTs has meant that continuously evolving skills are required to deploy such technologies (Ananiadou \& Claro 2009; Janssen et al., 2013). Employees not only require technical skills but also excellent skills in adapting to changing job requirements (Carnevale \& Smith, 2013; Wilson, Scalise, \& Gochyyev, 2015).

This chapter takes an in-depth look at managers' and senior executives' perspectives on 21st-century digital skills that are necessary for the creative industries workforce. The development of individual skills is relevant in industries where digitalization changes the way products and services are developed, manufactured, distributed and consumed (Goldkind \& Wolf, 2014). It is important to study whether managers pay enough attention to employees' 21 st-century digital skills in contemporary organizational practice. Since employees are considered the most important sources for innovation, the need for managers to account for the skills of their employees is vital. Individual skills are seen as the source for new product and service developments (Hotho \& Champion, 2011; Preston, Kerr, \& Cawley, 2009). However, concerning the creative industries, only a few studies, especially in the management literature, discuss individual skills (Kamprath \& Mietzner, 2015). To obtain a better insight into the role of skill development, interviews are conducted with managers and senior executives responsible for skill development of creative organizations based in the Netherlands. In this study, individual's skills are discussed with the general purpose to further strengthen the creative industries. In the beginning of the interviews, the digital aspect is excluded to allow the participants to disclose their own views on the use of ICTs with regard to each skill. Four research questions guide this study:

1) Which skills do managers and senior executives of the creative industries mention as meaningful for the current workforce?

2) Which 21st-century skills do managers and senior executives of the creative industries view as being most relevant for the current workforce?

3) To what extent do managers and senior executives of the creative industries consider 21st-century skills in application procedures and performance evaluations?

4) To what extent do managers and senior executives of the creative industries recognize the role of ICTs in reference to 21st-century skills?

By answering these questions, this study serves as a guideline for the 21stcentury digital skills that are needed in the current creative industries workforce. The interview approach is used to test the relevance of the developed 21stcentury digital skills framework in reference to the labor market. To the best of our knowledge, this is the first in-depth qualitative study exploring the views of managers and senior executives concerning 21st-century digital skills. In addition, it shows the role skill development plays in current organizational practices. The results are particularly useful for managers of the creative industries responsible for hiring qualified personnel.

\subsection{THEORETICAL BACKGROUND: 21ST-CENTURY DIGITAL SKILLS WITHIN THE CREATIVE INDUSTRIES}

This section overviews the 21st-century digital skills that can be considered essential for the workforce within the creative industries. In general, most theorist have defined creativity in the workplace as the development of ideas about products, services or procedures that are novel and potentially useful to the organization (e.g., Amabile, Conti, Coon, Lazenby, \& Herron, 1996; Shalley, Gilson, \& Blum, 2000; Woodman, Sawyer, \& Griffin, 1993). Organizations in the creative industries focus on goods and services that exploit intellectual property and creativity (Flew \& Cunningham, 2010). The creative industries remain a contested concept in terms of the specific disciplines that belong to the sector. The general consensus is that it includes performing arts (e.g. 
visual arts/crafts, theatre, music, and literature) as well as those that are more commercial (e.g., design, media, software, and publishing/advertising), all of which have creativity at their core (Hartley, 2015).

Furthermore, the creative industries workforce is distinctive from more conventional industries such as financial services or manufacturing because it is dominated by a high number of small-to-medium enterprises and work is often freelance or performed on a short-term contractual basis (Bridgstock, 2011). Uncertainty is deeply embedded into the nature of the creative industries, characterized by rapid technological changes where constantly new and complex knowledge is created and demanded and where underlying competences are needed to improve the skills permanently (Kamprath \& Mietzner, 2015). The creative industries are at the forefront of applying new technologies and are described as innovative and as state of the art in terms of adopting ICTs. The strong economic position of the creative industries, together with the potential for further economic growth, led the Dutch government to name the creative industries a 'top sector' (Hennekam \& Bennett, 2017) Müller, Rammer, and Trüby (2009) listed the three roles of creative industries in shaping an economy's innovation performance: (1) they are a major source of innovative ideas and thus contribute to an economy's innovative potential and to the generation of new products and services; (2) they offer services that may serve as input to innovative activities outside of organizations; and (3) they are intensive users of technology and often demand adaptations and new developments of technology, providing innovation opportunities to technology producers. All creative industries are similar in that creative professionals are their most important assets (Bridgstock, 2011; Mietzner \& Kamprath, 2013). They rely on creative professionals whose individual creativity is a key asset in responding to external changes and trends (Preston et al., 2009). In addition, Bilton and Leary (2002) argued that successful managers of creativity add value to the creative process by their ability to match individual employees to appropriate organizational tasks.

Because workers in the creative industries are intensive users of technology, technical skills are a first requirement to perform well. As a result, most studies concentrate on these skills, while the softer employee skills tend to be overlooked. Yet, the latter are required to develop the necessary innovation capabilities to handle technological and organizational changes at work (Kamprath \& Mietzner, 2015). Mietzner and Kamprath (2013) studied how the digital transformation process has an impact on the working conditions and skills from the perspective of professionals working within the creative industries. Four major skill-shifts emerged: working interdisciplinary, having an open mind about the new, permanently transforming job-specific knowledge, and balancing between a specialist and generalist attitude. Referring to the framework of 21stcentury digital skills, working in interdisciplinary teams demands considerable communication and collaboration skills from each member (Jeffcutt \& Pratt, 2002). Having an open mind about the new means that workers should be able to respond to changes with flexibility, rather than perceiving them as a threat. This requires self-reflection on one's own actions, openness to change, and taking the initiative to create opportunities. The permanent transformation of job-specific knowledge requires professionals working within the creative industries to explore new opportunities, to elaborate on new developments, and to be creative. Finally, it concerns the balance between specialists and generalists; a generalist has a basic understanding across many disciplines while a specialist is a person who has a deep understanding of a specific discipline. As a consequence, the generalist is proficient in defining the problem and the specialist has the skills to solve the problem. Furthermore, in the creative industries the degree of specialization is high, which means employers need specialists who can apply their knowledge. In fields where the degree of specialization is high, learning-by-doing is common practice to improve one's skills (Jeffcutt \& Pratt, 2002).

\subsection{METHOD}

Although the current research had some inclination of the 21st-century digital skills that are needed in the creative industries workforce, a related framework has not, to our knowledge, been examined among the workforce. This study adopted a qualitative research design and conducted in-depth, semi-structured interviews. Interviews were conducted with managers and senior executives of the creative industries to develop deeper insight into the importance of various 21 st-century digital skills held by professionals working within the creative industries.

\subsubsection{Semi-structured interviews}

Semi-structured interviews were applied as a suitable method, as this research had a framework of themes to be explored. In addition, our semi-structured interviews were explorative, allowing new ideas to be brought up in the 
interviews based on what each interviewee said (Longhurst, 2010). Open questions ensured stimulation of new insights and perspectives.

\subsubsection{Participants}

The participants were selected using purposive sampling method. They had to meet two selection criteria: holding a supervisor role, as we assumed that those employees are most likely to have an overall view of the industry, and covering a range of organizations which are concerned with the creative industries. The participants were screened by Linkedln and if suitable received an invitation by e-mail. Moreover, snowball sampling was used by asking the interviewees to propose another representative of the creative industries. We interviewed experts with first-hand knowledge of industry developments or personnel responsibility. In total, 24 managers and other senior executives of creative organizations based in the Netherlands were interviewed $(33.3 \%$ female). Among these were working professionals/managers $(\mathrm{N}=10)$, directors/ owners $(N=8)$, recruiters/HR-managers $(N=3)$, and board members $(N=3)$. The participants worked in the following professional fields: advertising, architecture, cultural and art, creative branch organizations, fashion, gaming, graphic design, industrial design, journalism, new media, museum, music, and publishing.

\subsubsection{Procedure}

Prior to the interviews, informed consent was obtained from the participants whereby consent to being interviewed and audio recorded was established verbally. Furthermore, it was clearly stated that the interview data and results would be handled confidentially. To start each conversation, each participant was asked to describe his or her organization and the job activities that he or she performs. To receive a first-hand account of managers' views on the spectrum of skills referenced, the participants were asked to describe skills that they viewed as being the most essential to creative job functions within their organizations. Furthermore, they were asked which of the stated skills are the most critical. An inductive approach was adopted to determine what the participants brought to the study, and code themes were derived from the raw data itself (Friese, 2014). Next, we investigated how the participants viewed the presented 21st-century skills. The 21st-century digital skills framework was used as a guideline (see Chapter 2). Skills were presented by presenting a card with each skill written on it with a short description. The participants were then asked if they recognized the skills as relevant to creative professionals.
For each skill, participants were required to explain why it is relevant (or not) to their work activities. A deductive approach was used to determine how the participants viewed the theoretical construct that the researcher was studying, so the code themes were derived from existing data as the researchers referred to their own framework (Friese, 2014). The participants were also asked what they expect from creative professionals with respect to 21 st-century skills and what has been asked for or tested in application procedures or performance evaluations. While descriptions given prior to this point were not focused on digital aspects of 21 st-century skills, by the end of the interviews, participants were required to determine whether ICTs offer additional value in terms of the proposed skills and to provide examples of digital tools that they use in their work activities. Finally, a broader question was asked concerning challenges to be faced by creative professionals and creative industries over the next five years. The interviews lasted between 60 and 90 minutes. Participation was completely voluntary, and no incentives were provided to the participants. It is important to note that the interviews were conducted by two researchers. The objective of the other researcher was to clearly define the creative industries by looking at an overall creative process and the job profiles involved. This chapter is focused on testing the relevance of the developed 21st-century digital skills framework in reference to the creative industries. Appendix 3.A displays the complete interview and coding scheme.

\subsubsection{Data analysis}

All interviews were transcribed verbatim and were analyzed with the help of ATLAS.ti. As our study was explorative, we applied a grounded theory approach based on an open coding system. The only predefined coding themes used were related to the 21 st-century digital skills. The other coding themes used were based on the content of the data. A multi-step content-analytic procedure was used to draw descriptive or explanatory conclusions clustered by theme. The main researcher initially divided the transcriptions into meaningful units of analysis that were then interpreted as a whole and were related to one another, forming a codebook. The second coder then used this codebook to code a sample of the transcriptions. A Cohen's kappa value of .72 was achieved denoting good agreement between the coders. After the coding session, all disagreements were resolved through discussion. 


\subsection{RESULTS}

3.4.1 Relevant skills from the perspective of industry experts

The results show that technical skills were most often cited as skills to take into consideration. Thereafter, creativity, communication, collaboration and analytical skills were often presented as skills that are useful to the creative professional. Technical skills were not only viewed as basic practical skills but also as an understanding of how things work from the backend.

"With craft skills, I strongly mean the digital aspects. Can you work with Photoshop? Can you work in 3D? Can you make an animation? Do you understand all computer terms and concepts to make computers accessible for you? (...) So, it has to do with vocabulary and, of course, understanding the logic of a computer."

The participants were asked to list the digital tools that they use in their work activities. They referred to generic tools (e.g., Google, Skype, social media and YouTube) and to job-specific tools (e.g., 3D modeling, Adobe, and Agile).

Creativity was described as the effective management of ideas and as the execution of successful ideas. Idea generalization was considered to be a precondition.

"You need to have imagination; otherwise, you can accomplish nothing in this world."

However, the participants often stated that while there is no shortage of ideas, there is a lack of successful idea implementation.

"Everyone has ideas, but to execute them, you know. Executing them is really difficult. (...) To give a concrete example, there are a lot of young people who think about a cool website or fun app, yet, there are only few ICT-skilled people who can actually develop these at the back-end."

Open and transparent communication was viewed as crucial, mainly because when several aspects are being developed, it is necessary for employees to inform one another on the progress being made. Collaboration skills were viewed as important, as creative work is complex and multidisciplinary, and professionals must work together to ensure results.

"As a creative person you have to be able to work together with other disciplines. Especially to ensure your creative output has maximum impact. (...) How strong you are as a creative person has to do with your ability to convince other disciplines about the way you meant it."
Analytical skills were viewed as critical, as many problems are faced throughout project execution, and it is thus necessary to find solutions. Based on the participants' explanations, analytical skills referred to problem-solving skills.

"When you have a preliminary design, you must be able to analyze what is required for this design to work well."

In addition to the framework, entrepreneurship was viewed as a meaningful skill, as it is either necessary to translate market needs into an idea or to make the market ready for your idea. Entrepreneurial skills were described as useful for not only conceptualizing ideas but also for finalizing products and the creative process.

"In the end it is about connecting your ideas to the market, and vice versa. Sometimes this process starts in the middle. The fun thing is that this is not that black or white."

The participants found it difficult to come up with an overview of skills that they considered to be crucial for their employees. Overall, meaningful skills that the participants described are in line with those listed in the 21st-century digital skills framework.

\subsubsection{1st-century skills}

Most participants stated that 21st-century skills are relevant for a creative professional and that they shape their work activities. Clearly, the participants acknowledged these skills, and we thus asked that they specify levels of importance. A key to success in the creative industries is the ability to conceptualize and realize ideas. Therefore, technical skills and creativity were viewed as crucial.

"Look, we are not a banking company where we search for a creative brain.

We are a creative company."

Additionally, problem solving, collaboration and communication were viewed as necessary. Problem solving was viewed as useful because when an idea does not work as expected, it is necessary to find a solution. Communication was viewed as useful, as each discipline comes with its own vocabulary that one must know to understand others in the field, and because it is about informing each other about the progress being made and future directions. 
"It is about open and transparent communication to each other. I think this is important because there is so much development you have to communicate with your people and employees about where we are going and what are the next steps to take."

Finally, collaboration was considered pivotal, as in a multidisciplinary industry the creative process involves working together to ensure results.

"We constantly try to bring the right people together, so you have more brainpower to solve problems."

The participants viewed ethical awareness, cultural awareness, information management and lifelong learning as less important. As an explanation for their negative responses on ethical and cultural awareness, participants noted that such skills do not determine the success of a creative professional.

"I don't think it is important for creativity. (...) I think it is not a driver. It is a thing which can be an inspiration, but because I like sustainability it doesn't mean I am a creative person. I can be a creative person who wants to work with sustainability, but the creativity comes first."

With regard to information management, the participants stated that this is a generic skill that everyone must possess and that it is not specifically pivota for creative professionals.

"Information management is not typical for the creative industries. This is true for journalism, but not for the creative industries as a whole. (...) There it is, of course, about the classical story of having multiple information sources. (...) And yes, make sure you check everything twice."

Lifelong learning was viewed as a skill that is not necessarily unique to the current timeframe and as a natural desire shared among creative professionals.

"I don't think that's important. For creative people it is not about lifelong learning. Creative people do it anyway. (...) It is a natural desire to learn."

Lastly, self-direction was mentioned to be dependent on the occupational level of an employee.

3.4.3 The role of 21st-century skills in application procedures and performance evaluations

According to the participants' self-reports, most 21st-century skills were taken into consideration in job interviews. However, it was noted that such skills are difficult to measure and that decisions are often made based on a professional's portfolio of past work.

"How could you measure that in an interview? Yeah, well, you can see it in their work right away. You can see whether they talk about their work with passion."

The participants were divided on whether or not to test employee performance. "That's a difficult one because we are not HRM people. We are not good at that."

"You have to think about goals and deliverables agreed upon with their managers. Every six months, their performance toward such goals is assessed."

It was stated that performance evaluations should depend on an organization's scale and on whether an organization has enough resources to conduct such large-scale assessments. When the participants stated that they used performance evaluations, these evaluations were always conducted during annual performance appraisals. A few participants also stated that they had insufficient knowledge to answer this question.

\subsubsection{The digital aspect of 21st-century skills}

Next, the participants were asked to describe the role of digital tools in 21stcentury skills. First, a more generic question regarding the role of ICTs and the Internet was asked, as participants found it difficult to elaborate on digita issues. They, for example, did not consider 21 st-century digital skills during application procedures. The participants suggested that to ensure one's professional development, new digital skills must be learned. They regarded ICTs and the Internet as digital instruments and tools that one must learn how to use.

"Digital resources create opportunities to explore new territories and to think of new types of solutions."

However, critical comments were made on the limitations of digital tools. A few participants argued that searching for available digital opportunities alone restricts one's creative thought.

"What you often see is that there are so many digital tools that these tools define your design space." 
Overall, most participants acknowledged the supportive functions of digital tools as part of the production process, but they were not viewed as tools for improving one's skills. Roles of digital tools that were most frequently mentioned included communication, collaboration, problem-solving and information management skills. Although the roles of digital tools for those skills were acknowledged, participants exhibited difficulties identifying digital aspects. They rarely identified uses of ICTs for 21st-century skills. In addition, except for lifelong learning, contextual skills were underrepresented. While the digital aspect of contextual skills is included in the framework, for the participants, it was problematic to grasp. They often referred to software packages and technical abilities.

Lastly, several of the participants stated that it is the responsibility of the employee and not that of the organization to remain up-to-date.

"Learning on the job accounts for about eighty percent of how someone

develops. Especially because we are so busy. (...) I do think we need to keep an eye on it."

Again, most participants described lifelong learning in terms of developing one's technical skills and did not deviate from describing technical abilities.

\subsubsection{Challenges faced by the industry and professionals}

Finally, the participants were asked to describe challenges facing creative professionals and creative industries. They often stated that the main challenge facing the industry pertains to the fact that organizations from outside the industry recognize their creative potential.

"Within the creative industries, people understand the added value of creativity while outside the industry this instantly stops. (...) All people acknowledge brilliant ideas but are not willing to pay for it. (...) They think they could come up with these ideas themselves. Well that's the difference, they couldn't have thought about that."

Challenges facing creative professionals were related to their skills: keeping one's skills up-to-date, technical skills that are needed to realize creative ideas, and the expansion of one's own skills.

"You should always make sure that you are state of the art."

"It is all about 21st-century skills and continuously developing those skills."

\subsection{DISCUSSION}

3.5.1 Main findings

Our first objective was to identify the skills that managers and senior executives working within the creative industries consider meaningful. Although creativity, communication, collaboration, problem solving, flexibility, self-direction and information management skills were considered, technical skills stood out in terms of importance. This finding stresses the technological deterministic viewpoint of skills - the idea that when technical skills are mastered, people can cope with new technologies. Since the participants appeared to have difficulties with mentioning content-related skills, it is likely that the skill requirements for professionals working within the creative industries are not top of mind. Worrisome, because managers have a responsibility to lead their employees by identifying specific requirements in the form of knowledge, skills and personal attributes for each role to ensure each employee makes an effective contribution at work (McGregor, Tweed, \& Pech, 2004). Most studies in the context of the creative industries focus on new technological developments, user behavior or new business models. Studies tend to overlook the soft factor of employees' skill level which is critical to adopting technological and organizational changes and to developing the necessary innovation capabilities (Kamprath \& Mietzner, 2015).

Our second objective was to identify which 21 st-century skills are considered most relevant. Although not top of mind, most managers did recognize the presented skills. As Silva (2009) argued, while the cited skills may not be new, the extent to which performance is predicted by such skills makes them newly important. The participants viewed technical skills followed by creativity, problem solving, collaboration and communication as the most relevant skills. Varying views were expressed on ethical awareness, cultural awareness, information management and lifelong learning. It might be concluded that to perform core skills, it is useful to take contextual skills into consideration. The core skill of information management was considered to be a generic skill that everyone must possess. The participants were more convinced on the relevance of the core skills than on that of the contextual skills. The findings show that managers can use the presented skills framework as a point of departure for assessing employees' skills. Most organizations seem to lack a description of the skills that are needed by their personnel. Organizations would benefit from a more explicit description of what is expected in each job function. In particular 
considering the fact that managers have difficulties with finding people with the right skills as the work they have to carry out is very specialist (Haukka, 2011).

Our third objective was to explore the role of 21st-century skills in application and performance procedures. Even if 21 st-century skills are considered for application procedures, attention to skill levels is limited, especially for those already employed. In the case that application procedures account for 21stcentury skills, usually only peoples' technical abilities are considered. The previous research shows that content-related skills are more important than technical skills to succeed on the job (Mitchell, Skinner, \& White, 2010; Robles, 2012). As a result, managers should acknowledge the importance of these skills. Furthermore, the majority of the participants stated that they do not conduct performance evaluations because they do not know how to evaluate these skills. If skills are evaluated, this happens by an annual performance appraisal. As we know from previous research, it is difficult for people to estimate their own skill levels (Dunning, Johnson, Ehrlinger, \& Kruger, 2003; Merritt, Smith, \& Renzo, 2005). Perhaps the most important and disturbing result is that the interviewed managers and senior executives do not know their employees' skill levels. Apparently, actions to monitor or improve 21 st-century skills are not considered urgent. Although the importance of these skills is acknowledged, there are little initiatives to improve or consolidate skill levels. Objective measurements are needed to monitor skill levels and to identify possible insufficiencies. Unfortunately, however, this seems to be an unusual organizational practice. In line with previous literature, within the creative industries, formal training does not serve as a means for selecting talent and screening skills (Mietzner \& Kamprath, 2013). In contrast, knowledge and skills are gained from learningby-doing (Jeffcutt \& Pratt, 2002). Many of the participants argued that it is the responsibility of the employee to remain up-to-date. Employees must take the responsibility to improve their own skill level by asking for training or by experimenting with new software. Limited opportunities for employees to engage in skill development and pressure on employees to keep pace with technological developments and to remain employable are ongoing issues in the creative industries workforce (Haukka, 2011).

Our fourth objective was to examine the digital aspects of 21 st-century skills. The participants found it difficult to discuss the role of ICTs and the Internet with regard to their work activities. Most participants referred to technical programs that support the development of end products. When describing 21st-century skills, it took them considerable effort to consider digital tools. This may be related to the fact that soft skills or content-related skills are underestimated and difficult to observe, quantify or measure (Cobo, 2013; Silva, 2009). The participants often stated that digital skills are almost considered a 'no brainer' for everyone in the creative industries. Information management, communication, collaboration and problem-solving skills are often acknowledged as skills in which ICTs play a dominant role; however, managers could not explain how. To give organizations and their employees more clarity about the content of the ICT-related job aspects, a digital profile could be helpful for each job function. Organizations can define digital skills areas for each job function group that are expected to successfully perform the job.

3.5.2 Limitations and future research directions

There are several points to consider in future research. First, we used the creative industries in the Netherlands as our study's context. Future studies may apply the same qualitative research methodology to study another occupation group and to prove whether our results are comparable with those of other industries. Similar studies on other samples would prove useful in comparing and extending our findings.

Furthermore, our findings are based on a small sample of 24 managers and senior executives, and so caution must be applied when generalizing the results. Although theoretical data saturation can be achieved with 12 interviews (Guest, Bunce, \& Johnson, 2006), the studied organizations illustrate the variety of creative industries in operation, rendering comparisons difficult. The challenge of coordinating such a diverse set of individuals with different skills is often held up as what makes the creative industries so distinctive (Hesmondhalgh, 2002). Future studies may thus conduct large-scale quantitative assessments on meaningful 21st-century skills within creative industries to validate our research results. It would be of value to determine if specific 21 st-century digital skills are more apparent within job function groups. In addition to further qualitative work, future studies might create more specificity by studying the similarities and differences of different subsectors (Hennekam \& Bennett, 2017). Although our findings provide valuable insights into 21 st-century digital skills for the creative industries workforce in the Netherlands, more research is needed to determine whether the patterns identified in our data can be applied to professionals working within the creative industries in other countries. Overall, there is still a need to clearly document 21 st-century digital skills that employees 
need to learn in the workplace before we can develop an effective assessment of their impact.

A few participants mentioned the interrelationships between various $21 \mathrm{st}$ century skills. They argued that 21st-century skills are not distinctive in the sense that several skills interact. For example, communication skills were often viewed as a precondition for collaboration. This is definitely worth considering in future studies on operational definitions of 21 st-century skills. Furthermore due to time constraints, we limited the amount of information presented to the participants. While we presented all twelve skills, complete conceptual definitions for each skill were not provided. Ambiguities may have resulted, as the participants occasionally asked for explanations. A few participants stated that entrepreneurship would have been a good addition, as it is extremely important to market one's product. The creative sector is a commercial industry and it is thus necessary to think about ways to render the market ready for one's product. An emerging body of research promotes entrepreneurial skills as necessary to secure viable and sustainable careers in the creative industries (Daniel \& Daniel, 2015).

Finally, it was difficult for the participants to consider the role of ICTs with regard to 21st-century skills. New ICTs were merely viewed as technologies to the participants and as self-evident tools used by the knowledge society in which we live. Besides, ICT tools are not required to perform 21st-century skills. ICTs rather provide us with new and powerful tools for supporting, for instance, problem solving. Nonetheless, problems can be solved without the use of ICTs. To address this indistinctness, it may be useful to define the digital concept earlier on. This study excluded the digital aspect at the beginning of each interview to allow the participants to disclose their own views on the use of ICTs with regard to each skill. While this was not in line with the 21 st-century digital skills perspective, we developed insight into which 21st-century skills benefit from ICT use from the creative industries workforce perspective.

\subsection{CONCLUSION}

Although the importance of 21 st-century skills is visible in policy and literature debates, organizations underestimate the need for adaptation of their human capital skills. Managers and senior executives responsible for skill development do not seem to have a clear overview of what professionals working within the creative industries require and what skill education and training should focus on.
Concerning 21st-century digital skills it is even harder to define what workers need. Organizations are recommended to pay more attention to developing skill profiles for each job function. For those already employed, effort is required to observe skill insufficiencies to succeed and stay competitive. Managers need to give skill development priority and realize that it is of key strategic importance to organizations. 


\section{APPENDIX 3.A INTERVIEW AND CODING SCHEME}

\section{Informed consent}

This interview is in the context of the research project 'e-skills, key to 21st century labor' funded by the NWO. I am going to ask you a few questions about the processes, job functions and skills in your organization. The data and results of this interview will be processed confidentially and will be used only for analysis and/or scientific presentations. You have the right to withdraw from this research at any time. Do you agree to participate in this research?

Topic list

General

- Can you tell me something about the company where you work and the work you perform?

\section{Creative process}

- What are the final products that you deliver?

a. For whom do you deliver these products? Who is the consumer?

- What is the process from order to end product?

a. Could you describe the different processes that lead to the end product?

*Participant draws the mentioned creative processes on a sheet of paper*

\section{Creative job functions}

- Can you describe what happens in each process?

- What are the most important creative processes within your company?

a. Which (groups of) employees (job functions) play a role in this regard?

*Participant writes down the job functions and places them next to the corresponding creative process*

\section{Creative industries}

- According to you, what is creativity?

- Would you classify the company in which you work under the creative industries?

a. If yes, why?

b. If no, why not?
- How do you notice it in the work performed by the employees? a. Can differentiation be made between different job functions?

\section{*Participant circles the creative job functions*}

21st-century skills

- Which skills do you consider to be the most important for creative job functions?

*Participant writes down the skills and places them next to the corresponding creative job functions*

- Which skills are needed to be successful in the creative industries?

a. Are these skills comparable to the ones in other business sectors? Why yes/no?

*A short introduction about the 21st-century skills found in the literature. Researcher shows the cards with each skill written on it with a short description.*

- Do you recognize the skills that you consider important for your employees?

- Which skills do you consider to be the most applicable to the different job functions?

a. Which of these skills do you consider to be the least applicable to the different job functions?

b. Do you consider some of these skills to not be applicable to the creative industries?

*Participant places the 21st-century skills cards next to the corresponding creative job functions*

- Do you have an addition to these skills?

Application procedures and performance evaluations

- Is the level of 21 st-century skills explicitly measured in application procedures? 
- In the meantime, is there a performance evaluation to determine if the skills are up-to-date?
a. If yes, how?
b. If no, why not?

\section{Digital aspect of 21st-century skills}

- According to you, can technology/ICT support or strengthen employees' skills?

a. If yes, in what way?

b. If no, why not?

- How is technology/ICT used to support or strengthen the various skills? a. Can you give examples?

- How is the digital aspect expressed in 21st-century skills?

\section{Challenges of the creative industries}

- What are the major challenges that employees working within the creative industries will face in the next five years?

Note: The interviews were conducted by two researchers. The other researcher focused on the creative process and job functions.

\section{Coding scheme}

1) Important skills
1.1 Analytical
1.2 Broadly oriented
1.3 Collaboration
1.4 Communication
1.5 Conceptual capacity
1.6 Creativity
1.7 Critical thinking
1.8 Curiosity
1.9 Empathy
1.10 Entrepreneurship
1.11 Financially informed
1.12 Flexibility
1.13 Hard working
1.14 Information management

1.15 Lifelong learning

1.16 Management

1.17 Marketing

1.18 Persistency

1.19 Self-directedness

1.20 Technical (craft)

1.21 Technical (digital)

1.22 Written skills - sector specific

1.23 Written skills - general

2) 21st-century skills

2.1 Recognizable

2.2 Term

2.3 Relation

2.4 Order

2.5 Applicable to other business sectors

3) Technical
3.1 Important
3.2 Less important
3.3 Meaning
3.4 Link to other skills
3.5 Link to the creative process

4) Information management
4.1 Important
4.2 Less important
4.3 Meaning
4.4 Link to other skills
4.5 Link to the creative process

5) Communication
5.1 Important
5.2 Less important
5.3 Meaning
5.4 Link to other skills
5.5 Link to the creative process 
6) Collaboration

6.1 Important

6.2 Less important

6.3 Meaning

6.4 Link to other skills

6.5 Link to the creative process

7) Creativity

7.1 Important

7.2 Meaning

7.3 Link to other skills

7.4 Link to the creative process

8) Critical thinking
8.1 Important
8.2 Less important
8.3 Meaning
8.4 Link to other skills
8.5 Link to the creative process

9) Problem solving

9.1 Important

9.2 Less important

9.3 Meaning

9.4 Link to other skills

9.5 Link to the creative process

9.6 Depending on the job function

10) Ethical awareness

10.1 Important

10.2 Less important

10.3 Meaning

10.4 Link to other skills

10.5 Link to the creative process
11) Cultural awareness

11.1 Important

11.2 Less important

11.3 Meaning

11.4 Link to other skills

11.5 Link to the creative process

12) Self-directed learning

12.1 Important

12.2 Less important

12.3 Meaning

12.4 Link to other skills

12.5 Link to the creative process

12.6 Depending on the job function

13) Flexibility

13.1 Important

13.2 Less important

13.3 Meaning

13.4 Link to other skills

13.5 Link to the creative process

14) Lifelong learning

14.1 Important

14.2 Less important

14.3 Meaning

14.4 Link to other skills

14.5 Link to the creative process

15) Initiating lifelong learning

15.1 Employee

15.2 Company

15.3 Combination 
16) Addition to 21st-century skills
16.1 Entrepreneurship
16.2 Anticipation
16.3 Benchmarking yourself
16.4 Reinvent yourself
16.5 International view
16.6 Knowledge-driven approach
16.7 Courage
16.8 Psychological awareness

17) Role of 21st-century skills in application procedures

17.1 Play a role

17.2 Play no role

17.3 No insight

18) Role of 21st-century skills in performance evaluations

18.1 Evaluated

18.2 Not evaluated

18.3 Depending on the organizational size

18.4 No insight

19) Role of ICT and the Internet

19.1 Instrument or tool

19.2 Supporting or adding value

19.3 Limitation

20) Examples of ICT tools

20.1 Generic

20.2 Job-specific

21) Role of ICT and the Internet in reference to 21 st-century skills 21.1 Technical

21.2 Information management

21.3 Communication

21.4 Collaboration

21.5 Creativity

21.6 Problem solving
21.7 Flexibility

21.8 Lifelong learning

22) No role of ICT and the Internet in reference to 21st-century skills 22.1 Critical thinking

22.2 Problem solving

22.3 Ethical awareness

22.4 Cultural awareness

22.5 Flexibility

22.6 Self-directed learning

23) Digital skill levels

23.1 Skilled workforce

23.2 Partially skilled workforce

23.2.1 Depending on the job function

23.2.2 Depending on the age

23.2.3 Depending on the ICT use

23.2.4 Depending on the educational background

24) Factors contributing to digital skill levels

24.1 Training

24.2 Knowledge-sharing among colleagues

25) Challenges creative industries

25.1 Remaining attractive on the labor market

25.2 Freelancers

25.3 Entrepreneurship

25.4 Transparency

25.5 Big data

25.6 Realizing a diverse workforce composition

26) Challenges creative professionals

26.1 Remaining up-to-date

26.2 Technical skills

26.3 Broadening skill sets

26.4 Managing pressure 
27) Trends creative industries

27.1 Interest of other business sectors

27.2 User-centered design

27.3 Technic and initiative shift toward each other

27.4 Short-term contracts

27.5 New job functions

28) Characteristics creative industries

28.1 Freelancers

28.2 Highly educated workforce

28.3 Broad range of skills 


\section{Chapter 4}

21st-century digital skills instrument aimed at working professionals: Conceptual development and empirical validation

Employees with high levels of 21st-century digital skills are beneficial for organizations characterized by rapid technological changes and complex knowledge bases. Although a number of instruments have been used to measure digital skills, they do not consider the broad range of 21 st-century skills. Additionally, available measures are often aimed at students or citizens in general, not at the working population. This chapter aims to develop a set of reliable measures that focuses on the frequency of activities performed by working professionals to assess each core 21 st-century digital skill. To this end we conducted cognitive interviews, a survey pilot, and a full survey among a large sample of professionals working within the creative industries. The result is a theoretical, empirically validated instrument that measures six types of 21st-century digital skills: information, communication, collaboration, criticalthinking, creativity, and problem-solving skills.

3 Van Laar, E., Van Deursen, A. J. A. M., Van Dijk, J. A. G. M., \& De Haan, J. (2018). 21stcentury digital skills instrument aimed at working professionals: Conceptual development and empirical validation. Telematics and Informatics, 35(8), 2184-2200. doi:10.1016/j. tele.2018.08.006. 


\subsection{INTRODUCTION}

Chapters 2 and 3 provide more clarity on the importance and meaning of 21 st-century digital skills in reference to the labor market. The current chapter focuses on the development of an instrument measuring the levels of digital skills. The original review of core 21st-century digital skills also considered technical skills. In this chapter, these skills were not included because creative industries are at the forefront of adopting and applying new technological devices (Müller, Rammer, \& Trüby, 2009). The following 21st-century digital skills are investigated: information management, communication, collaboration, creativity, critical thinking, and problem solving. All skills are fundamental for performing the necessary tasks in a broad range of occupations. The previous research shows that managers neither have skill requirements top of mind nor have a clear understanding of the role skill development plays in organizational management practices (Van Deursen \& Van Dijk, 2014; also see Chapter 3). However, measuring the level of employees' 21st-century digital skills is beneficial for organizations characterized by rapid technological changes and complex knowledge (Kamprath \& Mietzner, 2015).

Conceptually, the instruments available are limited by ambiguity because various labels are used for the same skills or the labels do not correspond to the skills being measured. Because of this ambiguity, technical abilities are often emphasized as opposed to the integration of the digital component in the whole range of 21 st-century skills. On a methodological level, an important challenge is the use of self-evaluation items that easily lead to individuals overrating their skill levels (e.g., Hargittai, 2005; Merritt, Smith, \& Renzo, 2005; Talja, 2005). Furthermore, the research tends to focus on citizens or students instead of on the skills required for working professionals (see Chapter 2). This study aims to overcome these limitations by developing a set of reliable measures that focus on the frequency of activities that working professionals perform to assess each core 21 st-century digital skill. The following research question is addressed:

1) Which set comprises the reliable measures for assessing the level of core 21st-century digital skills (information management, communication collaboration, critical thinking, creativity, and problem solving) among working professionals?

To answer this question, we reviewed the literature about existing skill measures, used as an input to develop an initial instrument. This instrument was improved following a three-fold approach: (1) cognitive interviews, (2) a pilot survey, and (3) a full survey. This approach is necessary to refine and test the validity of the latent skill constructs and corresponding items.

\subsection{INITIAL INSTRUMENT DEVELOPMENT}

A plethora of concepts and frameworks are used to describe what is needed to benefit from digital tools and media. Consequently, research directions define it in various ways. The digital divide research, for instance, has centered on the acquisition of the necessary digital skills for the general population to function well in an increasingly digital environment (e.g., Hargittai, 2010; Helsper \& Eynon, 2013; Van Deursen \& Van Dijk, 2010). Prominent in the new media literacy research is the assessment of critical media consumption and responsible media production, especially among youth (e.g., Buckingham 2007; Jenkins, Clinton, Purushotma, Robison, \& Weigel, 2006; Livingstone, 2004) Furthermore, a growing field of research is concerned with the teaching and learning practices to ensure students' mastery of 21st-century skills in the classroom as preparation for working life (e.g., Binkley et al., 2012; Dede, 2010; Siddiq, Scherer, \& Tondeur, 2016). These research directions have in common that they acknowledge that both basic skills necessary to use digital tools and skills required to comprehend and use online content should be accounted for. However, existing instruments do not capture the full range of digital skills necessary. The most important reason for the lack of skill tests might be that the literature concerning these skills is not consistent in the terms used and in the underlying concepts applied (Van Deursen \& Van Dijk, 2010). Moreover, the research often seems technical-oriented toward present digital technologies such as IT literacy, ICT literacy or computer literacy.

An important conclusion from our systematic literature review in Chapte 2 is that 21st-century skills emphasize a broad spectrum of skills, yet do not integrate the digital aspect. Digital skills, on the other hand, often do not cover the broad spectrum of skills posed by 21st-century skills. Besides, 21stcentury skills refer to an extensive list of skills on conceptual level while digital skills often refer to a limited number of skills on operational level. Our goal is to develop an instrument of data collection for 21 st-century digital skills that will adequately measure and reflect each skill's operational components. To accomplish this aim, we combined items from various existing scales and, in certain cases, added new items that are useful in the digital context. To develop the initial instrument, we elaborated on our framework of 21 st-century digital 
skills. Here, we provided conceptual definitions and key components for each 21st-century digital skill based on the academic literature. In this study, we focus on the following core 21st-century skills: information, communication, collaboration, critical thinking, creativity, and problem solving. Chapter 3 shows that professionals working within the creative industries considered the core skills to be more important than the contextual skills. Since few studies have been conducted to date to add the digital component to 21st-century skills, we also used the offline 21 st-century skills measures found in the literature as a point of departure. The digital aspect was added to the skill items by, for instance, mentioning the use of Internet applications. The Internet was explained as e-mail, web applications (e.g., Skype) and social media (e.g., Facebook, Twitter, and Linkedln). Each item measured the frequency of various activities that are related to the 21st-century digital skills definition. This information functioned as a behavioral indicator of skills. The respondents were asked to respond to the statements using a five-point Likert scale: (1) never, (2) rarely, (3) sometimes, (4) often, and (5) (almost) always.

\subsubsection{Information management}

Information management refers to the use of ICT to search, select, and organize information to make informed decisions about the most suitable information source for a given task. Key components include the ability to (1) define search terms, (2) access information from a variety of sources, (3) evaluate the reliability and usefulness of retrieved information, and (4) manage information to find it later. In total, fourteen items were used to measure the information components define, access and evaluate (Van Deursen \& Van Dijk, 2009). To measure the manage part of information management, we adapted three items from Majid, San, Tun, and Zar (2010) and three from Hwang, Kettinger, and Mun (2015), and we added one item ourselves.

\subsubsection{Communication}

Communication concerns using ICT to transmit information to others, ensuring that the meaning is expressed effectively. This study focuses on transmitting information in broad terms: (1) appropriateness, (2) expressiveness, (3) online profiling, and (4) online networking. Appropriateness concerns having knowledge about the online medium for your message to make it suitable for the situation. Expressiveness concerns coming across clearly to make sure your behavior indicates the intended feelings or thoughts. Four items for appropriateness were derived from Schulze, Schultze, West, and Krumm (2017) and one item came from Wrench (2004). To measure expressiveness, we adapted five items from Bakke (2010). To measure online profiling, we used the social media exploitation levels of Sigala and Chalkiti (2015) as inspiration. In total, sixteen items were considered such as updating your personal profile, sharing information for discussions, and identifying experts in your field. As a result, positive reactions, recommendations and new collaborations might emerge. Finally, online networking refers to an individual's ability to make connections for instrumental or expressive return (Lee \& Chen, 2017). Online networking skills were adapted from three items from Lee and Chen (2017) and one item from Burleson and Samter (1990), and we added three items. In addition, we added eight items regarding using your online network to generate new business, increase brand awareness or achieve policy goals.

\subsubsection{Collaboration}

Collaboration concerns using ICT to develop a social network and work in teams to exchange information, negotiate agreements, and make decisions with mutual respect for each other toward achieving a common goal. Components are limited to interaction and sharing ideas. This study extends these components to (1) responsibilities, (2) planning, (3) interdependence, and (4) knowledge-sharing. Responsibilities concern understanding your own and your collaborating partners' roles to support and complement the team To create measures for responsibilities, we adapted four items from Archibald Trumpower, and MacDonald (2014) and we added one item ourselves. Planning concerns monitoring team progress to accomplish tasks on time. The planning component was developed by adapting six items from Chiocchio, Grenier, O'Neill, Savaria, and Willms (2012) and one item from Van de Oudeweetering and Voogt (2018). Interdependence refers to the reliance on interactions among professionals who are all dependent on the others to accomplish their tasks (Bronstein, 2003). To measure interdependence, we adapted four items from Bronstein (2003) and we added one item ourselves. Knowledge-sharing refers to exchanging information to help team members perform tasks. To measure knowledge-sharing, we adapted five items from Chiocchio et al. (2012).

\subsubsection{Critical thinking}

Critical thinking is defined as using ICT to make informed judgments and choices regarding obtained information and communication using reflective reasoning 
and sufficient evidence to support claims. Key components are the abilities to (1) clarify the subject, (2) assess the suitability of a source, (3) invoke arguments for claims, and (4) link and suggest new ideas for discussion. Clarification and assessment items were developed from six items from Sosu (2013) about critical openness and reflection. Critical openness reflects the tendency to be actively open to new ideas, to be critical in evaluating these ideas, and to modify one's thinking in light of convincing evidence. Reflective skepticism conveys the tendency to learn from past experiences and question evidence. Justification was adapted from two items from the scoring criteria of Newman, Webb, and Cochrane (1995) and one item from Van de Oudeweetering and Voogt (2018). Novelty was based on three items from Newman et al. (1995).

\subsubsection{Creativity}

Creativity is defined as using ICT to generate new or previously unknown ideas or to treat familiar ideas in a new way and transform such ideas into a product, service or process that is recognized as novel within a particular domain. This study elaborates on the key component content creation. Content creation is the ability to create new content or elaborate on previous content to produce creative expressions (Ferrari, 2013). To measure creativity, several existing scales were used, and we developed two items ourselves. Six items were adapted from Zhou and George (2001) concerning idea generalization and performing tasks creatively. Furthermore, we added two items regarding generating innovative ideas or applications for your field from Carmeli and Schaubroeck (2007), one item about looking for potential work methods from Janssen (2000), and one item about judging an idea's usefulness from Scott and Bruce (1994). Finally, we changed the four scoring criteria (fluency, flexibility, originality, and elaboration) from Torrance (1972) into six items. The items are defined as the abilities to (1) quickly invent multiple options, (2) consider various alternatives, (3) think of innovative ideas, and (4) work out ideas in more detail.

\subsubsection{Problem solving}

Problem solving is defined as using ICT to cognitively process and understand a problem situation in combination with the active use of knowledge to find a solution. This study elaborates on the components knowledge acquisition and application. In line with these two components, knowledge must be first be acquired regarding a new problem situation, and subsequently, this novel information must be applied when solving a complex problem (Greiff
Kretzschmar, Müller, Spinath, \& Martin, 2014). Problem-solving skills are required to deal effectively with complex and nonroutine situations in different domains (Funke, Fischer, \& Holt, 2018). In total, we adapted eight items from the problem-solving confidence scale of Heppner and Petersen (1982) and two from Van de Oudeweetering and Voogt (2018).

\subsubsection{Cognitive interviews}

The first step to improve our survey design involved cognitive interviewing Cognitive interviews are a common method for improving instrument design by assessing respondents' understanding of questionnaire items (Knafl et al., 2007). Cognitive interviews serve an exploratory function by explaining people's responses. Furthermore, cognitive interviews help to identify which items may be possible to omit or represent an incomplete or misleading view (Desimone \& Le Floch, 2004). In line with this technique, respondents were encouraged to talk through their thought process as they answered the developed survey questions. In total, nine participants from our network were asked to complete the initial survey and express their thoughts. Respondents received an incentive of 10 Euros for their participation.

The interview results helped us evaluate whether the items proposed measured the skill constructs we intended. We checked whether all respondents understood the question, found the question relevant, and were able to formulate an answer on the provided scales. Items that were perceived as problematic were adjusted or removed. Appendix 4.A displays all skills as adjusted after conducting the cognitive interviews. Based on the interviews, an introductory sentence to distinguish searching information online from managing digital information was included. Moreover, the meaning of metadata appeared unclear and was specified. Finally, the item 'do you have difficulties assessing whether you have sufficient information to complete your task' was removed because it is context specific. For communication, the item 'do you update your online profile' was removed because it could be seen as fraudulent when you devote time to that task at work. In addition, the item 'do you update your online work portfolio' was altered to 'do you update your online work portfolio when your work situation changes' because it only makes sense to update your work portfolio when you have something relevant to add. For critical thinking, an introductory sentence was included to explain that the next statements were about online discussions. As a result, the reduced number of words per item may eliminate redundancy. For problem solving, 
we removed the item 'does the Internet help you analyze unknown situations' because it appeared too abstract. Moreover, the item 'do you solve problems using the Internet by investing sufficient time and energy' was altered because the amount of time you invest in problem solving depends on the problem's complexity. Overall, the participants made suggestions to specify words, shorten items, undo the reverse-coding, and randomize items.

\subsection{PILOT SURVEY RESULTS}

To further improve our survey, we conducted an online pilot survey among professionals working within the creative industries. The small-scale pilot survey was used to identify the problematic items and to improve the content coverage of the constructs. Potential respondents from our own network were approached via e-mail. The pilot was completed by 58 respondents from the population of interest in October 2017; sufficient for a pilot study where the purpose is preliminary survey or scale development (Johanson \& Brooks, 2010). Respondents received an incentive of 10 Euros for their participation. Respondents represented the following branches: (1) visual art/photography, (2) performing arts, (3) museums, (4) radio/television, (5) film, (6) books/magazines, (7) journalism, (8) publishing/media, (9) fashion/textile, (10) architecture, (11) industrial design, (12) graphic design, (13) advertising/marketing, (14) games, and (15) new media/software. The division of branches is based on a mapping document of the creative industries in the Netherlands (Raes \& Hofstede, 2005).

\subsubsection{Exploratory factor analysis (EFA)}

An EFA in SPSS (IBM Statistics) for each 21st-century digital skill was used. The aim was to explore the reliability of the constructed skill scales and to identify items that have caused problems. The factor solutions were based on the percentage of variance accounted for by the factors and on the cohesiveness of the items within the identified skill factors. In addition, varimax rotation was used because we knew from previous research that Internet skills are related. As such, we expected ambiguity in positioning some of the items, which might cause them to load on more than one factor. Factor loadings of .30 were considered significant for inclusion in a factor. Item loadings above .30 are acceptable in an exploratory factor analysis (Costello \& Osborne, 2005). For most skills, the operational components as identified in the literature were reflected in the fixed number of factors extracted. For creativity and problem solving, the factor solutions were based on the number of factors with eigenvalues that exceeded 1.0. The key operational components often resulted in separate constructs; therefore, items were added if less than five items loaded together on one factor. A factor with fewer than three items is generally weak and unstable; five items or more strongly loading items are desirable and indicate a solid factor (Costello \& Osborne, 2005). Furthermore, the EFA results show that the negatively formulated items often turned out to be outliers and were therefore adjusted or removed. Appendix 4.B displays the items as adjusted after pilot testing.

\section{Information management}

For information management, four items loaded together and represented define and access. For the full test, we added an item from Van Deursen and Van Dijk (2009). For evaluate, six items clustered together. The items 'look further than the top three results' and 'estimate the future value of information before you save it' did not appear to load on access or manage but on evaluate. After carefully considering the content, we decided that it is appropriate to label them as evaluate. To manage, we identified three items that loaded together; therefore, one item from Majid et al. (2010) and one item from us was added.

Communication

For communication, appropriateness and expressiveness were combined, and we identified seven items that loaded together. The item 'do you not know what behavior is appropriate in a particular situation on the Internet' was adjusted. We removed the reverse-coding because it seems reasonable to assume that this is the reason for being an outlier. Online profiling resulted in two factors, content sharing and contact building, with five items each loading together The item 'do you find Internet contacts who can inform you about your field' from networking was added to contact building. For content sharing, we altered 'does someone else share a message you posted' to 'do you share a message from someone else on Internet'. In addition, we altered 'receiving feedback' into 'giving feedback'. Networking resulted in ten items. The item 'do you respond to online messages from your network' from online profiling loaded on networking but was removed based on its content.

Collaboration

For collaboration, responsibilities resulted in four items. The item 'use the Internet to discuss strategies to achieve a common goal' from planning was 
added to responsibilities. Although this was not in line with our expectations, we decided that its content corresponds to the factor. Furthermore, we added one item in line with the items loaded together. Planning resulted in three items. Two items loaded on multiple factors and therefore we specified them toward planning. For interdependence, four items clustered together. We added one item from Bronstein (2003). Knowledge-sharing resulted in four items. The item 'do you have difficulties sharing work-related knowledge with each other via the Internet' was added after removing the reverse-coding.

\section{Critical thinking}

For critical thinking, six items clustered together on the factor labelled reflection. Two items loaded on justification. The item 'do you consider various arguments and opinions' loaded on both reflection and justification and therefore we altered this item to justification. Furthermore, two items loaded on novelty. As a result, we added two items to justification and three items to novelty from Newman et al. (1995).

\section{Creativity}

For creativity, eleven items clustered together. To improve the quality, 'do you use the Internet to become a creative role model' was altered into 'do you present yourself as a creative role model on the Internet'. Furthermore, the item 'do you search out new work procedures or techniques via the Internet' was adapted from Janssen (2000).

\section{Problem solving}

All items clustered together on problem solving. To finalize the scale, the item 'do you find the solution via the Internet even though initially no solution is immediately apparent' was added (Heppner \& Petersen, 1982).

\subsection{FULL SURVEY RESULTS}

\subsubsection{Sample and procedure}

The final step in instrument development was to conduct a full online survey among professionals working within creative industries in the Netherlands. The data were collected from October to December 2017. The sample included people who are directly involved in the creative work process (e.g., designers, engineers, and project managers). The data were collected by using two online panels (PanelClix and Panel Inzicht) and by approaching potential professionals individually. The selection mechanism of organizations was primarily based on information from overarching industrial branch organizations or knowledge institutions in the Netherlands. A Linkedln premium account and the employer's website were used to screen and contact potential professionals working within the creative industries. Linkedln is a business-oriented social networking site used to display professional information, connect with other professionals, and share employment opportunities. Especially because work within the creative industries is often based on temporal projects and teams, the use of personal networks is widely acknowledged (Grugulis \& Stoyanova, 2012). The two online panels used screenings questions to ensure that respondents were working within the creative industries. Panel members received a small incentive for their participation. The largest part of the respondents was approached individually by sending potential respondents an email invitation. After completing the online survey, they received an incentive of 10 Euros. The response rate of the e-mail invitation was $11.6 \%$. To ensure data quality, we excluded respondents based on response time, their job function, and the country where they work. In total, 776 respondents were recruited via e-mail and 446 via two online panels. This study used the data of 907 respondents because not every working professional could answer the items about collaboration. Especially because self-employed professionals do not always work in a team or project group. Table 4.1 on the next page shows the sample characteristics.

\subsubsection{Confirmatory factor analysis (CFA)}

CFA was used to test the model fit of the factor structures found with the EFA. Goodness of fit can be determined with the following indices (Byrne, 2010): chi-square test $\left(\chi^{2}\right)$, root-mean-square errors of approximation (RMSEA $\left.\leq .05\right)$, the comparative fit index (CFI $\geq .90)$, and the Tucker-Lewis index ( $T L I \geq .90)$. The initial model based on the previous step did not result in a fitted model. The model was tailored in an iterative process. To obtain model fit as well as sufficient discriminant and convergent validity, we needed to merge the separate skill components of collaboration and critical thinking. Furthermore, we needed to remove the definition and access components of information management. The final model including all factor structures has a good fit: $\chi^{2}(1665)=3922.18$, $\chi^{2} / \mathrm{df}=2.36 ; \mathrm{RMSEA}=.04 ; \mathrm{CFI}=.93 ; \mathrm{TLI}=.93$. 
Table 4.1 Sample characteristics ( $N=907)$

\begin{tabular}{|c|c|c|}
\hline & $\mathrm{N}$ & $\%$ \\
\hline \multicolumn{3}{|l|}{ Gender } \\
\hline Male & 507 & 55.9 \\
\hline Female & 400 & 44.1 \\
\hline \multicolumn{3}{|l|}{ Age } \\
\hline $18-30$ & 289 & 31.9 \\
\hline $31-45$ & 344 & 37.9 \\
\hline $46-60$ & 221 & 24.4 \\
\hline $60+$ & 52 & 5.7 \\
\hline Missing & 1 & 0.1 \\
\hline \multicolumn{3}{|l|}{ Education } \\
\hline Medium & 183 & 20.2 \\
\hline High & 724 & 79.8 \\
\hline \multicolumn{3}{|l|}{ Branch organization } \\
\hline Advertising/marketing & 110 & 12.1 \\
\hline New media/software & 93 & 10.3 \\
\hline Radio/television & 86 & 9.5 \\
\hline Performing art & 76 & 8.4 \\
\hline Architecture & 74 & 8.2 \\
\hline Graphic design & 68 & 7.5 \\
\hline Museum & 57 & 6.3 \\
\hline Gaming & 55 & 6.1 \\
\hline Industrial design & 50 & 5.5 \\
\hline Visual art/photography & 47 & 5.2 \\
\hline Journalism & 46 & 5.1 \\
\hline Publishing/media & 46 & 5.1 \\
\hline Film & 43 & 4.7 \\
\hline Fashion/textile design & 34 & 3.7 \\
\hline Books/magazines & 22 & 2.4 \\
\hline \multicolumn{3}{|l|}{ Function level } \\
\hline Junior & 139 & 15.3 \\
\hline Mid-Level & 288 & 31.8 \\
\hline Senior & 480 & 52.9 \\
\hline
\end{tabular}

4.4.3 Scale characteristics

To test whether the scales that resulted from the CFA show high reliability and good fit, we conducted a reliability analysis. All scales have good to high alpha values, ranging from .72 to .94 . See Table 4.2. Furthermore, information management obtained the highest mean score $(M=4.11, S D=0.75)$. Only communication sharing $(\mathrm{M}=2.63, \mathrm{SD}=0.88)$ and communication building $(\mathrm{M}=2.86, \mathrm{SD}=0.88)$ scored below 3 .

Table 4.2 Scale characteristics

\begin{tabular}{lcccc}
\hline Skills scale & Mean & SD & Variance & $\alpha$ \\
\hline Information evaluation & 3.68 & 0.72 & .51 & .72 \\
Information management & 4.11 & 0.75 & .56 & .74 \\
Communication expressiveness & 3.86 & 0.60 & .36 & .80 \\
Communication sharing & 2.63 & 0.88 & .77 & .77 \\
Communication building & 2.86 & 0.88 & .77 & .83 \\
Communication networking & 3.05 & 0.81 & .66 & .92 \\
Collaboration & 3.39 & 0.76 & .58 & .94 \\
Critical thinking & 3.44 & 0.66 & .44 & .94 \\
Creativity & 3.33 & 0.71 & .50 & .88 \\
Problem solving & 3.53 & 0.60 & .37 & .92 \\
\hline
\end{tabular}

4.4.4 Convergent and discriminant validity

To establish the validity of an instrument, there are four common types of validity: (1) face validity, (2) content validity, (3) criterion validity, and (4) construct validity. The first three types of validity focus on a substantial assessment. Face validity indicates that the measures appears to be valid; respondents are asked "their opinion about whether an instrument measures the concept intended" (Heale \& Twycross, 2015, p. 66). This type of validity is not based on the judgments of experts in the content area being assessed but rather on the opinions of respondents. Nunnally and Bernstein (1994) defined content validity as the degree to which the measurement items represent a proper sample of the theoretical content domain of a construct. This type of validity is usually assessed by a critical review of an expert panel for clarity and completeness and by comparing the relevant literature. After establishing face and content validity, researchers can establish criterion validity. Criterion validity demonstrates "the 
accuracy of the measure by comparing it to a previously established and valid instrument" (Burton \& Mazerolle, 2011, p. 28). In our case, we did not consider face validity to be sufficient and, therefore, we also rely on content validity. The latter was established by using theoretical concepts identified from the relevant academic literature (see Chapter 2). However, no criterion validity evidence was found for our instrument in the literature.

Construct validity means that a test designed to measure a particular construct is actually measuring that construct. Convergent and discriminant validity are important subtypes of construct validity (Campbell \& Fiske, 1959). If there is evidence for both, there is evidence for construct validity. Convergent validity takes two measures that are supposed to be measuring the same construct and shows that they are related. Conversely, discriminant validity shows that two measures that are not supposed to be related are, in fact, unrelated. To understand whether the factors show convergent and discriminant validity, Composite Reliability (CR), Average Variance Extracted (AVE) and Maximum Shared Variance (MSV) were performed (Gaskin, 2011). CR and AVE are used to assess the reliability of the constructs. The acceptance value of CR is .70 (Hair, Anderson, Tatham, \& Black, 1998) and it is found that all constructs have a high degree of internal consistency. Another reliability measure, AVE, reflects the overall amount of variance in the items accounted for by the latent construct. According to Fornell and Larcker (1981), an acceptable level of AVE is .50 or above for a construct. The constructs demonstrate sufficient convergent validity, except for information evaluation. In this instance, the AVE is below .50. To demonstrate the discriminant validity of the constructs, AVE for each construct should be greater than the level of MSV. Table 4.3 shows that all constructs demonstrate sufficient discriminant validity.

Table 4.3 Convergent and discriminant validity

\begin{tabular}{llll}
\hline Scale & CR & AVE & MSV \\
\hline Information evaluation & .72 & .46 & .10 \\
Information management & .75 & .50 & .04 \\
Communication expressiveness & .80 & .57 & .19 \\
Communication sharing & .78 & .53 & .43 \\
Communication building & .84 & .63 & .57 \\
Communication networking & .92 & .60 & .57 \\
Collaboration & .94 & .58 & .16 \\
Critical thinking & .94 & .55 & .16 \\
Creativity & .89 & .56 & .27 \\
Problem solving & .89 & .59 & .19 \\
\hline
\end{tabular}

Problem solving

106 | Chapter 4
4.4.5 Proposed 21st-century digital skills instrument

The final instrument with the estimate values per skill is displayed in Table 4.4. Items that were removed are marked with an asterisk in Appendix 4.B.

Table 4.4 Proposed items to measure 21st-century digital skills (factor loadings in between brackets) ( $\mathrm{N}=907)$

\begin{tabular}{|c|c|c|c|}
\hline Skill & At work, how often... & M & SD \\
\hline \multirow{3}{*}{$\begin{array}{l}\text { Information } \\
\text { management }\end{array}$} & do you save useful digital files directly to the right folder (0.751) & 4.24 & 0.80 \\
\hline & are you consistent in the naming of digital files (0.709) & 4.03 & 0.93 \\
\hline & do you organize digital files via a hierarchical folder structure (0.666) & 4.08 & 1.02 \\
\hline \multirow{3}{*}{$\begin{array}{l}\text { Information } \\
\text { evaluation }\end{array}$} & do you check the reliability of a website (0.725) & 3.59 & 0.98 \\
\hline & do you check the information found on a different website $(0.676)$ & 3.49 & 0.89 \\
\hline & do you check if the information found is up-to-date (0.639) & 3.95 & 0.82 \\
\hline \multirow{3}{*}{$\begin{array}{l}\text { Communication } \\
\text { expressiveness }\end{array}$} & do you get what you want from interactions on the internet (0.775) & 3.74 & 0.72 \\
\hline & are you via the internet effective in accomplishing what you want $(0.757)$ & 3.90 & 0.71 \\
\hline & do you know how to use the internet to express ideas clearly (0.729) & 3.94 & 0.71 \\
\hline \multirow{3}{*}{$\begin{array}{l}\text { Communication } \\
\text { sharing }\end{array}$} & do you post new messages on the internet (0.774) & 3.11 & 1.04 \\
\hline & do you post a blog/article on the internet $(0.720)$ & 2.30 & 1.09 \\
\hline & do you share information on the internet to start a discussion (0.697) & 2.49 & 1.04 \\
\hline \multirow{3}{*}{$\begin{array}{l}\text { Communication } \\
\text { building }\end{array}$} & do new collaborations emerge by approaching online contacts $(0.845)$ & 2.82 & 0.97 \\
\hline & do you establish online contacts to collaborate with $(0.837)$ & 3.06 & 1.02 \\
\hline & do you find experts on the internet to start a project with (0.695) & 2.71 & 1.04 \\
\hline \multirow[t]{8}{*}{$\begin{array}{l}\text { Communication } \\
\text { networking }\end{array}$} & $\begin{array}{l}\text { do you spend time and effort in online networking with people from } \\
\text { your field }(0.860)\end{array}$ & 3.05 & 1.01 \\
\hline & do you use your online network to benefit from it $(0.848)$ & 3.09 & 1.00 \\
\hline & do you use your online network to generate business (0.813) & 2.90 & 1.08 \\
\hline & do you build online relationships with people from your field (0.784) & 3.29 & 0.95 \\
\hline & does the internet help you approach new professional contacts $(0.757)$ & 3.32 & 0.88 \\
\hline & do you use your online network to increase brand awareness (0.757) & 3.16 & 1.10 \\
\hline & $\begin{array}{l}\text { do you start a conversation with other professionals via the internet } \\
(0.738)\end{array}$ & 2.85 & 1.05 \\
\hline & do you use your online network to achieve policy goals (0.632) & 2.77 & 0.99 \\
\hline \multirow[t]{2}{*}{ Collaboration } & $\begin{array}{l}\text { do you share important information with your team via the internet } \\
(0.832)\end{array}$ & 3.64 & 0.95 \\
\hline & $\begin{array}{l}\text { do you use the internet to share information that supports the work of } \\
\text { others }(0.826)\end{array}$ & 3.49 & 0.96 \\
\hline
\end{tabular}




\begin{tabular}{|c|c|c|c|}
\hline Skill & At work, how often... & M & SD \\
\hline & $\begin{array}{l}\text { do you use the internet to share resources that help the team perform } \\
\text { tasks }(0.823)\end{array}$ & 3.44 & 0.99 \\
\hline & $\begin{array}{l}\text { do you use the internet to provide each other with information that } \\
\text { progresses work }(0.817)\end{array}$ & 3.65 & 0.95 \\
\hline & does the internet help you get support from co-workers $(0.802)$ & 3.30 & 0.94 \\
\hline & $\begin{array}{l}\text { do you communicate via the internet with co-workers from other } \\
\text { disciplines }(0.738)\end{array}$ & 3.47 & 0.96 \\
\hline & $\begin{array}{l}\text { do you share work-related knowledge with each other via the internet } \\
(0.736)\end{array}$ & 3.45 & 0.91 \\
\hline & do you use the internet to give feedback to co-workers $(0.723)$ & 3.19 & 1.06 \\
\hline & $\begin{array}{l}\text { does the internet help you carry out tasks according to the planning } \\
(0.714)\end{array}$ & 3.41 & 1.07 \\
\hline & $\begin{array}{l}\text { do you use the internet to discuss your role and contributions with team } \\
\text { members }(0.692)\end{array}$ & 3.02 & 1.08 \\
\hline & does the internet help you use other professionals' expertise $(0.605)$ & 3.26 & 0.86 \\
\hline \multirow[t]{12}{*}{ Critical thinking } & do you give substantiated arguments or reasoning (0.785) & 3.63 & 0.90 \\
\hline & do you give proof or examples of arguments you give $(0.785)$ & 3.37 & 0.87 \\
\hline & do you give a justification for your point of view (0.777) & 3.50 & 0.89 \\
\hline & are you able to put the discussion into a new perspective $(0.765)$ & 3.29 & 0.84 \\
\hline & do you ask questions to understand other people's viewpoint (0.756) & 3.56 & 0.93 \\
\hline & $\begin{array}{l}\text { do you consider various arguments to formulate your own point of view } \\
(0.756)\end{array}$ & 3.60 & 0.83 \\
\hline & do you connect viewpoints to give a new turn to the discussion (0.754) & 3.29 & 0.88 \\
\hline & do you suggest new related points $(0.748)$ & 3.20 & 0.86 \\
\hline & do you filter the most important points from discussions (0.733) & 3.64 & 0.87 \\
\hline & do you generate new input from a discussion (0.708) & 3.32 & 0.81 \\
\hline & are you open for ideas that challenge some of your held beliefs $(0.681)$ & 3.59 & 0.84 \\
\hline & do you use the internet to justify your choices $(0.634)$ & 3.30 & 0.86 \\
\hline \multirow[t]{6}{*}{ Creativity } & $\begin{array}{l}\text { do you give a creative turn to existing processes using the internet } \\
(0.849)\end{array}$ & 3.20 & 0.87 \\
\hline & do you use the internet to generate innovative ideas for your field (0.814) & 3.38 & 0.87 \\
\hline & do you show originality in your work using the internet (0.772) & 3.24 & 0.93 \\
\hline & do you use the internet to execute your tasks creatively $(0.704)$ & 3.40 & 0.85 \\
\hline & do you follow trends on the internet to generate original ideas $(0.679)$ & 3.51 & 0.90 \\
\hline & do you use the internet to evaluate the usability of your ideas $(0.670)$ & 3.22 & 0.92 \\
\hline
\end{tabular}

\begin{tabular}{|c|c|c|c|}
\hline Skill & At work, how often... & M & SD \\
\hline \multirow[t]{8}{*}{ Problem solving } & does the internet help you find the best way to solve the problem $(0.817)$ & 3.58 & 0.73 \\
\hline & do you solve the problem using the internet (0.811) & 3.48 & 0.81 \\
\hline & do you come up with solutions to the problem via the internet $(0.800)$ & 3.59 & 0.77 \\
\hline & does the internet help you find ways to solve problems (0.792) & 3.74 & 0.72 \\
\hline & $\begin{array}{l}\text { are you confronted with a problem that you are sure you can solve using } \\
\text { the internet }(0.767)\end{array}$ & 3.40 & 0.82 \\
\hline & $\begin{array}{l}\text { do you make a decision using the internet that makes you feel happy } \\
\text { afterwards }(0.765)\end{array}$ & 3.57 & 0.73 \\
\hline & $\begin{array}{l}\text { do you find the solution via the internet even though initially no solution } \\
\text { is immediately apparent (0.706) }\end{array}$ & 3.32 & 0.76 \\
\hline & $\begin{array}{l}\text { does the actual outcome you achieved via the internet match what you } \\
\text { expected }(0.676)\end{array}$ & 3.57 & 0.70 \\
\hline
\end{tabular}

Note: The items were asked in Dutch on a 5 -point Likert scale: $1=$ never, $2=$ rarely, $3=$ sometimes,

$4=$ often, and $5=$ (almost) always

\subsection{DISCUSSION}

4.5.1 Main findings

Based on a critical evaluation of existing instruments, a set of measures for information, communication, collaboration, critical-thinking, creativity and problem-solving digital skills was developed. This instrument aimed to avoid common response formats such as self-evaluation (how good are you at...?) or agreement (how much do you agree?) scales. In most existing skill measurements, people are presented with a list of skills and are asked to evaluate how well they perform those skills. Measurements typically gather data based on people's own perceptions or estimations of their digital skills (Kuhlemeier \& Hemker, 2007). Self-evaluation survey data has significant validity problems (Hargittai, 2005; Merritt et al., 2005; Talja, 2005). Merritt and colleagues (2005), for example, checked the validity of self-assessments concerning computer skills and found that these were rated higher than actual skills. Interpretations of skills not only are perspective and context dependent but also depend upon with whom they compare themselves (Talja, 2005). As such, we used frequency scales (how often), ranging from 'never' to '(almost) always', instead of agreement scales to account for respondents' behavior. Findings from previous research show that frequency items are better suited as a proxy for actual digital skills measures than agreement scales (Van Deursen, 
Van Dijk, \& Peters, 2012). Therefore, the items of our instrument measured the frequency of various skill-related actions that are related to the 21st-century skills definition. Although the survey instrument used in this study avoids common response formats such as self-evaluation or agreement scales, the measures are based on self-reports.

To test the validity and reliability of our instrument, we used a three-fold approach. First, cognitive interviews were conducted to improve the clarity of the proposed skill items. Second, a pilot survey was conducted to explore the factor structure. Finally, a full survey was conducted to measure the consistency of the skill factors in a sample of professionals working within the creative industries. Our main contribution is that we developed a set of reliable measures for assessing 21st-century digital skills among working professionals, presented in Table 4.4

\subsubsection{Limitations and future research directions}

The creative industries were used to validate our instrument. Creative industries are major industries in the 21st century, a time in which knowledge generation through creativity and innovation is emphasized (Florida, 2002). Future studies may test whether the instrument also applies to other industries. Creative industries are a highly educated sector, which may clarify the high mean values. Similar studies on other samples would prove useful in comparing and extending our findings. For example, the necessity of particular skills could differ between industries. More specifically, this study only sampled people who are directly involved in the creative work process. Supporting staff such as office managers, financial leads and interns were not included. The focus is on content-related or higher-order digital skills since these are considered the most important. Nevertheless, for other industries such as manufacturing or retail, exploring the level of basic technical skills could be valuable. Future studies could easily measure basic technical skills by using available instruments. For example, Van Deursen and Van Dijk (2009) provided examples of basic operational skills. Additionally, contextual skills, such as ethical or cultural awareness, were not considered but do require research attention. Because of the number of skills, we had to make a choice; therefore, we focused on the core skills considered fundamental for performing necessary tasks at work.

The disadvantage of frequency scales is that you ask respondents whether they have engaged in an activity. The answer scales are commonly used in the empirical research on Internet uses (Van Deursen, Helsper, \& Eynon, 2016). Here, we avoid measuring Internet usage by including in each item a skill component within these activities. Items related to specific platforms or activities were avoided. In our instrument, for example, we did not ask respondents "how often do you use Photoshop?" using a frequency scale ranging from 1 'never' to 6 'several times per day'. Alternatively, the focus is on the skill component by asking how often 'do you check the reliability of a website' or 'do you get what you want from interactions on the Internet'. However, ideally, the measurement of 21 st-century digital skills should provide the possibility to perform skillrelated actions. Observational studies or performance tests prove to be very suitable to provide a realistic view of people's digital skills; however, the costs and time are strong limitations for large-scale data gathering. Future research is encouraged to develop a performance test for each 21st-century digital skill. In Chapter 8, we further elaborate on how to measure the levels of 21st-century digital skills by means of a performance test.

The use of Internet applications was mentioned in each skill item to capture the digital aspect. This choice was made because creative industries contain many key branches. A limitation is that the items could be perceived as too general because we do not mention digital programs specific to each branch. However, because we do explain the broader meaning of the Internet, the items are applicable to organizations outside creative industries, which is an advantage. With constant changes in ICTs, certain measures may become outdated while others rise in prominence and importance (Hargittai \& Hsieh, 2011).

With regard to the final instrument, we needed to remove the define/access components of information management. This result could be caused by the translation of the items. Future research is encouraged to test additional items. Furthermore, information evaluation had low convergent validity; therefore, it should be improved in future studies.

\subsection{CONCLUSION}

This chapter proposed an instrument to measure information, communication, collaboration, critical thinking, creativity and problem-solving digital skills aimed at working professionals. The developed instrument would not only be useful to assess the level of 21 st-century digital skills for working professionals but also to determine the impact of the individual labor situation or organizational policies on the level of 21 st-century digital skills. Measurements are needed to 
monitor skill levels and to identify the causes of potential skill insufficiencies. The 21st-century digital skills are essential for productive employees but ways to engage employees to ensure they can acquire these skills are also fundamental.

\section{APPENDIX 4.A ITEMS PER SKILL AFTER THE COGNITIVE}

\section{INTERVIEWS}

\section{Information management}

Define

1) ...formulate a problem statement before starting a search stream

2) ...have difficulties to come up with search terms

3) ...combine multiple search terms in one search action

4) ...think it is easy to choose appropriate search results

(Items 1-4 adapted from Van Deursen \& Van Dijk, 2009)

\section{Access}

1) ...specify the search action to limit the number of search results

2) ...change the search terms based on the obtained search results

3) ...use Booleans to limit the number of search results (e.g., AND, OR, " ")

4) ...look further than the top three search results

5) ...does the choice of a search result not yield what you expected

(Items 1-5 adapted from Van Deursen \& Van Dijk, 2009)

\section{Evaluate}

1) ...check the information found on a different website

2) ...check if the information found is up-to-date

3) ...check the reliability of a website

4) ...turn to multiple sources when searching for information

(Items 1-4 adapted from Van Deursen \& Van Dijk, 2009)

\section{Manage}

1) ...order digital information for easy retrieval

2) ....are you not able to find the digital file with the necessary information

3) ...add metadata (extra information) to your digital files

(Items 1-3 adapted from Majid et al., 2010)

4) ...lose time searching digital information

5) ...estimate the future value of information before you save it

6) ...remove outdated information

(Items 4-6 adapted from Hwang et al., 2015)

7) ...save useful digital files directly to the right folder 


\section{Communication}

Appropriateness

1) ...not know what behavior is appropriate in a particular situation on the internet

(Adapted from Wrench, 2004)

2) ...not share something online because it could hurt others

3) ...pay as much attention to the way you type things as to what you type

4) ...make a comment on the internet that hurts someone unintentionally

5) ...make sure your comments on the internet are appropriate to the situation

(Items 2-5 adapted from Schulze et al., 2017)

\section{Expressiveness}

1) ...know how to use the internet to express ideas clearly

2) ...are you via the internet effective in accomplishing what you want

3) ...get what you want from interactions on the internet

4) ....are your comments on the internet misunderstood

5) ...can you easily express your opinion via the internet

(Items 1-5 adapted from Bakke, 2010)

\section{Online profiling}

1) ...share information on the internet to start a discussion

2) ...update your online profile when your work situation changes

3) ...find experts on the internet to start a project with

(Items 1-3 adapted from Sigala \& Chalkiti, 2015)

4) ...post a new message on the internet

5) ...respond to online messages from your network

6) ...establish online contacts to collaborate with

7) ...post a blog/article on the internet

\section{Online profiling outcomes}

1) ....are you recommended by others via the internet

2) ...receive feedback on a shared blog/article

3) ...receive positive comments on your online profile

4) ...does someone else share a message you have posted

5) ...does a message that you have posted result in an online discussion

6) ...are you approached via your online profile
7) ...receive positive comments or 'likes'

8) ...do new collaborations emerge by approaching online contacts

\section{Networking}

1) ...have difficulties starting a conversation with other professionals via the internet

(Adapted from Burleson \& Samter, 1990)

2) ...build online relationships with people from your field

3) ...use your online network to benefit from it

4) ...spend time and effort in online networking with people from your field (Items 2-4 adapted from Lee \& Chen, 2017)

1) ...does the internet help you approach new professional contacts

2) ...use the internet to maintain contacts with people from your field

3) ...find the internet contacts who can inform you about your field

At work, how often do you use your online network to...
1) ...generate business
2) ...gain new ideas
3) ...obtain information
4) ...gain knowledge
5) ...influence opinions
6) ....increase brand awareness
7) ...stimulate innovation
8) ...realize policy goals

\section{Collaboration}

Responsibilities

1) ...use the internet to determine how other people's skills contribute to yours

2) ...use the internet to actively participate in meetings

3) ...use the internet to identify the competences of team members

4) ...use the internet to share your contributions with the team

(Items 1-4 adapted from Achibald et al., 2014)

5) ...use the internet to communicate the different roles of team members

Planning

1) ...use the internet to discuss strategies to achieve a common goal

(Adapted from Van de Oudeweetering \& Voogt, 2018) 
2) ...use the internet to make adjustments to the planning

3) ... does the internet help you monitor the progress of the team

4) ...does the internet help you carry out your tasks on time

5) ...does the internet help you make sure team members complete their tasks on time

6) ...use the internet to exchange information about 'who does what'

7) ...use the internet to discuss deadlines with each other

(Items 2-7 adapted from Chiocchio et al., 2012)

\section{Interdependence}

1) ... does the internet help you use other professionals' expertise

2) ...use the internet to give feedback to co-workers

3) ...use the internet to support others in their professional role

4) ...does the internet help you get support from co-workers

(Items 1-4 adapted from Bronstein, 2003)

5) ....are you via the internet informed about each other's progress

\section{Knowledge-sharing}

1) ...use the internet to provide each other with information that progresses the work

2) ...use the internet to provide each other with information that supports the work of others

3) ...use the internet to share resources that help the team to perform tasks

4) ...have difficulties sharing work-related knowledge with each other via the internet

5) ...share important information with your team via the internet

(Items 1-5 adapted from Chiocchio et al., 2012)

\section{Critical thinking}

Reflection

1) ...filter the most important points from discussions

2) ...think it is easier to understand other people's viewpoints via the internet

3) ...use the internet to justify your choices

4) ...use the internet to learn from other people's experiences

5) ...look critically at what you do on the internet

6) ....are you open for ideas that challenge some of your held beliefs

(Items 1-6 adapted from Sosu, 2013)

\section{Justification}

1) ...ask questions to understand other people's viewpoint (Adapted from Van de Oudeweetering \& Voogt, 2018)

2) ...give substantiated arguments or reasoning

3) ...consider the various arguments and opinions (Items 2-3 adapted from Newman et al., 1995)

\section{Novelty}

1) ...find it difficult to look at the bigger picture

2) ...suggest ideas

3) ...suggest new related points

(Items 1-3 adapted from Newman et al., 1995)

\section{Creativity}

1) ....are you the first person to come up with an idea

2) ....are you the one who quickly thinks about multiple possibilities

3) ...consider various alternatives at the same time

4) ...get compliments for your original ideas

5) ....are you the one who comes up with original ideas

6) ...work out ideas in more detail

(Items 1-6 adapted from Torrance, 1972)

7) ...look on the internet for potential work methods

(Adapted from Janssen, 2000)

8) ...use the internet to evaluate the usability of your ideas

(Adapted from Scott \& Bruce, 1994)

9) ...use the internet to generate innovative ideas for your field

10) ... give a creative turn to existing processes using the internet (Items 9-10 adapted from Carmeli \& Schaubroeck, 2007)

11) ...come up with creative ideas via the internet

12) ...come up with original solutions to problems using the internet

13)...use the internet to execute your tasks creatively

14) ....show originality in your work using the internet

15) ...suggest ideas found on the internet to improve existing products/ services

16) ...use the internet to be a creative role model

(Items 11-16 adapted from Zhou \& George, 2001)

17) ...follow trends on the internet to generate original ideas 
18) ...use the internet to show your work creatively to others

\section{Problem solving}

1) ...does the internet help you find ways to solve problems

2) ...does the internet help you find the best way to solve the problem

(Items 1-2 adapted from Van de Oudeweetering \& Voogt, 2018)

3) ...becomes the problem quickly clear via the internet

4) ...come up with solutions to the problem via the internet

5) ...make a decision using the internet that makes you feel happy afterwards

6) ....are you sure that you solved the problem via the internet

7) ...solve the problem using the internet

8) ...does the actual outcome you achieved via the internet matches what you expected

9) ....are you confronted with a problem that you are sure you can solve using the internet

(Items 3-9 adapted from Heppner \& Petersen, 1982)

\section{APPENDIX 4.B ITEMS PER SKILL AFTER THE PILOT TEST}

\section{Information management}

Define/access

1) ...change the search terms based on the obtained search results* $(\lambda=0.787)$

2) ...specify the search action to limit the number of search results* (e.g., date, type) $(\lambda=0.700)$

3) ...combine multiple search terms in one search action* $(\lambda=0.659)$

4) ...use Booleans to limit the number of search results* (e.g., AND, OR, " ") $(\lambda=0.314)$

5) ...think it is easy to come up with appropriate search terms* (Adapted from Van Deursen \& Van Dijk, 2009)

\section{Evaluate}

1) ...check the reliability of a website $(\lambda=0.732)$

2) ...check if the information found is up-to-date $(\lambda=0.710)$

3) ...look further than the top three search results* $(\lambda=0.686)$

4) ...check the information found at a different website $(\lambda=0.603)$

5) ...turn to multiple sources when searching for information* $(\lambda=0.447)$

6) ...estimate the future value of information before you save it ${ }^{\star}(\lambda=0.413)$

\section{Manage}

1) ...save digital files directly to the right folder* $(\lambda=0.756)$

2) ...add metadata (extra information) to your digital files $(\lambda=0.727)$

3) ...order digital files for easy retrieval* $(\lambda=0.660)$

4) ...organize digital files via a hierarchical folder structure (Adapted from Majid et al., 2010)

5) ....are you consistent in the naming of digital files ${ }^{\star}$

\section{Communication}

Appropriateness/expressiveness

1) ...make sure your comments on the internet are appropriate to the situation* $(\lambda=0.652)$

2) ...make a comment on the internet that hurts someone unintentionally* $(\lambda=0.630)$

3) ...know how to use the internet to express ideas clearly $(\lambda=0.629)$ 
4) ...pay as much attention to the way you type things as to what you type $(\lambda=0.499)$

5) ...get what you want from interactions on the internet $(\lambda=0.484)$

6) ....are you via the internet effective in accomplishing what you want $(\lambda=0.478)$

7) ...know what behavior is appropriate in a particular situation on the internet* $^{*}(\lambda=0.374)$

Content sharing

1) ...post a blog/article on the internet $(\lambda=0.743)$

2) ...give feedback on a shared blog/article* $(\lambda=0.693)$

3) ...post a new message on the internet $(\lambda=0.646)$

4) ...share information on the internet to start a discussion $(\lambda=0.531)$

5) ...share a message from someone else on the internet* $(\lambda=0.511)$

\section{Contact building}

1) ...find experts on the internet to start a project with $(\lambda=0.746)$

2) ...establish online contacts to collaborate with $(\lambda=0.657)$

3) ...do new collaborations emerge by approaching online contacts $(\lambda=0.654)$

4) ...find the internet contacts who can inform you about your field* $(\lambda=0.574)$

5) ....are you approached via your online profile* $(\lambda=0.565)$

\section{Networking}

1) ...spend time and effort in online networking with people from your field $(\lambda=0.810)$

2) ...build online relationships with people from your field $(\lambda=0.763)$

3) ...use your online network to increase brand awareness $(\lambda=0.731)$

4) ...use the internet to maintain contacts with people from your field* $(\lambda=0.708)$

5) ...does the internet help you approach new professional contacts $(\lambda=0.687)$

6) ...use your online network to generate business $(\lambda=0.662)$

7) ...use your online network to benefit from it $(\lambda=0.658)$

8) ...use your online network to influence opinions * $(\lambda=0.611)$

9) ...use your online network to achieve policy goals $(\lambda=0.586)$

10) ...start a conversation with other professionals via the internet $(\lambda=0.420)$

\section{Collaboration}

Responsibilities

1) ...use the internet to identify the competences of team members ${ }^{\star}$ $(\lambda=0.836)$

2) ...use the internet to determine how other people's skills contribute to yours $^{\star}(\lambda=0.824)$

3) ...use the internet to discuss strategies to achieve a common goal* $(\lambda=0.654)$

4) ...use the internet to communicate the different roles of team members ${ }^{\star}$ $(\lambda=0.615)$

5) ...use the internet to discuss your role and contributions with team members

\section{Planning}

1) ...does the internet help you monitor the progress of the team* $(\lambda=0.653)$

2) ...use the internet to make adjustments to the planning* $(\lambda=0.572)$

3) ...does the internet help you make sure team members complete their tasks on time* $(\lambda=0.516)$

4) ...does the internet help you carry out tasks according to the planning

5) ...use the internet to plan who is responsible for what* (Items 4-5 adapted from Chiocchio et al., 2012)

\section{Interdependence}

1) ...use the internet to give feedback to co-workers $(\lambda=0.723)$

2) ...does the internet help you use other professionals' expertise $(\lambda=0.722)$

3) ....are you via the internet informed about each other's progress ${ }^{\star}(\lambda=0.685)$

4) ...does the internet help you get support from co-workers $(\lambda=0.669)$

5) ...communicate via the internet with co-workers from other disciplines (Adapted from Bronstein, 2003)

\section{Knowledge-sharing}

1) ...use the internet to provide each other with information that progresses the work $(\lambda=0.875)$

2) ...share important information with your team via the internet $(\lambda=0.851)$

3) ...use the internet to share resources that help the team to perform tasks $(\lambda=0.793)$ 
4) ...use the internet to share information that supports the work of others $(\lambda=0.758)$

5) ...share work-related knowledge with each other via the internet (Adapted from Chiocchio et al., 2012)

\section{Critical thinking}

\section{Reflection}

1) ...use the internet to learn from other people's experiences* $(\lambda=0.803)$

2) ...use the internet to justify your choices $(\lambda=0.769)$

3) ...filter the most important points from discussions $(\lambda=0.745)$

4) ...think it is easier to understand other people's viewpoints via the internet* $^{*}(\lambda=0.618)$

5) ...are you open for ideas that challenge some of your held beliefs $(\lambda=0.524)$

6) ...look critically at what you do on the internet* $(\lambda=0.411)$

\section{Justification}

1) ...ask questions to understand other people's viewpoint $(\lambda=0.891)$

2) ...give substantiated arguments or reasoning $(\lambda=0.713)$

3) ...consider various arguments to formulate your own point of view

4) ...give proof or examples of arguments you give

5) ...give a justification for your point of view (Items 3-5 adapted from Newman et al., 1995)

\section{Novelty}

1) $\ldots$ suggest new related points $(\lambda=0.905)$

2) ...suggest new ideas ${ }^{\star}(\lambda=0.834)$

3) ...connect viewpoints to give a new turn to the discussion

4) ...generate new input from a discussion

5) ....are you able to put the discussion into a new perspective (Items 3-5 adapted from Newman et al., 1995)

\section{Creativity}
1) ...use the internet to generate innovative ideas for your field $(\lambda=0.835)$
2) ...show originality in your work using the internet $(\lambda=0.813)$
3) ...follow trends on the internet to generate original ideas $(\lambda=0.803)$
4) ...come up with creative ideas via the internet* $(\lambda=0.774)$

5) ...use the internet to execute your tasks creatively $(\lambda=0.751)$

6) ...give a creative turn to existing processes using the internet $(\lambda=0.727)$

7) ...use the internet to show your work creatively to others* $(\lambda=0.702$

8) ...use the internet to evaluate the usability of your ideas $(\lambda=0.632)$

9) ....are you the one who quickly thinks about multiple possibilities* $(\lambda=0.523)$

10) ...come up with ideas via the internet to improve existing products/

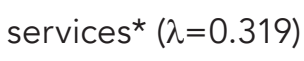

11) ...present yourself on the internet as a creative role mode ${ }^{*}(\lambda=0.315)$

12) ....search out new work procedures or techniques via the internet (Adapted from Janssen, 2000)

\section{Problem solving}

1) ...come up with solutions to the problem via the internet $(\lambda=0.909)$

2) ...does the internet help you find the best way to solve the problem $(\lambda=0.887)$

3) ...solve the problem using the internet $(\lambda=0.870)$

4) ....are you sure that you solved the problem via the internet ${ }^{\star}(\lambda=0.854)$

5) ...does the internet help you find ways to solve problems $(\lambda=0.851)$

6) ...make a decision using the internet that makes you feel happy afterwards $(\lambda=0.834)$

7) ...are you confronted with a problem that you are sure you can solve using the internet $(\lambda=0.812)$

8) ....becomes the problem quickly clear via the internet* $(\lambda=0.808)$

9) ...does the actual outcome you achieved via the internet matches what you expected $(\lambda=0.632)$

10) ...find the solution via the internet even though initially no solution is immediately apparent (Adapted from Heppner \& Petersen, 1982)

Note: Items that are excluded based on CFA results of the full survey are marked with an asterisk $(*)$. 


\section{CHAPTER 5 \\ THE SEQUENTIAL AND CONDITIONAL NATURE OF 21ST- CENTURY DIGITAL SKILLS}

The importance of 21st-century digital skills has been well established in Chapters 2 and 3 . However, the research often fails to examine how various skills relate to each other. Through a survey of a sample of 1,222 professionals working within the creative industries, we tested, by using path analysis, whether 21st-century digital skills have a sequential and conditional nature. The sequence of the model starts with information and communication digital skills followed by collaboration, critical-thinking and creative digital skills. All skills lead to problem-solving digital skills, indicating the importance of these skills in giving workers the ability to solve complex problems in different contexts. The results confirm that the analyzed skills build on each other sequentially. To understand what interventions might be successful, the relations among various digital skills should be considered. ${ }^{4}$

4 Van Laar, E., Van Deursen, A. J. A. M., Van Dijk, J. A. G. M., \& De Haan, J. (2019). The sequential and conditional nature of 21 st-century digital skills. International Journal of Communication 13, 3462-3487. 


\subsection{THEORETICAL FRAMEWORK: RELATIONS AMONG 21ST- CENTURY DIGITAL SKILLS}

The essence of what we call 21st-century digital skills is that they define what employees can do with ICT to support the broader spectrum of 21st-century skills and in turn take full advantage of ICTs. In most conceptualizations of digital skills and of 21st-century skills, the relevant skills are considered and analyzed separately, as if they are independent of each other. Yet, studies focusing on Internet skills have revealed that there is a sequential and conditional nature present among skills (Van Deursen, Helsper, Eynon, \& Van Dijk, 2017; Van Deursen \& Van Dijk, 2016). Lacking the more technical skills, for instance, means that one will not even have the opportunity to perform the other skills. This chapter aims to extend existing empirical knowledge regarding 21st-century digital skills by analyzing their sequential nature. Because a large number of policy initiatives are being developed that are aimed at a skilled workforce, a thorough understanding of how different types of skills relate to each other is important for designing interventions. The following research question is addressed:

1) What is the relation among the 21st-century digital skills pertaining to information, communication, collaboration, critical thinking, creativity and problem solving?

To obtain a comprehensive picture of how skills interrelate, this chapter builds upon the operationalized skills in Chapter 4: information management, information evaluation, communication expressiveness, communication contact-building, communication networking, communication content-sharing, collaboration, critical thinking, creativity, and problem solving. It is important to note that critical thinking and creativity are often considered to be individual attributes that one either has or does not have. However, these attributes are not simply innate traits but rather skills that can be developed through practice (Amabile \& Pillemer, 2012). For example, aspects of critical thinking (e.g., considering information from different viewpoints) and creativity (e.g., generating novel and useful ideas) can be learned through practice. This chapter focuses on the aspects of skills that can be improved by experience, learning and training. In what follows, we describe the expected relations among 21stcentury digital skills. Based on the literature, we build a conceptual model with on the highest-level problem-solving skills.
The growing use and spread of ICTs make it important for individuals to develop problem-solving digital skills. As routine tasks are increasingly automated, the demand for jobs that require employees to solve complex problems is on the rise. Employees need the skills to formulate the problem, recognize the context within which the problem occurs, and specify the demands that any solution needs to be successful. Problem solving is considered the highest form of learning (Gagné, 1985). It involves both the acquisition and the application of new knowledge in situations that must be actively explored to find and apply a solution (Mainert, Niepel, Murphy, \& Greiff, 2018). Knowledge can be derived from diverse sources accessible online. Web 2.0 engages people in collective learning; they help, support and encourage each other as they work on problems and seek new forms of knowledge.

When employees exhibit high creative digital skills at work, they are more likely to generate novel and useful ideas for new products, services and processes by using the Internet. The digital environment supports employees' creativity in knowledge gathering, integration and generation (Karakaya \& Demirkan, 2015). Digital technologies allow people to express themselves in new ways, to make original and valued contributions, and to broaden opportunities for realizing the products of their imaginations (Loveless, 2003). A person with high levels of creative digital skills knows the culture and norms of the online world and where to post and upload creative content within the boundaries of acceptable social behavior (Park, 2012). Creative thinking is an important component of web-based problem solving (Kuo \& Hwang, 2014). It involves the generation of a variety of ideas, which is a strong predictor of innovative problem solving (Dumas, Schmidt, \& Alexander, 2016). We hypothesize that:

H1: Creative digital skills contribute positively to problem-solving digital skills.

Critical-thinking digital skills involve making judgments about the quality of information and communication presented online (Manalo, Kusumi, Koyasu, Michita, \& Tanaka, 2013). These skills help individuals to consider content from different points of view (Wechsler et al., 2018) and to make informed judgments and choices about information and communication, enabling successful performance in a given task. In an age of disinformation and fake news, a person must think critically to determine whether information or communication is trustworthy (Keshavarz, 2014). Critical thinking is essential if one is to differentiate accurate information and communication from manipulation. 
Furthermore, in critical thinking, evidence and arguments need to be evaluated independently of prior beliefs and opinions that one may hold (West, Toplak, \& Stanovich, 2008). Critical thinking plays a role in the acquisition of knowledge, as it is only through engaging interpretations and inferences that new knowledge is created and internalized (Voskoglou \& Buckley, 2012). Creativity without critical thought reduces to mere novelty (Paul \& Elder, 2006). An accurate judgment of the creativity of ideas is as an important component underlying creative performance (Benedek et al., 2016; Eggers, Lovelace, \& Kraft, 2017). Critical thinking assumes that individuals have the skills to analyze evidence and test the "logic of ideas, proposals, and courses of action" (Rousseau, 2012, p. 3), thereby increasing creativity as measured through unique product designs created (Eggers et al., 2017). Furthermore, critical thinking is an important component of web-based problem solving (Kuo \& Hwang, 2014); it is expressed through reflection and open-minded thinking about alternatives, which is considered key to facilitating problem solving (Hong \& Choi, 2015; Hyytinen, Holma, Toom, Shavelson, \& Lindblom-Ylänne, 2014). Educating about critical thinking has a positive effect on problem-solving skills (Kanbay \& Okanlı, 2017). Whitten and Brahmasrene (2011) describe critical thinking as the "cognitive engine which drives problem solving and decision making" (p. 1). Through consideration of alternatives and exploration of contradictions and probabilities (Moeller, Cutler Fiedler, \& Weier, 2013), critical-thinking skills help individuals to make the right decision (Paul \& Elder, 2004). We hypothesize:

H2: Critical-thinking digital skills contribute positively to creative digital skills.

H3: Critical-thinking digital skills contribute positively to problem-solving digital skills.

Collaboration digital skills refer to the ability to operate cooperatively online in pursuit of a common objective (Green, Ashton, \& Felstead, 2001). Work is increasingly performed by teams of people with complementary roles and expertise. Successful collaboration is dependent on the ability to divide a task into pieces based on the strengths of the individuals while also ensuring that each team member has a clear sense of the entire project (Bronstein, 2003; Dede, 2010). Because of the importance of knowledge in today's competitive world as well as the growth of virtual communities and geographically dispersed teams, an understanding of how to enhance employees' online knowledge-sharing behavior has become critical, especially given that higher levels of interaction are necessary to accomplish interdependent work tasks.
Collaboration processes - managing interdependencies across time to achieve a common goal - are increasingly supported by ICT, which provides the flexibility to work collaboratively beyond the restrictions of time and place. We expect collaboration digital skills to contribute to better critical thinking, creative and problem-solving digital skills. Teamwork activities can encourage critical thinking development (Magrabi, Pasha, \& Pasha, 2018). Interactions involving conflicting viewpoints promote more discussion, and individuals actively engage in the application of knowledge (Jeong, 2003). The research revealed that to stimulate critical thinking, it is important to engage in collaborative processes such as reciprocal dialogues (Petrucco \& Ferranti, 2017). Moreover, shared knowledge is a useful resource for working on creative ideas and solutions (Binnewies, Ohly, \& Sonnentag, 2007). Creativity is often a result of a social process (PerrySmith \& Shalley, 2003; Sawyer \& DeZutter, 2009) in which employees share knowledge by communicating task-related ideas, information and know-how required by their colleagues (Wang \& Noe, 2010). In relation to problem solving, when the complexity of a problem increases, it becomes necessary to work collaboratively. Each team member possesses unique expert information that must be integrated to achieve a viable solution (Rentsch, Mello, \& Delise, 2010). Collaboration skills may help the individual and the group realize their potential (Dong, Bartol, Zhang, \& Li, 2017; Lin, Mills, \& Ifenthaler, 2016). We hypothesize:

H4: Collaboration digital skills contribute positively to critical-thinking digital skills.

H5: Collaboration digital skills contribute positively to creative digital skills.

H6: Collaboration digital skills contribute positively to problem-solving digital skills.

Communication digital skills pertain to effectively expressing and sharing online content by considering the audience and medium. These skills involve expressiveness, defined as the ability to express feelings and reactions clearly and openly in a digital environment. Additionally, these skills involve building and maintaining contacts, which are preconditions for using network contacts who possess the resources necessary to facilitate resource mobilization (Wolff \& Moser, 2010). Networking refers to individuals' ability to make online connections and contacts for instrumental or expressive returns (Lee \& Chen, 2017). Finally, communication digital skills concern content sharing, or the ability to participate in and make use of online platforms to share information (Sigala \& Chalkiti, 2015). Platforms such as social networking sites, blogs and wikis are 
increasingly used to share digital content. Chiu, Hsu, and Wang (2006) found that social interaction and socializing were related to online content-sharing behaviors. The rise of social network sites is intensifying the use of participatory online activities through communication among users who maintain existing social relations and make new social connections online (Boyd \& Ellison, 2007). Individuals are able to express themselves, establish relationships, and interact with others at any distance of time and space (Yu, Tian, Vogel, \& Kwok, 2010). This study focuses on the following components of communication digital skills: expressiveness, contact building, social networking, and content sharing. Because contact building, social networking and content sharing involve expression, expressiveness is expected to contribute to the level of these components. Furthermore, it is expected that one first needs to establish online contacts before starting to network and in turn share content. We hypothesize:

H7: Communication expressiveness has a positive influence on (a) communication building, (b) communication networking, and (c) communication sharing. Communication-building has a positive influence on (d) communication networking and (e) communication sharing. Communication networking has a positive influence on $(f)$ communication sharing.

Online communication (e.g., e-mail, discussion forums, and social media) has become an important way for individuals to interact (Li, Shi, \& Dang, 2014). Accordingly, extensive network contacts can increase team members' understanding of others' skills and knowledge and can help individuals find relevant experts when specific knowledge is required. Furthermore, the expression of critical thinking relies on communicative competences such as the ability to debate, express informed opinions, and evaluate and respect the opinion of others (Volman \& Ten Dam, 2015). Similar arguments account for creativity. The prior research has highlighted that employees who engage in higher levels of social media exploitation and who join various social networks and media achieve higher levels of creativity (Sigala \& Chalkiti, 2015). To engage in creative digital activities, a person needs the skills to understand issues such as media language and how to reach audiences (Park, 2012). Prior studies have revealed that social Internet skills directly relate to creative Internet skills (Van Deursen et al., 2017). Finally, the previous research has revealed that problem solving requires the effective use of communication skills (Erzokan, 2013). We hypothesize that:
H8: Communication digital skills (expressiveness, building, networking, and sharing) contribute positively to collaboration digital skills.

H9: Communication digital skills (expressiveness, building, networking, and sharing) contribute positively to critical-thinking digital skills.

H10: Communication digital skills (expressiveness, building, networking, and sharing) contribute positively to creative digital skills.

H11: Communication digital skills (expressiveness, building, networking, and sharing) contribute positively to problem-solving digital skills.

Information digital skills are defined as the ability to find, evaluate and effectively use information online (Kiliç-Çakmak, 2010; Kurbanoglu, Akkoyunlu, \& Umay, 2006). Given the rapid increase in new ICTs and the multiplication of information sources, the importance of information digital skills is increasing (Yilmaz, 2016). It is possible to access numerous resources on any subject online. However, one has to decide whether the information accessed is reliable and worthwhile enough to be useful. Especially in an information-dense society where knowledge changes and becomes outdated rapidly (Ross, Perkins, \& Bodey, 2016), employees will need skills to manage the quantity and quality of information. Information skills are considered multidimensional, and key components include management and evaluation. Information management skills are needed to organize information effectively for easy retrieval. Because the Internet offers opportunities for everyone to publish regardless of the quality of the information dispatched, it is essential for individuals to first develop the skills that are required to manage digital information (Siddiq, Scherer, \& Tondeur, 2016). Information evaluation skills are needed to make informed decisions about the quantity and quality of the received information (e.g., in terms of reliability, relevance, and accuracy). We hypothesize:

H12: Information management has a positive influence on information evaluation.

Once information has been found and organized, a person can transform and develop that information in a variety of ways to communicate it more effectively to others and to develop his or her own ideas or interpretations on the basis of the task to be solved (Ananiadou \& Claro, 2009). Additionally, the ability to analyze, interpret and evaluate information online is positively related to communication networking skills (Lee \& Chen, 2017). Similarly, a recent study revealed that information-navigation skills directly relate to 
having online social skills (Van Deursen et al., 2017). We also expect a direct contribution to collaboration skills because the prior research has revealed that information skills predict collaboration on Facebook (Khan, Wohn, \& Ellison, 2014). Moreover, in line with the previous research, it is expected that critical thinking requires information retrieval and evaluation first (Koltay, 2011; Weiner, 2011). Finally, web-based problem solving is a higher-order thinking process which also consists of searching for information on the Internet (Kuo \& Hwang, 2014). To solve challenging tasks in problem situations, individuals have to perform cognitive activities such as activating existing knowledge and organizing new information (Ifenthaler, 2012). We hypothesize:

H13: Information digital skills (evaluation and management) contribute positively to communication digital skills (expressiveness, building, networking, and sharing).

H14: Information digital skills (evaluation and management) contribute positively to collaboration digital skills.

H15: Information digital skills (evaluation and management) contribute positively to critical-thinking digital skills.

H16: Information digital skills (evaluation and management) contribute positively to problem-solving digital skills.

According to the theoretical considerations discussed above, we propose the conceptual model in Figure 5.1.

\subsection{METHOD}

5.2.1 Sample

The final sample included 1,222 professionals who were directly involved in creative work processes that spanned initial analysis of the problem to the introduction of a product, process or service in the market. See Table 5.1.

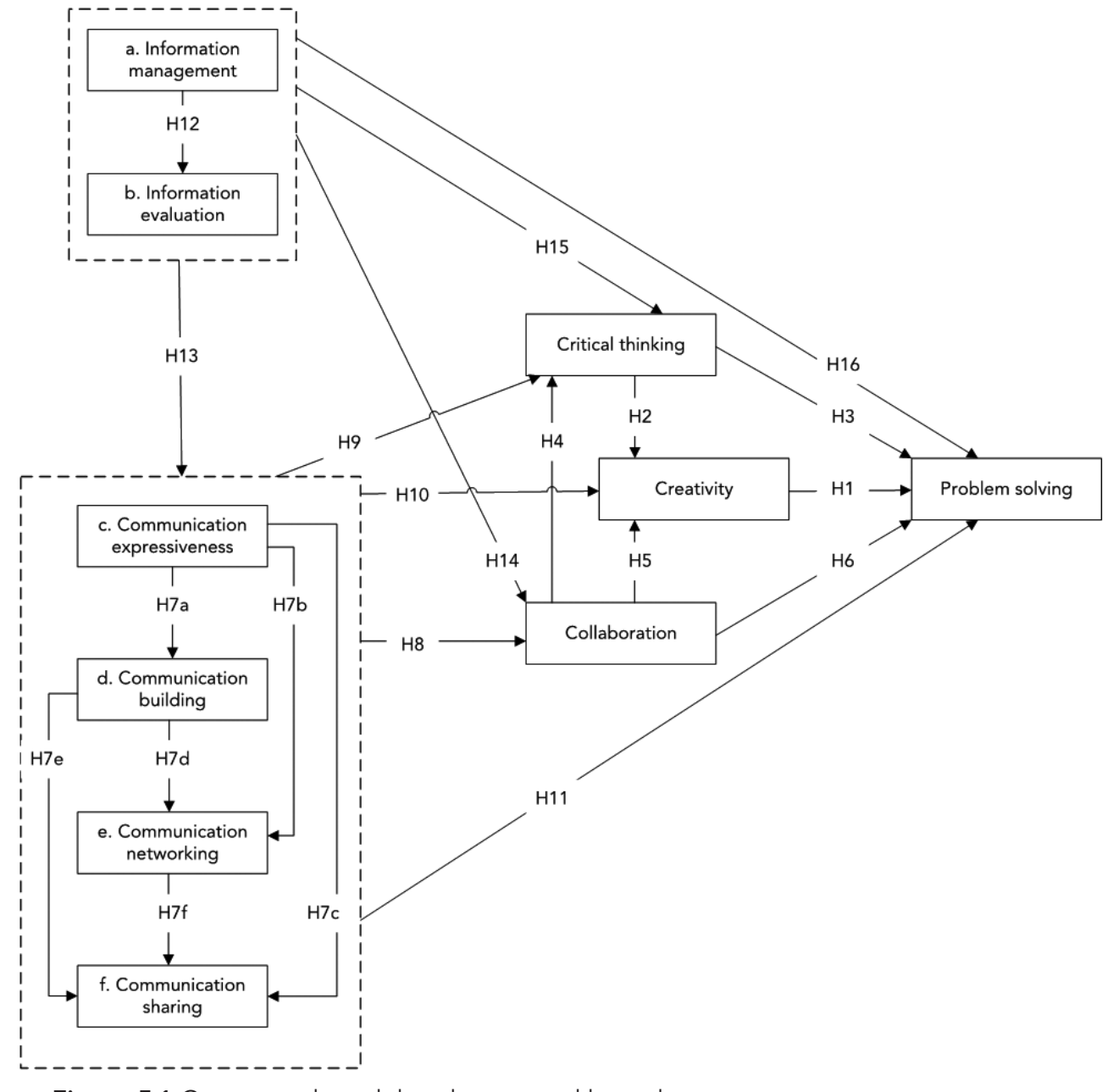

Figure 5.1 Conceptual model and proposed hypotheses

Table 5.1 Sample characteristics $(\mathrm{N}=1,222)$

N $\%$

\begin{tabular}{lll}
\hline $\begin{array}{l}\text { Gender } \\
\text { Male }\end{array}$ & 646 & 52.9 \\
Female & 576 & 47.1 \\
Age & & \\
$18-30$ & 373 & 30.6 \\
$31-45$ & 467 & 38.3 \\
$46-60$ & 303 & 24.8
\end{tabular}




\begin{tabular}{lll}
\hline & $\mathrm{N}$ & $\%$ \\
\hline 60+ & 77 & 6.3 \\
Missing & 2 & 0.2 \\
Education & & \\
Medium & 294 & 24.1 \\
High & 928 & 75.9 \\
Branch organization & & \\
Advertising/marketing & 136 & 11.1 \\
Graphic design & 115 & 9.4 \\
Performing art & 106 & 8.7 \\
New media/software & 105 & 8.6 \\
Radio/television & 97 & 7.9 \\
Visual art/photography & 89 & 7.3 \\
Architecture & 84 & 6.9 \\
Publishing/media & 72 & 5.9 \\
Journalism & 72 & 5.9 \\
Industrial design & 64 & 5.2 \\
Fashion/textile design & 61 & 5.0 \\
Museum & 61 & 5.0 \\
Gaming & 58 & 4.7 \\
Film & 53 & 4.3 \\
Books/magazines & 49 & 4.0 \\
Employment situation & & \\
Paid employment - permanent contract & 241 & 19.7 \\
Paid employment - temporary contract & 592 & 48.4 \\
Temporary agency worker & 12 & 1.0 \\
Self-employed & 377 & 30.9 \\
Junction level & & \\
Mid-Level & 200 & 16.4 \\
Senior & 402 & 32.9 \\
\hline & & 50.7 \\
\hline
\end{tabular}

\subsubsection{Measures}

Ideally, the measurement of 21st-century digital skills should involve the actual use of Internet applications (Fraillon, Ainley, Schulz, Friedman, \& Gebhardt, 2014). Performance tests have proved to be well-suited to provide a realistic view of people's digital skills, but its cost and time required to conduct such tests are strong limitations for large-scale data gathering. Therefore, selfassessment has been widely reported as a proxy measure of actual digital skill levels (Siddiq, Hatlevik, Olsen, Throndsen, \& Scherer, 2016). However, selfassessments have significant validity problems because people have difficulty judging their own skills. The evidence shows that especially young men overrate their performance (Hargittai \& Shafer, 2006). Other measures derive the level of digital skills from the intensity of engagement in a variety of skill-related actions. They are less subject to overrating and show higher correlations with actual performance tests compared to the use of agreement scales (Van Deursen, Van Dijk, \& Peters, 2012)

To measure the relations among 21st-century digital skills, we used our 21stcentury digital skills instrument developed in Chapter 4 . The only difference is that we removed two collaboration items that could not be answered by every working professional. As a result, we were able to use the data of all respondents. Frequency scales were used to measure how often respondents perform certain skill-related actions at work, and that information functioned as a behavioral indicator of skills. Respondents were asked to answer the items using a five-point Likert scale ranging from 1 'never' to 5 '(almost) always'. Cronbach's alpha exceeded the required threshold of .70, which implies high internal consistency of the scales. Table 5.2 on the next page displays the measures used including the means, standard deviations and reliability scores.

\subsubsection{Data analysis}

To test our hypotheses, we applied path modeling using Amos 23.0. Because we used validated scales that consisted of a large number of items, we submitted composite scales to the analysis rather than the individual items (Bandalos \& Finney, 2001). To obtain a comprehensive model fit, we included the indices suggested by Hair, Black, Babin, Anderson, and Tatham (2006): the $\chi^{2}$ statistic, the ratio of $\chi^{2}$ to its degree of freedom $\left(\chi^{2} / \mathrm{df}\right)$, the standardized root mean residual (SRMR), the Tucker-Lewis index (TLI), and the root mean square error of approximation (RMSEA) 
The next statements are about processing information for work-related purposes. At work, how often...

Information management $(\alpha=.76)$

$4.06 \quad 0.79$

1.....do you save useful digital files directly to the right folder

$\begin{array}{ll}4.21 & 0.82\end{array}$

2 .... are you consistent in the naming of digital files

$4.00 \quad 0.95$

3....do you organize digital files via a hierarchical folder structure

$3.98 \quad 1.07$

The next statements are about searching information for work-related purposes. At work, how often...

Information evaluation ( $\alpha=.71$ )

$3.67 \quad 0.72$

1 .... do you check the reliability of a website

$2 \ldots$... you check the information found on a different website

$3.50 \quad 0.89$

3.... do you check if the information found is up-to-date

$3.95 \quad 0.82$

The next statements are about profiling yourself online for work-related purposes. At work, how often...

Communication expressiveness $(\alpha=.79)$

$3.83 \quad 0.60$

1 ....do you get what you want from interactions on the internet

$3.71 \quad 0.73$

2....are you via the internet effective in accomplishing what you want

$3.87 \quad 0.72$

3....do you know how to use the internet to express ideas clearly

$3.90 \quad 0.72$

Communication building $(\alpha=.84)$

$2.83 \quad 0.90$

1....do new collaborations emerge by approaching online contacts

$2.81 \quad 0.99$

2....do you establish online contacts to collaborate with

3....do you find experts on the internet to start a project with

$\begin{array}{lll}2.65 & 1.07\end{array}$ Communication networking $(\alpha=.92$

$3.04 \quad 0.81$

1.... do you spend time and effort in online networking with people from your $3.04 \quad 1.00$ field

2....do you use your online network to benefit from it

3.... do you use your online network to generate business

4....do you build online relationships with people from your field

5 ....does the internet help you approach new professional contacts

$3.29 \quad 0.90$

6 .... do you use your online network to increase brand awareness

$3.16 \quad 1.09$

7 .... do you start a conversation with other professionals via the internet

$2.81 \quad 1.04$

8 ....do you use your online network to achieve policy goals

\begin{tabular}{lcc}
\hline & M & SD \\
\hline Communication sharing $(\alpha=.77)$ & 2.64 & 0.89 \\
1....do you post new messages on the internet & 3.11 & 1.05 \\
2....do you post a blog/article on the internet & 2.36 & 1.12 \\
3....do you share information on the internet to start a discussion & 2.46 & 1.04 \\
\hline
\end{tabular}

$3.31 \quad 0.79$

Collaboration $(a=93)$

$\begin{array}{lll}1 \ldots . . \text { do you share important information with your team via the internet } & 3.47 & 1.05 \\ 2 \ldots \text { do you use the internet to share information that supports the work of } & 3.38 & 1.00\end{array}$ others

3....do you use the internet to share resources that help the team perform tasks $3.27 \quad 1.06$

4....do you use the internet to provide each other with information that $3.52 \quad 1.00$ progresses work

5....does the internet help you get support from co-workers 3.190 .98

6....do you communicate via the internet with co-workers from other disciplines $\quad \begin{array}{llll}3.32 & 1.03\end{array}$

7....do you share work-related knowledge with each other via the internet $\quad \begin{array}{lll}3.35 & 0.94\end{array}$

8....do you use the internet to give feedback to co-workers $\quad 3.09 \quad 1.08$

9....does the internet help you use other professionals' expertise

$3.24 \quad 0.85$

The next statements are about having online discussions (e.g., e-mail, Skype, online forums) for work-related purposes. At work, how often...

Critical thinking $(\alpha=.94)$

$3.39 \quad 0.70$

1 .... do you give substantiated arguments or reasoning

$3.57 \quad 0.93$

$2 \ldots$.. do you give proof or examples of arguments you give

$3.34 \quad 0.91$

3....do you give a justification for your point of view

4.... are you able to put the discussion into a new perspective

$3.45 \quad 0.91$

5 ....do you ask questions to understand other people's viewpoin

$3.25 \quad 0.86$

6....do you consider various arguments to formulate your own point of view $\quad 3.54 \quad 0.88$

7....do you connect viewpoints to give a new turn to the discussion $\quad 3.22 \quad 0.91$

$\begin{array}{llll}8 . . . \text { do you suggest new related points } & 3.15 & 0.89\end{array}$

9....do you filter the most important points from discussions $\quad 3.59 \quad 0.91$

10....do you generate new input from a discussion $\quad 3.26 \quad 0.85$

11....are you open for ideas that challenge some of your held beliefs $\quad \begin{array}{lll}3.50 & 0.86\end{array}$

$\begin{array}{lll}12 \ldots . . \text { do you use the internet to justify your choices } & 3.25 & 0.89\end{array}$ 
At work, how often..

Creativity ( $\alpha=.89$ )

1 ....do you give a creative turn to existing processes using the internet

2....do you use the internet to generate innovative ideas for your field

$3 . .$. do you show originality in your work using the internet

4 ... do you use the internet to execute your tasks creatively

5 .... do you follow trends on the internet to generate original ideas

6 .... do you use the internet to evaluate the usability of your ideas

$3.21 \quad 0.93$

The next statements are about problems at work that you want to solve by using the Internet. At work, how often..

Problem solving $(\alpha=.92)$

1....does the internet help you find the best way to solve the problem

$2 \ldots$. do you solve the problem using the internet

$3 \ldots .$. do you come up with solutions to the problem via the internet

4.... does the internet help you find ways to solve problems

5....are you confronted with a problem that you are sure you can solve using $\begin{array}{llll}3.38 & 0.82\end{array}$ the internet

6....do you make a decision using the internet that makes you feel happy $3.56 \quad 0.75$ afterwards

7....do you find the solution via the internet even though initially no solution $3.32 \quad 0.77$ is immediately apparent

8.... does the actual outcome you achieved via the internet match what you $\quad 3.55 \quad 0.71$ expected

Note: The items were asked in Dutch on a 5-point Likert scale: $1=$ never, $2=$ rarely,

$3=$ sometimes, $4=$ often, and $5=($ almost) always

\subsection{RESULTS}

5.3.1 Structural and path model

The conceptual model as presented in Figure 5.1 resulted in a slightly overfit model, meaning that the model has more parameters than can be justified by the data, reducing generalizability. To improve model fit, we removed ten insignificant paths. The resulting model provided a good fit: $\chi^{2}(12)=16.71 ; \chi^{2} /$ $\mathrm{df}=1.39 ; \mathrm{SRMR}=.01 ; \mathrm{TLI}=.99 ; \mathrm{RMSEA}=.02,90 \% \mathrm{Cl}[.00, .09]$. Table 5.3 provides the correlations among the skills. Figure 5.2 provides the path models with coefficients and variances explained.

Table 5.3 Correlation matrix

\begin{tabular}{lcccccccccc}
\hline & 1 & 2 & 3 & 4 & 5 & 6 & 7 & 8 & 9 & 10 \\
\hline 1. Evaluation & - & $.15^{\star \star}$ & $.25^{\star \star}$ & $.22^{\star \star}$ & $.29^{\star \star}$ & $.19^{\star \star}$ & $.20^{\star \star}$ & $.29^{\star \star}$ & $.22^{\star \star}$ & $.18^{\star \star}$ \\
2. Management & - & - & $.18^{\star \star}$ & -0.02 & .02 & .02 & $.12^{\star \star}$ & $.10^{\star \star}$ & .05 & $.14^{\star \star}$ \\
3. Expressiveness & - & - & - & $.27^{\star \star}$ & $.24^{\star \star}$ & $.24^{\star \star}$ & $.26^{\star \star}$ & $.28^{\star \star}$ & $.35^{\star \star}$ & $.40^{\star \star}$ \\
4. Sharing & - & - & - & - & $.54^{\star \star}$ & $.50^{\star \star}$ & $.31^{\star \star}$ & $.30^{\star \star}$ & $.40^{\star \star}$ & $.17^{\star \star}$ \\
5. Building & - & - & - & - & - & $.66^{\star \star}$ & $.36^{\star \star}$ & $.34^{\star \star}$ & $.42^{\star \star}$ & $.20^{\star \star}$ \\
6. Networking & - & - & - & - & - & - & $.43^{\star \star}$ & $.33^{\star \star}$ & $.51^{\star \star}$ & $.21^{\star \star}$ \\
7. Collaboration & - & - & - & - & - & - & - & $.43^{\star \star}$ & $.38^{\star \star}$ & $.28^{\star \star}$ \\
8. Critical thinking & - & - & - & - & - & - & - & - & $.36^{\star \star}$ & $.25^{\star \star}$ \\
9. Creativity & - & - & - & - & - & - & - & - & - & $.42^{\star \star}$ \\
10. Problem solving & - & - & - & - & - & - & - & - & - & - \\
\hline
\end{tabular}

Note: Significant at $\mathrm{p}<.01$

\subsubsection{Overview of the hypotheses}

The standardized path coefficients in Figure 5.2 reveal several significant direct and indirect paths among the 21 st-century digital skills. Table 5.4 summarizes the hypotheses.

The first hypothesis is confirmed; creative digital skills contribute positively to problem-solving digital skills. Critical-thinking digital skills contribute positively to creative digital skills, offering support for hypothesis 2 . Because criticalthinking digital skills only contribute indirectly to problem-solving digital skills, hypothesis 3 is partially supported.

Collaboration digital skills contribute positively to critical-thinking, creative and problem-solving digital skills, offering support for hypotheses 4, 5 and 6 .

Hypotheses 7a-f are also supported, confirming the conditional nature among the digital communication components. Expressiveness has a positive influence on contact building, networking and content sharing. Contact building has a positive influence on networking and content sharing. Finally, networking positively influences content sharing.

All communication digital skills contribute positively to collaboration digital skills, confirming hypothesis 8 . Hypothesis 9, concerning the relation between the digital communication components and critical-thinking digital skills, is 
partly supported. Communication expressiveness, contact building and content sharing have a positive direct effect on critical thinking; however, networking only has a positive indirect effect on critical thinking. Hypothesis 10, concerning the relation between the digital communication components and creative digital skills, is also partly supported. Communication expressiveness, networking and content sharing have a positive direct effect on creativity; however, contact building only has an indirect positive effect on creativity. Finally, communication expressiveness has a positive direct effect on problem-solving digital skills, but contact building, networking and content sharing only have a positive indirect effect, offering partial support for hypothesis 11 .

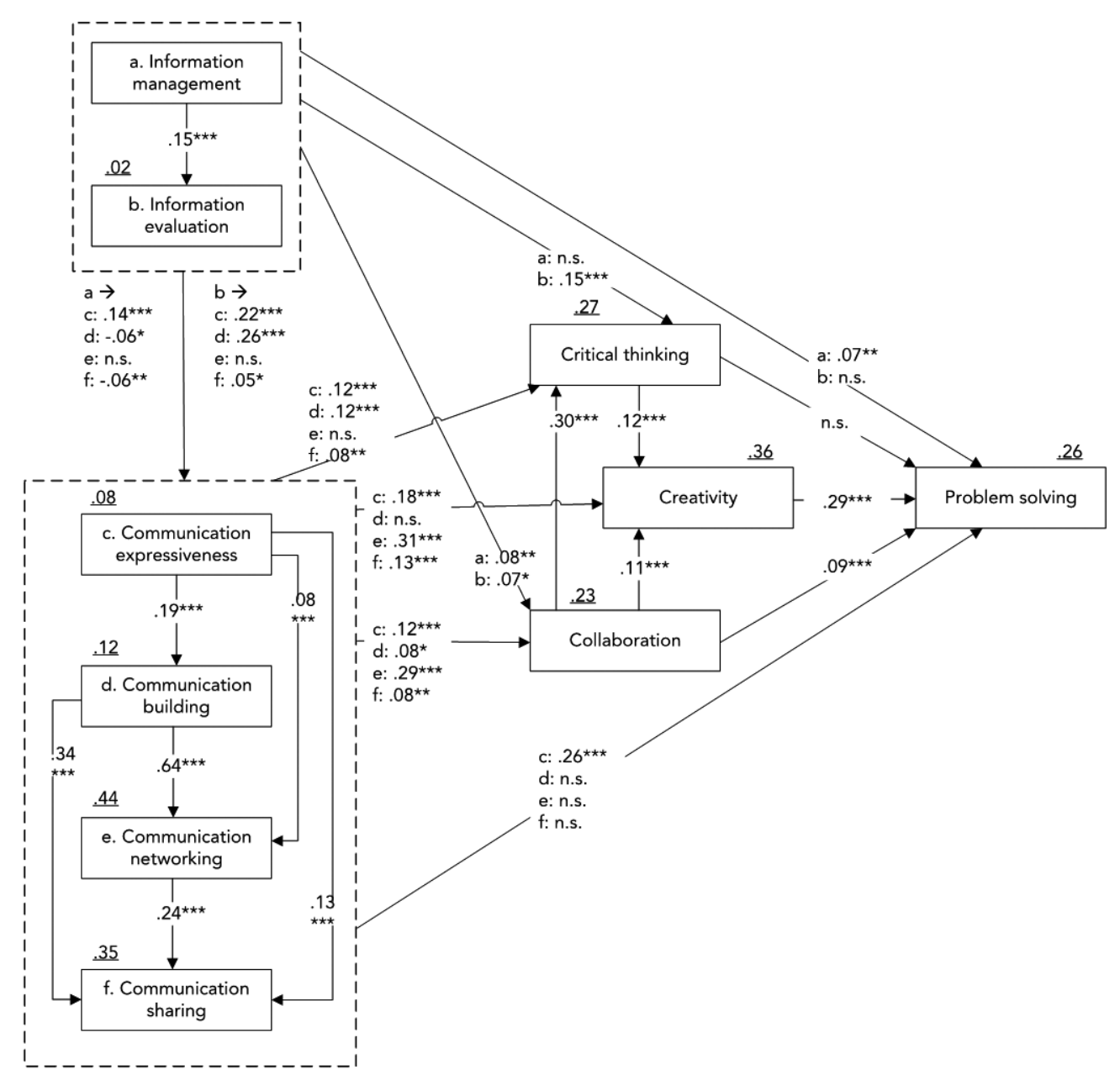

Figure 5.2 Results for the research model with path coefficients

Note: " $p<.05 ; " * p<.01 ; * * * p<.001$ level. Squared multiple correlations are underlined.
Hypothesis 12, concerning the relation among the digital information components, is supported: information management has a positive influence on information evaluation.

Hypothesis 13 involves the positive relation among the digital information components and all the digital communication components. Information management only has a direct and positive effect on expressiveness. The direct effect of information management on contact building and content sharing is negative. However, we did find a positive indirect effect of information management on contact building and content sharing. Furthermore, we found a positive indirect effect of information management on networking. Information evaluation has a direct and positive effect on expressiveness, contact building and content sharing. However, we only found a positive indirect effect of information evaluation on networking; hypothesis 13 is therefore partly supported. Because both information digital skills contribute positively to collaboration digital skills, hypothesis 14 is confirmed. Concerning hypothesis 15 , information management only has a positive indirect effect and information evaluation has a positive direct effect on critical thinking. Therefore, hypothesis 15 is partly supported. Finally, information management has a positive direct effect on problem-solving digital skills, and information evaluation has a positive indirect effect, offering partial support for hypothesis 16.

Table 5.4 Standardized direct, indirect and total effects

\begin{tabular}{lcccl}
\hline Hypotheses & Direct $\beta$ & Indirect $\beta$ & Total $\beta$ & Validation \\
\hline H1. Creativity $\rightarrow$ Problem solving & .29 & - & .29 & Supported \\
H2. Critical thinking $\rightarrow$ Creativity & .12 & - & .12 & Supported \\
H3. Critical thinking $\rightarrow$ Problem solving & - & .03 & .03 & Partly \\
H4. Collaboration $\rightarrow$ Critical thinking & .30 & - & .30 & Supported \\
H5. Collaboration $\rightarrow$ Creativity & .11 & .04 & .15 & Supported \\
H6. Collaboration $\rightarrow$ Problem solving & .09 & .04 & .13 & Supported \\
H7a. Expressiveness $\rightarrow$ Building & .19 & - & .19 & Supported \\
H7b. Expressiveness $\rightarrow$ Networking & .08 & .12 & .20 & Supported \\
H7c. Expressiveness $\rightarrow$ Sharing & .13 & .11 & .24 & Supported \\
H7d. Building $\rightarrow$ Networking & .64 & - & .64 & Supported \\
H7e. Building $\rightarrow$ Sharing & .34 & .16 & .50 & Supported \\
H7f. Networking $\rightarrow$ Sharing & .24 & - & .24 & Supported \\
H8. Expressiveness $\rightarrow$ Collaboration & .12 & .09 & .21 & Supported
\end{tabular}




\begin{tabular}{lcccl} 
Table 5.4 Continued & & & & \\
\hline Hypotheses & Direct $\beta$ & Indirect $\beta$ & Total $\beta$ & Validation \\
\hline H8. Building $\rightarrow$ Collaboration & .08 & .23 & .31 & Supported \\
H8. Networking $\rightarrow$ Collaboration & .29 & .02 & .31 & Supported \\
H8. Sharing $\rightarrow$ Collaboration & .08 & - & .08 & Supported \\
H9. Expressiveness $\rightarrow$ Critical thinking & .12 & .10 & .22 & Supported \\
H9. Building $\rightarrow$ Critical thinking & .12 & .13 & .25 & Supported \\
H9. Networking $\rightarrow$ Critical thinking & - & .11 & .11 & Partly \\
H9. Sharing $\rightarrow$ Critical thinking & .08 & .02 & .10 & Supported \\
H10. Expressiveness $\rightarrow$ Creativity & .18 & .14 & .32 & Supported \\
H10. Building $\rightarrow$ Creativity & - & .33 & .33 & Partly \\
H10. Networking $\rightarrow$ Creativity & .31 & .08 & .39 & Supported \\
H10. Sharing $\rightarrow$ Creativity & .13 & .02 & .15 & Supported \\
H11. Expressiveness $\rightarrow$ Problem solving & .26 & .11 & .37 & Supported \\
H11. Building $\rightarrow$ Problem solving & - & .12 & .12 & Partly \\
H11. Networking $\rightarrow$ Problem solving & - & .14 & .14 & Partly \\
H11. Sharing $\rightarrow$ Problem solving & - & .05 & .05 & Partly \\
H12. Management $\rightarrow$ Evaluation & .15 & - & .15 & Supported \\
H13. Management $\rightarrow$ Expressiveness & .14 & .03 & .17 & Supported \\
H13. Management $\rightarrow$ Building & -.06 & .07 & .01 & Partly \\
H13. Management $\rightarrow$ Networking & - & .02 & .02 & Partly \\
H13. Management $\rightarrow$ Sharing & -.06 & .04 & -.02 & Rejected \\
H13. Evaluation $\rightarrow$ Expressiveness & .22 & - & .22 & Supported \\
H13. Evaluation $\rightarrow$ Building & .26 & .04 & .30 & Supported \\
H13. Evaluation $\rightarrow$ Networking & - & .21 & .21 & Partly \\
H13. Evaluation $\rightarrow$ Sharing & .05 & .18 & .23 & Supported \\
H14. Management $\rightarrow$ Collaboration & .08 & .04 & .12 & Supported \\
H14. Evaluation $\rightarrow$ Collaboration & .07 & .13 & .20 & Supported \\
H15. Management $\rightarrow$ Critical thinking & - & .08 & .08 & Partly \\
H15. Evaluation $\rightarrow$ Critical thinking & .15 & .14 & .29 & Supported \\
H16. Management $\rightarrow$ Problem solving & .07 & .07 & .14 & Supported \\
H16. Evaluation $\rightarrow$ Problem solving & - & .13 & .13 & Partly \\
\hline & & & & \\
\hline
\end{tabular}

\subsection{DISCUSSION}

5.4.1 Main findings

Given the rapid rate of change and the influence of technology, employees must develop 21st-century digital skills (information, communication, collaboration, critical thinking, creativity, and problem solving) to cope and thrive. The development of these skills, however, requires a thorough understanding of how these skills interrelate; we cannot expect that all these skills will be developed independently. Yet, existing conceptualizations of both digital skills and of 21stcentury skills consider each skill separately. Although this might provide useful insights into the level of a specific skill, it remains difficult to actually design interventions without an understanding of the other skills that are required to perform well on a specific skill. For example, directly focusing on the improvement of collaboration skills will be less effective compared to programs that first focus on repairing insufficient information and communication skills, which are required for performing well on collaboration digital skills. Thus, the purpose of this study was to reveal how the most important 21st-century digital skills interrelate. The results of this study emphasize the importance of this idea; the 21st-century digital skills under investigation showed gradients of difficulty. In other words, the skills build on each other sequentially; a person who lacks one type of skill is also likely to lack another. Our empirically tested mode begins with being able to manage and evaluate digital information followed by communication digital skills, and it ends with being able to solve problems using the Internet. The intermediaries are collaboration, critical-thinking and creative digital skills.

An important finding is that except for critical-thinking digital skills, the results confirm that all skills lead directly to problem-solving digital skills. The specific requirements of information-intensive knowledge societies are becoming increasingly strategic (Lanvin \& Kralik, 2009). Problem solving has always been a major human asset but with new global technologies interacting with complex, opaque and dynamic problems, it is increasingly important for producing competitive products (Anderson, 2008; Neubert, Mainert, Kretzschmar, \& Greiff, 2015). Furthermore, it will not be possible to effectively solve complex problems without the control of information, communication collaboration and creative digital skills. The absence of these skills means that one will not even reach the point of performing problem-solving digital skills. This is important because this strong dependence has major implications concerning the development and justification of interventions targeting skill 
improvement. Insights gained from this study can be used to justify the order in which the proposed 21st-century digital skills are developed. In the work context, for instance, it is reasonable to first design and develop effective instruction to develop employees' information digital skills. Once the level of information digital skills is sufficient, it is, for instance, useful to focus on the development of communication digital skills.

5.4.2 Limitations and future research directions

The model as presented in Figure 5.2 provides the best-fitting solution of the sample data; professionals working within the creative industries. In light of the conceptual and empirical evidence, the presented model provides a realistic overview of the sequence of the skills under investigation. Yet, future research should further build upon the idea that skills interrelate. Other models might be possible, as for instance we did not account for two-way interactions between skills.

Future research could also extend this study by incorporating other skills For example, entrepreneurship is recognized as an increasingly important 21stcentury skill (Voogt \& Pareja Roblin, 2012) and is also multiple times mentioned as an important skill in academic literature (see Chapter 2). Moreover, the ability to clearly define information needs is defined as a key operational component of information digital skills (e.g., Çoklar, Yaman, \& Yurdakul, 2017; Katz, 2007). However, the instrument that we used did not cover this component. Although these are just examples, they indicate that there might be as yet unrecognized skills and key operational components of skills that could extend our understanding of 21 st-century digital skills. The adopted framework of 21 st-century digital skills departs from the multitude of existing concepts (e.g. 21st-century skills, digital competence, digital literacy, and digital skills) aimed at the skills of knowledge workers; however, the digital skills that are needed to work in the 21 st century are continuously evolving (Redecker \& Johannessen, 2013). Although we aimed to test digital skills, the previous research has shown that participants find it difficult to separate the offline from the online when evaluating their own skill levels (see Chapter 3) (Helsper, Van Deursen, \& Eynon, 2015). However, engaging in certain skill-related activities online may not automatically lead to achieving the related skills offline. Future research could test to what extent offline 21st-century skills show comparable results.

Finally, considering the general nature of the skill components used in this study, there is no reason to think that the results of this study would apply only to creative industries in the Netherlands. The creative industries are characterized by considerable variation within the workforce (Chen, Chang, \& Lo, 2015) and we chose this sector because of its knowledge-intensive work activities and the representation of a wide range of industries. Yet, the identified interrelation among the different skills should also be tested in different contexts. The relative importance of some skills might differ among domains, and such differences might also affect the sequential and conditional nature of 21 st-century digital skills

\subsection{CONCLUSION}

To conclude, 21st-century digital skills show gradients of difficulty and have a sequential and conditional nature. In other words, these skills build on each other sequentially. This suggests that improving specific skills alone will not be enough. The conclusion that the broad range of 21 st-century digital skills depend on each other has received minimal attention thus far. For a bette understanding of how skill divides emerge, or what type of skill improvement interventions might be most successful, it is important to consider the relations among various digital skills. These increasingly determine people's positions in the labor market and social life in our contemporary knowledge society. Furthermore, we still need to develop a better understanding of how the range of digital skills may vary because of the different individual or organizational background variables. In Chapters 6 and 7, we focus on factors, at the level of the individual worker, that might contribute to workers' skill levels. 


\section{CHAPTER 6}

\section{DETERMINANTS OF 21ST-CENTURY SKILLS AND DIGITAL SKILLS FOR WORKERS: A SYSTEMATIC LITERATURE REVIEW}

This chapter brings attention to the determinants of 21st-century skills and 21stcentury digital skills. The following skills are investigated: technical, information, communication, collaboration, critical-thinking, creativity, and problem-solving skills. To understand differences in the level of these skills amongst workers, we need to know the factors that determine an individual's skill level. A systematic literature review was conducted to provide a comprehensive overview of empirical studies measuring skill determinants. The results show that there is strong need for research on determinants of communication and collaboration skills. In a digital context, determinants for creativity and critical thinking are hardly studied. Furthermore, the identified determinants of 21 st-century skills studies are limited to personality and psychological determinants, neglecting for example, social determinants such as social support. Although digital skills studies show more variety, they mostly cover demographic and socioeconomic determinants. 


\subsection{INTRODUCTION}

Employees need to be prepared to shift jobs and to be flexible in acquiring skills. While the importance of 21 st-century digital skills to fulfill the demands for workers in the 21st century has been well-established in Chapters 2 and 3, the research has identified that comprehensive knowledge about skills assessment is lacking (Voogt \& Pareja Roblin, 2012). Although various components of digital skills have been described in theory (e.g., Claro et al., 2012; Jara et al., 2015; Siddiq, Gochyyev, \& Wilson, 2017), it remains unclear which of these skills are influenced by what variables. Moreover, the majority of articles on 21st-century skills describe the skills on conceptual level with little evidence of corresponding data (Siddiq, Hatlevik, Olsen, Throndsen, \& Scherer, 2016). As such, it is useful to synthesize existing knowledge concerning the factors that cause differences in the level of 21 st-century digital skills amongst workers. We know relatively little about how the range of digital skills may vary due to the different individual background variables (Helsper \& Eynon, 2013). The aim of this chapter is to provide a state-of-the-art overview of empirical studies on determinants relevant to each type of skill. A systematic literature review is conducted to synthesize the academic English-language literature concerned with determinants of 21st-century skills and 21st-century digital skills. We expect that determinants of 21st-century skills also play a role in understanding $21 \mathrm{st}$ century digital skills. The review also shows what methods are currently used to measure skills. The overview of determinants and skills indicates relevant factors that encourage or hinder skill development, it can contribute to the development of a parsimonious model to explain differences in mastering these skills, and it identifies the research areas that gained little attention. The results are also useful for designing interventions or justify skill development policies. Furthermore, the overview will help educational experts who need to equip students with skills that meet the demands of the workforce and employers who are responsible for the development and consolidation of employees' skill levels. Two research questions are addressed:

1) Which are significant determinants of 21st-century (digital) skills?

2) What are the non-significant determinants of 21st-century (digital) skills?

\subsection{THEORETICAL BACKGROUND}

This chapter elaborates on the core skills supported by the use of ICT as proposed in Chapter 2. Here, we deliberately distinguish between 21st-century skills and digital skills as they are often considered separately. Therefore, we first discuss the core 21 st-century skills and in the next paragraph we systematically add the digital component.

\subsubsection{1st-century skills}

Technical skills. To maintain competitive advantage, employees must be fluent in the skills and languages of ever-changing technologies (Lemke, 2002). For increasing productivity, new technology is developed and, as a consequence, technology is increasingly replacing manual labor and being integrated into most aspects of work (Fuchs, 2010). Workforces need to be capable of continuously adapting to shifting job requirements related to new skill-intensive technologies (Levy \& Murnane, 2004). As workplaces have become more complex and supported by ICT, more jobs require technical skills.

Information skills. The abundance of information and data implies that employees in nearly all sectors of the economy must be able to search, evaluate and organize information, often coming from multiple sources (Silva, 2009). The quick access to a wide range of information sources means that people need to recognize when information is needed and to evaluate the reliability and relative value of information (Marchionini \& White, 2007; Starkey, 2011).

Communication skills. Communication skills are vital in the growing service sector and concern the ability to transmit information, ensuring that the meanings are effectively expressed by taking into account the audience and medium (Ananiadou \& Claro, 2009; Katz, 2007). One must be able to effectively regulate one's needs and goals with those of the larger society to successfully navigate in the current social world (Voogt, Erstad, Dede, \& Mishra, 2013). Because of the interconnectedness of our global economy, employers demand people with communication skills (Levy \& Murnane, 2004).

Collaboration skills. Work is becoming more knowledge-based interdisciplinary and specialized. The complexity of tasks requires employees to collaborate, as individuals cannot possess all knowledge and skills (Wang, 2010). As a consequence, work is increasingly performed by teams of people with complementary expertise and roles (Dede, 2010; Fraser \& Hvolby, 2010). Employees are often dependent on others to accomplish their tasks (Bronstein 2003). To function interdependently, they need a clear understanding of their own roles and those of their collaborating partners.

Critical-thinking skills. Critical thinking broadly refers to making informed choices about obtained information and communication by using sufficient 
reflection and reasoning. It concerns the ability to think reflectively and judge skillfully, so as to decide what information or communication is relevant in a given context (Gut, 2011). The ability to filter the amount of incoming data to formulate your own point of view is a key 21st-century skill (Dede, 2010). To think critically, employees need knowledge that is central to the particular domain to formulate an independent, well-grounded perspective or opinion (Van de Oudeweetering \& Voogt, 2018)

Creativity skills. In addition to being able to process and transmit information, it is necessary to transform information into new knowledge. The previous research has often reasoned that complex problems necessitate creative solutions (Kaufman, 2013). Creativity is related to the production of new and useful ideas on products, services or processes that are both novel and potentially useful (e.g., Amabile, 1988; Oldham \& Cummings, 1996). Because employee creativity is presented as an imperative for long-term organizational success (DiLiello \& Houghton, 2008), it arises as a critical skill for organizations to lead or adapt to change.

Problem-solving skills. Since the workforce is increasingly confronted with challenging and non-recurrent problems (Autor, Levy, \& Murnane, 2003) employees need the skills to solve domain-specific problems. Situations that are complex and uncertain and that have no precedent require problem-solving skills (Keane, Keane, \& Blicblau, 2016). Problem solving is often conceptualized as the knowledge and skills that are required to deal effectively with complex and nonroutine situations (Funke, Fischer, \& Holt, 2018). Although domainspecific knowledge plays an important role, it is not just prior knowledge. An employee must identify necessary actions, possible gaps and steps to obtain this information (Rausch \& Wuttke, 2016).

\subsubsection{Adding the digital component}

Technical skills are similar as proposed in the notion of 21st-century skills. These are the skills that workers need to use software or operate a digital device. They are dynamic, involving a continual effort to keep up with new technologies and practices.

Information digital skills. The information abundance caused by ICT requires skills for searching, evaluating and organizing information in digital environments (Catts \& Lau, 2008). Information management includes the ability to (1) clearly define information needs, (2) identify digital information, and (3) select digital information in an effective and efficient way (Ananiadou \& Claro,
2009). Once the information has been found, workers need the skills to evaluate how valuable the source and its contents are for the task. Moreover, workers need the skills to store and organize the digital information for easy retrieval. As today's workers often use multiple digital devices, they need the skills to distribute and maintain information across their digital devices (Song \& Ling, 2011).

Communication digital skills. ICT has made it easier to reach a wide audience and communicate at a distance, faster and more ubiquitously. Individuals are able to express themselves, establish relationships and interact with others at any distance in time and space (Yu, Tian, Vogel, \& Kwok, 2010). ICT-based communication is regarded as a means of generating social interactions and strengthening social relationships (Hwang, 2011). It is imperative that workers understand how to appropriately and effectively communicate using e-mail, social networking sites and instant messaging services (Lewin \& McNicol, 2015; Wang, Hsieh, \& Song, 2012). People are encouraged to share ideas and opinions within organizations and online forum communities (Lu \& Lee, 2012) Workers need the skills to contact other members, maintain those contacts, and share online content and media with their contacts. Online content-sharing activities range from sharing status updates, posts, photos and videos to writing comments and blogs (Brandtzæg, Lüders, \& Skjetne, 2010).

Collaboration digital skills. Collaboration processes - managing interdependencies across time to achieve a common goal - are increasingly supported by ICT. ICT is especially useful when teams must share information and make decisions across business and national boundaries (Wang, 2010). With the use of collaboration software as chats (e.g., Skype or WhatsApp) colleagues can instantaneously interchange ideas, information and experiences. Workers therefore need the skills to connect and collaborate with others beyond a constrained physical environment (Starkey, 2011). Moreover, with the help of content management systems it is possible to work on the same document at the same time. As such, workers need the skills to work together on shared documents and projects beyond the restrictions of time and place (Lewin \& McNicol, 2015). In today's knowledge society, given the emergence of online collaborative platforms, it is even more important to understand and manage the sharing of information across the organization (Bălău \& Utz, 2017).

Critical-thinking digital skills. Critical thinking has been identified as being particularly important because in a global online environment people participate and resources are created with various intentions and competences (Starkey, 
2011). Online contents must be critically assessed in this age of disinformation and fake news. It is crucial that people understand its nature and source. The focus is on the quality of messages in relation to performance in argumentation. It is crucial for workers to rapidly filter incoming online information and communication and to extract valuable information (Dede, 2010). They must be able to induce critical reflection upon the points that are being discussed online and give sustained arguments that steer the online discussion.

Creative digital skills. ICT can support creativity in multiple ways including developing ideas and creating or realizing ideas (Loveless, 2007). Digital environments allow workers to assess various design concepts, experiences and ideas. Furthermore, Web 2.0 technology enables workers to produce and share content in new ways. Online content creation is the use of online spaces to create content including weblogging and photo and video sharing (Brake, 2014). User-generated content creation becomes a common creative practice (Lai \& Yang, 2014; Lessig, 2008) in which creativity determines if the onlinegenerated content is successfully received by the audience.

Problem-solving digital skills. In an information-abundant society, problems can be defined differently, and multiple solutions can be found online. The disadvantage is that the knowledge to solve specific problems can be available online but possibly remain unnoticed because of a lack of an integrated view (David \& Foray, 2002). As such, workers need online problem-solving skills to either formulate the problem or find strategies to determine the best solution for a problem. They need the skills to find multiple solutions, solve unfamiliar problems, and transfer knowledge to new situations (Barak, 2018). ICT has become an important medium for accessing and connecting information and, thereby, solving problems.

\subsubsection{Determinants of 21st-century (digital) skills}

There is widespread consensus among researchers that to use the Internet in meaningful ways, users must develop sufficient digital skills (Jenkins, Purushotma, Weigel, Clinton, \& Robison, 2009; Mossberger, Tolbert, \& Stansbury, 2003). However, regarding how users could develop these skills, different answers are provided. Most initial investigations of the digital divide tended to look at basic demographic and socioeconomic predictors of mere access such as gender, age, education, income and employment status (DiMaggio, Hargittai, Celeste, \& Shafer, 2004). The digital divide approach based on inequalities in Internet access has evolved into a divide that includes differences in skills to use the Internet (Fuchs, 2009; Selwyn, 2004; Van Dijk, 2005). Several studies have demonstrated that once access to technology is equal, the differences in how effectively it is used relate to economic, cultural and social variables (Jara et al., 2015).

Most of the literature reviews related to skills research attempted to structure and synthesize conceptualizations instead of evaluating skills assessments in empirical studies (Siddiq, Hatlevik, Olsen, Throndsen, \& Scherer, 2016). Moreover, existing reviews of digital skills related assessments mainly focused on unidimensional aspects such as basic Internet skills (Litt, 2013). Van Deursen and Van Dijk (2010) showed that similar determinants of Internet access and use determine Internet skills; however, the relative influence of these determinants depends on the type of skill measured. Given the controversies of definition that are apparent, an extended perspective on assessments of digital skills as a broader concept is missing. The main goal of this systematic literature review is to develop a comprehensive description of state-of-the-art 21st-century (digital) skills assessments by identifying the variety of empirical studies that aim to measure determinants of these skills. This study furthermore establishes an empirical base to indicate the determinants impact on these skills and to highlight potential interventions. To present the findings of the review, we categorized the identified determinants adapted from the resources and appropriation theory (De Haan, 2004; Van Dijk, 2005). This theory relates the differences in people's digital skills to a distribution of resources (temporal, material, mental/motivational, social, and cultural) that, in turn, are explained by personal categories and positions in society. Here, we divided personal and positional categorical inequalities into demographic, socioeconomic and personality/psychological determinants. Demographic determinants cover concepts such as gender, age and race/ethnicity while the personality and psychological determinants refer to a person's traits and intelligence. Socioeconomic determinants include positional categories such as education, income and labor position. Temporal determinants mean having the time to use digital media. Material determinants concern a person's possessions. Mental and motivational determinants refer to a person's learning style, motivation and skills (as they can also be a determinant of other skills). Social determinants concern having a social network to assist in using digital media. Finally, cultural determinants cover variables such as religion, language and attitude toward other cultures. 


\subsection{METHOD}

6.3.1 Systematic literature review

A systematic literature review attempts to collate all relevant evidence that fits pre-specified eligibility criteria to answer a specific research question (Shamseer et al., 2015). It uses an explicit, reproducible methodology to minimize bias in the identification, selection and summary of studies. This method fits our research purpose because it helps synthesize all academic articles that measure determinants of 21 st-century skills and 21 st-century digital skills. The review was conducted in accordance with the Preferred Reporting Items for Systematic Reviews and Meta-Analyses (PRISMA) approach (Moher et al., 2015). This approach intends to guide the documentation of systematic literature reviews by creating a guideline to improve the transparency, accuracy and completeness of publications.

\subsubsection{Search terms}

The search action was conducted using the Scopus, Web of Science and PsycINFO databases, which together cover an inclusive range of social science journals. The first search stream included core skill dimensions in agreement with several keywords for determinants. The keywords had to be in the title of the article to specify the search stream. Additionally, the keywords skills, competence and literacy were added. As a result, the first Boolean search action was conducted:

("technical" OR "information literac*" OR "communication competenc*" OR "collaborativ*" OR "teamwork*" OR "creativ*" OR "critical thinking" OR "problem solving") AND ("associat*" OR "antecedent*" OR "contribut" OR "determin" OR "factor*" OR "influenc*" OR "predict" OR "related" OR

"relation" OR "moderat*") AND ("skills" OR "competenc*" OR "literac*")

Since the skills mentioned above depart from the multitude of existing concepts, a second search stream included 21st-century skills and digital skillrelated terms and keywords for determinants. The keywords had to be in the abstract, title or keywords of the article. As a result, the second Boolean search action was conducted:

("21st-century skills" OR "twenty-first century skills" OR "e-skills" OR "digital skills" OR "digital competenc*" OR "digital literac*" OR "internet skills" OR "ICT skills" OR "ICT competenc*" OR "ICT literac*") AND ("associat*" OR "antecedent*" OR "contribut*" OR "determin*" OR "factor*" OR "influenc*" OR "moderat" OR "predict" OR "related" OR "relation*")

\subsubsection{Selection criteria}

A number of criteria were specified to select relevant English language articles The searches were refined by specifying the following six selection criteria:

1) Contain skills (technical, information management, communication, collaboration, creativity, critical thinking, and problem solving) as the dependent variable because the focus is on the factors that influence an individual's skill level.

2) Include the impact of determinants of 21 st-century (digital) skills at the level of the individual worker. Organizational determinants (e.g., organizational culture and leadership style) fall outside the scope.

3) Present original quantitative empirical data rather than qualitative data or an overview of previously reported data because the aim is to examine significant determinants. The mixed method is included in our analysis when it provides us with quantitative data on the determinants of $21 \mathrm{st}$ century (digital) skills.

4) Report directional significant effects $(p<.05)$ rather than correlation effect sizes to provide the strongest empirical support for the determinants.

5) Involve participants from secondary school age and older because this group represents preparation for working life and the workforce.

6) Be published in a peer-reviewed journal because such journals are considered the most reliable source of scientific information.

\subsubsection{Study selection}

The study selection was performed in three steps. First, the titles of all retrieved articles were screened for eligibility based on the abovementioned inclusion criteria. Second, the abstracts of all initially relevant articles were screened by applying the same six uniform criteria. Third, the full text of all remaining publications was checked for inclusion. For each article deemed relevant, information from the full-text article was extracted. Each potential article was coded in terms of the following: the names of the authors, the date published, the journal, the aims, the method, the dependent variables and their operationalization, the independent variables, the results and the conclusion The coding of the articles was performed to ensure that all relevant articles were selected. 


\subsubsection{PRISMA flowchar}

Given the restrictions of the document type and language, 4,266 articles were identified from the Boolean search actions. Out of the 4,266, 1,706 were duplicates, which means that 2,560 different articles were screened. After the title and abstract screening, 339 were read in full text, of which 154 articles met all six inclusion criteria. Appendix 6.A presents the references of the included studies. Figure 6.1 presents the flowchart for selection. Additional records were not identified through other sources because the references of the included articles did not contribute to the received information. There were seven reasons for excluding a full-text screening: (1) no skills as dependent variable; (2) no full-text available; (3) no independent variable; (4) no quantitative research; (5) no directional effect; (6) only organizational determinants; and (7) no participants in the age category of secondary school or older.
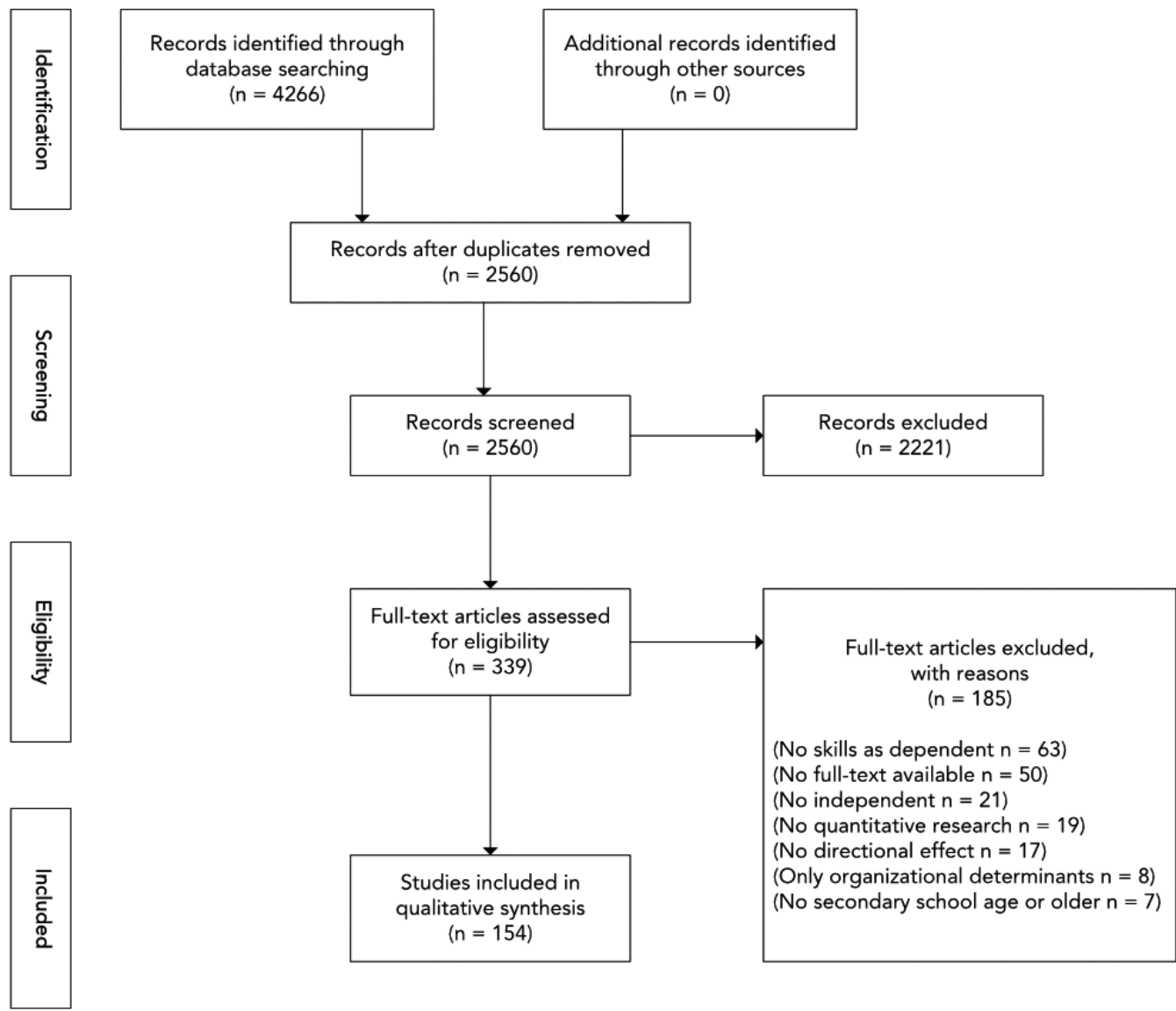

Figure 6.1 PRISMA flowchart of the literature selection process

\subsubsection{Selection bias}

To verify that the selected articles met the selection criteria, $10 \%$ of the articles derived from both search actions in Scopus $(n=209)$ were independently coded by a second coder. Publication bias in a systematic literature review occurs mostly during the selection process, and a transparent selection process is necessary to minimize such bias. A second coder performed both search actions and followed the study selection steps of title, abstract and full-text evaluation according to a predefined instruction. The inter-rater reliability was .90 , which shows a good agreement between the two coders. Any differences of opinion about whether or not to include an article were resolved through discussion until a consensus was reached.

\subsection{RESULTS}

6.4.1 Categorization of selected studies

The number of studies measuring determinants of 21 st-century skills (Table 6.1) and 21st-century digital skills (Table 6.2) were categorized by type of skill and method. The categorizations of skills were based on the operationalization used. If a study measured multiple skills combined as the dependent variable, we placed the determinants into all corresponding skills categories. It is important to note that technical, information and communication were frequently combined as a dependent 21st-century digital skill. For 21st-century skills studies, creativity $(33.7 \%)$, critical thinking $(22.9 \%)$ and problem solving $(18.1 \%)$ were the most investigated skills. Technical (2.4\%) and information skills $(2.4 \%)$ were underrepresented. For 21st-century digital skills studies, technical (38.3\%) and information skills (29.7\%) were the most investigated skills, while critical thinking (3.9\%) and creativity (2.3\%) were underrepresented. Both measured determinants of problem solving relatively frequently, while communication and collaboration were underreported. Furthermore, surveys were the most commonly employed method. Additionally, for 21 st-century skills, creativity was relatively often measured in experiments and problem solving in performance tests. For 21st-century digital skills, technical, information and problem-solving skills were relatively often measured in performance tests. 
Table 6.121 st-century skills studies categorized by type of skill and method

\begin{tabular}{|c|c|c|c|c|c|}
\hline Skills Method & Survey & Performance test & Experiment & Mixed method & Total \\
\hline Technical & $2(3.4 \%)$ & $0(0 \%)$ & $0(0 \%)$ & $0(0 \%)$ & $2(2.4 \%)$ \\
\hline Information & $2(3.4 \%)$ & $0(0 \%)$ & $0(0 \%)$ & $0(0 \%)$ & $2(2.4 \%)$ \\
\hline Communication & 9 (15.3\%) & $0(0 \%)$ & $0(0 \%)$ & 1 (33.3\%) & 10 (12.0\%) \\
\hline Collaboration & $6(10.2 \%)$ & $1(11.1 \%)$ & $0(0 \%)$ & $0(0 \%)$ & $7(8.4 \%)$ \\
\hline Critical thinking & 15 (25.4\%) & $1(11.1 \%)$ & $2(16.7 \%)$ & 1 (33.3\%) & 19 (22.9\%) \\
\hline Creativity & 19 (32.2\%) & $2(22.2 \%)$ & $7(58.3 \%)$ & $0(0 \%)$ & 28 (33.7\%) \\
\hline Problem solving & $6(10.2 \%)$ & $5(55.6 \%)$ & $3(25.0 \%)$ & 1 (33.3\%) & 15 (18.1\%) \\
\hline Total & 59 & 9 & 12 & 3 & 83 \\
\hline
\end{tabular}

Table 6.2 21st-century digital skills studies categorized by type of skill and method

\begin{tabular}{|c|c|c|c|c|c|}
\hline Skills Method & Survey & Performance test & Experiment & Mixed method & Total \\
\hline Technical & 35 (44.3\%) & $10(25.6 \%)$ & $1(20.0 \%)$ & $3(60.0 \%)$ & 49 (38.3\%) \\
\hline Information & $24(30.4 \%)$ & $10(25.6 \%)$ & $3(60.0 \%)$ & 1 (20.0\%) & 38 (29.7\%) \\
\hline Communication & $9(11.4 \%)$ & $3(7.7 \%)$ & $0(0 \%)$ & $1(20.0 \%)$ & 13 10.2\%) \\
\hline Collaboration & $1(1.3 \%)$ & $1(2.6 \%)$ & $0(0 \%)$ & $0(0 \%)$ & $2(1.6 \%)$ \\
\hline Critical thinking & $1(1.3 \%)$ & $3(7.7 \%)$ & $1(20.0 \%)$ & $0(0 \%)$ & $5(3.9 \%)$ \\
\hline Creativity & $2(2.5 \%)$ & $1(2.6 \%)$ & $0(0 \%)$ & $0(0 \%)$ & $3(2.3 \%)$ \\
\hline Problem solving & $7(8.9 \%)$ & $11(28.2 \%)$ & $0(0 \%)$ & $0(0 \%)$ & $18(14.1 \%)$ \\
\hline Total & 79 & 39 & 5 & 5 & 128 \\
\hline
\end{tabular}

6.4.2 Significant determinants of 21st-century skills and 21st-century digital skills

The results of the review are presented in schemes matching the seven core skills and eight groups of determinants. An overview of all significant determinants is displayed in Appendix 6.B. Table 6.3 shows the number of significant determinants for 21st-century skills and Table 6.4 the number of significant determinants for 21 st-century digital skills. A list of all determinants per skill is displayed in Appendix 6.C for 21st-century skills and in Appendix 6.D for 21 st-century digital skills. For 21st-century skills studies, creativity $(n=82)$, critical thinking $(n=38)$ and problem solving $(n=30)$ reported a large number of determinants. They clearly show the determinants in a particular direction.
Personality and psychological determinants were mainly covered in studies that examined problem solving (66.7\%), critical thinking (57.9\%) and creativity (50.0\%) Examples were the Big Five dimensions of personality (Openness to experience, Extraversion, Conscientiousness, Agreeableness, and Neuroticism). Moreover, mental and motivational determinants were well represented for studies measuring creativity (22.0\%). Two studies measuring ethical decision making and time management styles were mainly responsible for this number. Although studies examining communication and collaboration skills were underreported, they show the determinants in a particular direction. Communication mainly addressed social (25.0\%), mental/motivational (25.0\%) and cultural determinants (20.8\%). One study measuring sensitivity to the partner while communicating was mainly responsible for the social determinants. Examples of cultural determinants were cultural capital and intercultural sensitivity. Collaboration focused on personality and psychological determinants (63.6\%) such as personality traits, emotional intelligence and thinking styles.

For 21st-century digital skills studies, technical ( $n=197)$, information ( $n=139)$, problem solving $(n=67)$ and communication $(n=66)$ reported a large number of determinants. Demographic and socioeconomic determinants were well represented in studies measuring these skills. Gender, age and educational level were frequently reported as significant. Personality and psychological determinants were well represented for communication (16.7\%), problemsolving (14.9\%) and information skills (12.2\%). Examples of these determinants include ICT self-efficacy and academic achievements. Temporal determinants such as ICT use and ICT experience accounted for the largest share in studies examining information (15.8\%) and technical skills (14.2\%). Material determinants such as ICT access were mainly covered in studies examining problem-solving (9.0\%), technical (5.6\%) and information skills (5.0\%). Mental and motivational determinants were again the most prevalent in studies that examined technical (22.3\%), information (17.3\%) and problem-solving skills (14.9\%). ICT training was frequently a significant mental/motivational determinant. Social determinants were often reported as significant for technical (7.1\%) and information skills (6.5\%). Social support was frequently a significant social determinant. Cultural determinants were often reported as significant for problem-solving (17.9\%), communication (16.7\%) and information skills (11.5\%). However, it is important to note that one author measured cultural determinants in multiple studies and therefore is primarily responsible for this number. 

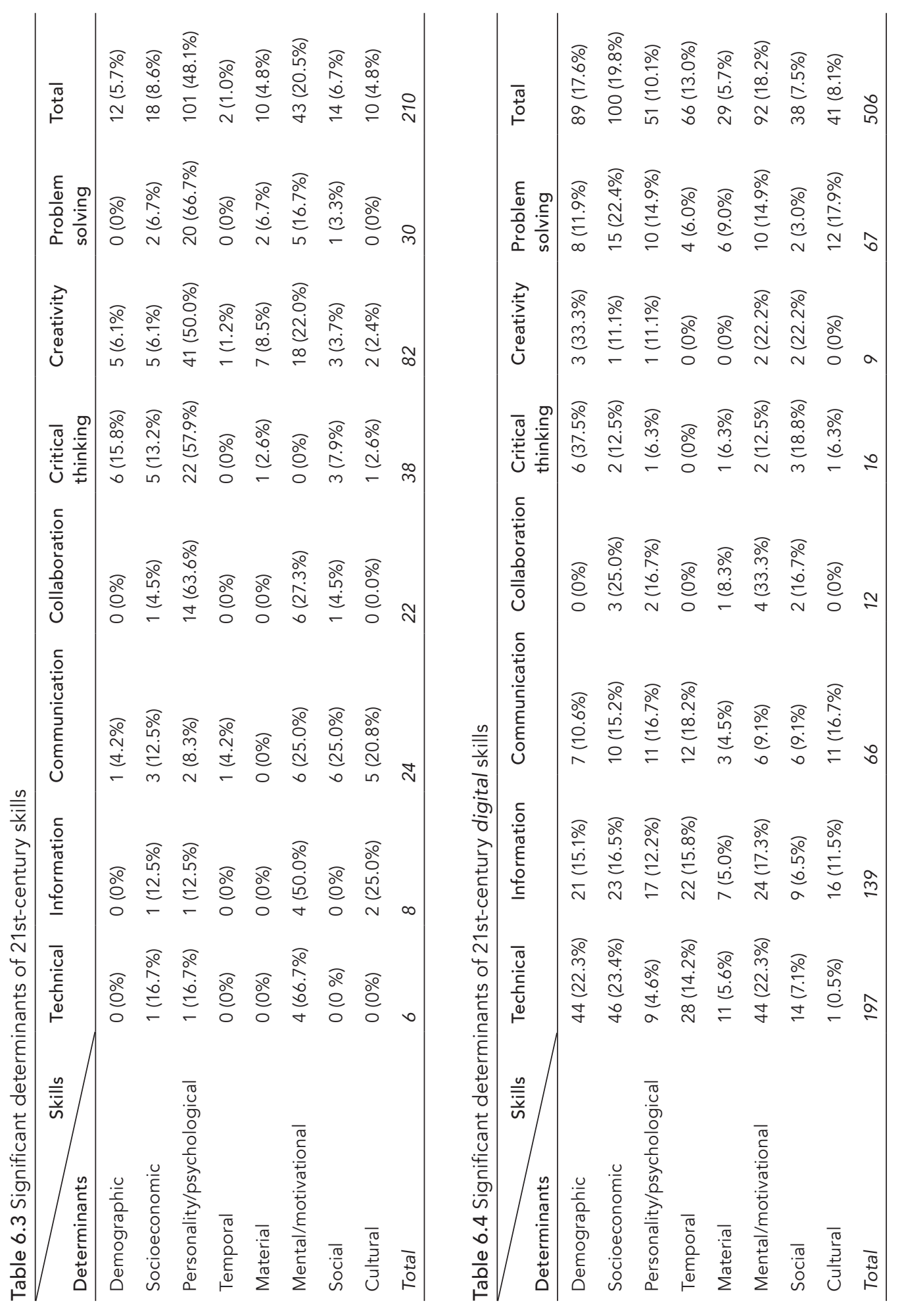

6.4.3 Non-significant determinants of 21st-century skills and 21st-century digital skills

Tables 6.5 and 6.6 show the non-significant determinants. A low number of significant determinants has to do with either a lack of studies examining this determinant or the fact that they turned out to be non-significant. For 21stcentury skills studies, collaboration (81.8\%), creativity (52.9\%), critical thinking (51.9\%) and problem solving (19.1\%) reported a large number of non-significant personality and psychological determinants. However, except for collaboration skills, personality and psychological determinants turned out more frequently to be significant. For creativity studies, material determinants such as available resources appeared as non-significant.

For 21st-century digital skills studies, although demographic, socioeconomic, temporal, material and mental/motivational determinants show a large number of non-significant determinants, they appeared more frequently as significant for technical and information skills. By contrast, technical and information skills studies were inconclusive about the effect of social determinants $(n=14$ compared to $n=15$ and $n=9$ compared to $n=7$ ). For problem-solving skills, demographic determinants (e.g., gender and age) and temporal determinants (e.g., frequency of ICT use) appeared more frequently as non-significant. 

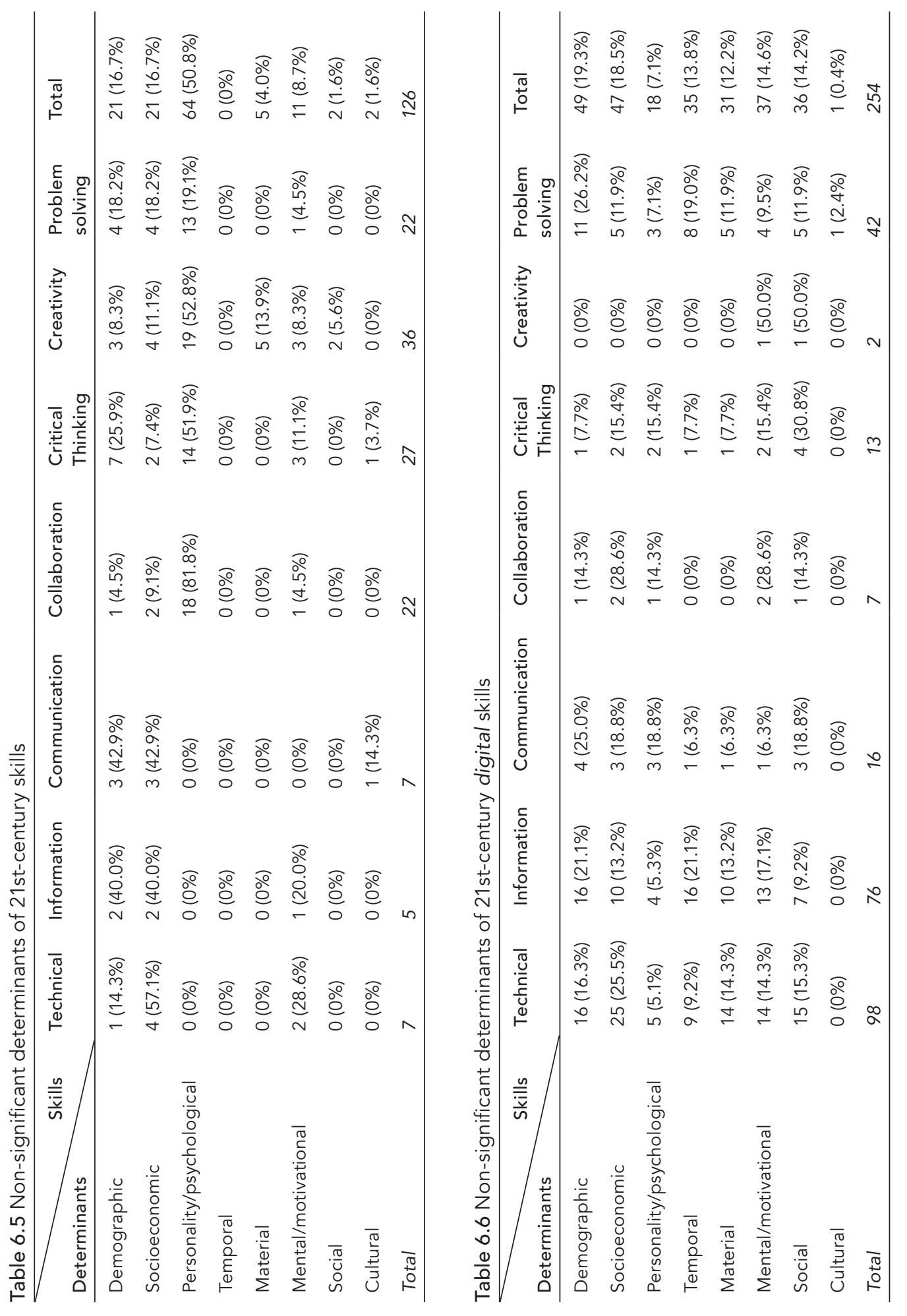

\subsection{DISCUSSION}

6.5.1 Main findings

This systematic literature review provides a state-of-the art overview of empirical studies on determinants of 21st-century (digital) skills, and we show the skills and determinant groups that warrant future research attention. Revealing the research gaps can contribute to a continued focus on developing and monitoring the variety of 21st-century skills people should attain in the digital context. A first conclusion is that the determinants for creativity and critical thinking are less studied in a digital context. One conceivable explanation for why some skills are frequently digitally considered is that creativity and critical thinking can more easily be separated from digital contexts in comparison with technical and information management skills. Nevertheless, academic thinking shows each 21st-century skill has a digital variant. Moreover, 21st-century skills and 21st-century digital skills studies measured the determinants of problemsolving skills relatively frequently, while collaboration and communication skills studies were underreported. Similarly, Siddiq and colleagues (2016) showed that a large majority of existing tests assess students' digital information and technical skills while other aspects of ICT literacy are not equally covered. It is therefore necessary to understand how to measure, for example, problem solving, communication and collaboration with ICT. Although communication and collaboration are viewed as essential (Ahonen \& Kinnunen, 2015), they are scarcely covered in the academic literature. One possible explanation of why some skills are studied more frequently than others is that technology and society are mutually shaping (MacKenzie \& Wajcman, 1985). While technologically deterministic viewpoints consider that society is shaped by technology, this technical viewpoint is avoided by social construction theorists. From their point of view, social aspects are more important than technological characteristics for determining how a technology is used. In this respect, instead of only focusing on technical skills, so-called content-related skills (e.g., communication and collaboration) become more important, as they strongly influence the outcomes of how the Internet is used and thus the outcomes of work performance. As a consequence of the mutual shaping of technology and society, most studies concentrate on technical skills first. Another possible reason for the lack of attention is that content-related skills are more difficult to observe, quantify or measure (Cobo, 2013; Silva, 2009). Furthermore, the 21st-century digital skills concept is broad, making it difficult to develop one test that covers all (Aesaert \& Van Braak, 2015). 
A second conclusion is that for 21 st-century skills studies, the most frequently reported significant determinants are personality and psychological factors. Personality and psychological determinants are often reported as significant in studies that examined creativity, critical thinking, problem solving and collaboration skills. The determinants of 21 st-century skills show less variety than those of 21 st-century digital skills. The determinant groups are better represented in studies measuring the digital aspect of technical, information, communication and problem-solving skills. In particular, demographic, socioeconomic, temporal and mental/motivational determinants are frequently reported as significant. These results show that digital skills studies take into account a variety of determinants. Learning styles and sources of help are examples of determinants that were part of 21 st-century digital skills studies, in contrast to 21 st-century skills studies. Additionally, digital-related determinants such as ICT experience, ICT use and ICT training are mostly covered in $21 \mathrm{st}$ century digital skills studies. Remarkably, there are many studies around personality in relation to 21st-century skills in contrast to digital skills literature where sociological explanations are more prominent. The digital divide generally implies differences in access based on socio-economic divisions (Van Deursen \& Van Dijk, 2015a)

A third conclusion is that, except for collaboration skills, personality and psychological determinants more frequently appear to be significant than nonsignificant for creativity, critical thinking and problem-solving skills. Personal determinants are proven to be important for these 21st-century skills. For 21st-century digital skills studies, the same holds true for demographic, socioeconomic, temporal and mental/motivational determinants of technical, information and communication skills. By contrast, for problem-solving skills, demographic and temporal determinants appear more frequently as nonsignificant. Determinants such as gender, age, ICT experience and ICT use more frequently appear to be non-significant than significant. Because of the number of different determinants and the scattered overview that they provide, it is difficult to note the factors that can possibly be ignored by research for specific skills. Overall, factors such as gender, age, socioeconomic status, personality traits and intelligence are often investigated but are difficult to account for in skill policies - these are more permanent and belong to an individual's position in society. This is in line with a previous systematic literature review which showed that digital skills studies are largely limited to demographic and socioeconomic determinants (Hargittai, 2010; Scheerder, Van Deursen, \& Van
Dijk, 2017). To conclude, surveys are the most commonly employed method to measure skill determinants. Technical, information and problem-solving skills are relatively frequently measured in performance tests.

\subsubsection{Limitations}

Although peer-reviewed journal articles are considered to be validated knowledge likely to have high scientific impact (Keupp, Palmié, \& Gassmann, 2012), this review might have excluded other relevant work as we did not consider books or conference papers. Besides, this review was limited by the choices that were made in the search streams. Within the first search stream, the keywords had to be in the title. Although this choice was needed to specify the search results, it means that potential articles mentioning the terms only in the abstract or full text were excluded. Additionally, the terms skills, competence or literacy were inserted to specify the search stream. Consequently, studies measuring the determinants of skills without mentioning these keywords in the title or abstract were excluded. These design choices were based on the balance between sensitivity, finding as many articles as possible that may be relevant, and specificity, ensuring that those articles are relevant. Because of the heterogeneity of the data and study designs reviewed, we did not conduct a meta-analysis but aimed to present an overview of past empirical evidence concerning skill determinants. Furthermore, we made the decision to focus on the core skills. As a result, for example, ethics and responsibility were excluded even if they could certainly be valuable. Moreover, we decided to include articles that measured multiple skills combined. It must be observed that technical, information and communication skills were often part of this combined dependent variable. Furthermore, we had to perform a categorization to make the number of determinants manageable. Although a categorization is arbitrary, we made it transparent by providing an overview of all significant determinants. Another limitation of our review is that the conditions within the organization were not considered. Determinants of skills at the level of individual workers are more often linked to a person and, therefore, a separate search stream would be necessary to synthesize the organizational determinants. Finally, we used significance as an indicator to select relevant publications. Critics call for a broader approach because $\mathrm{p}$-values are commonly misused and misinterpreted (Wasserstein \& Lazar, 2016). The validity of scientific conclusions, including their reproducibility, depends on more than statistical methods. Nevertheless, as 
p-values are widely used and easily recognized in papers, we decided, though aware of these objections, to use them.

\subsubsection{Future research agenda}

First, we can conclude that the research on the whole range of 21st-century digital skills requires a thorough investigation to define policies for the development of these important skills; in particular, studies that focus on determinants of creativity, critical thinking, collaboration and communication are underreported. To do so, it would be interesting to look at the 21 st-century skills research because here, except for communication skills, determinants are more frequently measured. Moreover, identifying the relevant factors influencing the differences in digital skills can be considered the background knowledge for explaining these differences. To understand these differences, it is necessary to build an explanatory model. Such a model needs to be parsimoniousness, which requires not only identifying but also selecting relevant aspects based on theoretical insights that contribute to the consistency of the model and to the specification of the relations between these aspects.

Furthermore, although concerns about the lack of performance tests are increasingly addressed for technical, information and problem-solving skills, surveys are still the most commonly employed method. Even though self-report questionnaires have advantages such as the ability to present a large number of questions on a wide range of skills in a short period of time, the method has problems of validity (Hargittai, 2005). Many of the existing studies gather data based on people's own perceptions or estimations of their skills. It is likely that people overrate their own skill levels because they link the concept of 21stcentury digital skills to basic technical skills instead of the content-related skills (Talja, 2005). To gain insight into an individual's actual skill level, there is a strong need for a performance-based measurement for each type of skill.

Although numerous studies have been conducted to identify determinants, the main emphasis is on positional determinants, which an individual cannot manage. Future research could focus on determinants that can be influenced by the users of the technologies themselves as well as policy makers, educators and managers in organizations. The research concerning material, temporal, mental/motivational, social and cultural determinants might identify factors that can be altered. A stronger focus on these determinants in future investigations might help define better focused policies on how to improve individuals' skil levels. A variety of studies have highlighted the importance of participation in guided ICT training and informal social networks (e.g., Brandtweiner, Donat, \& Kerschbaum, 2010; Helsper \& Eynon, 2013). Additionally, it could be important to look into the qualitative aspects of support and training. Future research could measure a person's satisfaction level after asking for help and the reasons for not attending ICT training.

Lastly, future research could focus on the consequences of the differences in people's skill levels. Several scholars have argued that digital divides should be approached more comprehensively, in which not only Internet access, skills and use are addressed but also the consequences of Internet skills (e.g., Fuchs, 2009; Scheerder et al., 2017; Selwyn, 2004). In the labor market context, it would be interesting to know to what extent skills contribute to the quality of work performance, higher incomes, and chances of employment. Additionally, skills are also assumed to be important for its contribution to people's emancipation empowerment, and self-fulfillment (Punie, 2007). 


\section{APPENDIX 6.A REFERENCES INCLUDED STUDIES}

Adachi, P. J. C., \& Willoughby, T. (2013). More than just fun and games: The longitudinal relationships between strategic video games, self-reported problem-solving skills and academic grades. Journal of Youth and Adolescence, 42(7), 1041-1052. doi:10.1007/s10964-013-9913-9.

Afshar, H. S., \& Movassagh, H. (2017). On the relationship among critical thinking language learning strategy use and university achievement of Iranian English as a foreign language majors. The Language Learning Journal, 45(3), 382-398. doi:10.1080/ 09571736.2014 .914238

Akarawang, C., Kidrakran, P., \& Nuangchalerm, P. (2015). Enhancing ICT competency for teachers in the Thailand basic education system. International Education Studies, 8(6), 1-8. doi:10.5539/ies.v8n6p1.

Alazzam, A., Bakar, A. R., Ramlah, H., \& Asimiran, S. (2012). Effects of demographic characteristics, educational background and supporting factors on ICT readiness of technical and vocational teachers in Malaysia. International Education Studies, 5(6), 229-243. doi:10.5539/ies.v5n6p229.

Albert, R. T., Albert, R. E., \& Radsma, J. (2002). Relationships among bilingualism, critical thinking ability and critical thinking disposition. Journal of Professional Nursing 18(4), 220-229. doi:10.1053/jpnu.2002.127015.

Algren, M., \& Eichhorn, K. C. (2007). Cognitive communication competence within public relations practitioners: Examining gender differences between technicians and managers. Public Relations Review, 33(1), 77-83. doi:10.1016/j.pubrev.2006.11.010.

Almerich, G., Orellana, N., Suarez-Rodriguez, J., \& Dıaz-Garcıa, I. (2016). Teachers' information and communication technology competences: A structural approach. Computers \& Education, 100(1), 110-125. doi:10.1016/j.compedu.2016.05.002.

Baas, M., Nevicka, B., \& Ten Velden, F. S. (2014). Specific mindfulness skills differentially predict creative performance. Personality and Social Psychology Bulletin, 40(9), 1092-1106. doi:10.1177/0146167214535813.

Baro, E., \& Fyneman, B. (2009). Information literacy among undergraduate students in Niger Delta University. Electronic Library, 27(4), 659-675. doi:10.1108/02640470910979606.

Basadur, M., \& Hausdorf, P. A. (1996). Measuring divergent thinking attitudes related to creative problem solving and innovation management. Creativity Research Journal 9(1), 21-32. doi:10.1207/s15326934crj0901_3.

Blissett, S. E., \& McGrath, R. E. (1996). The relationship between creativity and interpersonal problem-solving skills in adults. The Journal of Creative Behavior 30(3)، 173-182. doi:10.1002/j.2162-6057.1996.tb00766.x.

Borg, M. O., \& Stranahan, H. A. (2010). Evidence on the relationship between economics and critical thinking skills. Contemporary Economic Policy, 28(1), 80-93. doi:10.1111/ j.1465-7287.2008.00134.x

Brandtweiner, R., Donat, E., \& Kerschbaum, J. (2010). How to become a sophisticated user: A two-dimensional approach to e-literacy. New Media \& Society, 12(5), 813833. doi:10.1177/1461444809349577.
Brown, F. W. \& Bielinska-Kwapisz, A. (2015). Understanding the nature and determinants of critical thinking among senior business undergraduate students. Journal of Education for Business, 90(7), 359-368. doi:10.1080/08832323.2015.1068156.

Brown, T., Etherington, J., \& Williams, B. (2017). Emotional intelligence and personality traits as predictors of undergraduate occupational therapy students' teamwork skills: A cross-sectional study. British Journal of Occupational Therapy, 80(7), 432-439. doi:10.1177/0308022617691539.

Bulger, M. E., Mayer, R. E., \& Metzger, M. J. (2014). Knowledge and processes that predict proficiency in digital literacy. Reading and Writing, 27(9), 1567-1583. doi:10.1007/s11145-014-9507-2.

Calvani, A., Fini, A., Ranieri, M., \& Picci, P. (2012). Are young generations in secondary school digitally competent? A study on Italian teenagers. Computers \& Education 58(2), 797-807. doi:10.1016/j.compedu.2011.10.004

Caviglia, F., \& Delfino, M. (2016). Foundational skills and dispositions for learning: An experience with information problem solving on the web. Technology, Pedagogy and Education, 25(4), 487-512. doi:10.1080/1475939X.2015.1080756.

Chen, C. J., Shih, H. A., \& Yeh, Y. C. (2011). Individual initiative, skill variety and creativity: The moderating role of knowledge specificity and creative resources. The International Journal of Human Resource Management, 22(17), 3447-3461. do: 10.1080/09585192.2011.599940.

Claro, M., Cabello, T., San Martín, E., \& Nussbaum, M. (2015). Comparing margina effects of Chilean students' economic, social and cultural status on digital versus reading and mathematics performance. Computers \& Education, 82, 1-10. doi:10.1016/j.compedu.2014.10.018

Claro, M., Preiss, D. D., San Martín, E., Jara, I., Hinostroza, J. E., Valenzuela, S., Cortes, F., \& Nussbaum, M. (2012). Assessment of 21st century ICT skills in Chile: Test design and results from high school level students. Computers \& Education, 59(3), 1042 1053. doi:10.1016/j.compedu.2012.04.004.

Clifford, J. S., Boufal, M. M., \& Kurtz, J. E. (2004). Personality traits and critical thinking skills in college students: Empirical tests of a two-factor theory. Assessment, 11(2) 169-176. doi:10.1177/1073191104263250.

Coklar, A. N., Yaman, N. D., \& Yurdakul, I. K. (2017). Information literacy and digital nativity as determinants of online information search strategies. Computers in Human Behavior, 70, 1-9. doi:10.1016/j.chb.2016.12.050.

Danial, J., \& Mohamed, S. (2014). Factors influencing the acquisition of employability skills by students of selected technical secondary school in Malaysia. International Education Studies, 7(2), 117-124. doi:10.5539/ies.v7n2p117.

Danner, R. B., \& Pessu, C. O. A. (2013). A survey of ICT competencies among students in teacher preparation programmes at the University of Benin, Benin City, Nigeria. Journal of Information Technology Education: Research, 12(1), 33-49.

Dayan, M., Zacca, R., \& Di Benedetto, A. (2013). An exploratory study of entrepreneuria creativity: Its antecedents and mediators in the context of UAE firms. Creativity and Innovation Management, 22(3), 223-240. doi:10.1111/caim.12036. 
De Wit, K., Heerwegh, D., \& Verhoeven, J. C. (2012). Changes in the basic ICT skills of freshmen between 2005 and 2009: Who's catching up and who's still behind? Education and Information Technologies, 17(2), 205-231. doi:10.1007/s10639-011 9154-z.

De Wit, K., Heerwegh, D., \& Verhoeven, J. C. (2014). Can openness to ICT and scientific research predict the ICT skills and ICT use of bachelor's students? Computers \& Education, 78, 397-413. doi:10.1016/j.compedu.2014.07.003.

Desjardins, R., \& Ederer, P. (2015). Socio-demographic and practice-oriented factors related to proficiency in problem solving: A lifelong learning perspective. International Journal of Lifelong Education, 34(4), 468-486. doi:10.1080/02601370. 2015.1060027

Dong, Y., Bartol, K. M., Zhang, Z. X., \& Li, C. (2017). Enhancing employee creativity via individual skill development and team knowledge sharing: Influences of dual-focused transformational leadership. Journal of Organizational Behavior, 38(3), 439-458. doi:10.1002/job.2134.

Emir, S. (2013). Contributions of teachers' thinking styles to critical thinking dispositions (Istanbul-fatih sample). Educational Sciences: Theory \& Practice, 13(1), 337-347.

Eshet-Alkalai, Y., \& Amichai-Hamburger, Y. (2004). Experiments in digital literacy. Cyberpsychology \& Behavior, 7(4), 425-434

Eynon, R., \& Helsper, E. (2015). Family dynamics and Internet use in Britain: What role do children play in adults' engagement with the Internet? Information, Communication \& Society, 18(2), 156-171. doi:10.1080/1369118X.2014.942344.

Fabbi, J. L. (2015). Fortifying the pipeline: A quantitative exploration of high schoo factors impacting the information literacy of first-year college students. College \& Research Libraries, 76(1), 31-42. doi:10.5860/crl.76.1.31.

Fahim, M., Miri, M., \& Najafi, Y. (2014). Contributory role of collaborative assessment in improving critical thinking and writing. International Journal of Applied Linguistics and English Literature, 3(1), 1-11. doi:10.7575/aiac.ijalel.v.3n.1p.1.

Fahim, M., \& Nasrollahi-Mouziraji, A. (2013). The relationship between Iranian EFL students' self-efficacy beliefs and critical thinking ability. Theory and Practice in Language Studies, 3(3), 538-543. doi:10.4304/tpls.3.3.538-543.

Fraser, K., \& Hvolby, H. H. (2010). Effective teamworking: Can functional flexibility act as an enhancing factor? An Australian case study. Team Performance Management: An International Journal, 16(1-2), 74-94. doi:10.1108/13527591011028933.

Furnham, A., Batey, M., Booth, T. W., Patel, V., \& Lozinskaya, D. (2011). Individual difference predictors of creativity in art and science students. Thinking Skills and Creativity, 6(2), 114-121. doi:10.1016/j.tsc.2011.01.006.

Gerber, S., \& Scott, L. (2011). Gamers and gaming context: Relationships to critical thinking. British Journal of Educational Technology, 42(5), 842-849. doi:10.1111/ j.1467-8535.2010.01106.x.

Goktas, Y., Yildirim, Z., \& Yildirim, S. (2009). Investigation of k-12 teachers' ICT competencies and the contributing factors in acquiring these competencies. The New Educational Review, 17(1)، 276-294.
Goldhammer, F., Naumann, J., Stelter, A., Tóth, K., Rölke, H., \& Klieme, E. (2014). The time on task effect in reading and problem solving is moderated by task difficulty and skill: Insights from a computer-based large-scale assessment. Journal of Educational Psychology, 106(3), 608-626. doi:10.1037/a0034716.

Goode, N., \& Beckmann, J. F. (2010). You need to know: There is a causal relationship between structural knowledge and control performance in complex problem-solving tasks. Intelligence, 38(3), 345-352. doi:10.1016/j.intell.2010.01.001.

Green, F., Ashton, D., \& Felstead, A. (2001). Estimating the determinants of supply of computing, problem-solving, communication, social and teamworking skills. Oxford Economic Papers, 53(3), 406-433. doi:10.1093/oep/53.3.406.

Greiff, S., Kretzschmar, A., Müller, J. C., Spinath, B., \& Martin, R. (2014). The computerbased assessment of complex problem solving and how it is influenced by students' information and communication technology literacy. Journal of Educational Psychology, 106(3), 666-680. doi:10.1037/a0035426.

Greiff, S., \& Neubert, J. C. (2014). On the relation of complex problem solving personality, fluid intelligence and academic achievement. Learning and Individual Differences, 36, 37-48. doi:10.1016/j.lindif.2014.08.003.

Gross, M., \& Latham, D. (2007). Attaining information literacy: An investigation of the relationship between skill level, self-estimates of skill and library anxiety. Library \& Information Science Research, 29(3), 332-353. doi:10.1016/j.lisr.2007.04.012.

Grosser, M. M., \& Lombard, B. J. J. (2008). The relationship between culture and the development of critical thinking abilities of prospective teachers. Teaching and Teacher Education, 24(5), 1364-1375. doi:10.1016/j.tate.2007.10.001.

Gui, M. (2007). Formal and substantial Internet information skills: The role of sociodemographic differences on the possession of different components of digital literacy. First Monday, 12(9). doi:10.5210/fm.v12i9.2009.

Hakkarainen, K., llomäki, L., Lipponen, L., Muukkonen, H., Rahikainen, M., Tuominen, T., Lakkala, M., \& Lehtinen, E. (2000). Students' skills and practices of using ICT: Results of a national assessment in Finland. Computers \& Education, 34(2), 103-117. doi:10.1016/S0360-1315(00)00007-5.

Han, Q., Hu, W., Liu, J., Jia, X., \& Adey, P. (2013). The influence of peer interaction on students' creative problem-finding ability. Creativity Research Journal, 25(3), 248258. doi:10.1080/10400419.2013.813754

Hargittai, E. (2010). Digital na(t)ives? Variation in Internet skills and uses among members of the "net generation". Sociological Inquiry, 80(1), 92-113. doi:10.1111/j.1475682X.2009.00317.x.

Hatlevik, O. E. (2017). Examining the relationship between teachers' self-efficacy, their digital competence, strategies to evaluate information and use of ICT at school. Scandinavian Journal of Educational Research, 61(5), 555-567. doi:10.1080/00313 831.2016.1172501.

Hatlevik, O. E., \& Christophersen, K. A. (2013). Digital competence at the beginning of upper secondary school: Identifying factors explaining digital inclusion. Computers \& Education, 63, 240-247. doi:10.1016/j.compedu.2012.11.015. 
Hatlevik, O. E., \& Guðmundsdóttir, G. B. (2013). An emerging digital divide in urban school children's information literacy: Challenging equity in the Norwegian schoo system. First Monday, 18(4). doi:10.5210\%2Ffm.v18i4.4232.

Hatlevik, O. E., Guðmundsdóttir, G. B., \& Loi, M. (2015a). Digital diversity among upper secondary students: A multilevel analysis of the relationship between cultural capital, self-efficacy, strategic use of information and digital competence. Computers \& Education, 81, 345-353. doi:10.1016/j.compedu.2014.10.019.

Hatlevik, O. E., Guðmundsdóttir, G. B., \& Loi, M. (2015b). Examining factors predicting students' digital competence. Journal of Information Technology Education: Research, 14, 123-137.

Hatlevik, O. E., Ottestad, G., \& Throndsen, I. (2015). Predictors of digital competence in 7th grade: A multilevel analysis. Journal of Computer Assisted Learning, 31(3), 220-231. doi:10.1111/jcal.12065

Heerwegh, D., De Wit, K., \& Verhoeven, J. C. (2016). Exploring the self-reported ICT skill levels of undergraduate science students. Journal of Information Technology Education: Research, 14, 19-47.

Helsper, E. J., \& Eynon, R. (2013). Distinct skill pathways to digital engagement. European Journal of Communication, 28(6), 696-713. doi:10.1177/0267323113499113.

Heppner, P. P., Walther, D. J., \& Good, G. E. (1995). The differential role of instrumentality, expressivity and social support in predicting problem-solving appraisal in men and women. Sex Roles, 32(1), 91-108. doi:10.1007/BF01544759.

Herrmann, D., \& Felfe, J. (2013). Moderators of the relationship between leadership style and employee creativity: The role of task novelty and personal initiative. Creativity Research Journal, 25(2), 172-181. doi:10.1080/10400419.2013.783743.

Hohlfeld, T. N., Ritzhaupt, A. D., \& Barron, A. E. (2013). Are gender differences in perceived and demonstrated technology literacy significant? It depends on the model. Educational Technology Research and Development, 61(4), 639-663. doi:10.1007/s11423-013-9304-7.

Hon, A. H. (2012). When competency-based pay relates to creative performance: The moderating role of employee psychological need. International Journal of Hospitality Management, 31(1), 130-138. doi:10.1016/j.ijhm.2011.04.004.

Hughes, D. J., Furnham, A., \& Batey, M. (2013). The structure and personality predictors of self-rated creativity. Thinking Skills and Creativity, 9, 76-84. doi:10.1016/j. tsc.2012.10.001.

Hunter, J. A., Abraham, E. H., Hunter, A. G., Goldberg, L. C., \& Eastwood, J. D. (2016). Personality and boredom proneness in the prediction of creativity and curiosity. Thinking Skills and Creativity, 22, 48-57. doi:10.1016/j.tsc.2016.08.002.

Hunter, S., Pitt, V., Croce, N., \& Roche, J. (2014). Critical thinking skills of undergraduate nursing students: Description and demographic predictors. Nurse Education Today, 34(5), 809-814. doi:10.1016/j.nedt.2013.08.005.

Hwang, G., \& Kuo, F. (2015). A structural equation model to analyse the antecedents to students' web-based problem-solving performance. Australasian Journal of Educational Technology, 31(4), 400-420.
Jara, I., Claro, M., Hinostroza, J. E., San Martín, E., Rodríguez, P., Cabello, T., Ibieta, A., Labbé, C. (2015). Understanding factors related to Chilean students' digital skills: A mixed methods analysis. Computers \& Education, 88, 387-398. doi:10.1016/]. compedu.2015.07.016.

Jiménez-Cortés, R., Vico-Bosch, A., \& Rebollo-Catalán, A. (2017). Female university student's ICT learning strategies and their influence on digital competence. International Journal of Educational Technology in Higher Education, 14(10), 1-12. doi:10.1186/s41239-017-0040-7.

Juhász, M. (2010). Influence of personality on teamwork behaviour and communication Social \& Management Sciences, 18(2), 63-77. doi:10.3311/pp.so.2010-2.02.

Kale, R. B., Meena, M. S., \& Rohilla, P. P. (2016). Determining factors and levels of e-skills among agriculture experts of Krishi Vigyan Kendras in India. Journal of Agricultural Science and Technology, 18, 1749-1760.

Kao, C. Y. (2014). Exploring the relationships between analogical, analytical and creative thinking. Thinking Skills and Creativity, 13, 80-88. doi:10.1016/j.tsc.2014.03.006.

Kao, C. Y. (2016). Analogy's straddling of analytical and creative thinking and relationships to big five factors of personality. Thinking Skills and Creativity, 19, 26-37. doi:10.1016/j.tsc.2015.08.001

Katrinli, A., \& Penbek, S. (2010). The role of cultural sensitivity on creativity of academic expatriates: The moderating effect of culture. African Journal of Business Management, 4(5), 755-763.

Kazemi, M. F., Gholipour, N., \& Bakhshalipour, V. (2016). The relationship between the use of information and communication technology with creativity and communication skills in physical education students of Tehran University. International Journal of Advanced Biotechnology and Research, 7(4), 46-53.

Khan, M. L., Wohn, D. Y., \& Ellison, N. B. (2014). Actual friends matter: An Internet skills perspective on teens' informal academic collaboration on Facebook. Computers \& Education, 79, 138-147. doi:10.1016/j.compedu.2014.08.001.

Kiliç-Çakmak, E. (2010). Learning strategies and motivational factors predicting information literacy self-efficacy of e-learners. Australasian Journal of Educational Technology, 26(2), 192-208. doi:10.14742/ajet.1090.

Kim, H. S., Kil, H. J., \& Shin, A. (2014). An analysis of variables affecting the ICT literacy level of Korean elementary school students. Computers \& Education, 77, 29-38. doi:10.1016/j.compedu.2014.04.009.

Kozina G., Dukić G., \& Dukić D. (2012). A study of computer literacy among Croatian students as support in planning the higher education development, Technical Gazette, 19(4), 735-742.

Krumsvik, R. J., Jones, L. Ø., Øfstegaard, M., \& Eikeland, O. J. (2016). Upper secondary school teachers' digital competence: Analysed by demographic, personal and professional characteristics. Nordic Journal of Digital Literacy, 11(3), 143-164. doi:10.18261/issn.1891-943x-2016-03-02. 
Kuhlemeier, H., \& Hemker, B. (2007). The impact of computer use at home on students' Internet skills. Computers \& Education, 49(2), 460-480. doi:10.1016/j. compedu.2005.10.004

Kuo, F. Y., Tseng, F. C., Lin, C. I., \& Tang, W. H. (2013). Critical success factors for motivating and sustaining women's ICT learning. Computers \& Education, 67, 208218. doi:10.1016/j.compedu.2013.03.006

Kwon, N. (2008). A mixed-methods investigation of the relationship between critical thinking and library anxiety among undergraduate students in their information search process. College \& Research Libraries, 69(2), 117-131. doi:10.5860/crl.69.2.117.

Lakey, S., \& Canary, D. (2002). Actor goal achievement and sensitivity to partner as critical factors in understanding interpersonal communication competence and conflict strategies. Communication Monographs, 69(3), 217-235. doi:10.1080/03637750216542.

Lee, K. S., \& Chen, W. (2017). A long shadow: Cultural capital, techno-capital and networking skills of college students. Computers in Human Behavior, 70, 67-73. doi:10.1016/j.chb.2016.12.030.

Li, Y., \& Ranieri, M. (2010). Are 'digital natives' really digitally competent? A study on Chinese teenagers. British Journal of Educational Technology, 41(6), 1029-1042. doi:10.1111/j.1467-8535.2009.01053.x.

Liao, P. A., Chang, H. H., Wang, J. H., \& Sun, L. C. (2016). What are the determinants of rural-urban digital inequality among schoolchildren in Taiwan? Insights from Blinder-Oaxaca decomposition. Computers \& Education, 95, 123-133. doi:10.1016/j. compedu.2016.01.002.

Lin, S., \& Overbaugh, R. C. (2013). Autonomy of participation and ICT literacy in a selfdirected learning environment (SDLE). Quality \& Quantity, 47(1), 1-13. doi:10.1007/ s11135-011-9505-2b.

Lin, S., Shih, T. H., \& Lu, R. (2013). ICT Proficiency and gender: a validation on training and development. International Journal of Technology and Design Education, 23(2) 179-190. doi:10.1007/s10798-011-9173-5.

Lopez, E. J., Shavelson, R. J., Nandagopal, K., Szu, E., \& Penn, J. (2014). Factors contributing to problem-solving performance in first-semester organic chemistry. Journal of Chemical Education, 91(7), 976-981. doi:10.1021/ed400696c.

Mahmood, K. (2013). Relationship of students' perceived information literacy skills with personal and academic variables. Libri, 63(3), 232-239. doi:10.1515/libri-2013-0018.

Manalo, E., Kusumi, T., Koyasu, M., Michita, Y., \& Tanaka, Y. (2013). To what extent do culture-related factors influence university students' critical thinking use? Thinking Skills and Creativity, 10, 121-132. doi:10.1016/j.tsc.2013.08.003.

Mcilroy, D., Sadler, C., \& Boojawon, N. (2007). Computer phobia and computer selfefficacy: Their association with undergraduates' use of university computer facilities. Computers in Human Behavior, 23(3), 1285-1299. doi:10.1016/j.chb.2004.12.004.

McKinney, B. C., Kelly, L., \& Duran, R. L. (1997). The relationship between conflict message styles and dimensions of communication competence. Communication Reports, 10(2), 185-196. doi:10.1080/08934219709367674.
Medeiros, K. E., Partlow, P. J., \& Mumford, M. D. (2014). Not too much, not too little: The influence of constraints on creative problem solving. Psychology of Aesthetics, Creativity, and the Arts, 8(2), 198-210. doi:10.1037/a0036210.

Molnár, G., Greiff, S., \& Csapó, B. (2013). Inductive reasoning, domain specific and complex problem solving: Relations and development. Thinking Skills and Creativity, 9, 35-45. doi:10.1016/j.tsc.2013.03.002

Mumford, M. D., Waples, E. P., Antes, A. L., Brown, R. P., Connelly, S., Murphy, S. T., \& Devenport, L. D. (2010). Creativity and ethics: The relationship of creative and ethical problem-solving. Creativity Research Journal, 22(1), 74-89. doi:10.1080/10400410903579619

Niepel, C., Mustafić, M., Greiff, S., \& Roberts, R. D. (2015). The dark side of creativity revisited: Is students' creativity associated with subsequent decreases in their ethical decision making? Thinking Skills and Creativity, 18, 43-52. doi:10.1016/j. tsc.2015.04.005

Novakovich, J. (2016). Fostering critical thinking and reflection through blog-mediated peer feedback. Journal of Computer Assisted Learning, 32(1), 16-30. doi:10.1111/ jcal.12114

Oguz, A., \& Ataseven, N. (2016). Relationship between the lifelong learning tendency and information literacy self-efficacy of students. Anthropologist, 24(1), 28-34. doi:10.1080/09720073.2016.11891986.

Owens, J., \& Lilly, F. (2017). The influence of academic discipline, race and gender on web-use skills among graduate-level students. Journal of Computing in Higher Education, 29(2), 286-308. doi:10.1007/s12528-017-9137-1.

Park, Y. J. (2013). Offline status, online status: Reproduction of social categories in personal information skill and knowledge. Social Science Computer Review, 31(6) 680-702. doi:10.1177/0894439313485202.

Payne, H. J. (2005). Reconceptualizing social skills in organizations: Exploring the relationship between communication competence, job performance and supervisory roles. Journal of Leadership \& Organizational Studies, 11(2), 63-77. doi:10.1177/107179190501100207.

Puente-Díaz, R., \& Cavazos-Arroyo, J. (2017). The influence of creative mindsets on achievement goals, enjoyment, creative self-efficacy and performance among business students. Thinking Skills and Creativity, 24, 1-11. doi:10.1016/j. tsc.2017.02.007.

Pullen, D. (2015). The influence of the home learning environment on middle schoo students' use of ICT at school. Australian Educational Computing, 30(1), 1-25.

Puryear, J. S. (2015). Metacognition as a moderator of creative ideation and creative production. Creativity Research Journal, 27(4), 334-341. doi:10.1080/10400419.20 15.1087270

Quintana, M. G. B., Pujol, M. C., \& Romaní, J. R. (2012). Internet navigation and information search strategies: How do children are influenced by their participation in an intensive ICT project. International Journal of Technology and Design Education 22(4), 513-529. doi:10.1007/s10798-011-9158-4. 
Rausch, A. (2016). Dispositional predictors of problem solving in the field of office work. Vocations and Learning, 2(10), 177-199. doi:10.1007/s12186-016-9165-4.

Redmond, M. V. (1985). The relationship between perceived communication competence and perceived empathy. Communications Monographs, 52(4), 377 382. doi:10.1080/03637758509376119.

Rhee, J., Parent, D., \& Basu, A. (2013). The influence of personality and ability on undergraduate teamwork and team performance. SpringerPlus, 2(16), 1-14. doi:10.1186/2193-1801-2-16.

Ritchie, S. J., Luciano, M., Hansell, N. K., Wright, M. J., \& Bates, T. C. (2013). The relationship of reading ability to creativity: Positive, not negative associations. Learning and Individual Differences, 26, 171-176. doi:10.1016/j.lindif.2013.02.009.

Ritzhaupt, A. D., Liu, F., Dawson, K., \& Barron, A. E. (2013). Differences in student information and communication technology literacy based on socio-economic status, ethnicity and gender: Evidence of a digital divide in Florida schools. Journal of Research on Technology in Education, 45(4), 291-307.

Rohatgi, A., Scherer, R., \& Hatlevik, O. E. (2016). The role of ICT self-efficacy for students' ICT use and their achievement in a computer and information literacy test. Computers \& Education, 102, 103-116. doi:10.1016/j.compedu.2016.08.001.

Ruscio, J., Whitney, D. M., \& Amabile, T. M. (1998). Looking inside the fishbowl of creativity: Verbal and behavioral predictors of creative performance. Creativity Research Journal, 11(3), 243-263. doi:10.1207/s15326934crj1103_4.

Sarwari, A. Q., \& Abdul Wahab, M. N. (2017). Study of the relationship between intercultural sensitivity and intercultural communication competence among international postgraduate students: A case study at University Malaysia Pahang Cogent Social Sciences, 3(1), 1-11. doi:10.1080/23311886.2017.1310479.

Scherer, R., Greiff, S., \& Hautamäki, J. (2015). Exploring the relation between time on task and ability in complex problem solving. Intelligence, 48, 37-50. doi:10.1016/j. intell.2014.10.003.

Scherer, R., \& Gustafsson, J. E. (2015). The relations among openness, perseverance and performance in creative problem solving: A substantive-methodological approach. Thinking Skills and Creativity, 18, 4-17. doi:10.1016/j.intell.2014.10.003.

Scherer, R., \& Tiemann, R. (2012). Factors of problem-solving competency in a virtual chemistry environment: The role of metacognitive knowledge about strategies. Computers \& Education, 59(4), 1199-1214. doi:10.1016/j.compedu.2012.05.020.

Shalley, C. E., \& Perry-Smith, J. E. (2001). Effects of social-psychological factors on creative performance: The role of informational and controlling expected evaluation and modeling experience. Organizational Behavior and Human Decision Processes, 84(1), 1-22. doi:10.1006/obhd.2000.2918.

Siddiq, F., Gochyyev, P., \& Wilson, M. (2017). Learning in digital networks - ICT literacy: A novel assessment of students' 21st century skills. Computers \& Education, 109, 11-37. doi:10.1016/j.compedu.2017.01.014.
Siddiq, F., Scherer, R., \& Tondeur, J. (2016). Teachers' emphasis on developing students' digital information and communication skills (TEDDICS): A new construc in 21st century education. Computers \& Education, 92, 1-14. doi:10.1016/j. compedu.2015.10.006.

Sorgo, A., Bartol, T., Dolnicar, D., \& Boh Podgornik, B. (2016). Attributes of digital natives as predictors of information literacy in higher education. British Journal of Educational Technology, 48(3), 749-767. doi:10.1111/bjet.12451.

Storm, B. C., \& Hickman, M. L. (2015). Mental fixation and metacognitive predictions of insight in creative problem solving. The Quarterly Journal of Experimenta Psychology, 68(4), 802-813. doi:10.1080/17470218.2014.966730.

Tijdens, K., \& Steijn, B. (2005). The determinants of ICT competencies among employees. New Technology, Work and Employment, 20(1), 60-73. doi:10.1111/ j.1468-005X.2005.00144.X

Tondeur, J., Sinnaeve, I., Van Houtte, M., \& Van Braak, J. (2011). ICT as cultural capital: The relationship between socioeconomic status and the computer-use profile o young people. New Media \& Society, 13(1), 151-168. doi:10.1177/1461444810369245.

Tüfekci, F.G., Küçükoglu, S., Bölükbaş, N., Tezel, A. (2011). Critical thinking dispositions of nursing students and influencing factors in Turkey. HealthMED, 5(4), 831-836.

Uzun, L. (2016). The educational and technical courses in the ELT program in Turkey: Do they contribute to ICT skills? Cogent Education, 3(1), 1-12. doi:10.1080/233118 6X.2016.1141454

Uzuntiryaki-Kondakci, E., \& Capa-Aydin, Y. (2013). Predicting critical thinking skills of university students through metacognitive self-regulation skills and chemistry selfefficacy. Educational Sciences: Theory \& Practice, 13(1), 666-670

Van Deursen, A. J. A. M., \& Van Diepen, S. (2013). Information and strategic Internet skills of secondary students: A performance test. Computers \& Education, 63, 218 226. doi:10.1016/j.compedu.2012.12.007.

Van Deursen, A. J. A. M., \& Van Dijk, J. A. G. M. (2009). Using the Internet: Skill related problems in users' online behavior. Interacting with Computers, 21(5-6), 393-402. doi:10.1016/j.intcom.2009.06.005.

Van Deursen, A. J. A. M., \& Van Dijk, J. A. G. M. (2011a). Internet skills and the digital divide. New Media \& Society, 13(6), 893-911. doi:10.1177/1461444810386774.

Van Deursen, A. J. A. M., \& Van Dijk, J. A. G. M. (2011b). Internet skills performance tests: Are people ready for eHealth? Journal of Medical Internet Research, 13(2) doi:10.2196/jmir.1581.

Van Deursen, A. J. A. M. \& Van Dijk, J. A. G. M. (2014). Loss of labor time due to malfunctioning ICTs and ICT skill insufficiencies. International Journal of Manpower 35(5), 703-719. doi:10.1108/IJM-07-2012-0102.

Van Deursen, A. J. A. M., \& Van Dijk, J. A. G. M. (2015). Internet skill levels increase, but gaps widen: A longitudinal cross-sectional analysis (2010-2013) among the Dutch population. Information, Communication \& Society, 18(7), 782-797. doi:10.1080/13 69118X.2014.994544. 
Van Deursen, A. J. A. M., \& Van Dijk, J. A. G. M. (2016). Modeling traditional literacy, Internet skills and Internet usage: An empirical study. Interacting with Computers, 28(1), 13-26. doi:10.1093/iwc/iwu027.

Van Deursen, A. J. A. M., Van Dijk, J. A. G. M., \& Peters, O. (2011). Rethinking Internet skills: The contribution of gender, age, education, Internet experience and hours online to medium-and content-related Internet skills. Poetics, 39(2), 125-144. doi:10.1016/j.poetic.2011.02.001.

Verhoeven, J. C., Heerwegh, D., \& De Wit, K. (2010). Information and communication technologies in the life of university freshmen: An analysis of change. Computers \& Education, 55(1), 53-66. doi:10.1016/j.compedu.2009.12.002.

Verhoeven, J. C., Heerwegh, D., \& De Wit, K. (2012). First year university students' self-perception of ICT skills: Do learning styles matter? Education and Information Technologies, 17(1), 109-133. doi:10.1007/s10639-010-9149-1.

Verhoeven, J. C., Heerwegh, D., \& De Wit, K. (2016). ICT learning experience and research orientation as predictors of ICT skills and the ICT use of university students. Education and Information Technologies, 21(1), 71-103. doi:10.1007/s10639-0149310-3.

Vörös, Z., \& Rouet, J. F. (2016). Laypersons' digital problem solving: Relationships between strategy and performance in a large-scale international survey. Computers in Human Behavior, 64, 108-116. doi:10.1016/j.chb.2016.06.018.

Weinert, D. J., \& Palmer, E. M. (2007). Influence of an information literacy course on students' information search behavior. Journal of Allied Health, 36(1), 1-12.

West, R. F., Toplak, M. E., \& Stanovich, K. E. (2008). Heuristics and biases as measures of critical thinking: Associations with cognitive ability and thinking dispositions. Journa of Educational Psychology, 100(4), 930-941. doi:10.1037/a0012842.

Wiseman, R. L., Hammer, M. R., \& Nishida, H. (1989). Predictors of intercultura communication competence. International Journal of Intercultural Relations, 13(3) 349-370. doi:10.1016/0147-1767(89)90017-5.

Wolf, K. M., \& Mieg, H. A. (2010). Cognitive determinants of the success of inventors: Complex problem solving and deliberate use of divergent and convergent thinking. European Journal of Cognitive Psychology, 22(3), 443-462. doi:10.1080/09541440902916845.

Wu, M., Ho, S., Lin, H., Chang, W., \& Chen, L. (2013). How do thinking styles influence collaborative dispositions? A study on the relationships between thinking styles and collaborative dispositions for youngsters in Taiwan. Educational Sciences: Theory \& Practice, 13(4), 2059-2070. doi:10.12738/estp.2013.4.1681.

Yang, Y., Lee, P. K. C., \& Cheng, T. C. E. (2016). Continuous improvement competence, employee creativity and new service development performance: A frontline employee perspective. International Journal of Production Economics, 171(2), 275 288. doi:10.1016/j.ijpe.2015.08.006.

Yang, Y. T. C., \& Chou, H. A. (2008). Beyond critical thinking skills: Investigating the relationship between critical thinking skills and dispositions through different online instructional strategies. British Journal of Educational Technology, 39(4), 666-684. doi:10.1111/j.4678535.2007.00767.x.
Yi, X., Plucker, J. A., \& Guo, J. (2015). Modeling influences on divergent thinking and artistic creativity. Thinking Skills and Creativity, 16, 62-68. doi:10.1016/j. tsc.2015.02.002.

Ying, L. C., Kheng, F. K., Hiong, T., Goh, K., Lim, A., \& Lee, E. (2014). Is problem solving and systems thinking related? A case study in a Malaysian university. Pertanika Journal of Social Sciences \& Humanities, 22(1), 345-363.

Youssef, B. A., Dahmani, M., \& Omrani, N. (2015). Information technologies, students' e-skills and diversity of learning process. Education and Information Technologies, 20(1), 141-159. doi:10.1007/s10639-013-9272-x.

Zampetakis, L. A., Bouranta, N., \& Moustakis, V. S. (2010). On the relationship between individual creativity and time management. Thinking Skills and Creativity, 5(1), 23-32 doi:10.1016/j.tsc.2009.12.001.

Zhang, K., \& Toker, S. (2011). Stimulating critical thinking in a virtual learning community with instructor moderations and peer reviews. Knowledge Management \& E-Learning: An International Journal, 3(4), 534-547.

Zhang, X., \& Bartol, K. M. (2010). The influence of creative process engagement on employee creative performance and overall job performance: A curvilinear assessment. Journal of Applied Psychology, 95(5), 862-873. doi:10.1037/a0020173.

Zhong, Z. J. (2011). From access to usage: The divide of self-reported digital skills among adolescents. Computers \& Education, 56(3), 736-746. doi:10.1016/j. compedu.2010.10.016. 


\section{APPENDIX 6.B SIGNIFICANT INDIVIDUAL DETERMINANTS}

\section{CATEGORIZED}

Demographic Age, family settlement, gender, geographical area, marital status, nationality, race and ethnicity, residential environment, rural/urban

Socioeconomic Academic aspirations, academic discipline, academic experience, community college transfer, curriculum track, degree program, degree level, educational level, educational level of mother, educational level of parents, expertise, expressivity, field, grade level, having a job while studying, home university, household income, household socioeconomic status, intention become researcher, intention become not researcher, international status, job function, number of honor courses, nursing experience, orientation towards academic and scientific research, prior related experience, professional or vocational orientation, social class, socioeconomic group, sociodemographic background, socioeconomic status, study degree, study discipline, study domain, study level, study orientation (ambivalent, vocational), study year, task difficulty, task novelty, type of school, type of institution, vocational training, work experience

Personality/ Ability level, academic self-perception, academic achievement, achievements at psychological school, ACT score, actively open-minded thinking, act with awareness, alertness to opportunity, analogical thinking (verbal, figural), analytic intelligence, analytical thinking, cognitive ability, computer anxiety, confidence in doing simple ICT tasks, conflict message style, creative self-efficacy, critical thinking dispositions, divergent thinking attitudes (creative individual stereotypes, preference for ideation, tendency to make premature), domain relevant skills (assuredness, difficulty, exhibited uncertainty), domain-specific knowledge, emotional intelligence (emotional management of others, emotional reasoning), empathy, familiarity with computers, fluid intelligence, general reasoning, grade point averamiliarity with cors, grades, growt self-efficacy advance, ICT self efficacy basic, ind self-eficacy advanced, ICT self-efficacy basic, independence, individual initiative, individual skilts development, inductive reasoning, instrumentality, intelligence (similarities, verbal comprehension index) interdependence, Internet self-efficacy, $1 \mathrm{Q}$, knowledge structures, library anxiety, locomotion, mastery orientation, metacognition (conditional knowledge, debugging, declarative knowledge, knowledge of cognition, regulation of cognition), mental fixation, metacognitive self-regulation, need for achievement, mindfulness skills, need for cognition, need for power, negative thinking (personal maladjustment), personality traits (agreeableness, conscientiousness, emotional stability, emotionality, extraversion, neuroticism, openness to experience), openness in problem solving, perseverance to problem solving, physical health, positive thinking (other evaluation), prio knowledge, reading ability, reasoning, SAT/ACT score, self-concept, self-efficacy, self-efficacy beliefs regarding their ICT skills, self-estimates of skill level, systems thinking, team creative self-efficacy, thinking style (anarchic, conservative, holistic, judicial), traditional literacy, university achievement
Appendix 6.B Continued

Temporal Age of first PC experience, computer experience, frequency of computer use

(ICT situation) at home, frequency of computer use at school, frequency of daily online use, frequency of ICT use, frequency of ICT use at home, frequency of using a computer at home, history of using ICTs, hours spent per week surfing for pedagogical purposes, ICT experience, ICT penetration rate, ICT use, ICT use at home, ICT use purposes, ICT experience, ICT penetration rate, ICT use, ICT use at home, ICT use initial computer experience, intensity ICT use, log usage time for study, log usage time other purposes than study, number of years online, number of use years, number of years using PC's, regular home use, screen time, use ICT to chat, use ICT to download, use ICT to send messages using social networks, use ICT to visit a personal account, use the computer to e-mail or chat, use the computer to surf weekly, use the computer for text processing, weekly web hours, workload, years of experience using a computer, years of Internet experience, years of use

Access locations, availability of discipline-specific software, computer access at home, computer access at school, computer classroom, computer ownership, constraints (fundamentals, information, resources), creative example, creative model, embedded technology, ICT access, informational evaluation, instructional strategy, Internet access at home, Internet connection at home, knowledge specificity, location of access, number of access locations, number of computers at home, number of weekly computer classes, PC at home, primary location of Internet use, structural knowledge, task-technology fit, time on task

Mental/

Action count, application-directed learning style (certificate directed, use of knowledge, vocational directed), autonomy of participation, behavior expressing a positive attitude towards $\mathrm{PC}$, completion status of computer courses, computer attitude, computer training, continuing ICT education, control of computers, creative process engagement, creativity relevant processes (concept identification wide focus), digital-cultural production, domain-specific problem solving, digital nativity, ethical decision making (business practices, data management, professional practices, study conduct), followed an Internet course, formal ICT training, ICT course attendance, ICT course in secondary school, ICT course in university, ICT education, ICT necessary for researcher, ICT necessary for scientific research, ICT training, ICT training at school, improvement capability, industria training, ICT literacy, information use, Internet competence, information literacy, mation literacy course, information seeking skills sharing skills (creative, comments), intrinsic motivation, job performance, learning intention, learning mechanisms (learning by doing, learning by using), learning motivation (control belief of learning), learning satisfaction, learning strategies (autonomous, conventional, critical thinking, effort management, elaboration, metacognitive), learning strategies and techniques, learning time, meaningdirected learning style (concrete processing, construction of knowledge, personally interested, relating and structuring), medium-related skills, number of ICT-rich university courses, off-job training, on-job training, on-the-job learning, participation in career development activities, participation in an Internet course, perceived ease of use, perceived usefulness, perceived usefulness of ICT, preservice ICT course, research skills, satisfaction level of students in classes using ICT, skill variety, successful completion of a computer course, self-study of ICT, self-taught ICT activities, sources of help (books/lnternet), strategic use of information, strategies to evaluate information, strategic video gameplay, technical knowledge, techno-capital, time management (daily planning, confida for disorganization, traing in the use of IT, traing with informce solving activities, usefulness of computers, web information seeking 


Assistance required, availability of help and support, blog-mediated peer
feedback, collaborative and cooperative learning, collaborative assessment,
digital support networks, effectiveness and appropriateness, Facebook
friends' instrumental support, goal achievement (instrumental, relational, self-
presentation), goal sensitivity (perception of own sensitivity, perception of
partner's sensitivity), group construction, learn from peers, learning strategy
(collaborative), peer review, learn from teachers, number of "actual" Facebook
friends, social capital, social and scientific activity, social environment (colleague
users), social isolation, social support (co-workers), sources of help (co-workers,
helpdesk), support from family, team communication effectiveness, team
experience, team knowledge sharing
Attitude towards other culture, best language, country culture, cultural
background, cultural capital, cultural possessions at home, cultural sensitivity,
educational expenditure, educational resources at home, English language
proficiency, household cultural possessions, immigrant/language status,
intercultural sensitivity, language integration, linguistic capital, level of foreign
language, minority status, negative stereotypes, number of books read in a month,
reading at home, reading at work, world mindedness

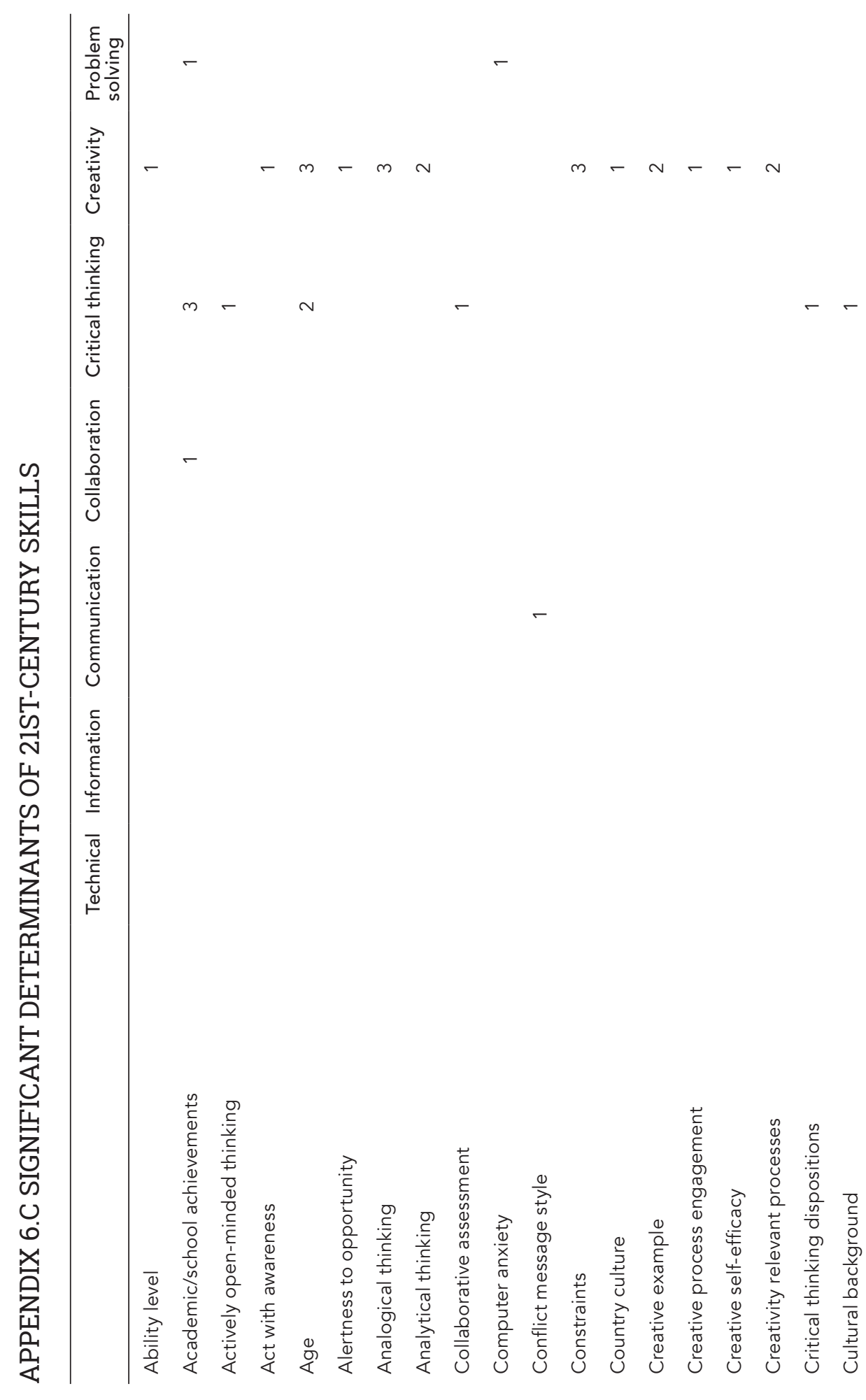



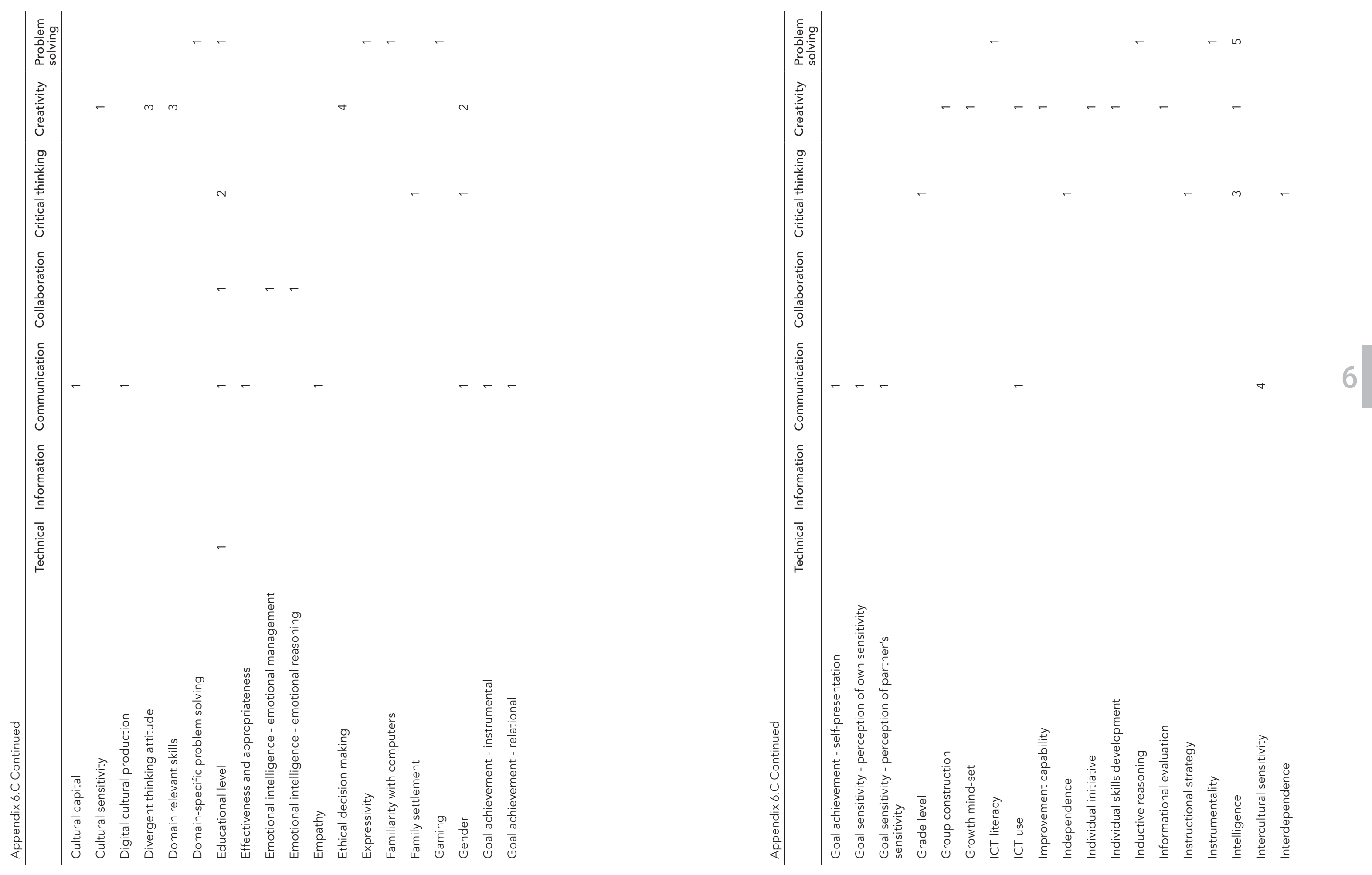

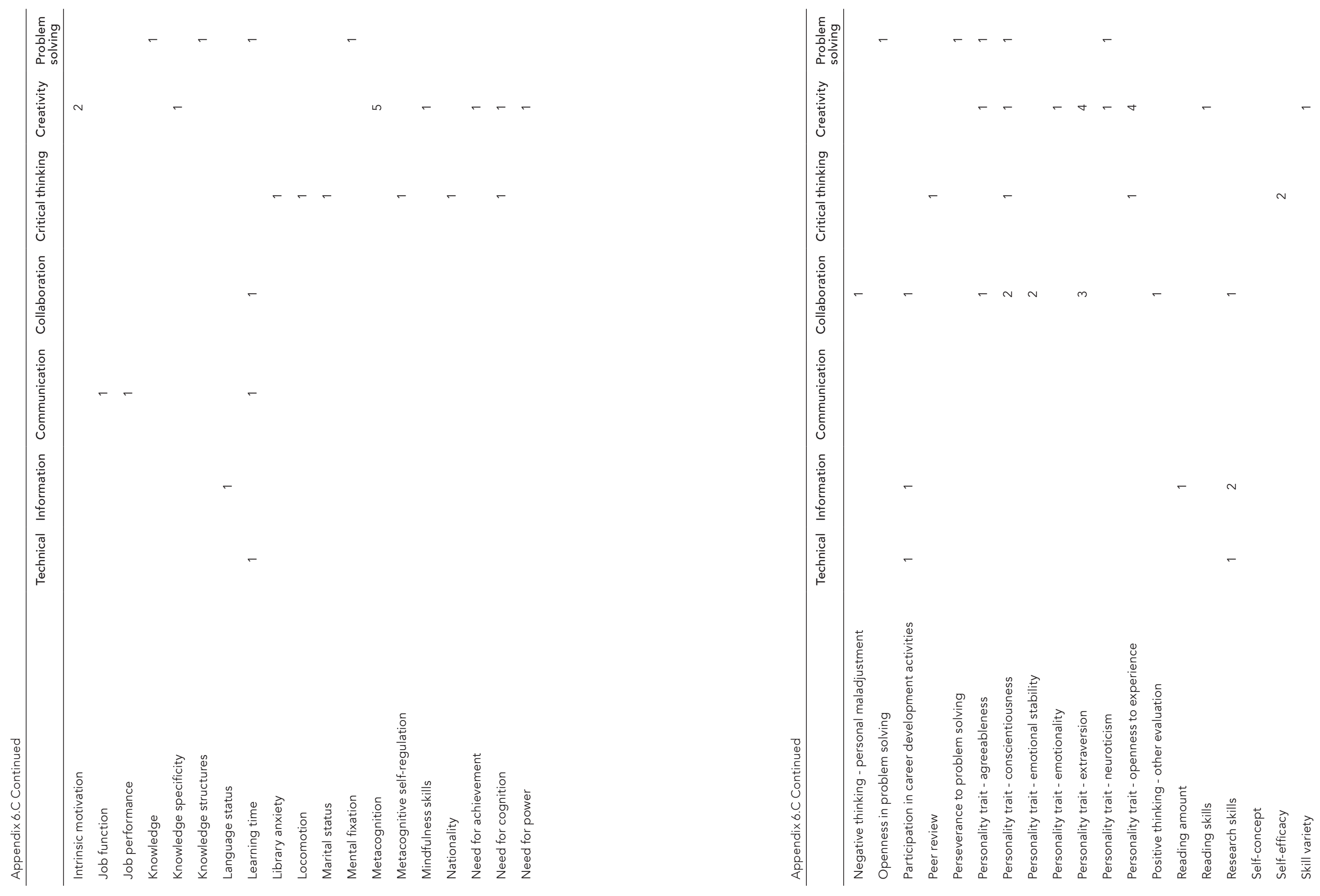

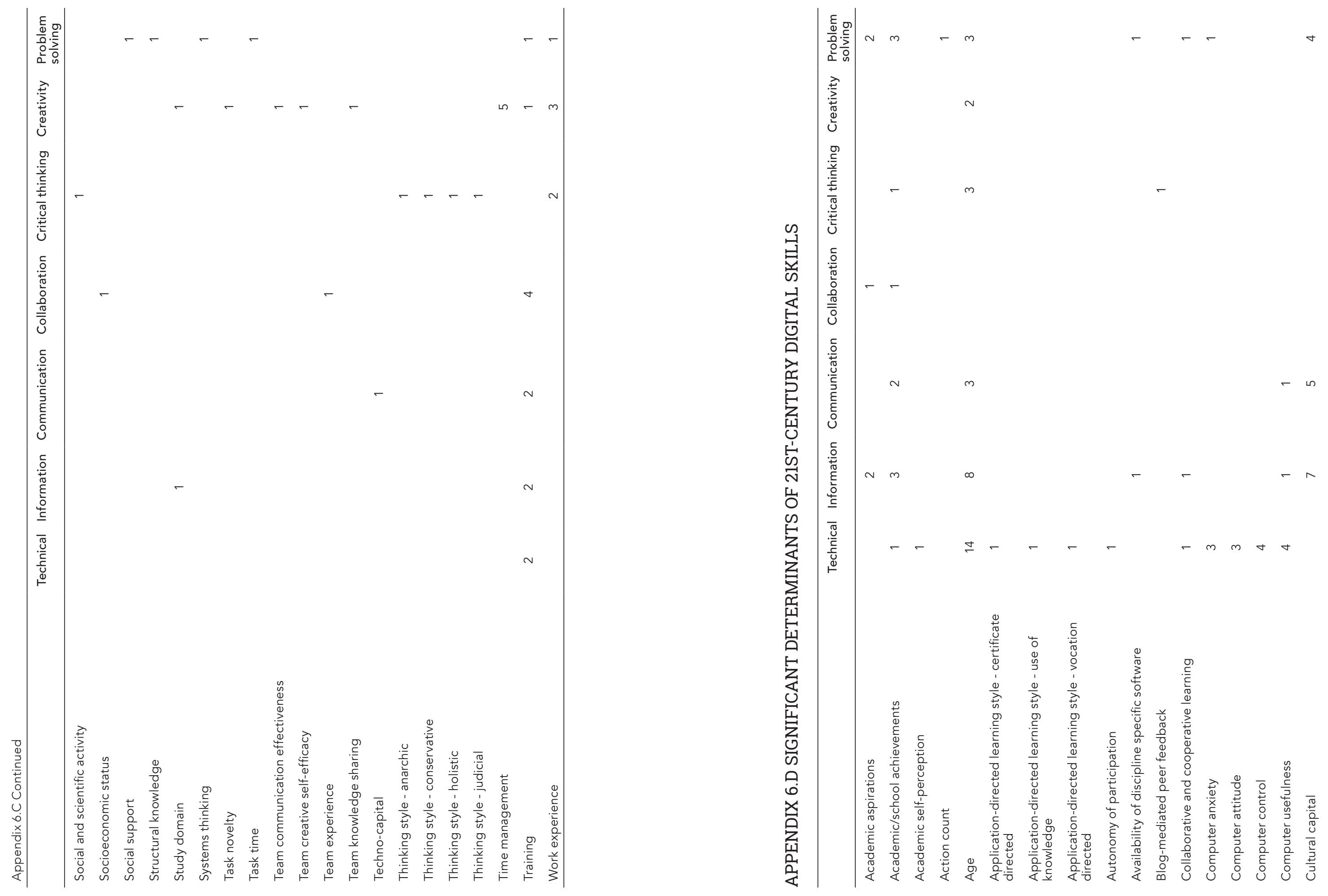

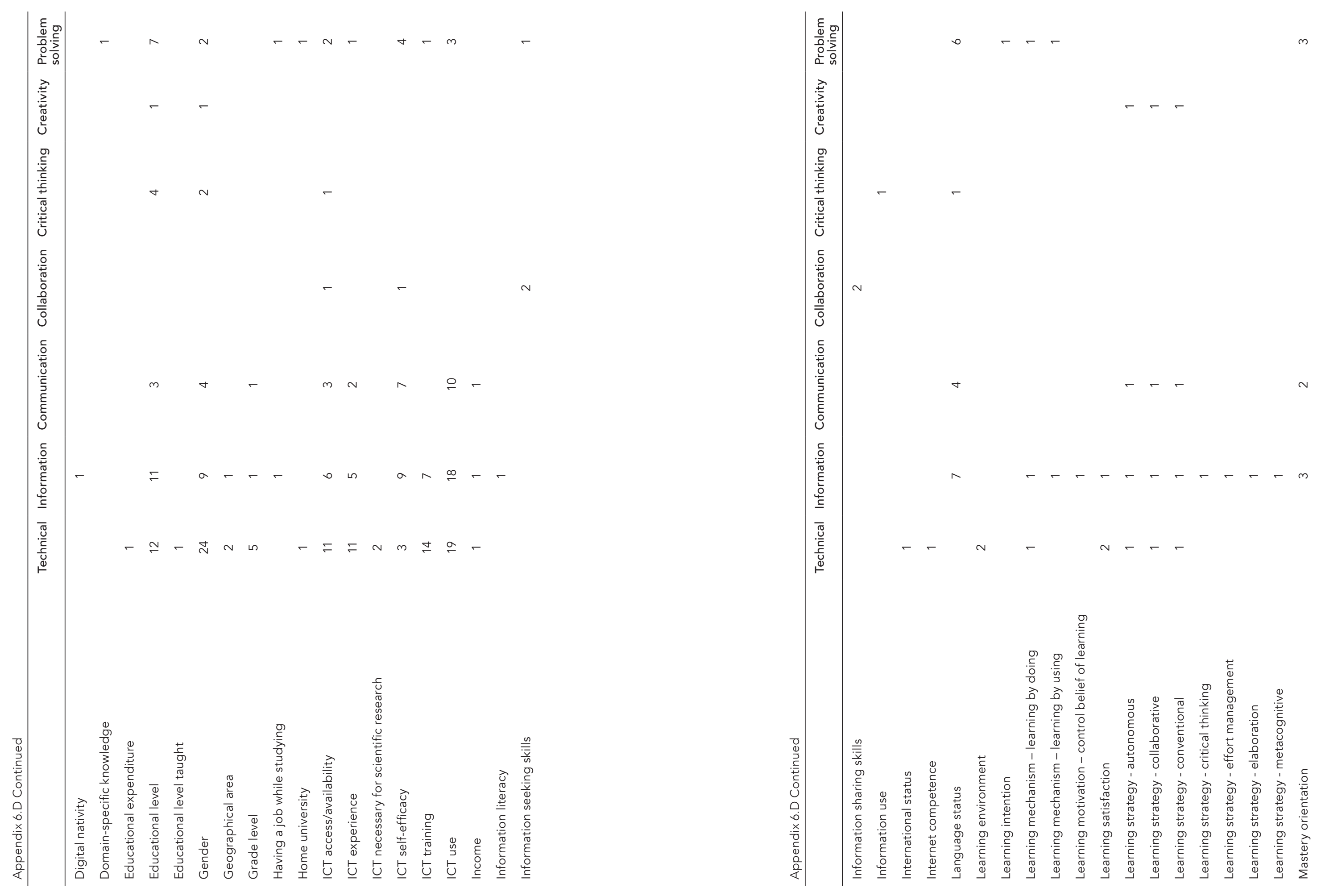


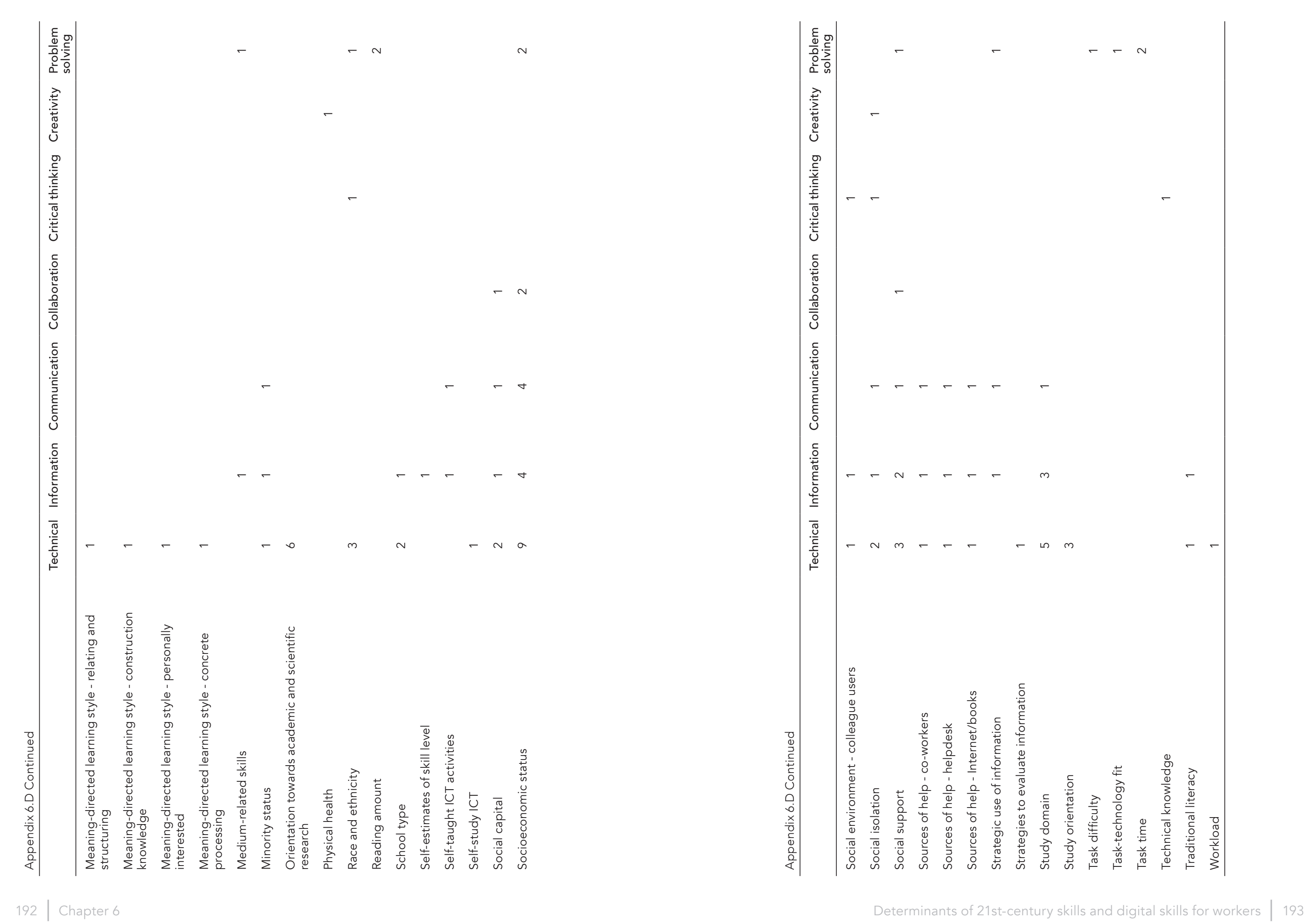




\section{CHAPTER 7}

DETERMINANTS OF 21ST-CENTURY DIGITAL SKILL LEVELS:

A LARGE-SCALE SURVEY AMONG WORKING

\section{PROFESSIONALS}

The current workplace increasingly asks for workers with highly digitally skilled knowledge who produce and distribute ideas and information. As such, understanding the factors behind differences in the level of various 21stcentury digital skills is of decisive importance. This chapter aims to examine (1) the level of 21 st-century digital skills among knowledge workers and (2) the determinants contributing to the level of these skills. The following digital skills are investigated: information, communication, collaboration, critical thinking, creativity, and problem solving. The potential determinants, as identified in Chapter 6, that can be influenced by stakeholders are also included (e.g., social support and training). A large-scale online survey was conducted among professionals $(N=1,222)$ who work within knowledge-intensive creative industries. The results show that the level of 21 st-century digital varies considerably. Furthermore, each 21st-century digital skill is explained by a different set of determinants, thereby requiring unique approaches for the development of each skill. ${ }^{5}$

5 Van Laar, E., Van Deursen, A. J. A. M., Van Dijk, J. A. G. M., \& De Haan, J. (2019). Determinants of 21st-century digital skills: A large-scale survey among working professionals. Computers in Human Behavior, 100, 93-104. doi:10.1016/j.chb.2019.06.017. 


\subsection{INTRODUCTION}

Although ICTs are pervasive at work, not all employees have the skills to take advantage in terms of the richness of activities and the variety of learning opportunities ICTs offer. Numerous studies show that people vary greatly with regard to their digital skill levels (e.g., Hargittai, 2010; Van Deursen \& Van Dijk, 2011a; Verhoeven, Heerwegh, \& De Wit, 2016). Research is needed to identify the causes of potential skill insufficiencies. Unfortunately, existing studies are often limited by a focus on technical-oriented skills with less attention given to the broader spectrum of skills (e.g., communication and collaboration) (Gonçalves, Oliveira, \& Cruz-Jesus, 2018; also see Chapter 2) or by merging different components of digital skills into a single measure. Consequently, it remains unclear which skills are influenced by which determinants. Furthermore, the primary focus in digital skills research is on sociodemographic and -economic determinants (Hargittai, 2010; Scheerder, Van Deursen, \& Van Dijk, 2017). The previous chapters resulted in a survey instrument to measure 21stcentury digital skills, and an overview of factors that contribute to those skills (see Chapters 4 and 6). This chapter aims to explain differences in the level of various 21 st-century digital skills by examining potential personal, motivational and social determinants at the level of the individual worker. The emphasis is on determinants that can be influenced by the users of the technologies themselves as well as by policy makers, educators and managers in organizations. Factors such as taking the initiative, participating in training and asking for social support are taken into account. Organizational characteristics, or determinants of skills specific to the organizational context (e.g., organizational culture, leadership style), fall outside the scope of this contribution. Not only is it essential to investigate the relation between various 21st-century digital skills (see Chapter 5) but also to identify the factors that determine skill levels. As employees with a high level of skills are needed, the focus is on explaining why some working professionals have more proficiency in 21st-century digital skills than others. Hypotheses are proposed and tested in the knowledge-intensive creative industries, which comprise organizations focusing on "the creation, production, and distribution of creative or cultural goods and services" (Kohn \& Wewel, 2018, p. 2). One of the key characteristics is the dynamic, heterogeneous and temporal nature of services offered (Pina \& Tether, 2016). Succeeding as a knowledge-intensive organization requires the capacity to be creative, innovative and entrepreneurial. Innovation, especially in the creative industries, relies on workers and their ability to generate knowledge to solve problems and innovate in organizations. In the creative industries new ideas and approaches flourish and human capital is a crucial factor for success (Piergiovanni, Carree, \& Santarelli, 2012). They exemplify the increasing demand for highly skilled knowledge workers whose job is to produce intellectual capital. The following research questions are addressed:

1) What is the level of 21st-century digital skills (information, communication, collaboration, critical thinking, creativity, and problem solving) among the professionals working within the creative industries?

2) Which determinants, at the level of the individual worker, contribute to 21st-century digital skills?

As creative industries are typically composed of a relatively large number of self-employed (including freelance) workers (Trip \& Romein, 2014), we address the questions above for both employed and self-employed workers. It is reasonable to assume that self-employed workers may have less access to formal support sources (e.g., a supervisor or colleague) than employed workers (Annink, Den Dulk, \& Steijn, 2016). Similarly, with regard to training opportunities, self-employed workers may have neither the time nor the financial resources to undertake training. Additionally, they may be more inclined to actually take the initiative and are more proactive by nature (Plomp et al., 2016). Because of the limited literature available, we use a more explorative approach to address the role of employment status in relation to pathways to skill development, or in other words, whether some skill determinants might be more important for self-employed than employed workers.

\subsection{THEORETICAL FRAMEWORK: DETERMINANTS OF 21ST- CENTURY DIGITAL SKILLS}

This chapter has an exploratory nature in identifying potential determinants of the skills. Instead of choosing a specific line of inquiry, we utilize perspectives from the resources and appropriation theory as a conceptual lens to classify determinants (De Haan, 2004; Van Dijk, 2005). This theory relates the differences in people's access to a technology (attitudes, physical access, skills, and usage) to a distribution of resources that, in turn, are explained by personal categories and positions in society. In this chapter, we focus on common personal categories of gender and age and the positional category of education (Scheerder et al., 2017). In the resources and appropriation theory, 
the resources considered are classified under material, temporal, cultural, social and mental resources. Material (e.g., access to an Internet connection) and temporal resources (e.g., time to use ICT) should be considered primary conditions to employ skills; without these resources, skills will not be developed. In the current context, mental, social and cultural resources are more interesting for explaining differences in people's skills. They concern resources such as the perceived ease of use for using ICT, self-directed learning capabilities, a status related to performing well on skills, or social-contextual factors such as available support.

Starting with the process of access, we first consider ICT attitude as potential determinant of 21 st-century digital skills. ICT attitude refers to the overall affective reaction of a person to the use of a technology (De Wit, Heerwegh, \& Verhoeven, 2014). It is widely accepted in the social psychology literature that behavior is predicted by attitudes (Fishbein \& Ajzen, 1975). The research confirms that the level of digital skills is directly influenced by ICT attitudes (Tondeur, Sinnaeve, Van Houtte, \& Van Braak, 2011; Van Deursen \& Van Dijk, 2015b). We hypothesize:

H1: ICT attitude contributes positively to the level of 21st-century digital skills.

In terms of resources, perceived ease of use is considered first. This term can be defined as the degree to which a person believes that using ICTs would be free of effort (Davis, 1989). It involves the perception of the difficulty of learning to use a particular technology. Perceived competence is associated with higher levels of web content creation skills (Correa, 2010). The previous research has confirmed that perceived ease of use results in higher levels of ICT skills (Heerwegh, De Wit, \& Verhoeven, 2016; Verhoeven et al., 2016) and plays a strong role in the willingness to develop new skills (Edmunds, Thorpe, \& Conole, 2012). This suggests that the development of a feeling of control over computers can contribute to 21st-century digital skills. We hypothesize:

H2: Perceived ease of use contributes positively to the level of 21 st-century digital skills.

ICT self-regulation is defined as the tendency to maintain focus and effort toward goals despite potential distractions online (Zimmerman, 2000). A person working on an information-related task can be easily distracted by other activities such as checking e-mails or surfing the web (Goundar, 2014). ICT self-regulation has also proven to be effective at enhancing problem solving (Zimmerman, 2000). Self-control processes help individuals to concentrate on the task and to optimize their efforts (Senkbeil \& Ihme, 2017). We hypothesize:

H3: ICT self-regulation contributes positively to the level of 21 st-century digital skills.

Self-directed learning involves individuals developing plans and strategies and monitoring their behaviors to attain their anticipated goals (Zampetakisa, Bouranta, \& Moustakis, 2010). To solve challenging tasks in problem situations, individuals must set specific goals, plan their activities, monitor their performance during the problem-solving process, and evaluate the efficiency of their actions (Ifenthaler, 2012). Acquiring new skills can be enhanced if people are encouraged to employ self-directed learning processes (Zimmerman, 2002). Self-regulating learners maintain an active and ongoing awareness of task demands, the effectiveness of learning strategies, and their progress toward task completion (Wolters, 2010). Effective self-directed learners evaluate the limitations of their knowledge and skills and strategically respond to new learning challenges (Vassallo, 2014). We hypothesize:

H4: Self-directed learning contributes positively to the level of 21st-century digital skills.

We consider the following distinct individual goal orientations: (1) learning, which focuses on skill development and task mastery; (2) performance approach, which focuses on gaining favorable evaluations and outperforming others; and (3) performance avoidance, which focuses on avoiding mistakes and negative evaluations (VandeWalle, 1997). The value of goal orientation lies in regulating employees' attention and effort to develop creative solutions to problems at work. Learning goal-orientated individuals seek challenges that provide them with learning opportunities. They approach a task to understand something new or to enhance their skill levels (Yi \& Hwang, 2003). Performance goal orientated individuals aim to achieve higher skill levels compared to their colleagues (VandeWalle, 1997). They pursue performance goals to demonstrate their competence and to gain favorable judgements (Yi \& Hwang, 2003). As such, learning and performance goal orientation are expected to relate to skill acquisition. In contrast, avoidance goal-orientated individuals are concerned with avoiding failure and negative judgements from others (VandeWalle, 1997) 
They are anxious that their incompetence may be revealed by sharing irrelevant knowledge and therefore withhold the effort that is crucial for the learning experience to occur (Pintrich, 2000). We hypothesize:

H5: Learning goal orientation contributes positively to the level of 21stcentury digital skills.

H6: Performance goal orientation contributes positively to the level of 21stcentury digital skills.

H7: Avoidance goal orientation contributes negatively to the level of 21stcentury digital skills.

Personal initiative is a form of proactivity and is defined as behavior resulting in people taking an active and self-starting approach to work and going beyond what is required in a given job (Frese, Fay, Hilburger, Leng, \& Tag, 1997). People with high initiative are more likely to take actions to solve problems (Chen, Shih, \& Yeh, 2011). Furthermore, Joo, Yang, and McLean (2014) found that the extent to which employees possess proactivity is associated with creative skills. To actively pursue learning, people need the ability and willingness to go beyond narrow task requirements and to approach work proactively (Den Hartog \& Belschak, 2007; Frese et al., 1997). We hypothesize:

H8: Personal initiative contributes positively to the level of 21st-century digital skills.

Social support involves individuals asking for help from people in their social network (Liang, Ho, Li, \& Turban, 2011). This study focuses on informational support, which refers to providing messages, for example recommendations, advice or knowledge that could be helpful for solving online problems. A distinction is made between formal (supervisor, coworkers, and ICT service) and informal (family, friends, and Internet contacts) support. The more an employee is supported by formal or informal support sources, the more expertise, social networks and material resources are available when developing creative ideas (Oldham \& Cummings, 1996; Scott \& Bruce, 1994). Additionally, instrumental social support is positively related to employees' knowledge acquisition and application capabilities (e.g., Heppner, Walther, \& Good, 1995; Kim \& Lee, 2010). Online help-seeking provides individuals with useful information to self-regulate their follow-up behaviors for resolving problems. We hypothesize:

H9: Formal social support contributes positively to the level of 21 st-century digital skills.
H10: Informal social support contributes positively to the level of 21st-century digital skills.

Attendance of an ICT-related training may result in the positive consequence that employees who attended such a training have more opportunities to practice some digital skills. We hypothesize:

H11: Training contributes positively to the level of 21st-century digital skills.

Finally, we consider gender, age and level of education attained. Although men and women do not differ greatly in their online abilities, the research proves that women self-assess their skill levels significantly lower (Hargittai \& Shafer, 2006). Moreover, the general opinion is that younger generations are considered digitally skilled, as they have had exposure to the Internet throughout their entire life (Dutton, Heslper, \& Gerber, 2011; Van Deursen, Van Dijk, \& Peters, 2011). Finally, the research confirms that the level of educational attainment results in higher levels of digital skills (Gui \& Argentin, 2011; Hargittai, 2010; Van Deursen \& Van Dijk, 2011a). Altogether, this leads to the following hypotheses:

H12: Men have higher levels of 21st-century-digital skills than women.

H13: Age has a negative influence on the level of 21st-century digital skills.

H14: Level of education has a positive influence on the level of 21st-century digital skills.

\subsection{METHOD}

7.3.1 Sample

The sample corresponds to the one used in Chapter 5. In total, 776 respondents were recruited via e-mail and 446 via two online panels. As a result, 1,222 professionals who are directly involved in creative work processes (e.g., designers, engineers, and project managers) were part of this study.

\subsubsection{Dependent measures}

The survey instrument developed in Chapter 4 was used to test the level of 21st-century digital skills. Each item measured the frequency of various skillrelated actions. The frequency scales ranged from 1 'never' to 5 '(almost) always'. Cronbach's alpha values exceeded the normally accepted .70 threshold. Appendix 7.A displays the means, standard deviations and reliability scores of 
each 21st-century digital skill for the full sample, employed and self-employed workers.

\subsubsection{Independent measures}

To measure ICT attitude, we adapted three items from Chou (2010), two from Van Damme and colleagues (2005), and one item from Tondeur and colleagues (2011). To measure perceived ease of use, we adapted four items from Heerwegh and colleagues (2016) and added one item ourselves. ICT self-regulation was measured by adapting five items from Senkbeil and Ihme (2017). Self-directed learning was measured by adapting three items from the instrument of Choy and colleagues (2016), and we added two items. Goal orientation was divided into learning goal orientation, performance goal orientation and avoidance goal orientation. The instrument from VandeWalle (1997) was used to assess each type of goal orientation and we used five items to measure these constructs. Personal initiative was measured by adapting five items from the instrument of Frese and colleagues (1997). Social support was included by asking the question: "who do you ask for help when you have problems with the internet at work?" The answer possibilities were divided into either asking for help or not asking for help. The potential formal support sources were: 'supervisor' (17.5\%), 'colleagues' (66.8\%), 'ICT services/helpdesk at work' (47.3\%) and 'external ICT services/helpdesk' (14.2\%). The potential informal support sources were: 'friends/family outside of work' (23.4\%) and 'Internet contacts/persons online' (14.1\%). The potential reasons for asking nobody for help were: 'no help needed' (10.6\%), 'no help available' (2.2\%) and 'problems are too complex/specialized' (2.9\%). Training was included as a dichotomous variable by asking the question: "Did you attend a training about Internet applications and digital skills within the past 3 years?". Most participants (71.1\%) stated that they did not follow an ICT-related training. Lastly, the background characteristics gender, age and educational level were included.

To test the structure of the independent variables, we conducted a confirmatory principal component analysis with varimax rotation. Factor loadings of 0.40 were considered to be significant for inclusion of the items in a factor (Stevens, 2012). After the first run, we excluded seven items that did not load on any factors or loaded on different factors than anticipated. Then, we performed a rerun which confirmed eight independent variables with eigenvalues above 0.90 (eigenvalues above the 0.70 are acceptable; Jolliffe, 1972), explaining $61 \%$ of the variance. Internal consistency of the factors revealed a reliable factor solution. Cronbach's alpha values ranged from .72 to .82. Appendix 7.B displays the scales used for the independent measures including the means, standard deviations and reliability scores for the full sample, employed and self-employed workers.

\subsection{RESULTS}

7.4.1 Level of 21st-century digital skills

Figure 7.1 on the next page shows that information management obtained the highest mean score $(M=4.06, S D=0.79)$. All other skills obtained scores below 4. Communication content-sharing $(\mathrm{M}=2.64, \mathrm{SD}=0.89)$ and communication contact-building ( $M=2.83, S D=0.90)$ scored the lowest, with mean scores below 3. An independent samples t-test was conducted to examine whether differences between employed and self-employed workers were significant. See Figure 7.1.

7.4.2 Determinants of 21st-century digital skills

To test which determinants of 21 st-century digital skills are significant, we used multiple linear regression analysis. The analysis was carried out using SPSS (IBM Statistics). Before conducting the regression analyses, we checked for the assumptions of normality, linearity, homoscedasticity, and absence of multicollinearity by using a normal P-P plot, a scatterplot of the residuals, and calculating the Variance Inflation Factors (VIF). The model residuals are normally distributed and homoscedastic, so linearity was not a problem. All VIF values were between 1 and 2.5, showing only moderate correlations, not warranting corrective actions.

Table 7.1 on the next page shows the results of the multiple linear regression analysis to predict 21 st-century digital skills. To uncover differences between self-employed and employed workers, we added a dummy variable 'employment' to the model. Furthermore, we included the interaction effects for the independent variables in relation to employment. The independent variables explain the highest proportion of variance for communication expressiveness (39\%) and the lowest for information evaluation skills (11\%). Overall, the results show that the level of each 21st-century digital skill is explained by a different set of determinants.

Hypothesis 1 concerns the impact of ICT attitude and is partially supported. ICT attitude contributes positively to communication expressiveness and 
networking, collaboration and problem-solving skills. In the case of collaboration skills, ICT attitude is more important for self-employed compared to employed workers. Table 7.1 also shows that perceived ease of use contributes to multiple 21 st-century digital skills. Hypothesis 2 is supported except for communication contact-building and networking, collaboration and critical-thinking skills. The effect of perceived ease of use is strongest for self-employed workers in the case of information management and creativity skills. ICT self-regulation only contributes positively to communication expressiveness and creativity skills, offering partial support for hypothesis 3 .

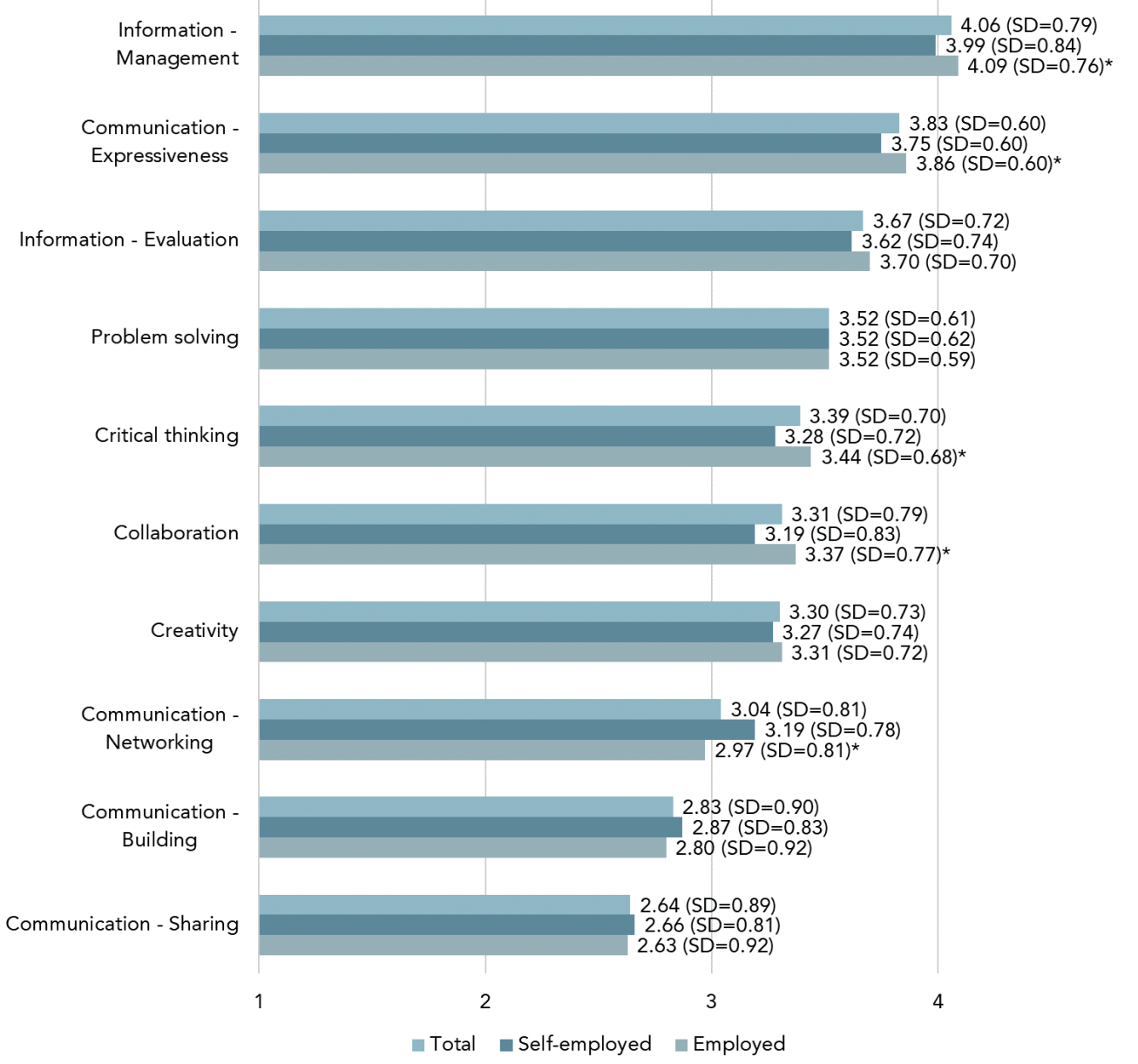

Figure 7.1 21st-century digital skill levels from highest to lowest mean scores Note: Asterisks $(*)$ mark significant differences $(p<.05)$ between employed and self-employed workers
Table 7.1 Regression analysis to predict 21st-century digital skills for workers

\begin{tabular}{|c|c|c|c|c|c|}
\hline & IM & IE & CE & CB & $\mathrm{CN}$ \\
\hline \multicolumn{6}{|l|}{ Gender (ref. Male) } \\
\hline Female & .01 & .04 & -.03 & .00 & .03 \\
\hline \multicolumn{6}{|l|}{ Age (ref. 18-35) } \\
\hline $36-50$ & .00 & -.04 & $-.12^{\star \star \star}$ & -.02 & .04 \\
\hline $51-65$ & .02 & -.02 & $-.07^{\star \star}$ & .00 & .02 \\
\hline $66+$ & .01 & .02 & .02 & -.02 & -.01 \\
\hline \multicolumn{6}{|l|}{ Education (ref. Medium) } \\
\hline High & .01 & .02 & -.01 & .02 & .02 \\
\hline ICT attitude & .01 & -.01 & $.13^{*}$ & .06 & $.13^{*}$ \\
\hline Perceived ease of use & $.36^{\star \star \star}$ & $.15^{\star}$ & $.29^{\star \star \star}$ & .06 & .00 \\
\hline ICT self-regulation & .04 & .10 & $.13^{\star \star}$ & .02 & .03 \\
\hline Self-directed learning & $.16^{*}$ & .09 & 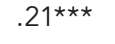 & .06 & .07 \\
\hline Learning goal orientation & -.03 & $.14^{*}$ & -.07 & .03 & .08 \\
\hline Performance goal orientation & -.06 & -.05 & .07 & .09 & $.17^{\star \star}$ \\
\hline Avoidance goal orientation & -.06 & -.04 & -.03 & .01 & .05 \\
\hline Personal initiative & .07 & -.05 & $.12^{\star \star}$ & $.17 * \star$ & $.14^{\star \star}$ \\
\hline \multicolumn{6}{|l|}{ Social support } \\
\hline Supervisor & -.06 & .01 & -.00 & .07 & .07 \\
\hline Colleagues & .04 & .00 & -.00 & .04 & .03 \\
\hline ICT Services/helpdesk at work & .01 & .08 & .02 & .10 & -.06 \\
\hline External ICT Services/helpdesk & $.14^{\star \star}$ & .04 & -.00 & .06 & .03 \\
\hline Family/friends outside work & .04 & .05 & -.00 & .01 & .00 \\
\hline Internet contacts/persons online & .07 & .04 & .04 & $.14^{\star \star}$ & $.10^{\star \star}$ \\
\hline $\mathrm{ICT}$ training & -.02 & .10 & .02 & $.15^{\star *}$ & $.14^{\star}$ \\
\hline \multicolumn{6}{|l|}{ Employment (ref. Self-employed) } \\
\hline Employed & $.15^{\star \star}$ & -.04 & -.35 & .20 & .01 \\
\hline ICT attitude * Employed & -.13 & .11 & .03 & -.13 & -.20 \\
\hline Perceived ease of use * Employed & $-.98^{\star \star \star}$ & -.01 & .36 & -.36 & -.37 \\
\hline ICT self-regulation * Employed & .19 & -.12 & .04 & -.14 & -.13 \\
\hline Self-directed learning * Employed & -.24 & .16 & $-.66^{* *}$ & -.14 & -.02 \\
\hline Learning goal orientation* Employed & -.18 & -.57 & $.61^{\star}$ & 10 & .09 \\
\hline Performance goal orientation * Employed & .28 & .00 & -.25 & -.08 & -.06 \\
\hline Avoidance goal orientation * Employed & -.03 & .12 & .19 & 18 & .19 \\
\hline
\end{tabular}




\begin{tabular}{|c|c|c|c|c|c|}
\hline & IM & $\mathrm{IE}$ & CE & $\mathrm{CB}$ & $\mathrm{CN}$ \\
\hline Personal initiative * Employed & -.01 & $.54^{\star}$ & .09 & .38 & .38 \\
\hline \multicolumn{6}{|l|}{ Social support } \\
\hline Supervisor * Employed & .11 & -.05 & .02 & -.10 & -.08 \\
\hline Colleagues` Employed & -.01 & -.01 & .03 & .01 & -.00 \\
\hline ICT Services/helpdesk at work * Employed & .02 & -.07 & -.04 & -.04 & .08 \\
\hline External ICT Services/helpdesk * Employed & -.06 & -.07 & -.02 & -.05 & -.02 \\
\hline Family/friends outside work * Employed & -.07 & -.00 & -.00 & .00 & .02 \\
\hline $\begin{array}{l}\text { Internet contacts/persons online * } \\
\text { Employed }\end{array}$ & -.02 & .01 & -.00 & -.03 & .01 \\
\hline ICT training * Employed & .01 & -.07 & -.02 & -.06 & -.07 \\
\hline$R^{2}$ & .13 & .11 & .39 & .16 & .22 \\
\hline \multirow[t]{2}{*}{$F$} & $4.91^{\star \star \star}$ & $3.85^{\star \star \star}$ & $21.14^{\star * *}$ & $6.20^{\star \star *}$ & $9.01^{\star * \star}$ \\
\hline & CS & $\mathrm{COL}$ & CT & CREA & PS \\
\hline \multicolumn{6}{|l|}{ Gender (ref. Male) } \\
\hline Female & .04 & $-.07 * \star$ & $-.09 * \star$ & -.00 & $-.11 \star \star \star$ \\
\hline \multicolumn{6}{|l|}{ Age (ref. 18-35) } \\
\hline $36-50$ & .03 & $-.07 *$ & -.05 & $-.07 *$ & $-.13^{\star \star \star}$ \\
\hline $51-65$ & .03 & -.03 & -.05 & $-.10^{* *}$ & $-.17^{\star \star \star}$ \\
\hline $66+$ & -.01 & -.06 & -.04 & $-.06^{\star}$ & $-.09^{\star \star}$ \\
\hline \multicolumn{6}{|l|}{ Education (ref. Medium) } \\
\hline High & .00 & $.06^{*}$ & .04 & -.05 & -.04 \\
\hline ICT attitude & .06 & $.26^{\star \star \star}$ & .04 & .05 & $.15^{\star}$ \\
\hline Perceived ease of use & $.15^{\star}$ & .04 & .10 & $.16^{\star \star}$ & $.19 * \star$ \\
\hline ICT self-regulation & .02 & .04 & .05 & $.12^{\star}$ & .08 \\
\hline Self-directed learning & -.05 & $.15^{\star}$ & .05 & -.11 & .03 \\
\hline Learning goal orientation & -.01 & .00 & $.16^{\star}$ & $.27^{\star \star \star}$ & .06 \\
\hline Performance goal orientation & $.11^{*}$ & $.24^{\star \star \star}$ & $.20 * \star \star$ & $.12^{\star}$ & .02 \\
\hline Avoidance goal orientation & .01 & .01 & .01 & .10 & .01 \\
\hline Personal initiative & $.16^{* *}$ & .02 & .06 & .07 & -.04 \\
\hline \multicolumn{6}{|l|}{ Social support } \\
\hline Supervisor & -.01 & .08 & .04 & .08 & .06 \\
\hline Colleagues & .03 & $.11^{*}$ & .04 & .01 & .01 \\
\hline ICT Services/helpdesk at work & .04 & .04 & .02 & -.04 & -.08 \\
\hline
\end{tabular}

Table 7.1 Continued

\begin{tabular}{|c|c|c|c|c|c|}
\hline & CS & $\mathrm{COL}$ & CT & CREA & PS \\
\hline External ICT Services/helpdesk & .03 & .08 & .00 & .03 & -.02 \\
\hline Family/friends outside work & .02 & .02 & -.07 & .01 & .03 \\
\hline Internet contacts/persons online & $.13^{\star \star}$ & .03 & .02 & $.10^{\star}$ & $.12^{\star \star}$ \\
\hline $\mathrm{ICT}$ training & $.12^{\star}$ & .09 & .08 & $.13^{*}$ & .03 \\
\hline \multicolumn{6}{|l|}{ Employment (ref. Self-employed) } \\
\hline Employed & -.35 & .54 & .64 & -.08 & $-.83^{*}$ \\
\hline ICT attitude * Employed & -.11 & $-.61^{\star \star \star}$ & -.04 & .26 & -.25 \\
\hline Perceived ease of use * Employed & -.20 & -.06 & -.21 & $-.54^{\star}$ & .40 \\
\hline ICT self-regulation * Employed & .07 & -.14 & -.12 & -.22 & -.11 \\
\hline Self-directed learning * Employed & -.08 & -.22 & .05 & .15 & $-.56^{\star}$ \\
\hline Learning goal orientation* Employed & .44 & .49 & -.37 & -.06 & .30 \\
\hline Performance goal orientation * Employed & .04 & $-.36^{\star}$ & -.18 & -.04 & .07 \\
\hline Avoidance goal orientation * Employed & .16 & .13 & -.05 & .14 & .18 \\
\hline Personal initiative * Employed & -.11 & .29 & .32 & $.47^{\star}$ & $.66^{\star \star}$ \\
\hline \multicolumn{6}{|l|}{ Social support } \\
\hline Supervisor * Employed & .02 & -.09 & -.06 & -.06 & .01 \\
\hline Colleagues ${ }^{\star}$ Employed & .00 & .01 & -.01 & .03 & .08 \\
\hline ICT Services/helpdesk at work * Employed & .00 & -.04 & -.01 & .04 & .07 \\
\hline External ICT Services/helpdesk * Employed & -.04 & $-.09^{\star}$ & -.03 & -.06 & -.00 \\
\hline Family/friends outside work * Employed & -.00 & -.06 & .06 & .03 & -.01 \\
\hline $\begin{array}{l}\text { Internet contacts/persons online * } \\
\text { Employed }\end{array}$ & -.02 & .02 & .04 & .00 & -.00 \\
\hline ICT training * Employed & .12 & -.06 & -.08 & -.12 & .06 \\
\hline$R^{2}$ & .15 & .20 & .17 & .26 & .28 \\
\hline$F$ & $5.75^{\star \star \star}$ & $8.12^{\star \star \star}$ & $6.68^{\star \star \star}$ & $11.35^{\star \star \star}$ & $12.50^{\star \star \star *}$ \\
\hline \multicolumn{6}{|c|}{ 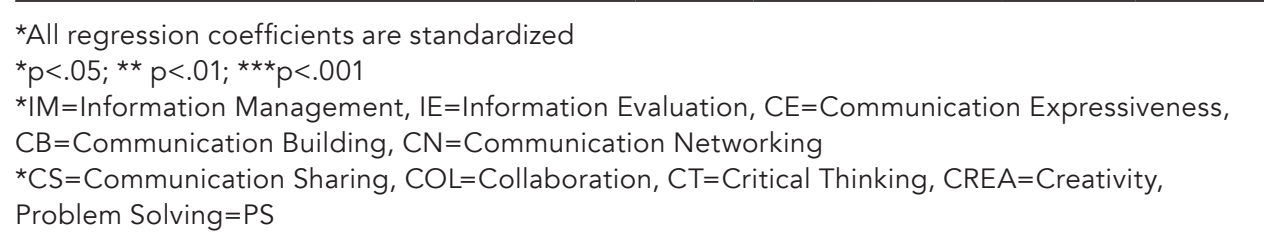 } \\
\hline
\end{tabular}


Self-directed learning contributes positively to the level of information management, communication expressiveness and collaboration skills. For communication expressiveness, it is relatively more important for self-employed workers. Self-directed learning furthermore emerges as significant contributor to problem-solving skills for self-employed workers. Hypothesis 4 is partially supported. The results also offer partial support for hypotheses 5 and 6 . Learning goal orientation contributes positively to information evaluation, critical-thinking and creativity skills. A person who looks for opportunities to develop new skills and enjoys challenging tasks is especially a strong predictor for digital creative skills. Learning goal orientation furthermore emerges as significant contributor to communication expressiveness skills for employed workers. Performance goal orientation is accepted for communication networking and content-sharing, collaboration, critical-thinking and creativity skills. The contribution of showing your abilities and accomplishments remains stronger for self-employed professionals in the case of collaboration skills. Avoidance goal orientation did not contribute to any of the skills and hypothesis 7 is therefore rejected.

Personal initiative is an important determinant for communication expressiveness, contact-building, networking and content-sharing skills. For employed professionals, it is also relevant for information evaluation, creativity and problem-solving skills. Most 21st-century digital skills ask for a proactive working approach.

Regarding informal and formal support sources, we found a positive contribution for support from people online on communication contactbuilding, networking and content-sharing skills. Furthermore, this source of support contributes positively to creativity and problem-solving skills. Additionally, support from colleagues contributes positively to collaboration skills. These skills are also supported by an external helpdesk in the case of selfemployed workers. Furthermore, this source of support contributes positively to information management skills. Altogether, hypotheses 9 and 10 are partially supported.

Attending training about Internet applications and digital skills contributes positively to multiple 21 st-century digital skills. Hypothesis 11, concerning the positive contribution of training, is accepted for communication contactbuilding, networking and content-sharing, and creativity skills.

Hypothesis 12 is partly supported, as men outperform women in collaboration, critical-thinking and problem-solving skills. Age contributes negatively to communication expressiveness, collaboration, creativity and problem-solving skills. Hypothesis 13 is partially supported. Finally, hypothesis 14 , concerning the level of educational attainment, is only accepted for collaboration skills.

\subsection{DISCUSSION}

7.5.1 Main findings

A first noteworthy result is that the levels of all skills vary substantially. The scores on communication content-sharing and contact-building seem to be relatively low. These skills are, for instance, supported by ICT-related training; offering support for a potential practice targeting skill improvement at the same time. While the level of information management skills seems relatively high, the findings suggest that overall the levels of all 21st-century digital skills are mediocre. This finding calls for further examination, as the skills investigated should be considered highly important for workers within creative industries. Excellent communication and networking skills are basic requirements (Carey \& Naudin, 2006). Considering that our sample is, in general, highly educated, this is also worrisome for other workers, as 21 st-century digital skills will be increasingly important for all workers in all industries.

Perceived ease of use, performance goal orientation, and support from internet contacts are prominent factors determining the level of 21st-century digital skills. In line with previous findings, perceived ease of use supports the development of digital skills (Heerwegh et al., 2016). From our findings, we conclude that perceived ease of use not only predicts basic technical skills but also content-related digital skills. Another prominent result is that help from Internet contacts or persons online is the most important support source determining the level of 21st-century digital skills. This is contrary to the common finding that mainly formal support sources assist in difficulties with content-related digital skills (Van Deursen, Courtois, \& Van Dijk, 2014). Based on our findings, help from colleagues only contributes to the development of collaboration skills. A possible explanation for this finding might be that formal training eliminates the effect of other formal support sources such as a supervisor or colleague. This suggests that training efforts might reduce the number of difficulties experienced online and thereby reduces the need to ask the ICT service desk or colleagues for help. Furthermore, the results highlight that performance goal orientation not only predicts social and creative skills 
offline (e.g., Huang, 2016; Liu, Wang, \& Yao, 2017) but also several 21st-century digital skills.

The results reveal several differences between employed and self-employed workers. For example, personal initiative is of importance for both, but particularly for employed professionals in the case of information evaluation, creativity and problem-solving skills. They need the ability and willingness to go beyond narrow task requirements and to approach work proactively by showing initiative (Den Hartog \& Belschak, 2007; Frese et al., 1997). The initiative concept seems very interesting, as it shares a central argument with recent learning theories that view learning as an active process (Hetzner, Heid, \& Gruber, 2012). A possible explanation for why personal initiative is relatively more important for employed workers might be that the degree of initiative for self-employed workers is likely to be higher (Frese, 1995). Self-employed workers have no superior and have to self-start their actions (Frese et al., 1997). They are not always able to delegate tasks and responsibilities to someone else.

Overall, an important conclusion from this chapter is that the level of each 21 st-century digital skill is explained by a unique set of determinants. From Chapter 5 we know that the analyzed skills have a sequential nature, which means that a person who lacks one type of skill is also likely to lack another. Our results highlight another barrier to skill development, as the proposed skills vary due to the different individual background variables. Not only does the development of each skill asks for a specific order in which they should be learned, it also requires accounting for a different set of determinants. Self-directed learning, for instance, contributes to the level of information management, communication expressiveness and collaboration digital skills, but does not have an impact upon other communication skills, creativity, criticalthinking or problem-solving digital skills. This has implications concerning the development of policies that target skill improvement. The development of each 21 st-century digital skill asks for a unique approach. A thorough understanding of the factors that affect the development of skills at the level of the individual worker is important for designing appropriate initiatives.

7.5.2 Limitations and future research directions

First, the generalizability of the results is limited to professionals working within creative industries in the Netherlands. Future research may further examine whether present findings can be applied to other work contexts and to creative industry professionals in other countries. Nonetheless, creative industries bring together a combination of creative content and ICT skills (Bakhshi, Freeman, \& Higgs, 2012) and, therefore, serve as a suitable context for investigating the determinants contributing to the level of 21 st-century digital skills aimed of knowledge workers.

The 21st-century digital skills are measured using a self-reported method. Self-reported measures may not reflect the actual individuals' skill levels, since this can lead to overrated or underrated skills (Talja,_2005). Surveys are useful methods to quantify potential determinants on large samples but not to draw conclusions about absolute levels of performance. Relevant here is also the debate on the type of scales (e.g., agreement versus frequency) that best reflect actual skills (see for example Van Deursen, Helsper, \& Eynon, 2016) The best way to address the limitations of self-reports is conducting observational studies in which actual performances are measured (Hargittai, 2005, Talja, 2005; Van Deursen \& Van Dijk, 2011a); however, they are labor-intensive and more difficult to replicate on large samples. Nevertheless, a useful contribution would be to subject participants to online tasks to test their range of 21 st-century digital skills. This limitation is addressed in Chapter 8, because here we measure various 21 st-century digital skills by means of a performance test.

Although ICT-training emerges as a prominent determinant, based on our results it is not clear whether the person attended an ICT-related training via the organization, via self-study or via their own initiative. Furthermore, it is not clear if the person followed a technically-oriented skills training (e.g., learning a software program) or a training focused on content-related skills (e.g., learning how to collaborate effectively and respectfully). Future research is encouraged to look into the specific context in which a person attended the ICT-related training. Additionally, it might be worthwhile to investigate the qualitative aspects of support and training by measuring a person's satisfaction level after asking for help and the reasons for not attending ICT training

Finally, multiple determinants that can be influenced by the users of the technologies themselves, as well as by policy makers, educators and managers in organizations, are accounted for. However, this study only includes mental resources (having the technical ability and motivation) and social resources (having a social network to assist in the use of digital media). According to the resources and appropriation theory, future research could also include temporal (e.g., time to use digital media), material (e.g., possessions and income) and cultural (e.g., cultural beliefs, norms and values) resources to explain differences in skill levels. 


\subsection{CONCLUSION}

Despite the near consensus that there is a rising demand for 21st-century digital skills (information, communication, collaboration, critical thinking, creativity, and problem solving), the research often neglects to examine a broad spectrum of skills and determinants beyond the sociodemographic and socioeconomic factors. This chapter provides empirical evidence to further our understanding of the determinants contributing to the level of these skills. Various mental and social resources are included to explain differences in people's 21st-century digital skill levels. In the next chapter, we develop a performance test to measure the level of 21st-century digital skills.

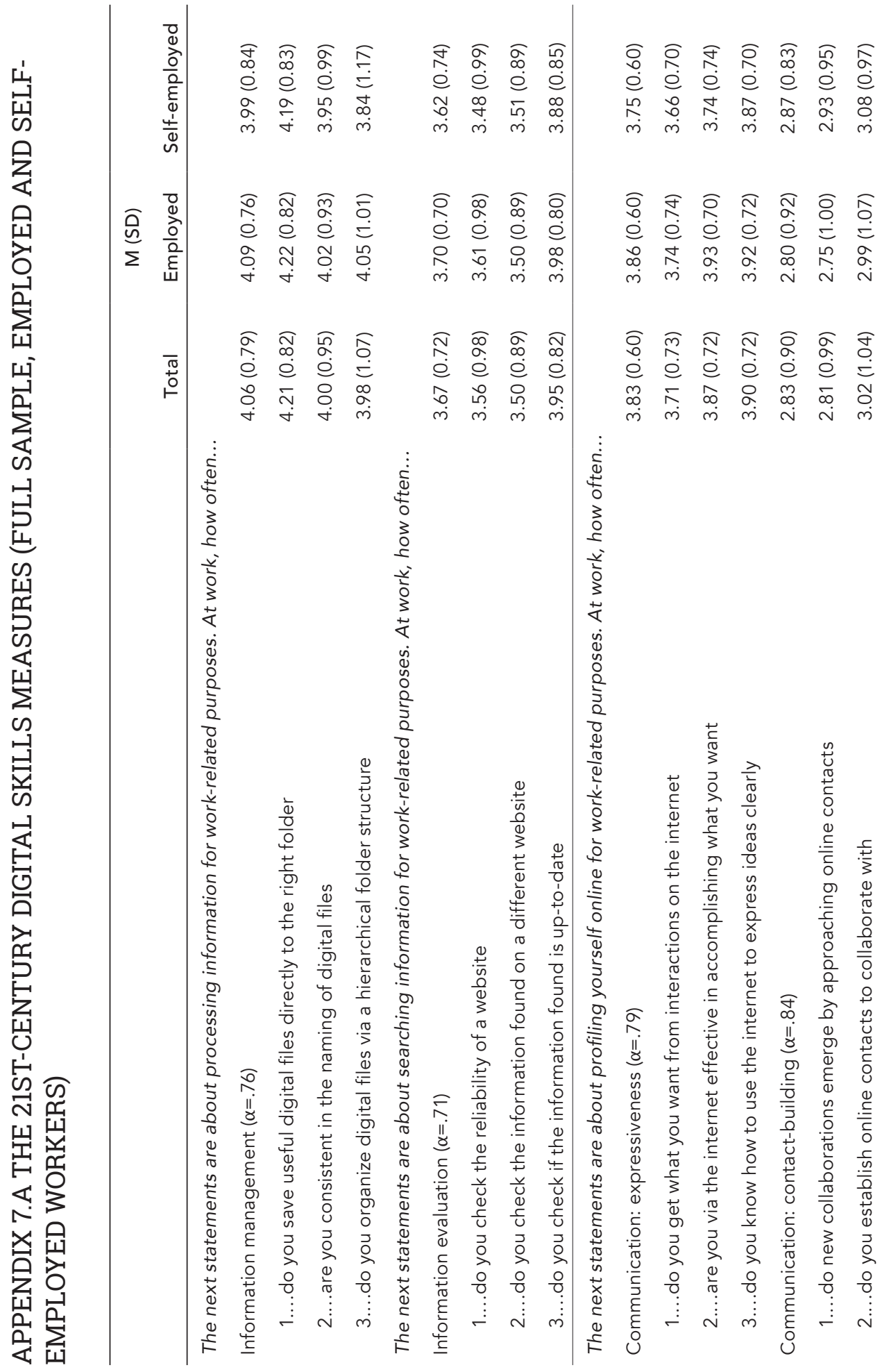




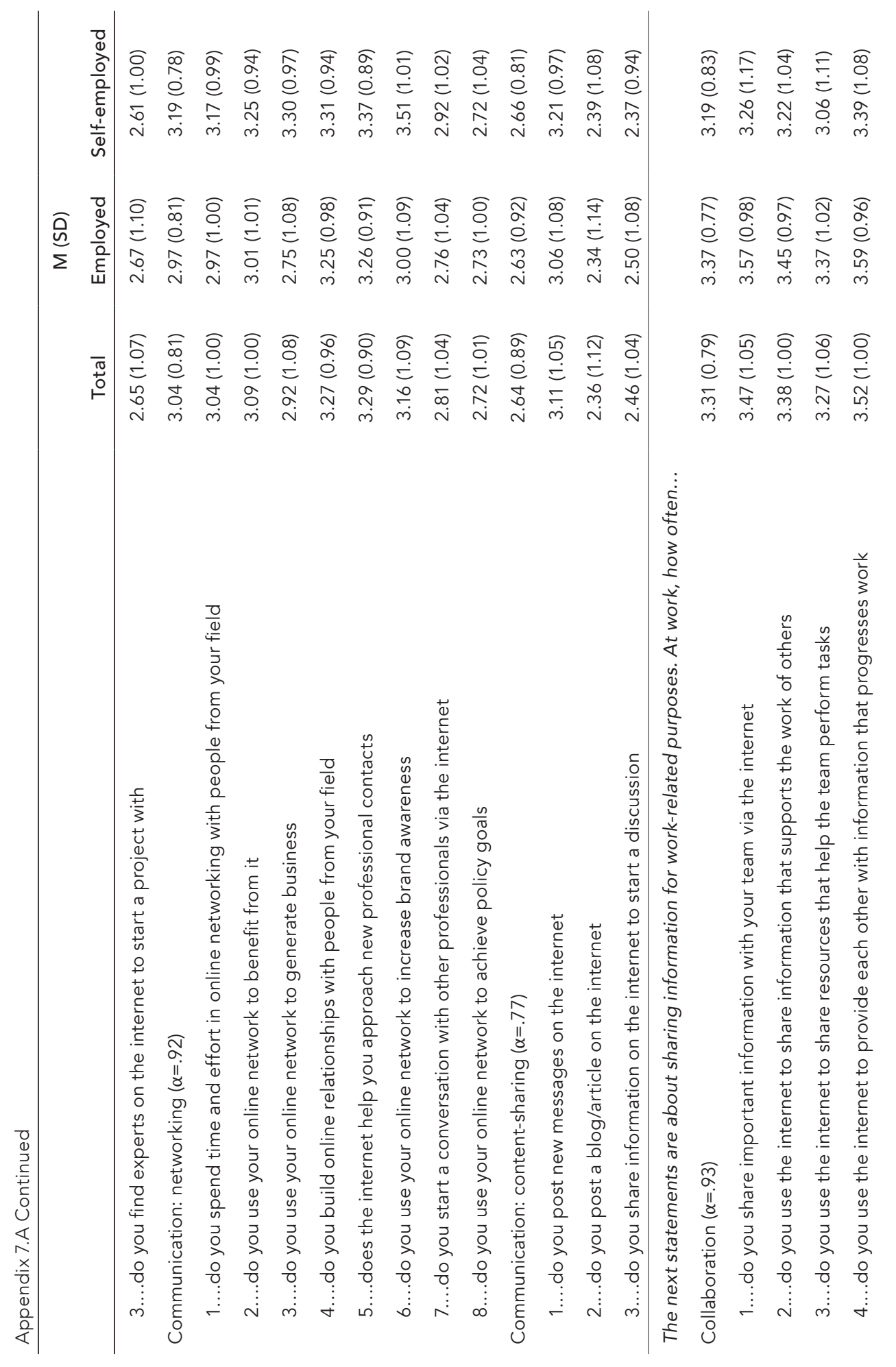

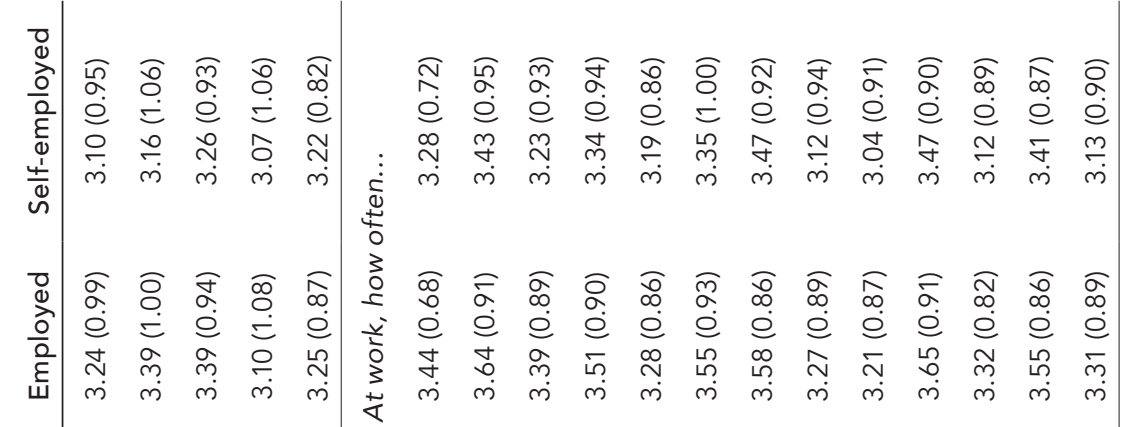

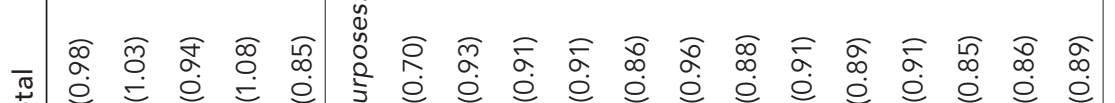

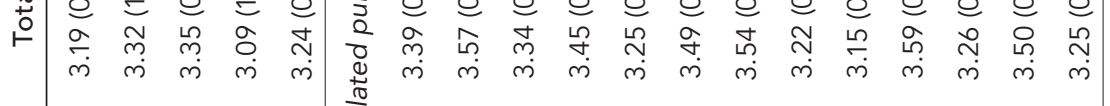

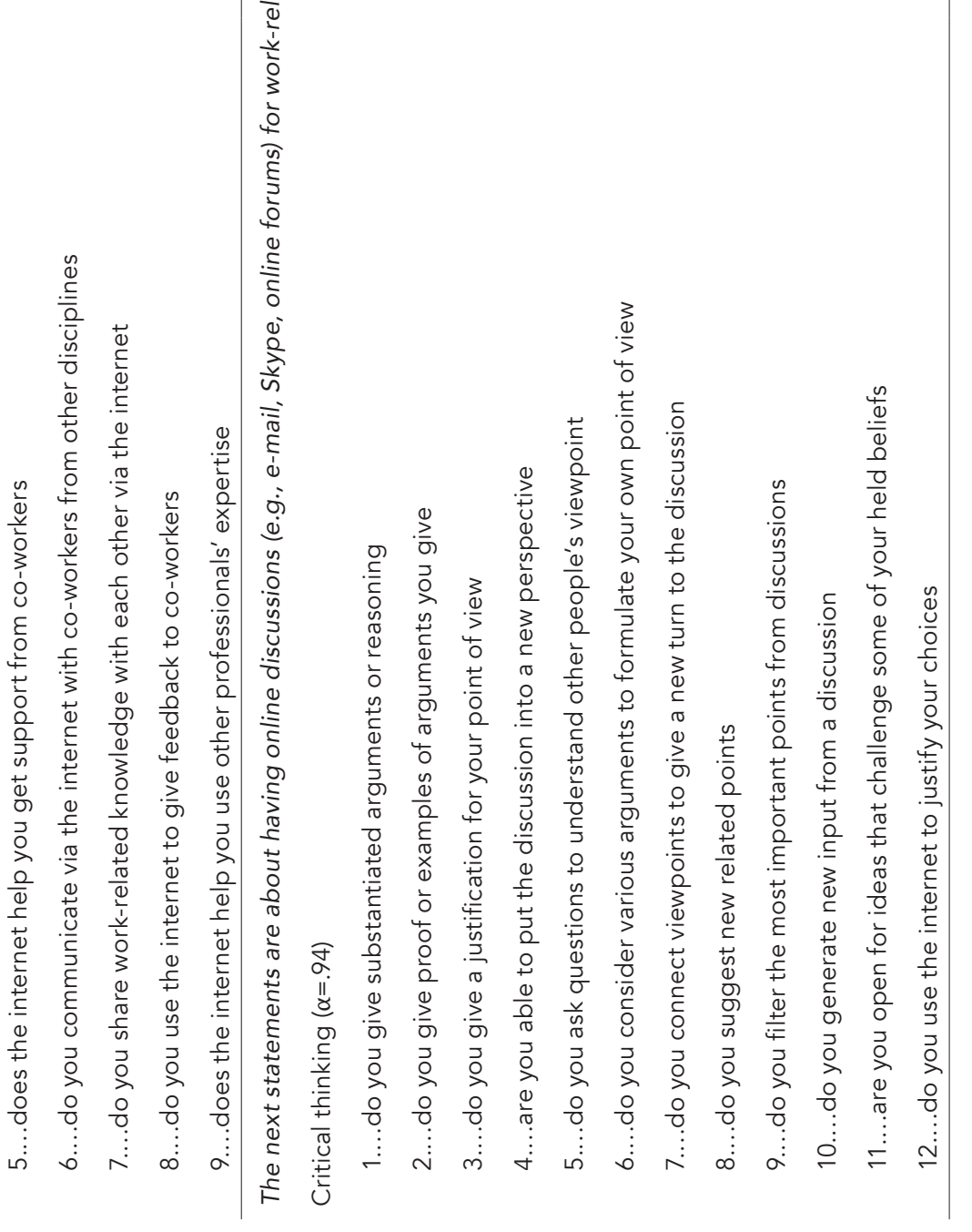



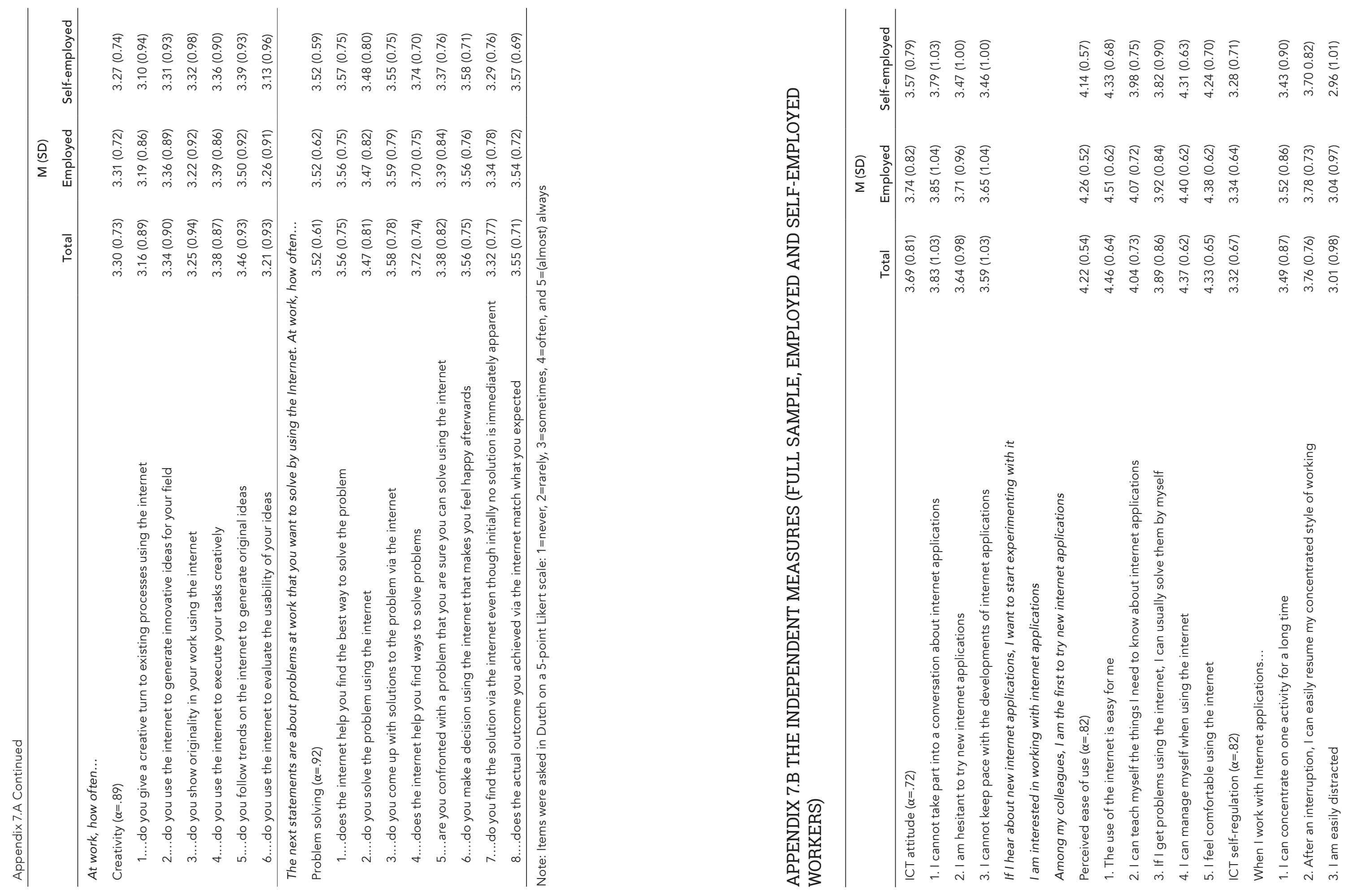

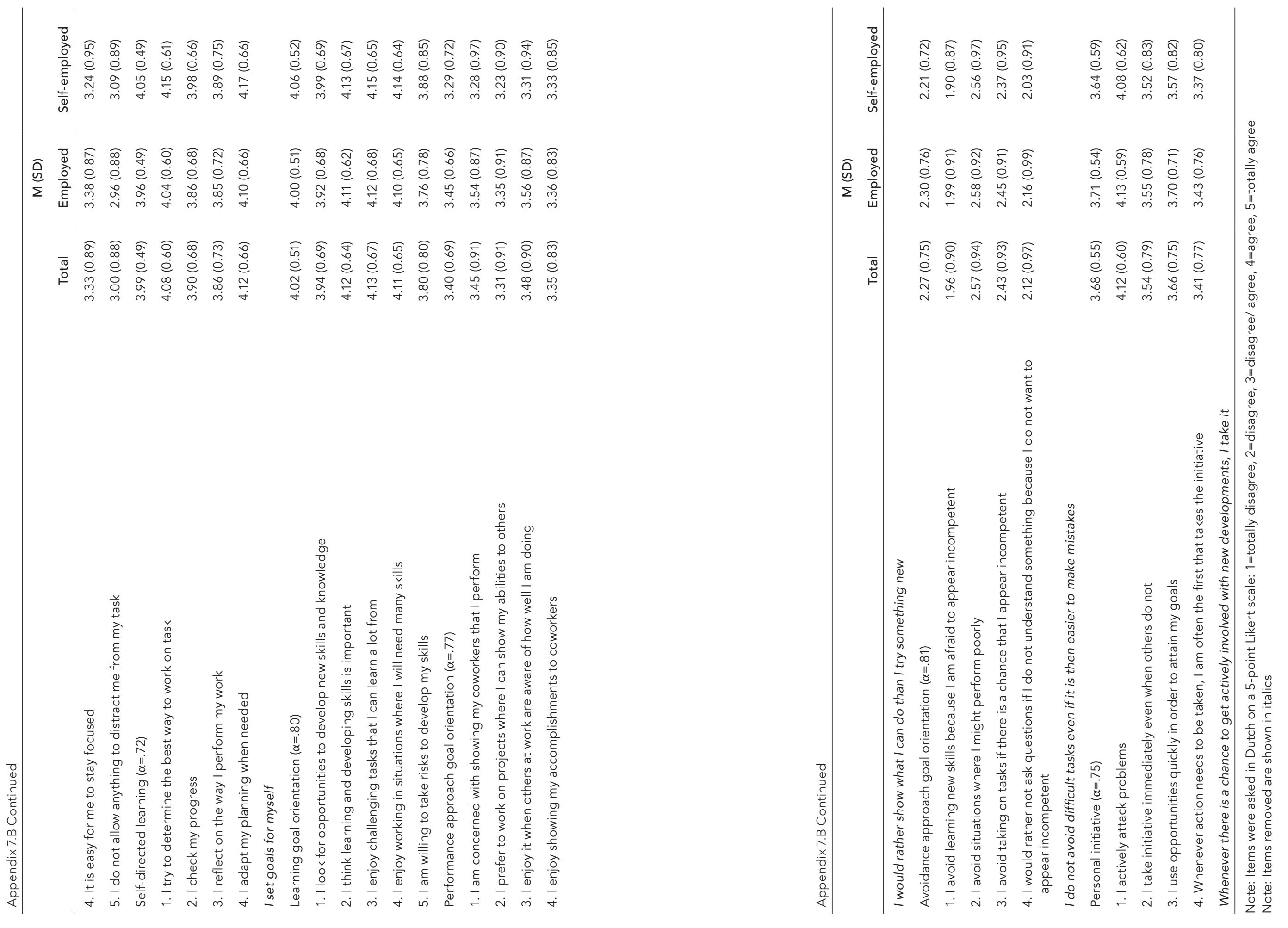


\section{CHAPTER 8}

MEASURING THE LEVELS OF 21ST-CENTURY DIGITAL SKILLS AMONG WORKING PROFESSIONALS:

\section{A PERFORMANCE-BASED APPROACH}

The main aim of this chapter is to measure working professionals' actual levels of 21st-century digital skills. Therefore, the levels of the following four types of 21st-century digital skills were examined by means of a performance test: information, critical-thinking, creativity, and problem-solving skills. Authentic tasks were developed for each skill and were performed by professionals working within the creative industries $(\mathrm{N}=87)$. As a result, one observational test directly measured a refined set of indices for each skill. The results reveal that the participants have most difficulties with digital information evaluation and problem-solving skills. For example, the participants rarely checked thei answers on another website or provided multiple solutions with an explanation. The results contribute to determining detailed skill indices related to the differences in working professionals' digital skill levels. 


\subsection{INTRODUCTION}

The 21st-century workforce requires workers who can search for relevant information, justify their choices, generate innovative and worthwhile ideas for their fields, and find solutions to the problem in digital environments (e.g., Şendağ \& Odabaşı, 2009; Yang, 2015). This chapter focuses specifically on the following 21st-century digital skills: information, critical-thinking, creativity, and problem-solving skills. These skills are c0onsidered highly important, as work is increasingly knowledge-based and performed in digital environments (e.g., Ananiadou \& Claro, 2009; Silva, 2009; Voogt \& Pareja Roblin, 2012). To accurately assess levels of digital information, critical-thinking, creativity and problem-solving skills, objective measurements are needed. Communication and collaboration digital skills are not included in this study because social interaction is required to measure these skills. In addition, to observe or test the performance of four digital skills is already a highly labor-intensive process (Van Deursen \& Van Diepen, 2013). Most studies measure digital skills by using large-scale surveys in which respondents must estimate their own skill levels. Self-reports have significant validity problems (Merritt, Smith, \& Renzo, 2005). Ideally, the levels of digital skills should be derived from actions performed online. The question then is how to obtain a direct observation of performance on digital information, critical-thinking, creativity and problem-solving skills with tasks or assessments. Especially creative and critical-thinking digital skills are seldom measured in performance tests (see Chapter 6). This study explores how to measure skills by means of a performance test with a task-based approach. The following research question is addressed:

1) How to measure the level of digital information, critical-thinking, creativity and problem-solving skills by means of a performance test?

The main contributions of this chapter are that (1) the study involves the measurement of a broader range of 21st-century digital skills and (2) the skills are actually performed by professionals working within the creative industries. The creative industries are strongly linked to knowledge-intensive activities (Bontje, Musterd, Kovács, \& Murie, 2011) where ideas or knowledge function as commodities (Anderson, 2008). Technological developments, knowledge creation and innovation are at the core of their work activities (Müller, Rammer, \& Trüby, 2009) and the four types of 21st-century digital skills (information, critical-thinking, creativity, and problem-solving skills) are important assets for professionals working within the creative industries.

\subsection{THEORETICAL BACKGROUND}

This section provides an in-depth discussion of information, critical thinking, creativity and problem solving, which can be considered core 21st-century digital skills for working professionals (see Chapter 2). The aim is to provide more details about the specific indices that each skill contains.

\subsubsection{Information digital skills}

Working professionals in a variety of domains rely upon information retrieval systems to gather information necessary to formulate policy, impart advice and make important decisions (Russell-Rose, Chamberlain, \& Azzopardi, 2018). Today, it is possible to access many resources on any subject through the Internet, which has created the need for information digital skills. Information digital skills consist of the skills to search, select and evaluate information online (Katz, 2007). Once the search system is chosen, workers need the skills to formulate search queries matching the information need. Defining the information need represents an awareness of the features of the required information (Çoklar, Yaman, \& Yurdakul, 2017; Zhang, Majid, \& Foo, 2010). A person must be able to formulate the correct search terms derived from a task or question (Aesaert \& Van Braak, 2015; Aesaert et al., 2015). The quality of the search terms directly affects the quality of the generated search results (Van Deursen \& Van Dijk, 2009). As today's knowledge society challenges people with overabundant information available on the Internet, it is also important for a person to be able to limit the number of search results when accessing information. The use of advanced search operators or Boolean searches can improve the precision of search results (Eastman \& Jansen, 2003; Willoughby, Anderson, Wood, Mueller, \& Ross, 2009). Furthermore, workers need the skills to select relevant websites from the result list (Willoughby et al., 2009) and subsequently read the requested information effectively. Finally, workers need the skills to evaluate whether information satisfies or fulfills the information need (Katz, 2007). The ability to identify subjective, biased or even false information has become a key issue (Eshet-Alkalai \& Chajut, 2009). Thus, the skills to check retrieved information on a different website is a key component of this skill. Altogether, the indices considered are (1) defining search queries, (2) selecting websites to seek information, (3) selecting information on websites or in search results, and (4) evaluating the information found. The skill indices are inspired by several researchers who conducted a performance test on information digital 
skills (Aesaert \& Van Braak, 2015; Eshet-Alkalai \& Amichai-Hamburger; Hargittai, 2002; Katz, 2007; Van Deursen \& Van Dijk, 2009).

\subsubsection{Critical-thinking digital skills}

In a digital age in which anyone may publish anything online, higher-order thinking skills such as critical thinking become especially important. The ability to present one's own point of view supported by arguments requires criticalthinking skills (Mulnix, 2012). Critical thinking includes self-disciplined thinking, during which an individual assesses, synthesizes and interprets relevant information that is associated with a situation (Hyytinen, Toom, \& Postareff, 2018). A worker needs the skills to see both sides of an issue and to reason independently of prior beliefs (West, Toplak, \& Stanovich, 2008; Willingham, 2008). One way to justify arguments is through the use of examples. The Internet provides people with opportunities to engage in critical-thinking processes, such as seeking alternatives and considering other points of view. Furthermore, a person can demonstrate critical thinking by being able to perceive a situation from a new perspective (Choy \& Cheah, 2009). A worker needs the skills to assess the strength of argumentation and the reasons that are relevant to the particular context. Finally, critical thinking involves the careful acquisition and interpretation of information to reach a sound conclusion or answer. Ennis (1993) argued that reflective thinking is an essential component; critical thinking is about "reasonable, reflective thinking that is focused on what to believe or do" (p. 180). Thinking critically is defined as a process that enables an individual to make an informed decision about conflicting claims (Ennis, 1991). One needs to carefully and deliberately determine whether to accept, reject or suspend judgment about a claim (Moore \& Parker, 2007). In addition, Nussbaum and Schraw (2007) emphasize that effective argumentation includes not only considering counterarguments but also weighing and combining the arguments to support a final conclusion. Therefore, effective argumentation involves the analysis of alternatives in relation to one's aims and the justification of a conclusion. In this study, the scoring criteria of Newman, Webb, and Cochrane (1995) are used to assess critical thinking skills. In line with the above-stated research, the indices considered are (1) justification, (2) breadth of understanding, and (3) critical reflection.
8.2.3 Creative digital skills

Workers' digital creativity is considered key to success in today's competitive and dynamic environment. Creative digital skills are defined as the use of information technology to encourage the creative process by looking at tasks from a new perspective or by forming new combinations of existing ideas (Chung, Lee, \& Choi, 2015). The growth and diversification of online participatory platforms has led to a significant proliferation of creative activity in the digital context (Literat \& Glaveanu, 2018). Workers can use the Internet as a participatory platform to directly engage the public in the creation of work (Henriksen, Mishra, \& Fisser, 2016; Literat, 2012). The use of digital technology provides an appealing means of creative self-expression (Hoffmann, Ivcevic, \& Brackett, 2016). Digital environments support creativity at two different levels, namely, the generation of creative ideas and the design of creative products, processes or services (Greene, 2002). In the era of wikis, social networks and user-generated content platforms, workers can easily access external ideas (Füller, Hutter, \& Faullant, 2011). Access to new and diverse online information as a source of creativity may enhance employees' generation of ideas (Oldham \& Da Silva, 2015). Workers who have access to a variety of alternatives or examples of potentially relevant ideas are more likely to make connections that could lead to creativity (Amabile, Conti, Coon, Lazenby, \& Herron, 1996). Moreover, technological change is driven by individual creativity and in turn provides new contexts and tools for creative output (Henriksen et al., 2016). Individuals may extend the available opportunities offered by digital tools to further broaden the design space. Here, the main focus is on generating ideas rather than, for instance, designing software tools. The skill of generating ideas is valued across a variety of occupations and industries. Idea generation - also referred to as divergent thinking, refers to the process of generating numerous original ideas for a given topic or problem (Guilford, 1967; Pásztor, Molnár, \& Csapó, 2015). As originality is often defined in terms of unusualness or infrequency, an idea is original if it is proposed by one or very few individuals (Runco, 1993). In the context of creativity at work, novelty is not enough; ideas must also be useful to be considered creative (Zhou \& George, 2003). In this study, creativity is assessed in terms of (1) fluency (the number of ideas) and (2) originality (the infrequency of ideas). A precondition is that the developed ideas are useful and thereby apply to a particular context. The skill indices are inspired by the Torrance test of creative thinking (Torrance, 1968). 


\subsubsection{Problem-solving digital skills}

Problem-solving skills help individuals and teams acquire and apply knowledge that is needed to solve complex problems at work (Mainert, Niepel, Murphy, \& Greiff, 2018). Given an increase in the number of jobs that require employees to solve complex problems in real time and a corresponding decrease in the number of jobs that involve executing well-defined organizational practices and routines, problem-solving skills are likely to grow in importance (Autor, Levy, \& Murnane, 2003; Neubert, Mainert, Kretzschmar, \& Greiff, 2015). In light of the widespread reliance upon the Internet as an information repository, the effective use of online information is crucial to generating valid solutions for the problem (Laxman, 2010). Problem-solving digital skills consist of the skills to use ICTs to analyze a problem situation and the use of this knowledge in finding a solution to the problem. Solving problems involves both the acquisition and the application of new knowledge in situations that must be actively explored to find and apply a solution (Mainert et al., 2018). Workers needs the skills to represent the problem, explore potential solutions to the problem, and justify the solutions to decide which best fits their goals (Çevik, 2015). The ease with which a problem can be solved often depends on the quality of the available problem representations (Slof, Erkens, Kirschner, \& Helms-Lorenz, 2013). Therefore, the skill to generate meaningful problem representations by integrating the information in a given situation is of decisive importance. Furthermore, successfully solving complex problems involves actively engaging in a process of making sense of the knowledge domain in question by considering multiple perspectives of the problem (Slof, Erkens, Kirschner, Jaspers, \& Janssen, 2010). The opportunity to exchange or combine knowledge from multiple online sources can foster the problem-solving process. Finally, since problem solvers select the solution(s) from a group of many possible solutions, they must justify the selected solution by defending it against other alternatives (Chen, 2010). In line with the above stated, the indices of problem-solving skills refer to the extent to which someone is able to identify, provide and explain possible solutions (Kauffman, Ge, Xie, \& Chen, 2008). In this study, the assessment is focused on (1) the identification of the problem, (2) the provision of appropriate solutions, and (3) the explanation of solutions.

\subsubsection{Measuring digital skills}

The most commonly employed method to measure digital skills is surveys. In surveys, measurements are mostly directed toward self-reported measures of ICT self-efficacy and digital skills (Hargittai, 2005, Van Deursen \& Van Dijk 2011a). Self-efficacy is an individual's belief in his or her capacity to perform certain Internet actions to produce a given goal (Eastin \& LaRose, 2000). Selfefficacy is not a measure of skill; rather, this type of question captures what individuals believe they can do with the skills they possess. To measure digital skills, in most cases, people are presented with a list of skills and are asked to evaluate how well they perform those skills. The advantages of self-reported surveys are the ability to present a large number of questions on a wide range of skills in a short time, simple scoring and cost effectiveness (Kuhlemeier \& Hemker, 2007). Although these measures are useful for investigating selfperceived skills within large samples, they are less appropriate for measuring actual digital skill levels. It is well known that measures that are based on people's own judgment have significant problems of validity because of the misalignment between perceived and actual skills (e.g., Bunz, Curry, \& 2007; Hargittai, 2005; Merritt et al., 2005; Litt, 2013). For example, men and younger people tend to overestimate their skill levels (Van Deursen \& Van Dijk, 2011a).

A few scholars have incorporated observational or performance-based assessments of Internet users' skills. For example, Hargittai (2002) conducted one of the first performance-based studies in which she observed participants' abilities to find several types of information online. Eshet-Alkalai and AmichaiHamburger (2004) carried out another pioneering performance-based study They designed tasks for various age groups aimed at testing digital literacy skills. The authors argued that digital literacy skills involve more than the ability to use software or operate a digital device. They conducted a taskbased assessment in which each task assessed one of the following digital skill dimensions: photovisual literacy, reproduction literacy, information literacy, branching literacy, and socioemotional literacy. Comparably, Van Deursen and Van Dijk (2008) developed performance tests of operational, formal, information and strategic Internet skills. Moreover, the research often has been conducted to measure the actual levels of digital skills possessed by pupils or students. For example, Aesaert, Van Nijlen, Vanderlinde, and Van Braak (2014) used a performance-based ICT competence test to measure pupils' actual proficiency in digital information processing and communication. Although observations and performance-based measures have higher validity, they are also time consuming, expensive and difficult to conduct with large samples (Aesaert \& Van Braak, 2015). To overcome some of these limitations, scenario-based performance tasks have been established in which students solve information 
problems using simulated software such as email, web browser or presentation software (Katz, 2007). Scenario-based performance tasks can be completed online by a larger sample. However, a characteristic of this approach is that it requires questions with one answer or solution; therefore, skills such as critical thinking and creativity are inappropriate for this method.

Performance-based tests using authentic tasks are considered the most valid method of measuring digital skills. Although the above-stated performancebased studies have great scientific value, they primarily focused on pupils, students or citizens. Furthermore, the available performance tests mainly address basic technical, information and problem-solving skills. Our study contributes to the existing literature by conducting a detailed performance test aimed at measuring a broader range of digital skills among professionals working within the creative industries. A unique combination of the levels of four digital skills (information, critical thinking, creativity, and problem solving) were measured in the labor context. An authentic performance test with a refined set of indices per skill was developed to provide a detailed analysis of the skill levels.

\subsection{METHOD}

8.3.1 Assignments

A test was created with two parts. The first part consisted of tasks with the topic of 'crowdfunding'. Four tasks measured information skills and one task measured problem-solving skills. In the information tasks, the participants were asked to search for fact-based information with one correct answer. They were asked to search for (1) a specific type of crowdfunding, (2) a regulation for crowdfunding platforms that applies when companies can obtain a loan, (3) a tool for crowdfunding platforms to check whether a consumer's investment is justified, and (4) an investment rule for crowdfunding platforms. In the problem-solving task, a scenario was presented to the participants in which they had invested in a successful crowdfunding project but were faced with a payment default. The participants were asked to use the Internet to determine what actions they could have taken to prevent this situation. For successful completion, the task required several actions and an explanation. In the first part of the test, no time limits were imposed.

The second part of the test consisted of online tasks about the Internet of Things. One task measured creativity skills and one task measured critical- thinking skills. In the creativity task, the participants were asked to use the Internet to generate as many ideas as possible concerning Internet of Things applications that improve productivity at work. They had to mention the device and the corresponding application. The participants were given 10 minutes to complete this assignment. The creative task was adapted from Torrance test of creative thinking, primarily used to examine divergent thinking (Torrance, 1968). In the critical-thinking task, participants had to reflect on the statement: "The Internet of Things makes life easier, healthier and safer". The idea was for the participants to argue their own points of view with the help of information online. The participants were given 15 minutes to finish this critical-thinking assignment. They were allowed to finish early if they decided they had completed the assignment. For the second part of the test, large time limits were imposed to ensure participants had enough time to complete each task. At the same time, the maximum time for completion gave them an inclination of how much time they should spend on a task. For each task, the participants had to start a new search query. All tasks were pilot tested with nine participants to ensure comprehensibility and applicability. See Appendix 8.A for a complete overview.

\subsubsection{Participants}

The test was conducted among professionals working within the creative industries in the Netherlands. The participants were recruited by approaching respondents who had previously participated in the large-scale survey about 21st-century digital skills at work (see Chapter 7). Professionals who are directly involved in creative work processes (e.g., designers, engineers, and project managers) were included in this study. If they agreed to participate, they were contacted by phone to schedule a date and time for the research session. In total, 87 respondents participated in the performance test. The participants represented a large variety of professions, ranging from directors, project managers and producers to artists, designers and engineers. The sample characteristics are displayed in Table 8.1 on the next page.

\subsubsection{Procedure}

The performance tests were conducted from April 1 through August 15, 2018 Before the start of the assignments, informed consent was obtained from each participant. The participants had to accomplish assignments on the Internet. TeamViewer was used to view and record the participant's actions on the 


\begin{tabular}{|c|c|c|}
\hline & $\mathrm{N}$ & $\%$ \\
\hline \multicolumn{3}{|l|}{ Gender } \\
\hline Male & 45 & 51.7 \\
\hline Female & 42 & 48.3 \\
\hline \multicolumn{3}{|l|}{ Age } \\
\hline $18-30$ & 32 & 36.8 \\
\hline $31-45$ & 33 & 37.9 \\
\hline $46-60$ & 21 & 24.1 \\
\hline $60+$ & 1 & 1.1 \\
\hline \multicolumn{3}{|l|}{ Education } \\
\hline Medium & 5 & 5.7 \\
\hline High & 82 & 94.3 \\
\hline \multicolumn{3}{|l|}{ Branch organization } \\
\hline Advertising/marketing & 10 & 11.5 \\
\hline Radio/television & 10 & 11.5 \\
\hline Visual art/photography & 10 & 11.5 \\
\hline Architecture & 7 & 8.0 \\
\hline Graphic design & 7 & 8.0 \\
\hline Industrial design & 6 & 6.9 \\
\hline Journalism & 6 & 6.9 \\
\hline Performing art & 6 & 6.9 \\
\hline Museum & 6 & 6.9 \\
\hline New media/software & 5 & 5.7 \\
\hline Film & 4 & 4.6 \\
\hline Gaming & 3 & 3.4 \\
\hline Fashion/textile design & 3 & 3.4 \\
\hline Publishing/media & 2 & 2.3 \\
\hline Books/magazines & 2 & 2.3 \\
\hline
\end{tabular}

Internet remotely. The participants were asked to install TeamViewer on their computers before their scheduled appointments. On the date of the test, the participants were asked over the phone whether they had questions about the procedure. During the session, the researcher and participant stayed connected by phone or TeamViewer's chat function. If any problems or concerns arose, the participants had the option to contact the researcher directly. No questions related to the tasks were allowed. The tests took approximately 1 hour, and participants received an incentive of 20 Euros.

\subsubsection{Data analysis}

A coding scheme was developed based on the skill components as discussed in the theoretical background section. All components were double-checked by the researcher during the video recording analyses. See Appendix 8.B.

\subsection{RESULTS}

8.4.1 Information digital skills

Table 8.2 provides an overview of the information-related skill indices grouped by the participants who correctly and incorrectly answered the tasks. Of the participants, $15 \%$ correctly answered task 1, 25\% task 2, 62\% task 3, and 79\% task 4 . The participants who answered the tasks correctly spent more time on the first task but less time on the subsequent tasks than the participants who answered incorrectly. The results show that participants who answered incorrectly on a task conducted more search queries. Often, they searched for information with a whole sentence or question instead of using keywords. For all tasks, the participants with incorrect answers more often selected irrelevant websites, while those with correct answers more often selected relevant websites. More specifically, for participants who provided the correct answer, the first website they selected more frequently yielded the information of interest. The use of Boolean searches or advanced search methods were uncommon practices for all participants, as was the evaluation of retrieved information.

Concerning task 1, the participants from both groups had difficulties with directly formulating a search query emergent from the task. Multiple times, they formulated an appropriate search query later in the process. However $39 \%$ of the participants with correct answers and $51 \%$ with incorrect answers did not formulate a search query that combined 'crowdfunding' with 'types' or 
a synonym. Remarkably, $70 \%$ of the participants with incorrect answers actually looked at a webpage where the answer was visible. This finding shows that participants found it difficult to select information that was appropriate to the task. Furthermore, $62 \%$ of the participants with correct answers checked the retrieved information on another website. This evaluation strategy was less common for participants with incorrect answers (39\%).

Concerning task 2, the participants with correct answers more often formulated a search query emergent from the task (55\% compared to $39 \%$ ). Of participants with incorrect answers, 28\% (compared to 9\% of those with correct answers) did not formulate an appropriate search query at all. Furthermore, $46 \%$ actually visited a webpage where the answer was visible. The participants who answered this task correctly more frequently selected relevant hyperlinks on a website (86\% compared to $65 \%$ of participants with incorrect answers). Often they had to display more information on a website to find the answer. Finally, they more often checked the information on another website (23\% compared to $19 \%) ;$ however, the percentage was still low.

In task 3, only two participants (6\%) with incorrect answers directly used a search query emergent from the task (see Table 8.2). Additionally, for $67 \%$ of the participants, the answer was not visible on the webpages they visited. The average number of relevant websites selected was quite low. Remarkably, in this group, 39\% did not even select one relevant website. Furthermore, there was a large difference between the groups with respect to the percentage of participants who directly selected a relevant website (82\% of those with correct answers compared to $24 \%$ of those with incorrect answers). Finally, participants with correct answers more frequently used a new search query for the answer found (15\% compared to 6\%) and checked the information on another website (22\% compared to $0 \%$ ).

Regarding task 4, the percentage of correct answers was quite high (79\%). However, $21 \%$ did not find the correct answer. Of the participants with incorrect answers, 94\% were not able to formulate an appropriate search query. As a result, the percentage of participants who were able to directly select a relevant website was also quite low (17\%). A relatively high percentage in this group (67\%) did not select one relevant website. In both groups, checking the information (23\% of those with correct answers compared to $6 \%$ of those with incorrect answers) and using a new search query (12\% compared to $0 \%$ ) to evaluate the information found were rarely applied.

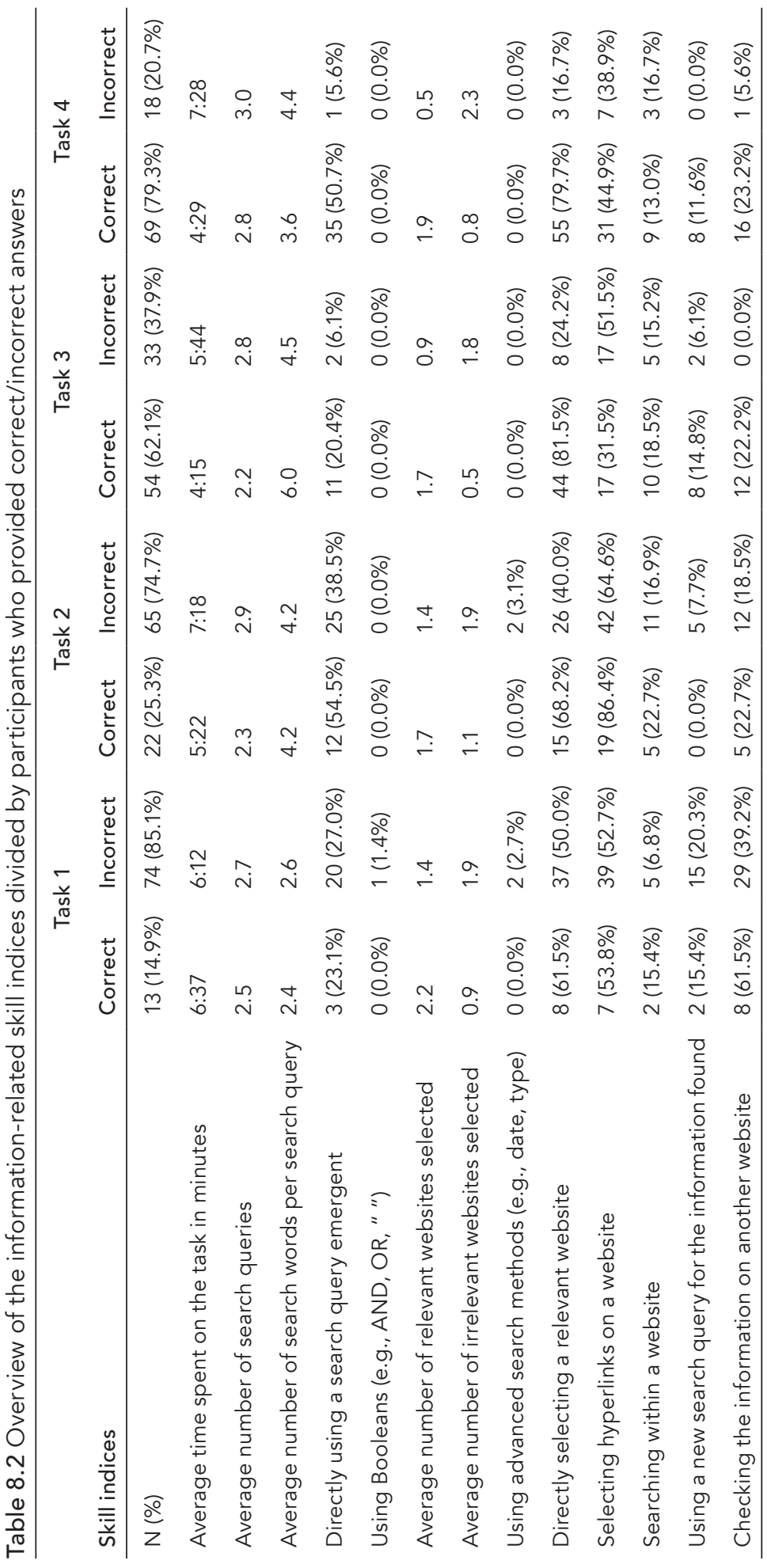




\subsubsection{Critical-thinking digital skills}

Table 8.3 shows that on average, the participants spent approximately twelve minutes justifying their points of view with the help of information found on the Internet. A relatively high percentage was able to provide arguments for multiple perspectives: $36 \%$ for two perspectives and $44 \%$ for all three perspectives (comfort, health, and security). A relatively high percentage (74\%) was also able to provide proof or examples for the arguments presented. Moreover, $46 \%$ of the participants provided positive and negative arguments for one or multiple perspectives. Furthermore, more than half of the participants (51\%) provided new perspectives. With regard to critical assessment, the participants often assessed their arguments (53\%) before they formulated a conclusion (64\%).

Table 8.3 Overview of the critical thinking-related skill indices $(\mathrm{N}=87)$

\begin{tabular}{ll}
\hline Skill indices & $\mathrm{N}(\%)$ \\
\hline Average time spent on the task in minutes & $11: 58$ \\
Argumentation & \\
$\quad$ Providing no arguments (-/) & $5(5.7 \%)$ \\
$\quad$ Providing arguments for one perspective (-) & $13(14.9 \%)$ \\
$\quad$ Providing arguments for two perspectives (+) & $31(35.6 \%)$ \\
$\quad$ Providing arguments for three perspectives (+/+) & $38(43.7 \%)$ \\
Proof/examples & \\
Providing no proof/examples for the arguments (-) & $23(26.4 \%)$ \\
$\quad$ Providing proof/examples for the arguments (+) & $64(73.6 \%)$ \\
Perspective-taking & \\
Not presenting both sides of a perspective (-) & $47(54.0 \%)$ \\
Presenting both sides of a perspective (+) & $40(46.0 \%)$ \\
Breadth of understanding & \\
Providing no new perspective (-) & $43(49.4 \%)$ \\
Providing a new perspective (+) & $44(50.6 \%)$ \\
Critical reflection & \\
Not assessing the arguments (-) & $41(47.1 \%)$ \\
Assessing the arguments (+) & $46(52.9 \%)$ \\
Not drawing a conclusion (-) & $31(35.6 \%)$ \\
Drawing a conclusion (+) & $56(64.4 \%)$ \\
\hline
\end{tabular}

8.4.3 Creative digital skills

Table 8.4 shows that, on average, the participants spent approximately nine minutes on the Internet to seek Internet of Things devices and applications. They proposed an average number of 3.7 devices and 4.7 applications to encourage productivity at work. In total, $24 \%$ proposed a device that was not mentioned by other participants. Additionally, $45 \%$ proposed a device that was mentioned three or fewer times, which could still be considered quite original. The most frequently mentioned devices were smartwatches, smartphones and smart lighting. Examples of original devices were apparel, a handheld text scanner and a virtual reality headset.

The participants had less difficulty inventing unique applications (48\%) than inventing unique devices. Additionally, 62\% devised an application that was mentioned three or fewer times. The most mentioned applications were focused on regulating temperature, turning on/off lights and stimulating movement. Original applications varied from those offering compliments and recognizing emotions to those training an employee, recording travel expenses and digitally transforming drawings.

\section{Table 8.4 Overview of the creativity-related skill indices $(\mathrm{N}=87)$}

\begin{tabular}{ll}
\hline Skill indices & $\mathrm{N}(\%)$ \\
\hline Average time spent on the task in minutes & $9: 12$ \\
Fluency & \\
$\quad$ Average number of devices & 3.7 \\
Average number of applications & 4.7 \\
Originality & \\
Proposing a device mentioned once & $21(24.1 \%)$ \\
Proposing a device mentioned three or fewer times & $39(44.8 \%)$ \\
Proposing an application mentioned once & $42(48.3 \%)$ \\
Proposing an application mentioned three times or fewer & $54(62.1 \%)$ \\
\hline
\end{tabular}

8.4.4 Problem-solving digital skills

Table 8.5 shows that, on average, participants spent approximately nine minutes on the Internet to seek solutions. They found an average of 2.2 solutions but only half of these solutions were accompanied with an explanation. Again, the participants had difficulties directly formulating a search query derived from 
the problem situation (39\%). Furthermore, one participant could not come up with any solution, $39 \%$ proposed one solution and $60 \%$ proposed multiple solutions. The number of explanations provided was rather low relative to the number of solutions proposed. In total, 35\% did not provide any explanation, $41 \%$ provided one explanation and $24 \%$ provided multiple explanations.

Table 8.5 Overview of the problem-solving-related skill indices ( $N=87)$

\begin{tabular}{ll}
\hline Skill indices & $\mathrm{N}(\%)$ \\
\hline Average time spent on the task in minutes & $9: 13$ \\
Problem representation & \\
Directly using a search query derived from the problem situation (+) & $53(60.9 \%)$ \\
$\quad$ Not directly using a search query derived from the problem situation (-) & $34(39.1 \%)$ \\
Solutions & \\
Average number of appropriate solutions & 2.2 \\
Proposing no solution (-) & $1(1.1 \%)$ \\
Proposing one solution (+/-) & $34(39.1 \%)$ \\
Proposing multiple solutions (+) & $52(59.8 \%)$ \\
Explanations & \\
Average number of explanations & 1.1 \\
Providing no explanation (-) & $30(34.5 \%)$ \\
Providing one explanation (+/-) & $36(41.4 \%)$ \\
Providing multiple explanations (+) & $21(24.1 \%)$ \\
\hline
\end{tabular}

\subsection{DISCUSSION}

\subsubsection{Main findings}

The contemporary economy requires workers who have the skills to use the digital environment to support information searching, critical thinking, creativity and problem solving. However, the assessment of these and other skills needed for the 21st century is limited (Voogt \& Pareja Roblin, 2012). Current assessments often do not successfully measure the actual digital skill levels and call for taskbased approaches (Siddiq, Gochyyev, \& Wilson, 2017). However, performance tests are scarce, especially related to creativity and critical thinking (see Chapter 6). This study outlines the development of a performance test pertaining to information, critical-thinking, creativity and problem-solving skills. A refined set of skill indices is proposed to provide an in-depth analysis of the skill levels. The observations below illustrate that it is possible to measure a broader range of digital skills actually performed by professionals working within the creative industries. The test results reflect working professionals' actual skills and does not rely on their own judgment. The proposed operationalizations can be adapted in future research to fit the sample.

A first observation concerning information digital skills is that participants rarely double-check the information they find online. This finding is in line with the previous research that shows that information seekers frequently do not spend time critically evaluating information they find online (Metzger, 2007). A possible explanation for this finding might be that they use heuristic cues that guide information evaluation while minimizing cognitive effort (Metzger, Flanagin, \& Medders, 2010). In general, information seekers must refine search queries quite often to find appropriate information. People often adjust their original search according to what they were able to find (Walraven, BrandGruwel, \& Boshuizen, 2008). In the present study, even if the correct answer was visible, the participants encountered difficulties with extracting the correct information. They found it difficult to accurately identify and define the information needed.

In relation to critical-thinking digital skills, the results were promising. The participants often provided arguments for multiple perspectives supported with proof or examples. In the critical thinking task, most participants were able to draw a conclusion but were not able to combine and translate the arguments into support for a final conclusion. It was most challenging for the participants to see and compare both sides of the arguments. To be a proficient critical thinker, it is necessary to have a certain detachment from one's own beliefs with a willingness to consider alternative viewpoints (Mulnix, 2012). One could argue that most people have insufficient skills to be actively open to new ideas, to be critical in evaluating these ideas, and to modify their thinking in light of convincing evidence (Sosu, 2013).

With regard to creative digital skills, the participants proposed multiple devices and applications within the time frame. The key to interpreting these findings is remembering that originality is vital for creativity (Runco et al., 2011). Although the participants were able to produce a large number of ideas, the ability to generate both common and original ideas was more difficult Nevertheless, a relatively large portion of the participants proposed devices 
and applications that were mentioned by not more than two other participants. Many participants from this group mentioned unique examples.

Finally, concerning problem-solving digital skills, a relatively small percentage of the participants were able to provide more than one solution accompanied by an explanation. This finding is worrisome because problemsolving skills are highly valued in today's workplace. Work is no longer defined by the possession of a specialty or technical ability but rather by the task or problem a worker and his or her team is trying to solve (Wagner, 2008). The low levels of problem-solving digital skills may be explained by the relatively high cognitive capacity that is necessary for this skill (Greiff, Kretzschmar, Müller, Spinath, \& Martin, 2014). Moreover, as problem-solving digital skills require a high level of information digital skills (see Chapter 5), another explanation might be that those who have low levels of information digital skills are also unable to use the online environment to come up with solutions.

The findings demonstrate the need to learn more about how the process of skill acquisition occurs within the workplace. Research needs to define and test detailed policy recommendations on how organizations can improve the skill levels of their workers. For example, some researchers favor courses and guided learning for skill development (Mossberger, Tolbert, \& Stansbury, 2003) while others propose learning by trial-and-error (Matzat \& Sadowski, 2012). As such, it is necessary to obtain contextual information and capture data from professionals working within the creative industries. For example, it could be useful to discuss practical solutions for skill improvements with managers responsible for skill development to be effectively incorporated into organizations. Policy recommendations should be aimed at helping working professionals acquire, maintain and improve their digital skills.

\subsubsection{Limitations and future research directions}

Eighty-seven professionals working within the creative industries participated in the current study. It is not possible to generalize the results. However, the aim was to deepen our understanding of the levels of four 21st-century digital skills. Due to the labor-intensive process, performance tests often involve only a small sample. Future research could look further into how to incorporate performance assessments in tests that also include more constructed response items. Another research direction could be to combine survey questions with more standardized performance-based assignments in one test.
Furthermore, this study is potentially limited by the topics of the assignments. Although we have developed realistic informational tasks, we do not know whether the topics might have, for example, affected the participants' motivation to complete the assignments. On the other hand, one could also argue that in a test situation, the pressure to succeed might be higher, and participants are therefore more willing to complete an assignment. Remarkably, participants scored relatively low on the first information skills assignment in comparison with the final assignment. Thus, the participants might need some time to familiarize themselves with the topic. During the development of the tasks, every effort was made to adhere to the skill indices. However, the results evidently depend on the difficulty of the proposed tasks. In future tests, more tasks should be developed, and other topics might be used to determine whether the same pattern of results occurs.

A final limitation to address is that digital communication and collaboration skills were not included in our performance test. Although we investigated the possibility to include social skills, they remain difficult to measure by means of a performance test because a form of social interaction is required. Overall, measuring 21st-century digital skills by means of a performance test is a complex task. Although this study builds upon the previously developed survey questions in Chapter 4, this does not lead to a simple translation to tasks. As a researcher you have to make a choice in the skill indices that can be incorporated in a task-based approach. For example, the item 'do you give proof or examples of arguments you give' can be more easily translated into an assessment criteria than 'do you communicate via the Internet with co-workers from other disciplines'. The assessment of social skills is even more complex and, therefore, future research could look into how to measure such skills by means of a performance test.

\subsection{CONCLUSION}

A strategy to objectively measure digital skill levels is by means of a performance test. This chapter proposes a performance test to measure a refined set of indices for information, critical thinking, creativity and problem-solving digital skills. The results are an important step forward in the exposure of detailed skill indices to provide a deeper analysis of working professionals' levels of digital skills. Future research is encouraged to build on our test experiences and to validate the observations. Overall, the results suggest the need to monitor and 
measure the skills that workers should attain. A next step is to elaborate on the ways to equip working professionals with such skills. Future research must take an active role to prioritize and incentivize programs to empower workers to have the skills they need for the current workforce.

\section{APPENDIX 8.A ASSIGNMENTS}

\section{Information digital skills}

Assignment 1.1

Imagine you have invented smart toothbrushes that are capable of making a profile of your brushing technique and can share this information with the dentist. However, it is not easy to find financing to produce them. You are now investigating how you can finance your new company by means of 'the crowd'. Multiple variants are possible; the basic principle is that many people collectively fund a venture by providing parts of the requested funding. You want to finance your new company by means of a loan from 'the crowd'.

Start a search query on Google to answer the following question:

- Which form of crowdfunding best fits the abovementioned situation best?

\section{Assignment 1.2}

There are regulations for crowdfunding platforms when, for example, loans are provided to consumers and/or companies.

Start a new search query on Google to answer the following question:

- What specific condition is imposed on crowdfunding platforms when companies can obtain a loan?

\section{Assignment 1.3}

Your crowdfunding campaign has received a lot of interest from consumers. A consumer is willing to invest 5.000 Euros in your new company.

Start a new search query on Google to answer the following question:

- What tool should crowdfunding platforms use to see if a consumer invests a responsible part of his/her capital?

\section{Assignment 1.4}

Imagine that a consumer is willing to invest 10.000 Euros. This particular consumer has a total capital of 75.000 Euros.

Start a new search query on Google to answer the following question: - Is an investment of 10.000 Euros justified? Explain your answer. 


\section{Problem-solving digital skills}

Assignment 2.1

As with any form of investment, crowdfunding can also cause problems. Imagine that you are an investor who has participated in a successful crowdfunding project. Unfortunately, you have been deceived because the crowdfunding platform is not willing to pay anything.

Start a new search query on Google to answer the following question:

- What actions could you have taken to prevent the above stated situation?

\section{Creative digital skills}

\section{Assignment 3.1}

Refrigerators, thermostats, TVs and cars: more and more devices are connected to the Internet. Together, they form the Internet of Things (IoT), a network of devices that share information. One of the most visible forms of the loT is the advent of wearables such as watches or bracelets that are connected to the Internet.

On the next page, you will find an assignment. You have ten minutes to complete this assignment.

Use the Internet to come up with as many original 'Internet of Things' applications, within ten minutes, that improve productivity at the workplace. For example, you might think of applications that enable working faster and more efficiently.

- Write down 1) the device and 2) the corresponding application. Briefly explain your applications.

\section{Critical-thinking digital skills}

\section{Assignment 4.1}

The prediction is that the loT will have a huge impact on our daily lives. The loT is often presented as the trend that will connect each device in one large network and thereby make maximum use of the collected data.

On the next page, you will find an assignment.
A utopian view of the loT is described. The statement is as follows:

"The Internet of Things makes life easier, healthier and safer"

- To what extent do you agree with the above statement? Justify your point of view with the help of information found on the Internet. You have fifteen minutes for this assignment. 


\section{APPENDIX 8.B CODING SCHEME}

\section{Information digital skills}

Defining the search queries

Directly using a search query emergent from the task

Using Booleans to limit search results (e.g., AND, OR, " ")

The average number of search words per search query

The average number of search queries

Selecting a website to seek information

Using advanced search methods (e.g., date, type)

Directly selecting a relevant website

Checking more than the first three search results

The average number of relevant websites

The average number of irrelevant websites

Selecting information on websites or in search results

Selecting hyperlinks on a website

Searching within a website

Selecting information appropriate to the task

\section{Evaluating the information found}

Using a new search query for the information found

Checking the information on another website

\section{Critical-thinking digital skills}

Justification

Providing arguments

Providing proof/examples

Presenting both sides of a perspective

\section{Breadth of understanding}

Providing a new perspective
Critical assessment

Assessing the arguments

Drawing a conclusion

\section{Creative digital skills}

Fluency

The average number of devices/applications

Originality

Proposing a device/application that is mentioned once

Proposing a device/application that is mentioned three or fewer times

Problem-solving digital skills

Identifying the problem

Directly using a search query derived from the problem situation

Providing appropriate solutions

Proposing multiple appropriate solutions to the problem

The average number of solutions

Explaining the solutions

Providing an explanation for the solutions proposed

The average number of explanations 


\section{CHAPTER 9}

DEVELOPING POLICY AIMED AT 21ST-CENTURY DIGITAL SKILLS FOR THE CREATIVE INDUSTRIES: AN INTERVIEW STUDY WITH MANAGING DIRECTORS

The previous chapters revealed the 21 st-century digital skills that require most attention and the personal labor conditions that support these skills. This chapter considers how organizations within the creative industries support skill development and under what conditions. The aim of this chapter is twofold: (1) to offer a deeper analysis of the nature and level of 21st-century digital skills and (2) to explore the roles of both the individual worker and the organization in the development of 21st-century digital skills. In total, 24 interviews were conducted with directors and founders of creative organizations based in the Netherlands. The interview results show that managers often do not explicitly refer to our 21st-century digital skills framework. Managers seem to believe that workers' technical skill levels are naturally high; while in fact, they might require attention when content-related digital skills are considered. The first priority in this case should be to raise awareness of the problem within an organization's management. Thereafter, intentional and structural efforts on the part of individual workers and organizations are needed to improve learning and skill development practices in the workplace. 


\subsection{INTRODUCTION}

Knowing workers' difficulties in mastering 21st-century digital skills (see Chapters 7 and 8) and which factors, at the level of the individual worker, contribute to these differences (see Chapter 7) provide a base for discussing some of the preliminary findings with the directors and founders of organizations working within the creative industries. Taken together, the previous chapters reveal the 21st-century digital skills that require the most attention and the individual labor conditions that support the required improvements. However, the question of how organizations within the creative industries support skill development and under what conditions is largely unexplored territory. Only a few studies have focused on the qualitative experiences of skill development within the creative industries (Hotho \& Champion, 2011; Kamprath \& Mietzner, 2015). A distinctive characteristic of the creative industries is the temporary nature of projects and their variability over time (Bettiol \& Sedita, 2011), which affects organizations as well as individuals because they are often forced to adapt and to reorganize their existing knowledge and skills (Scarbrough et al., 2004). Engaging in learning and applying digital skills not only within but across a variety of contexts requires employees to develop a range of generic skills (Kersh, 2015). Our substantive 21st-century digital skills framework demonstrates a set of general usable skills across changing work contexts (see Chapter 2). The proposed skills in Chapter 2 are device- and platform-independent because ICT devices, platforms and content are ever-changing and multiplying (Helsper \& Van Deursen, 2015) Higher-order or content-related skills with a strong digital component (e.g., critical thinking, creativity, and problem solving) are essential for workers' flexibility. The rapid technological development and the expansion of digital technologies have a profound impact both on the nature of the learning space at work and the types of skills that are required by contemporary workplaces (Evans \& Kersh, 2014). In such fast-moving working contexts, digital skills mus be continuously empowered as a strategic factor for global competitiveness (Manuti, Pastore, Scardigno, Giancaspro, \& Morciano 2015). Organizational support for the continuous skill development of employees has been referred to as one of the factors that facilitates a learning workplace (Evans \& Kersh, 2014). Through in-depth interviews, this chapter focuses on the types of 21stcentury digital skills with which the directors and founders of organizations within the creative industries may experience difficulties with and the ways in which they give meaning to skill development practices. First, we offer a deeper analysis of the nature and level of 21st-century digital skills among professionals working within the creative industries. Second, we explore the roles of both the individual worker and the organization in the development of 21st-century digital skills. The following research questions are addressed:

1) What is the importance of being digitally skilled for employees in the 21st century?

2) What is the level of 21st-century digital skills among incoming and existing employees?

3) What is the role of the individual worker concerning skill development practices?

4) Do organizations use particular practices to strengthen employees' levels of 21st-century digital skills?

5) Do organizations feel the need to continuously develop initiatives to support the development of 21st-century digital skills? If so, do they experience difficulties?

These five questions are themes to explore with the participants, and their insights serve as input for skill development policy. At the end of this chapter we directly link the results from our case study to policy implications for the organization as well as the individual worker.

\subsection{METHOD}

9.2.1 Semi-structured interviews

Semi-structured, in-depth interviews were conducted using the questions that emerged from our previous studies. This method was chosen to obtain deep insights from the participants. Not all the questions were designed and phrased beforehand, allowing both the researcher and the participant some flexibility to discuss specific issues as they arise. Open-ended questions were used to generate a rich data set. In doing so, the participants were encouraged to express their opinions and experiences and to further expand on their views.

\subsubsection{Participants}

The interviews were conducted across the Netherlands with members of the top-level management (e.g., directors and founders) of organizations within the creative industries. The sample selection was not random but was driven by a specific purpose. Purposive sampling means that the participants are selected because "they accommodate certain features or processes that the 
researcher wishes to investigate" (Silverman, 2001, p. 250). In our case, the following inclusion criteria for the participants were applied: (1) holding a supervisory position, (2) having a close connection with the workforce, and (3) working in a company of at least 10 employees. The samples are selected for the specific purposes of the research, even if the samples are not fully representative (Zikmund, Babin, Carr, \& Griffin, 2010). To recruit participants for this study, the selection mechanism was primarily based on information from various network and industrial branch organizations associated with the creative industries. Often, the members are visible on the website of the various branch organizations (e.g., architecture, digital design, and gaming). In addition, the branch organizations often publish articles about organizations with which they are involved or interviews with key players. The company's website and Linkedln profiles are, in turn, used to screen and contact potential professionals. This study does not rely on personal contacts. Potential participants from the following professional fields were approached: architecture $(\mathrm{N}=18)$, marketing/ advertising ( $N=17)$, gaming $(N=12)$, digital design $(N=12)$, industrial/service design ( $N=10)$, Internet $(N=8)$, graphic design $(N=2)$, fashion $(N=1)$, film $(N=1)$, and music $(\mathrm{N}=1)$. In total, 24 interviews were conducted. In addition to their jobs, the majority of the participants were involved in teaching activities or served as members of a creative branch organization or knowledge institution. The final sample included 18 men (72\%) and 7 women (28\%); one interview was a double interview. They worked in the following professional fields: industrial/ service design ( $N=5)$, marketing/advertising $(N=4)$, gaming $(N=4)$, Internet $(\mathrm{N}=4)$, marketing/advertising $(\mathrm{N}=3)$, digital design $(\mathrm{N}=3)$, graphic design $(\mathrm{N}=1)$ Through purposive sampling, a diverse range of organizations were included that share the characteristic of being intensive users of technology and bringing together a combination of creative content and ICT skills.

\subsubsection{Procedure}

Informed consent was obtained verbally from all the participants included in the study. They were fully informed about the purpose of the research, their rights, and the storage and use of data prior to the interviews. The interviews were conducted via a Skype video call or by telephone, per the preference of the interviewee. The data were collected between February and April 2019. A key focus of the interviews was to ask the participants about their perception of the meaning of being digitally skilled today. Thereafter, we asked them how they viewed the level of digital skills among their employees. Attention was paid not only to the digital skill levels of existing employees but also to employees entering the workplace. They were asked if they experience difficulties with attracting and hiring highly qualified personnel. The notion that there is a mismatch between the skills of graduates and the skills demanded by employers was discussed. Thereafter, they were confronted with the results of our previous studies concerning 21st-century digital skill levels among professionals working within the creative industries. In particular, the levels of communication contact-building and networking, information evaluation and problem-solving digital skills remained worrisome (also see Chapters 7 and 8). Although the results were based on other organizations, the participants were asked to reflect upon the workforce skills and compare the results found with their own organization. Next, they were asked to express their thoughts about who is responsible for skill development. They were asked to provide guidance on how they as an organization give meaning to skill development practices. In addition, the role of the individual worker in their own skill development was a topic of interest. A specific focus was on the lifelong learning capabilities of their employees. Furthermore, the participants were first asked to express their own opinion about the factors that might contribute to workers' skill levels before the researcher shared some of the findings. The role of interest/motivation, personal initiative, support from Internet contacts and participation in training was further elaborated upon. Finally, the participants expressed feelings of urgency and described the challenges related to the development of digital skills. The interviews lasted between 40 and 60 minutes. Participation was completely voluntary, and no incentives were provided to the participants. Appendix 9.A displays the interview and coding scheme.

\subsubsection{Data analysis}

All interviews were recorded and transcribed not to lose any details of the conversation. Each transcript was coded using thematic analysis. Thematic analysis was used as "a method for identifying, analyzing, and reporting patterns (themes) within the data" (Braun \& Clarke, 2006, p. 79). The researchers used semantic themes to identify the explicit meaning of the data (Braun \& Clarke, 2006; Riessman, 2008). We took an explorative approach because the themes identified were strongly linked to the data from our previous studies. This explorative approach is considered to be most appropriate considering the limited number of studies on 21st-century digital skills in relation to skill 
development. Overall, the data analysis was an iterative process of rereading the transcripts, refining codes and recoding.

\subsection{RESULTS}

This section is divided into five parts. First, we discuss the importance of being digitally skilled for employees in the 21 st century according to our participants. Next, the level of 21st-century digital skills is discussed. Thereafter, the focus is on who is responsible for skill development and what the individual worker and organizations do to support the level of 21st-century digital skills. Additionally, their thoughts about potential contributors to skill levels are outlined. Lastly, the question of whether there is a need to develop initiatives to support the development of 21st-century digital skills is addressed, including potential barriers and opportunities with regard to skill development.

\subsubsection{Digitally skilled in the 21st century}

\section{Consequences of digitization in terms of skills}

First, the participants described how digital skills are becoming 'core' to diverse ways of working. They reflected on the consequences of digitization for workers' skills. Important consequences include the constant need to develop new disciplines and to work with a variety of digital tools or systems.

"To give a concrete example, a few years ago, we switched completely to Google. This means that the storage of documents, retrieval of documents, collaboration in documents, and sharing of documents improve efficiency by speeding up our core processes."

"The market and technologies we use change rapidly and continue to develop. So, it is mainly a matter of keeping yourself up-to-date and keeping your eyes open."

A few participants felt that the digital transformation of business has put workers in an 'always on situation,' which results in increasing expectations toward the rate and promptness of response.

"What you see, I think across the breadth of entrepreneurship, is that the problem arises that you end up in a kind of always on situation. (...) If a client has a request, sends an email, and doesn't receive a response, another WhatsApp message will be sent."

"When you talk about skills, immediacy is expected. You must act and respond to something immediately."
A few participants even stated that because digital tools are becoming more accessible and user-friendly, thinking levels in the digital era must be improved.

"Technically speaking, where you used to go deep into the code in order to get something done, it is now becoming a service which you can easily implement. This means that, in terms of digital skills, the level of thinking must be improved but the technical part looks more complex than it is."

Overall, the participants mainly described the consequences of digitization in terms of medium-related skills; the frequency and intensity of the adoption and the use of digital tools.

Meaning of digital skills

All the participants considered digital savviness to be part of everyone's skill set as all roles have some type of digital element. Most participants considered digital skills to be related to one's ability to use technology effectively and rapidly as well as certain qualities such as interest and curiosity in digital technologies and proactivity in learning

"Essentially, it means that if you are not able to do something digitally, then you simply look it up. You can find someone who made a YouTube video or wrote an article. You can teach it to yourself. I think that's a person who is digitally skilled."

Moreover, digitally skilled persons were often seen as those who are able to build on their acquired digital skills and apply them, aside from the technology involved, to a variety of working situations. They are confident in using digital tools regardless of how they are developed.

"You have to understand, okay, these are the results that I want to achieve, and these are the techniques that I can use for this, and it doesn't matter to me which one I will use. (...) Your digital savviness must not be seen as a goal in itself but as a means by which to reach your final goal. People with that mindset can start working here."

Overall, the participants considered employees' digital skills in terms of the routinization and integration of digital technologies into their daily work activities.

Level of digital skills

Most participants were satisfied about the level of digital skills within their organization. Such skills were understood to predominantly involve technical or medium-related skills such as 3D modeling, animation and design software 
programs. Often, the participants' digital skill levels were considered to be particularly high because they intensively use and develop digital tools. Sometimes they even help their own clients to become more digitally skilled.

"I would say that our digital skill levels are above average, and I link that to the fact that we only work digitally, we use many digital tools, and we also develop things in this area ourselves."

"The people who work here are not only digitally skilled themselves but also make people on the client side more digitally skilled."

A few participants critically noted that they encounter relative differences in employees' skill levels. As such, some of their employees still need to make some progress.

"Yes, in our company, the situation is pretty good. I think seventy percent of the people are just really good and thirty percent of the people still have to learn. Even in a technically oriented company like ours, there are quite a number of people who have to take some steps to familiarize themselves with the technology and to acquire the technological skills."

Although the participants stated there is a high demand for digital skills (e.g., DTP skills), applicants are not always expected to possess these skills; they are assessed based on potential that can be developed as long as the person wants to learn and engage.

"I think their digital skills are high enough to understand and use the programs and digital tools. (...) I think it is more a matter of whether people are also interested enough to use them effectively and meaningfully."

An illustrative comment was made about the fact that specific technical aspects of digital skills might soon be outdated.

"Digital is constantly evolving. So, the skills you have today are outdated tomorrow, and you have to make sure that you are constantly learning and developing."

\section{Skills mismatch}

The participants who did not experience difficulties with recruiting qualified personnel for job vacancies mostly relate that to the attractiveness of the jobs offered and the possibility to recruit from abroad. Most participants recognized the skills mismatch between employer demand and worker supply. Although they acknowledged that you cannot expect incoming employees to know all the job specifics, skill development sometimes takes more effort than expected.
"You expect that a certain type of employee possesses a specific skill set, but this often turns out to be disappointing."

Specifically, specialized job-related knowledge and skills must be updated within the workplace, for instance, through on-the-job learning and working with an experienced mentor. Often, the participants indicate that they will team-up a junior with someone with more experience who can mentor them and bring them up to standard. One participant of a large-scale organization even stated that they developed their own academy to train interns and juniors.

"We actually train our people in the field of digital marketing because it simply doesn't exist. In the field of design, we see that people are educated on average level with an eye for details. For us it is important to work with color, typography, image, and there is little education in the digital spectrum."

In general, the participants stated that the educational programs were not sufficient to meet all of their expectations. Several participants mentioned that schools often use software that is outdated or not compliant with work requirements. Aside from specialized technical skills, they emphasized that education should prepare students with 'soft' skills.

"I think there was a time where the general thought was that if we provide people with a lot of hard digital skills, they can work in the field. That's true, but I sometimes miss the soft skills, so to speak. (...) Being able to properly analyze a problem, presenting it, and being able to listen and communicate well. (...) Sometimes you notice that people understand a tool very well, but then they don't know how to work with a similar tool because they don't understand what they are really doing."

Several participants argued that work experience, including work placement, is becoming essential to demonstrate employability.

"Educational programs need to somehow stay close to practice. (...) Internships are of great importance. People can just participate, and then they really learn what happens in the organization."

Furthermore, they often argued that education should remain in close contact with industry to keep abreast of current industry practices. Practical efforts such as inviting industry representatives to give lecturers or actively involving them in the curriculum development process were proposed. Another proposed practical effort was to allow students from different disciplines to work together. 
"We try to mix as many disciplines as possible and to be constantly curious. And what you see at schools, at the ones that I have seen, is that they are still very old-school. They are divided in silos and barely talk with each other." Overall, the participants expressed various examples of efforts to further improve the match between the skills students are taught and the skills required in the workplace.

\subsubsection{Level of 21st-century digital skills}

When the participants were confronted with the lower levels of multiple 21st-century digital skills (e.g., information, communication, and problemsolving digital skills), they differed in whether they saw opportunities for improvements. For some of the participants, the results were not recognizable mainly because their employees are self-reliant when working with online platforms. Other participants critically reflected on each skill. With regard to digital communication skills, they did not experience difficulties with online networking. However, a few participants mentioned that skills in understanding the rules for etiquette as well as tone of voice during online communication leave room for improvement.

"In general, they are all highly skilled in digital communication, but communicating properly online with the target group in the right way and in the right process is much more difficult."

"I think, for example, that if we make an Instagram post or we put something on Linkedln, then it should be written professionally, and it simply cannot contain things like colloquial language or emoticons. And maybe that's really old-fashioned, I don't know, but that's what I think. So yes, here their digital communication skills are lacking."

In addition, communication expressiveness in terms of getting one's needs met in online interactions was not considered to be a skill that everyone possesses.

"In particular with communication, making sure that you use it well and that you don't email just for the emailing, but that you ask the right questions and receive the right information, yes, that's complicated."

With regard to digital information evaluation skills, the quality and sources of online information found were often verified during the work process and embedded in the organization. However, a few participants mentioned that skills in interpreting online information could be improved.
"Before you know, you create your own truth, which I must confess myself guilty of. After all, if you have a certain proposition or opinion, it is very easy to go online and to find evidence for it."

"They are handy in subtracting information from the Internet, but maybe a little on the superficial side, you know. (...) Then they just copy-paste a few things found on webpages, but they don't engage in their own analysis." With regard to digital problem-solving skills, the participants often reported that solving problems creatively was part of their strategy. One participant even stated that they use a digital format that forces users to propose multiple options. However, several critical notes were made about whether their employees always use a considered, online problem-solving approach.

"To come up with multiple solutions is very difficult for people. They often return to what they think is the most logical and obvious thing to do at that time. Especially people who have not been working for long often fall short."

"I think in our company, it is often the case, 'well, I have a problem, this solves it, then done'. So, actually a quick-fix is looked for."

Most participants relate differences with regard to 21st-century digital skill levels to employees' personalities and experience as well as their persona interests and affinity with ICTs. Overall, the level of 21st-century digital skills was not considered to be a problem because it forms the basis of how they work.

\subsubsection{Skill development}

The participants provided little evidence that they are systematically assessing 21st-century digital skills. Often, they stated that if their digital skills were lacking, they would notice it in their day-to-day work

"That's something you notice day-to-day. Everyone works digitally, and also our clients expect that from us. You have to keep pace; otherwise, you lose clients. So, it goes without saying."

"If we deliver the projects at the right level, the skills are also sufficient. My feeling is that the digital skills are not leading, but the results are leading." Otherwise, the assessments tended to be rather basic and discussed, for instance, during performance reviews and appraisals. A few participants recognize the need for a more formal and systematic approach, and they pay attention to coaching and development goals.

"We have divided all disciplines into junior, medior and senior. And based on junior, medior and senior, you then have certain tasks and competencies 
that match your level. We have classified these levels per discipline in a job matrix. (...) In this way you can see what you need to do to grow to the next step."

One isolated comment was made about the systematic assessment of a broad set of digital skills.

"Every month, we have check-ins with our employees, and we are permanently measuring, say, whether people can keep up with what we call a t-set. (...) We are constantly looking for where the gaps are in broad as well as deep skills, and we try to retrain that."

In general, the participants assumed that 21st-century digital skills develop organically.

The participants differed in how responsibilities around skill development are managed, distributed or shared. A few participants considered it to be a shared responsibility of the organization and the individual worker.

"It is a mutual process. We have to indicate where our services should go to and what we want to be good at. From the employees we expect an active response, 'this is something I can do and want to do'. (...) You are responsible for your own development program."

"I think it is a joint effort. On the one hand, that lies with the employer, who should facilitate, say, an ecosystem where personal development is possible.

(...) On the other hand, it is also a mindset that needs to be shared among employees. So, training is something that needs to belong to the person to move forward in life and not something that you just do to keep a job." For most participants, the responsibility primarily rests with self-directed teams or the workers themselves.

"People who have the lead must make sure that their team members can actually translate their interest into a certain growth."

"I think the responsibility initially lies with the person, but, in practice, it is often the case that a supervisor tries to get things going. (...) My experience is that too few people are proactively involved in self-development or selfreflection."

The latter was in contrast to another participant who stated that one is too late when the initiative comes from the organization rather than the individual. In general, the participants agreed that some form of responsibility or initiative should rest with the individual worker.
Organizational practices

The participants provided little evidence on any formal or structured training programs. Formal training is sometimes provided when a specific skill need is identified, or new systems are implemented. When ICT systems or tools affect most of the employees in the workforce, group trainings are offered. The majority of training tends to be on an ad hoc basis to meet individual needs when requested.

"Our employees can say for themselves what they want to further develop.

This can be something digital such as video making, social media skills and so on. (...) Well, then there is a budget available to develop yourself."

Interestingly, one participant stated that the interest to study online is rather low in comparison with classroom training sessions.

"Our college program is all individual and involves a lot of online training.

(...) Especially the almost traditional classroom trainings, the ones with a coach or teacher or NLP expert, are very popular."

Skill development activities often happen informally. Peer-to-peer learning plays an important role in acquiring digital skills. Informal mentoring seems to be a means by which the individual worker can gain support and guidance to further develop a particular skill.

"Well, we have created mentorships, and that's a very nice program in which everyone has their own mentor. At the start of each year, you look at your own ambitions and the direction in which you want to grow. Then you look at which colleague of mine would be a good mentor to help you to reach those goals."

Learning digital skills is often reliant on just a few enthusiastic and dedicated employees who actively engage in activities promoting digital skills.

"I have five early adopters employed, the enthusiasts, and I need those people, and then it trickles down. Then they also see that that person works with very cool things or makes something really good, and I cannot do that, and I want to learn that too."

In addition, the value of regular informal gatherings to facilitate knowledgesharing was emphasized, for instance, through organizing lunchtime learning sessions, inspirational presentations and workshops. This was connected with the idea that the awareness of opportunities enables learning to happen. Knowledge is not only internally shared, but the value of external knowledge sources is also considered. 
"Four or five times a year, we organize a breakfast with an external speaker. We just invite our own people but also twenty or twenty-five managers from our clients. Then we have a kind of breakfast club, and we network and have breakfast with a speaker about a relevant subject for our profession." Altogether, the participants mentioned various organizational practices to strengthen employees' skill levels; however, the extent to which such practices were formally or systematically implemented differed. In general, they were unclear about the skills (e.g., job-related skills, medium-related skills, or contentrelated skills) on which the initiatives should focus.

Individual practices

For a number of participants, employees must remain informed about developments in their own field or even about subjects outside their own discipline or interests. The general viewpoint is to be curious and studious and to demonstrate a genuine passion for the product one makes.

"You should really be curious and be proactive. So, always be interested in new things and experience your field in such a way that you want to stay informed."

According to several participants, employees can take the initiative to acquire new knowledge and to ask for advice.

"You can read books, read articles, read blogs. You can take a course or go out yourself. You can obtain information yourself and remove your blinders and look a little bit outside your own field."

Moreover, having a purpose in learning is often seen as a driver to acquire or develop a skill.

"I think it is about awareness and, like all personal development, you have to make a plan, be really involved, and invest time into it. Of course, that's often difficult because it brings a lot in the long term, but it costs time in the short term."

Altogether, most participants expected their employees to have a growth mindset, the belief that they can learn what is needed to improve and develop themselves.

Lifelong learning capabilities

On the one hand, lifelong learning can be understood as an individual activity. On the other hand, it refers to policy that aims at securing the conditions and opportunities for individuals' learning. Most participants reported that their employees are typically enthusiastic and open to learning. However, the lifelong learning capabilities of employees were not without critics. The participants indicated that not every employee is equally motivated to actively participate in self-learning.

"I also occasionally read books about the discipline, which I then share with people. I know some people who find that very interesting and also suggest articles or share books or discuss coaching or at least they try to develop themselves. Other people need it less or are less involved in it."

"I think that people here are incredibly ambitious, and they want to learn and develop themselves. That makes them happier than an $x$-amount bonus. However, as I just said, there are only a few people who can really think like an entrepreneur. (...) Other people you have to take by the hand, you have to take the initiative for them, and you have to determine their direction." In general, the participants considered the pursuit of lifelong learning to be a core value and not something to be formally addressed. Often, the latter only occurs when necessary for work.

"We select people based on such capabilities, and it is also a culture that exists here. So, our people are always curious and always want to learn and get better. I find it more important that an intrinsic motivation is present than that we, as an organization, would impose that. I do think it is very important that we, as an organization, stimulate people who come to us with an intrinsic motivation as much as possible. I hope that we have created such an environment."

A few participants stated that they must sometimes restrain the motivation to learn.

"Designers always like new things, but sometimes the tool you are currently using is good enough or even more effective to use instead of using something new. (...) So, sometimes you have to say, 'well this is interesting but let's try it in the next trajectory rather than right now'."

Overall, most participants believed that their employees naturally possess lifelong learning capabilities. A few participants experienced that some of their employees need some extra guidance and direction, for instance, through regular coaching conversations, to help them take on greater responsibility toward skill development. 


\subsubsection{Factors contributing to skill levels}

The participants mentioned a diverse range of factors contributing to $21 \mathrm{st}$ century digital skill levels that apply to both the individual and the organization. From an individual perspective, they proposed factors such as awareness of the necessity for skill development and their own responsibility and power of expression in this process.

"Well, perhaps the feeling of the employee him- or herself that development is also part of your job. So, now it is often the case that it feels like, 'again, I didn't get back to my work because I completely dived into this,' while that's also part of your work."

From an organizational perspective, factors such as accepting challenging projects, creating time and offering training opportunities were proposed. Several participants also emphasized the importance of a supportive organizational culture in which employees feel confident and safe to experiment and explore.

"If you can take away the fear, it becomes fun. When it becomes fun, automatically, the need for deepening and exploration arises. So, digita skills, yes, you make them better by allowing people to playfully interact with it. That should be the focus, I think."

"I think you have to make sure that you establish a culture in which you can fail, in which you have to fail because otherwise people stay in their current routine, which is safer and therefore prevents them from developing themselves."

The participants did recognize the factors (motivation, initiative, social support and training) investigated in our previous studies. Essentially, individuals must actively seek out new knowledge and be self-inventive.

"Indeed, you must want to learn or be able to learn something. If you cannot figure it out yourself, you must dare to ask someone or look it up, and for that, you need initiative. It is all connected."

"It is about actively looking for new knowledge finding out yourself. I definitely recognize that in what you say. Yes, of course, that differs per person. We have people who are a bit quieter and who work much more on their own and other people who immediately reach out and do research themselves on the Internet or ask people from their network."

One participant even stated that behind these factors lies a deeper motivation.
"A deeper motivation for feeling the responsibility to move along and to strengthen the value of my organization or the value of myself within this organization."

Another isolated comment was made about the fact that it is sometimes difficult to find the right support sources for new areas of expertise.

"Everyone knows how to find support for the in-house areas of expertise. Only for the areas of expertise that we don't have yet, we have to reinvent where the real knowledge comes from, which is sometimes quite a search." Overall, for skill development to occur, employees must be proactively involved in their own learning process, while their organization must facilitate a supportive environment in which it is safe to experiment with new digital technologies.

\subsubsection{Importance of skill development initiatives}

The participants agreed that workers cannot afford technological obsolesce but differ in whether they feel the need to continually pay attention to the learning of digital skills. On the one hand, exploring, learning and integrating new digital skills are crucial as they often innovate and create with digital. They spoke of the rapid rate of technological change and the need to always stay one step ahead of their clients to meet their expectations and to remain competitive.

"It is the guideline for how someone operates within our projects and within our teams. Digital skills are, of course, not a goal in themselves but just a means of achieving the best results, and everything is measured against that."

"It is absolutely necessary to keep up with it and to make it part of your knowledge base. (...) You can never keep the entire organization at the same level, but that's not necessary. It must be taken further; it must not stand still."

They created the urgency and desirability of learning digital skills, for instance by accepting projects wherein employees are challenged to work differently.

On the other hand, for many participants digital was seen as part of their core business, and, as such, digital roles and responsibilities are standard practice. The notion to continually pay attention to the learning digital skills fades as it is part of their core activities. In addition, the assumption often held by our participants is that young people are digitally savvy.

"I just take it for granted. (...) Ninety percent of your job is that you are digitally skilled. So, I am not worried about that. This is also because we 
work with very young people. (...) That's just a generation born with a phone in their left hand and a selfie stick in their right hand."

\section{Skill development barriers}

Several participants emphasized the costs and time associated with skill development practices as important barriers. Additionally, identifying skil development practices such as suitable training differs per area of expertise.

"Often, from a business perspective, a trade-off between costs and benefits must be made. When people are going to develop their skills, it always costs money and time. I think you have to consider whether it adds up and whether it is worth the investment. I think that's the most important perspective."

"It mainly concerns time when it comes to programmers and developers because they don't follow a course in programming. Even if a program is designed, it is outdated knowledge anyway. So, they find out for themselves and start using it online."

A common dilemma faced by many of the participants is the rapid rise of digital technologies. In this light, knowing which digitally enabled business opportunities to explore and where to invest is critical for organizations.

"I find it really difficult to judge whether a digital tool is just a new gadget or really necessary. (...) I don't know that yet, I find that complicated."

"As a company you have to maintain focus and control, I think. If you always want to do the latest, in this instance, you can change every day. Of course, you no longer have a method. Generally speaking, I find that challenging." The challenge lies primarily in the cost and time associated with skill development in combination with not knowing in which direction digital technologies will develop.

Skill development opportunities

The participants mentioned multiple opportunities to further develop 21stcentury digital skills within the organization. Several times, they mentioned the involvement of employees in continuous learning and reflection, for instance, through the establishment of learning goals or personal development plans as an opportunity for organizations.

"Personnel pay little attention to it naturally, I think. (...) Maybe an obvious answer is to make people aware of this. A kind of annual plan with development and learning goals, or the like."
A few participants also stated that a potential opportunity for organizations is to encourage people to come forward and to share more knowledge. Not only can organizations improve their initiatives, but workers can also seek positive change in their careers. The purpose and direction of a knowledge worker's career was often considered to be the responsibility of the employee.

"Of course, I have to be curious, of course I have to be open-minded, of course I have to want to learn but, actually, I just have to redefine myself as a knowledge worker. What is the value I can add to the labor market, and how do I deal with the new reality?"

"There are people who just like to keep doing what they know, but that's not possible. It is going way too fast with the technology. So, you must be flexible; otherwise, you will not make it."

One participant stated that an employee can further develop within an organization, for instance, by immersing oneself in the company of colleagues with backgrounds that are different from one's own.

"Somehow people still feel the need to create cohesive groups or cliques.

That's something I try to get rid of. I am trying to collaborate and bring disciplines together."

Overall, the participants expected employees to anticipate and act on possible changes both in the internal and external labor markets of the future.

\subsection{DISCUSSION}

\subsubsection{Main findings}

The overall purpose of this study is to explore how 21st-century digital skills are currently understood, deployed and developed in the creative industries to inform policy. First, concerning the meaning of being digitally skilled in the 21stcentury, the participants often recognize that a distinctive feature of a digitally skilled person is the ability to recontextualize skills and knowledge to put them to work in new and changing contexts (Evans \& Guile, 2012; Hager \& Hodkinson, 2009). The idea of resilience in the face of changing technology is considered by most participants to be key to being digitally skilled (LeBlanc et al., 2015). The personal qualities associated with resilience include the ability to adapt to change and to be autodidactic. They must be confident in approaching digital activities regardless of how the digital tools develop (Parry, Eikhof, Barnes, \& Kispeter, 2018). However, the participants seem to have no holistic view of the content of the '21st-century digital skills' concept while multiple wider 
conceptions are prevalent in the literature (see Chapter 2). At a general level, these definitions incorporate a range of content-related informational, socia and creative digital skills to use technology (Helsper \& Eynon, 2013). In line with Chapter 3 , the results demonstrate that the participants find it difficult to deviate from describing technical abilities. Most participants perceive digital skills as the ability to easily work with various digital technologies and online platforms in a variety of contexts. The emphasis is initially on the technical and operational aspects of digital skills rather than on content-related digital skills. Creating and developing online content, for instance, is not explicitly mentioned as a key component. After the distinction between technical and content-related aspects of digital skills is explained, they gradually become less vague and provide more examples with regard to the meaning of a broader set of digital skills within their work activities. A possible explanation for this finding might be that content-related digital skills are routinized in their daily work activities; therefore, most participants already consider it to be a common and natural skill base. A policy recommendation for organizations is to outline the digital skills that are needed for employees to work in new and changing contexts. Most likely, not every employee needs the same level of digital skills. A thorough understanding of digital skills will expose the essential skill needs for knowledge workers. An overview of the required digital skills per creative process and job position makes it possible to identify skill gaps that can ultimately be used as a measurement guideline. By identifying the most critical skill shortages, it becomes easier to take steps to remedy those shortages.

With regard to the level of workers' digital skills reported by the participants, they predominantly relate them to technical skills. The technical notion is limited in how flexible digital skills can be deployed across occupational tasks and roles (Parry et al., 2018). The skills learned in this manner will soon be outdated as the technology moves forward and practical applications of digital technology require more substantial skills (Van Dijk \& Van Deursen, 2014). The substantive view is clearly expressed in our 21st-century digital skills framework. As such, we call for a broader notion of the digital skills that should be recognized and addressed within organizations. Various scholars argue that the focus on technical operations or the medium-related aspects of digital skills is too limited (e.g., Claro et al., 2012; Van Deursen \& Van Dijk, 2011a). However, the participants often do not refer to content-related digital skills and, as such, they might easily be overlooked and neglected by them. The acquisition and assessment of digital skills must be designed and evaluated around a broad definition. The participants tend to use technical skills as a reference point; as such, the entire range of 21st-century digital skills as defined in Chapter 2 is not considered. Overall, the participants report a high level of workers' technical-related digital skills; however, when confronted with our results, the participants are more critical in terms of their content-related digital skills. Some of the participants indicate that their employees experience difficulties with digital skills such as online expressiveness, the interpretation of information, and consideration of multiple solutions. However, many of the participants also do not recognize the 21st-century digital skill levels as found in Chapters 7 and 8 . The most important reason given is that their employees are self-reliant and confident in using digital technology because it is part of their core business. In addition, the participants often build on the assumption that a young workforce is sufficiently digitally skilled. This is worrisome because the previous performance tests show relative differences concerning the content-related information and strategic Internet skill levels of young people (Van Deursen, Van Dijk, \& Peters, 2011). Our participants seem to believe that workers' digital skill level is naturally high, while in fact, they might require attention when content-related digital skills are considered. They do not seem to have a skill development policy around 21 st-century digital skills. The first priority here should be to raise awareness of the problem among the management of organizations. As managers express that there are differences in employees' skill levels, they cannot operate based on the assumption that every employee develops digital skills organically. They must become aware that not everyone naturally possesses 21 st-century digital skills or develops them spontaneously. The results illustrate that it is not enough to expect that you select the appropriate candidates or consider skill development to be a solely individual task.

In addition, from an educational perspective, managers seem to focus on technical skills mismatch. A few participants argue that they expect graduates not only to bring advanced technical-related digital skills (e.g., coding) but also a more holistic and interdisciplinary understanding. They seek applicants who are flexible and who are motivated to learn to meet the developing occupational demands. Graduates require the capacity to rapidly adapt to changing skills requirements throughout their careers (Selwyn, Gorard, \& Furlong, 2006). The participants note that continued learning needs to occur, and they do not expect the educational system to do this alone. Nevertheless, educational initiatives might focus on improving the match between the skills of graduates and the demands of the workplace by staying close to practice. Policy could focus on 
inviting industry experts as guest lectures to various classes or involving them in curriculum development.

Concerning the role of organizations with regard to skill development practices, a number of the participants stress the particular importance of informal learning contexts. The importance of on-the-job coaching, mentoring and training emerged (Coll et al., 2009). A policy implication for organizations is to facilitate collaborative practices among peers and to structure the currently provided informal assistance. To further promote digitization throughout the organization, it is important to identify those people who are enthusiastic and open to digitization. Such people can, to a certain degree, promote digitization and accelerate the decision-making and knowledge-transfer processes (Kohnke, 2017; Kotter, 2014). Organizations can also facilitate knowledge-sharing and peer-to-peer learning practices by planning presentations or workshop sessions. This learning-from-others allows individuals to understand the learning choices that have been considered by others and the most valuable aspects of each choice.

Moreover, although training is a significant contributor to the levels of many 21st-century digital skills (see Chapter 7), formal learning contexts, which are composed of planned learning activities, are considered less often. Training and development are mostly ad hoc and in response to a specific skill need, and organizations could adopt a more planned approach to learning. A policy recommendation is to focus on targeted skill development practices. This could be achieved by encouraging employees to explore, with guidance, in which direction they want to further develop themselves. Personalized guidance remains critical for the development of digital skills (Margaryan, Littlejohn, \& Vojt, 2011). Through regular conversations employees can make their skill development needs known or receive support in identifying their learning goals. Not all employees take advantage of the available options for supporting their continuing learning, even if they are offered. As such, it becomes essential to help employees to critically reflect on their learning process and to make them aware of the training opportunities.

Furthermore, the cost and time associated with skill development emerge as salient barriers. Commercial pressure sometimes means that opportunities for skill development are neglected (Norman \& Jerrard, 2015), especially because much of the work in the creative industries is project-based. For most organizations, the question is no longer whether to invest in skill development, but, rather, how and where to invest for the best results. Due to the rapid rate of digital technological development and limited resources, organizations are forced to make choices. A policy recommendation is to offer structured testing and learning opportunities for employees to build the necessary 21stcentury digital skills and to drive innovation. By using new digital technologies in such a risk-free setting, employees are able to begin experimenting with new ways of working (Kohnke, 2017). As employees do not always recognize digital technologies as part of their work, an opportunity for organizations is to create the necessary conditions to encourage learning to take place on the job. In general, although learning digital skills is often linked to training or education, the most frequently used ways are informal. Organizations should realize that 21st-century digital skills do not always develop spontaneously in the desired manner; however, special efforts must be made ensure that they understand the value of learning.

Concerning the role of the individual worker with regard to skill development practices, for most participants, the responsibility for skill development extends beyond the organization. As the future of professions and nature of work are shifting, the challenge for individual workers is to redefine themselves as knowledge workers and to remain relevant. As such, they must recognize the value of continuous learning and ongoing professional development. On the one hand, learning can be triggered when it becomes apparent or worth it and, on the other hand, by an inherent interest or motivation in digital technology (Pennacchia, Jones, \& Aldridge, 2018). As such, for some workers it is a matter of expanding one's scope by developing new skills and for others of deepening one's knowledge of a particular area by choosing a more specialized practice. In both cases, workers must make time available for skill development as part of an ongoing work process.

Moreover, individual workers must make a realistic estimation of their digital skills and of the value they add to the organization. They can proactively seek new knowledge and identify and improve gaps in their knowledge. Informal means of learning by doing and with the help of the social environment are increasingly important (Selwyn et al., 2006). Organizations can steer their activities and needs in a particular direction; however, it is up to the employee to take advantage and exploit the opportunities being offered. Individual workers are expected to actively manage their employability.

To summarize, the most important policy conclusions that can be drawn from our findings are as follows: 
From an educational perspective:

1) Focus not only on technical-related digital skills but also on developing soft skills

2) Stay close to the industry to understand what is expected in the workplace

From an organizational perspective:

1) Realize that 21 st-century digital skills are important, perhaps even more important than digital skills as perceived by managing directors

2) Be aware that 21st-century digital skills do not always develop naturally or spontaneously at the worker's own initiative

3) Systematically structure learning and skill development in the workplace

From an individual perspective:

1) Realize that the requirement to learn is a lifelong imperative

2) Be aware that skill development is part of the job, and spend a significant amount of time learning on the job

3) Critically identify which skills are needed to add value to the organization or even to the labor market of the future

\subsubsection{Limitations}

The exploratory nature of this research limits the number of participants interviewed; however, we selected our interviewees in such a way that a voice was given to various types of organizations operating within the creative industries. As the research involved an in-depth study of a relatively small number of participants in a specific context, it cannot be claimed that the results can be transferred to other contexts. It is important to note that our aim was not to generalize findings from the sample but to develop a detailed understanding of how organizations within the creative industries account for workers' levels of 21 st-century digital skills. As such, the participants were selected because they suit the purpose of our study, not because they are representative of a larger population.

Furthermore, we interviewed managing directors because they are expected to have an overview of workers' skill levels. However, what we obtained were the managing directors' views on workers' skill levels and not workers' reflections on their own skills. The fact that our interviews were conducted via a Skype video call or by phone potentially limited our ability to observe the implicit behavior of the subjects during the interviews. Nevertheless, our impression was that the participants felt comfortable with this procedure and that they shared rich and detailed data for the purposes of the interview.

Finally, this research does not presume to indicate which organizational approach or strategy is superior to another. Exploring each of the strategies or approaches is beyond the purpose of this study. Diary studies could, for instance, provide insights concerning the effects of the provided recommendations. This is a useful method to obtain contextual information and capture data from professionals working within the creative industries while several of the provided recommendations are implemented. Moreover, focus groups could be used to discuss the types of policy recommendation that should be considered in the context of 21st-century digital skills. In our case, the provided insights are useful to raise awareness of skill development and to help the workforce to give meaning to skill development practices. Thus, here, we define detailed policy recommendations on how organizations and individuals can potentially strengthen 21st-century digital skill levels, and future research could test whether this actually benefits the workforce.

\subsection{CONCLUSION}

This chapter highlights the need for academic and industry to maintain an ongoing dialogue about the type of digital skills that are precisely required and how they can be proactively refined. The in-depth perspectives of directors and founders of organizations working within the creative industries provide a foundation on which to explore how 21st-century digital skills can be developed, supported and maintained. Overall, they could think about skil development in a more strategic and coordinated way. There is a risk in the tendency that employees learn digital skills for themselves as this could lead to a lack of attention to the role of organizations in skill development practices. Additionally, individual workers must realize that they, too, are responsible for their own skill levels. 


\section{APPENDIX 9.A INTERVIEW AND CODING SCHEME}

\section{Informed consent}

This interview is in the context of the research project 'e-skills, key to 21st century labor' funded by the NWO. I am going to ask you a few questions about the role of digital skills within your organization. The data and results of this interview will be processed confidentially and will be used only for analysis and/ or scientific presentations. You have the right to withdraw from this research at any time. Do you agree to participate in this research?

Topic list

General

- Can you briefly say something about the company where you work and the position that you hold?

- How many employees work at your company?

\section{Digitization}

The academic literature often discusses the rapid rise of technology and how it results in changes in the workplace.

- Does digitization have consequences in terms of skills required from employees?

\section{Level of digital skills}

- According to you, what makes someone digitally skilled?

- Is the level of digital skills sufficient or not sufficient among your employees?

- Do your employees ever lack digital skills? If so, which ones?

- Is the level of digital skills sufficient when employees begin working for you?

\section{Skills mismatch}

It is often argued that the current labor market is characterized by an increasing mismatch between the supply of and demand for skills.

- According to you, does the educational system respond well to the demands of the labor market?

a. If yes, what is being done?

b. If no, what needs to be changed?
Level of 21st-century digital skills

My research does not measure technical skills such as programming; however, it is focused on the so-called content-related digital skills such as the use of ICT and the Internet to search for information, communicate, collaborate, generate ideas and find solutions to problems. The results show that digital communication skills, such as approaching online contacts and online networking, lag behind among employees working within the creative industries. Employees also have difficulties evaluating the information found on the Internet as well as proposing multiple solutions and explaining them using information found on the Internet.

- Do you recognize these results in your employees? Why yes/no?

- Do you see the level of content-related digital skills among your employees as a problem?

- Do you think it is important to pay attention to content-related digital skills? Are they being discussed?

- Do you evaluate whether the level of content-related digital skills is sufficient among your employees?

a. If yes, how is it determined whether an employee is digitally skilled?

b. If no, why is this not an issue?

\section{Development of digital skills}

- Do you experience differences between employees' digital skill levels?

- Who do you think is responsible for developing digital skills? Who should initiate it?

- Does your company pay attention to the continued development of digital skills? If so, how?

- What do you think employees could do to contribute to the development of their digital skill levels?

\section{Lifelong learning}

A term I often come across in the academic literature is 'lifelong learning', which is defined as learning throughout the lifespan.

- How would you describe the lifelong learning capabilities of your employees? How do you identify such capabilities?

- How can you encourage employees to continuously develop themselves? 
Factors contributing to 21st-century digital skill levels

- In general, what do you think contributes to the development of digital skills?

My research considers factors from the perspective of the individual worker The results show that, among others, having motivation and interest in digital technologies, taking initiative, asking for help from online contacts, and following trainings with attention to digital skills contribute to the development of multiple digital skills.

- Does your company pay attention to one or perhaps several of the factors mentioned?
a. If yes, how is it initiated?
b. If no, why is this not an issue?

\section{Policy concerned with digital skills}

- Do you experience urgency that your employees continuously learn digital skills?

a. If yes, how do you, as a manager, create the sense of urgency in your employees that they continuously work on their digital skills?

b. If no, why is this not an issue?

- How is the development of digital skills taken care of in your company?

- Do you, as a manager, encounter difficulties with regard to the development of digital skills?

- What are the most important bottlenecks and/or missed opportunities concerning digital skills?

- Do you have advice on how the development of digital skills should ideally be supported?

\section{Coding scheme}

1) Background
1.1 Content of work
1.2 Job function
1.3 Organizational size
1.4 Flexible team
1.5 Average age

2) Digitization

2.1 Consequences of digitization for work

2.2 Meaning of being digitally skilled

3) Digital skills

3.1 Level among the workforce

3.2 Lacking digital skills

3.3 Level of incoming employees

3.4 Learning new digital skills

4) Skills mismatch

4.1 Recognizable

4.2 Problems with attracting employees

4.3 Connection between education and labor market

5) Level of 21st-century digital skills

5.1 Recognizable

5.2 Communication skills

5.3 Information evaluation skills

5.4 Problem-solving skills

5.5 Considered to be a problem

6) Monitoring of 21st-century digital skills

6.1 Paying attention to 21st-century digital skills

6.2 Evaluating skill levels among employees

7) Development of 21st-century digital skills

7.1 Differences between employees

7.2 Responsibility

7.3 Initiatives of the organization

7.4 Initiatives of the employee

8) Lifelong learning

8.1 Capacities among employees

8.2 Support of the organization 
9) Contributors to 21st-century digital skills

9.1 Factors according to the participant

9.2 Factors mentioned recognizable

9.3 Interpretation of the factors mentioned

10) Policy around 21st-century digital skills

10.1 The urge to continuously develop digital skills

10.2 The organization's approach toward skill development

10.3 Encountered difficulties with regard to skill development

10.4 Missed opportunities in the digital field

10.5 Potential improvements in the organization's approach 


\section{CHAPTER 10}

\section{GENERAL DISCUSSION}

Technological advances substantially change the way in which work is performed by augmenting or replacing workers in specific tasks (Strawn, 2017). As the content and nature of jobs change, so do the skills required to perform them (Grundke, Marcolin, Nguyen, \& Squicciarini, 2018). This dissertation considers the consequences of changing work on the level of the individual worker through the investigation of 21st-century digital skills. Identifying what 21st-century digital skills are and how they can be measured and developed are some of the questions that must be answered. This dissertation clarifies the concept of 21 st-century digital skills, operationalizes the skills in survey questions and performance tasks, and examines the potential causes of skil level differences. Furthermore, we shed light on the role of human work in the 21 st century and provide policy advice to strengthen 21 st-century digital skill levels among professionals working within the creative industries. The general discussion begins with an overview of our main findings (10.1) followed by the theoretical and methodological implications (10.2). Thereafter, the practical implications are presented (10.3). This chapter ends with the overall limitations and directions for future research (10.4). 


\subsection{MAIN FINDINGS}

10.1.1 21st-century digital skills: clarification

The first main scientific objective of this dissertation was to clarify the relation between 21st-century skills and digital skills. Many academic, policy and commercial initiatives are introduced to conceptualize the most important skills required in a digital environment. Often, not enough theoretical clarity is provided on what the skill dimensions are. Key skill dimensions are identified through a systematic literature review. Under a narrow definition, digital skills primarily focus on how to use the software and hardware of technology-based devices (Van Dijk, 2004). In line with recent theorization and measurement, this dissertation stresses that technical skills and content-related skills (e.g., critical thinking and communication) should be considered (e.g., Claro et al., 2012; Litt, 2013; Van Deursen \& Van Dijk, 2011a). Knowledge workers require skills to critically understand and engage with online content and applications (Van Audenhove, Vanwynsberghe, \& Mariën, 2018). In more recent years, a stronger emphasis has been placed on cognitive skills and socio-emotional skills (Berger \& Frey, 2015). The studies included in our systematic literature review, therefore, needed to apply an elaborate conceptualization or operationalization that goes beyond technical skills. The results provide insights into the relation between '21st-century skills' and 'digital skills' definitions (RQ1). First, 21stcentury skills often list or conceptualize a broad set of content-related skills whereas digital skills refer to a more limited set of operationalized contentrelated skills. Second, in contrast to digital skills, 21st-century skills often do not integrate the digital aspect with content-related skills. Technical skills are often considered to be a separate skill - implying that 21 st-century skills are not necessarily underpinned by ICT. The relation between 21 st-century skills and digital skills is the emphasis on content-related skills. This dissertation contributes to the research on 21 st-century skills by linking the digital aspect to the wide range of content-related skills. As such, the term '21st-century digital skills' is introduced to emphasize the skills required to integrate various digital tools to support the cognitive and social areas of managing digital resources and settings. The emphasis is on digital skills in the broader context posed by 21st-century skills that bring together ICT and content-related skills (Claro et al. 2012). The digital aspect must be integrated because the pervasiveness of ICTs leads to the use of digital tools to support 21st-century skills. In addition, the term 21st-century skills is often a vague and normative concept in the literature, and digital technologies provide a means by which to specify them.
It is important to note that the link between the digital aspect and 21stcentury skills is not yet accepted in the literature. As such, a systematic literature review was conducted on the closely related terms of 21 st-century skills and digital skills. The review resulted in a framework of 21 st-century digital skills (RQ2). The framework presents the following seven core skills supported by the use of ICT: technical, information, communication, collaboration, creativity, critical thinking, and problem solving. The following five contextual skills that play a role when using ICT are also presented: ethical awareness, cultural awareness, flexibility, self-direction, and lifelong learning. The concept of 21 stcentury digital skills consists of a variety of skills, and its scope is wide-ranging both in terms of skills and background: from education and computer science studies to media and literacy studies (Ilomäki, Paavola, Lakkala, \& Kantosalo, 2016). Our framework demonstrates the link between the digital aspect and 21 st-century skills. Today, communication requires the appropriate and effective use of e-mail and messaging services while collaborations often make use of information sharing and document collaboration tools. Moreover, the use of online discussion and chat forums has the potential to foster critical thinking. These are just a few examples to demonstrate how a variety of digital tools can be used to support 21st-century skills. As the concept of 21 st-century digital skills is not yet established, it is necessary to demonstrate and test the value of our 21 st-century digital skills framework. To determine if the identified skills are suitable for the workplace, the framework is tested within the creative industries (RQ2). Through interviews with industry experts, we conducted an in-depth study of their perspectives on the 21st-century digital skills that are necessary for the creative industries workforce. The interview study sheds light on the extent to which different types of skills are rewarded by industry experts (Grundke et al., 2018). While in-depth qualitative studies present challenges in terms of working within and across multiple fragmented creative industries, such studies have the potential to generate a deeper understanding of the characteristics of creative work (Hennekam \& Bennett, 2017). The interviews expand on the findings from the systematic literature review by showing the previously identified 21 st-century digital skills to determine if managers perceive them as relevant in their work context. Before illustrating the framework, they mentioned comparable skills as being relevant, which can be understood as a validation of the skills found in the literature review. The results only underscore the importance of 21 st-century skills, especially the core skills can be considered essential in the creative industries workforce. Nevertheless, there seems to be 
insufficient attention to the levels of these skills; they play a minor role during the selection and evaluation procedures. Thus, although managers recognize the 21st-century skills, they are seldom evaluated (see Chapter 3). Furthermore, initially, managers do not refer to the digital aspect of 21 st-century skills. They do not seem to recognize 21 st-century digital skills because they found it difficult to discuss the role of ICTs and the Internet with regard to their work activities and to deviate from describing technical abilities. Although the digital aspect of 21 st-century skills is difficult to clarify, the literature and respective study results illustrate that the proposed skills increasingly determine people's positions in the labor market (Claro et al., 2012). The systematic literature review and interview study show the importance of 21st-century digital skills for work. Together they provide a theoretical and practical basis for the requisite skills. The presented framework is a first attempt to provide operational components for each skill, as existing operational definitions fail to cope with the full range of skills required. The results of the interview study provide us with additional cues to further operationalize each 21st-century digital skill. Overall, the results highlight the need to further develop operational dimensions for each skill to measure the levels of 21 st-century digital skills.

10.1.2 21st-century digital skills: operationalization

The second main scientific objective of this dissertation was to propose an operational definition aimed at knowledge workers. An operational definition is required to determine what should be expected from workers (Voogt \& Pareja Roblin, 2012). The conceptual definition of each skill was used to further develop a 21st-century digital skills instrument (see Chapter 4). Most existing studies aiming to measure digital skills lack theoretical justification (Ilomäki, Kantosalo, \& Lakkala, 2011; Van Deursen \& Van Dijk, 2011a). Our 21st-century digital skills instrument builds upon the operationalization of the core 21st-century digital skills (information, communication, collaboration, critical thinking, creativity and problem solving) (see Chapter 2), which are perceived as necessary for a range of occupational tasks (see Chapter 3). The developed instrument was tested via cognitive interviews, a survey-pilot and a full survey among professionals working within the creative industries. Key issues in the available measures of digital skills are reliance on self-evaluation items and the operationalization of various skills into a single scale (Helsper \& Eynon, 2013). Furthermore, the research tends to focus on citizens or students instead of on the skills required for working professionals. To overcome these issues, a set of reliable measures that focus on the frequency of skill-related actions performed by working professionals are developed to measure each core 21st-century digital skill (RQ3). The items factually ask how often someone performs a skill-related action at work. They are disconnected from specific platforms or activities to be transferable across working situations (Hargittai \& Hsieh, 2012; Van Deursen, Helsper, \& Eynon, 2016). The result is an instrument with a broad range of 21stcentury digital skills supported by empirical data to validate the structure and content of each skill. The following 21st-century digital skills are operationalized:

Information digital skills: the skills to search, evaluate and manage digital information. The amount of online information and the proliferation of databases make using search engines effectively and efficiently essential (Punie \& AlaMutka, 2007; Ananiadou \& Claro, 2009). This dissertation specifically focuses on management and evaluation. Information management skills concern the ability to maintain information (Hwang, Kettinger, \& Yi, 2015) as workers must be able to manage their documents, files, emails, and other forms of digital information as part of their work activities. They require the skills of saving files in the proper place, being consistent in the naming of digital files, and organizing digital files via hierarchical folder structures. Information evaluation includes being able to judge the usefulness, relevance and reliability of retrieved digital information (Hwang, Tsai, Tsai, \& Tseng, 2008; Hatlevik \& Hatlevik, 2018). Workers need the skills to check whether the information found is correct and up-to-date.

Communication digital skills: the skills to transmit information online and to reflect upon the best way to present this information to a particular audience (Ananiadou \& Claro, 2009). As a result of globalization and technological developments, computer-mediated communication (e.g., instant messaging, chat, and email) has become prevalent in today's workplace (Schulze, Schultze, West, \& Krumm, 2017). This dissertation focuses on expressiveness, contactbuilding, networking and content-sharing skills. Communication expressiveness skills are the ability to shape interpersonal impressions and derive satisfactory outcomes from online interactions. Workers must be able to clearly articulate themselves through a variety of online media (Mishra \& Kereluik, 2011). The skills to choose the right location to post a message and to carefully consider its contents are crucial to get a message across and accomplish one's aims in online interactions (Van Deursen, Courtois, \& Van Dijk, 2014). Communication contact-building skills are needed because social applications offer individuals the opportunity to make and maintain contacts (Van Deursen et al., 2014). Closely related to this component are communication networking skills, the 
ability to mobilize online contacts to achieve a specific goal such as increasing brand awareness, facilitating resource mobilization or generating business (Wolff \& Moser, 2010). Finally, communication content-sharing skills are the skills required to share online content, from status updates, photos and videos to writing comments and blogs (Brandtzæg, Lüders, \& Skjetne, 2010; Lee, Park, \& Hwang, 2015).

Collaboration digital skills: the ability to work effectively and respectfully in teams to accomplish a common goal and to assume shared responsibility for completing tasks. Work is increasingly accomplished by diverse and interdisciplinary teams of people with complementary expertise and roles, as opposed to individuals engaging in isolated work (Mishra \& Kereluik, 2011). The teams involve individuals who are not collocated geographically and who share relevant experiences and information with each other through online media (Kang, Lee, \& Kim, 2017). Collaboration digital skills are required to identify specific functions for each member based on his or her expertise (Van Deursen et al., 2014). They go beyond communication digital skills as they concern the ability to support the work of others, for example, by working on the same document, simultaneously or not, and they take into account the progress made by team members.

Critical-thinking digital skills: the ability to make informed judgments about information and communication based on sufficient reflection and evidence. A person must consider multiple perspectives and decide whether the content is supported by objective data to establish substantiated arguments or reasoning (Higgins, 2014; Petrucco \& Ferranti, 2017). Critical thinking is regarded as the most important skill in discerning false, incomplete and obsolete online information and communication (Saadé, Morin, \& Thomas, 2012). It concerns the skills required to provide proof. Evidence and arguments must be evaluated independent of one's prior beliefs and opinions (West, Toplak, \& Stanovich, 2008). Workers need the skills to be open to ideas that challenge some of their beliefs and to consider various arguments before they formulate their own point of view. Critical thinking implies independent thinking and, therefore, being able to generate new input from an online discussion and to connect viewpoints.

Creative digital skills: the skills to appropriately use online tools to create online content. Workers must be able to use online platforms to give a creative turn to existing processes. ICTs enable employees to generate innovative ideas, perspectives and approaches from numerous online sources (Lee \&
Chen, 2015; Oldham \& Da Silva, 2015). They have the potential to increase the creativity of employees' ideas by providing them with unique and potentially diverse information. Moreover, people's creative potential is fostered by online platforms that enable them to be part of the design of software and to generate their own content (Petersen, 2008). The highly complex problems facing society in the 21st century necessitate new and creative solutions (Kereluik, Mishra, Fahnoe, \& Terry, 2013). Workers can use ICTs to show originality in their work and creatively execute their tasks.

Problem-solving digital skills: the skills to use ICTs to analyze a problem situation and deploy knowledge in finding a solution to the problem. Employees are increasingly confronted with complex, opaque and dynamic problems (Neubert, Mainert, Kretzschmar, \& Greiff, 2015). Problem solvers often use the Internet to generate and integrate information about the problem and to try and solve the problem according to the acquired information (Greiff \& Funke, 2017). In evaluating problem-solving skills, both flexibility and effectiveness should be considered (Yang, 2012). Flexibility results in a variety of unique responses to a problem that requires the skills to come up with multiple solutions to the problem using online platforms. Effectiveness ensures that the solutions are practical and thoroughly considered. This requires the skills to effectively use various online tools to reach a satisfactory decision or solution.

10.1.3 The measurement of workers' 21st-century digital skill levels

The third main scientific objective was to measure the level of 21 st-century digital skills among working professionals. The developed survey instrument is used to measure the level of 21st-century digital skills among professionals working within the creative industries. A noteworthy finding is that fairly high levels of 21st-century digital skills are reported (see figure 7.1, Chapter 7). Except for communication, content-sharing and contact-building skills, the skill levels are above average (RQ5). This finding can be explained considering that the creative industries represent a highly educated segment of the workforce (Cabrita, Machado, \& Cabrita, 2013). The creative industries are considered to be one of the nine key sectors in the so-called top sector policy of the Netherlands. The Dutch government decided that the creative industries should be one of the leading industries for the economy. However, one could also argue more is to be expected from such a highly educated workforce that is at the forefront of digital innovation. Except for information management skills, the skill levels are not exceptional high. It is reasonable to say that, for instance, 
communication networking skills are especially important within the creative industries as their market is characterized by the adoption of novel ideas within social networks for production and consumption (Hennekam \& Bennett, 2017 Potts, Cunningham, Hartley, \& Ormerod, 2008). They create ideas of expressive value that must be commercialized. Furthermore, the findings indicate relative differences in 21 st-century digital skill levels. If we consider the standard deviations of the mean scores, we observe that the skill levels show a large variation. This inevitably means that not all working professionals reach high skill levels, but there are still some who are lagging behind.

The relative differences in 21st-century digital skill levels become even more clear through performance testing. A key issue with respect to our survey measures is the reliance on self-reported survey data while the most valid way to measure skill levels is to rely on directly demonstrated performance. However, performance testing is much more expensive and effort-intensive and, therefore, difficult to conduct on large sample sizes. To date, skill levels have typically been derived from indirect self-reported measures. A useful contribution is to base the findings on the performance of working professionals who complete relevant tasks chosen to demonstrate 21st-century digital skills. This approach leads to the development of an authentic performance test using detailed indices per skill to assess task performance (see Chapter 8 ). The performance test further analyzes how to measure working professionals' actual levels of information, critical-thinking, creativity and problem-solving digital skills by means of a performance test. Communication and collaboration skills are not included due to the time-consuming nature of performance testing and the high levels of interaction (e.g., with clients or colleagues) that are required to measure such skills. The included four 21 st-century digital skills cannot all be captured in one answer or solution (e.g., critical thinking and creativity); therefore, we think of them as consisting of successful performance in novel, ill-defined situations and not only in certain concrete tasks (llomäki et al., 2016). A detailed qualitative analysis of the refined set of indices per skill reveals some important observations. A key observation is that the participants seem to have difficulty with information and problem-solving digital skills (RQ5). For example, they rarely check their answer on another website or provide multiple solutions with an explanation. With regard to critical-thinking and creative digital skills, the observations are promising as multiple skill indices are applied. For example, they provide arguments for multiple perspectives provided with proof or examples and are able to produce a large number of useful ideas. These observations are somewhat different than the survey results, which indicate slightly higher levels of information and problem-solving skills than critical-thinking and creativity skills. A possible explanation for this finding might be that the survey results are more vulnerable to response bias because they indicate workers' perceptions on their own skill levels. In comparison with performance testing, surveys may be less suitable to measure absolute skill levels; however, they are more suitable to quantify skill level differences because they can obtain data from relatively large and representative samples. From a more qualitative perspective, the performance test results confirm the relative differences in 21 st-century digital skill levels. The observations reveal that some working professionals have difficulties with all four 21st-century digital skills whereas others perform on almost all skill indices. An example concerning information skills is that some copy the complete question or use a too broad search query whereas others use specific keywords derived from the question. In the first case, multiple follow-up searches were required to generate relevant search results. An example of what went wrong concerning creativity skills is the fact that some come up with only one, nonoriginal, Internet of Things application such as automatically turning on and off the lights or thermostat. An example concerning critical thinking skills is that some do not provide any argumentation, nor do they provide examples to support or oppose even one of the perspectives on Internet of Things. Overall, the performance test results are an important step forward in the exposure of detailed skill indices to provide a deeper analysis of working professionals' levels of 21st-century digital skills.

10.1.4 The impact of the personal labor condition on 21st-century digital skill levels

The development of a quantitative survey instrument is part of a broader theoretical approach that aims at explaining differences in skill levels. The fourth main scientific objective was to explore the impact of the personal labor condition on the level of 21 st-century digital skills. The skill determinants are identified through a systematic literature review. The synthesis of skill determinants into multiple categories (demographic, socioeconomic, personality/psychological, temporal, material, mental/motivational, social, and cultural) enable a better understanding in the nature and extent of the empirical research on 21st-century skills and digital skills (see Chapter 6). The resulting overview demonstrates the skills and determinant groups that warrant future research attention (RQ6). First, 21st-century skills studies are largely 
limited to personality and psychological factors such as personality traits and intelligence. Digital skills studies show more variety; however, they mostly cover demographics (e.g., age and gender) and socioeconomic (e.g., education) and mental factors (e.g., training). Second, for 21st-century skills studies, creativity and critical thinking are the most investigated skills whereas technical and information skills are underrepresented. For digital skills studies, technical and information skills are the most investigated skills whereas critical thinking and creativity are underrepresented. The results show a lack of research on the determinants of communication and collaboration skills. Overall, factors such as gender, age, education, personality traits and intelligence are often investigated but are difficult to account for in skill interventions - these are more permanent and belong to an individual's position in society. The resources and appropriation theory was used as a broader framework to categorize the factors found in the literature (De Haan, 2004; Van Dijk, 2005). This theory allows us to categorize and explore a variety of factors. Thus, for instance, not only are personal characteristics and mental resources mentioned but also positional characteristics and material and social resources.

The systematic literature review was used to select the factors that can be influenced by the users of the technologies themselves as well as policy makers, educators and managers in organizations. A large-scale survey was conducted among professionals working within the creative industries to explain differences in the level of 21st-century digital skills (see Chapter 7). The focus is on various mental (ICT attitude, perceived ease of use, ICT self-regulation, selfdirected learning, goal orientations, ICT training), personal (individual initiative) and social resources (support sources). A noteworthy finding is that perceived ease of use, performance goal orientation, and support from Internet contacts online are prominent factors determining the level of various 21 st-century digital skills (RQ6). The results confirm that the belief that the technology is easy to use not only predicts technical skills but also content-related digital skills. The results also confirm that the tendency to outperform others to demonstrate one's own capability not only predicts social and creative skills offline but also in a digital environment. Lastly, the need for professionals to consider Internet contacts to be an informal support source is underscored. Overall, the level of each 21 st-century digital skill is explained by a different set of factors. To make it even more complex, the impact of the factors differs for employed and selfemployed workers. A noteworthy finding is that personal initiative is of particular importance for employed professionals whereas self-directed learning is of particular importance for self-employed professionals. A possible explanation for this finding might be that personal initiative is of particular importance for people who have no superior telling them what to do (Frese, Fay, Hilburger, Leng, \& Tag, 1997). As a consequence, self-employed professionals should already possess a high degree of initiative. With regard to self-directed learning, it might be especially important for self-employed professionals because they do not have regular access to formal learning and development opportunities (Haukka, 2011). Overall, while there are challenges in separately measuring various skills, the added value of working with separate skills is high because it allows for a more nuanced understanding of skill differences.

10.1.5 The development of policy to strengthen workers' level of 21stcentury digital skills

Aside from scientific objectives, this dissertation also focuses on practical objectives. The first main practical objective was to explore the role of human work, including potential employment, in the 21st century. On the one hand, automation and robotization have the potential to replace humans in routine, repetitive jobs (Berger \& Frey, 2015). On the other hand, humans are increasingly necessary in jobs created around the programming and managing of new ICTs. In defining 21st-century digital skills and why they matter, direction is taken from discussions around which skills allow human workers to stay employable. The implication is that 21 st-century digital skills are complemented rather than substituted by technology. The skills include not only the use of digital tools but also the higher-order skills for their critical and innovative applications The interview approach shows that the value of human work compared to automatization lies in the use of digital technology's potential to amplify human capacity for skills such as communication, collaboration and creativity. The results confirm the previous research in the sense that the human ability to communicate, collaborate and create are some of the skills that remain key to the workplace (e.g., Autor, 2015; Autor, Levy, \& Murnane, 2003). The top-level management working within the creative industries not only expressed the need to learn advanced technical skills, but they also referred to the importance of 21st-century skills. Digital technologies are increasingly being seen as an instrument to improve one's business results or processes. Human abilities are required to exploit the digital opportunities being offered and to understand and serve the demands of the market. Often, top-level management does not explicitly refer to content-related digital skills but only to technical-related 
digital skills. To ensure that the concept 21 st-century digital skills is more widely accepted in practice, our findings could be presented in conferences or symposiums focused on the creative industries. This may help to foster the discussion about the interpretation of 21st-century digital skills. Industry experts could play an important role in further operationalizing the skills needed for human work.

The second main practical objective was to develop policy to strengthen workers' levels of 21 st-century digital skills. The interview approach resulted in useful insights into policy initiatives with regard to skill development and how top-level management gives meaning to the results found in our previous studies (see Chapter 9). Often, top-level management expects individual workers to develop themselves. As technology is rapidly proliferating and becoming more ubiquitous in the workplace, a higher level of flexibility and the need to regularly update skills is expected from individual workers (Campbell, 2018). It is reasonable to suggest that lifelong learning is necessary to remain proficient in the changing workplace. However, skill developmen should not be considered to be solely an individual task. Overall, one could consider establishing the awareness of the need for skill development among the involved stakeholders (e.g., education, industry, and individual workers) to be an important first step toward targeted policy interventions (RQ7). The section on practical implications in this chapter discusses some concrete policy recommendations to strengthen workers' levels of 21st-century digital skills.

Not only does the interview approach hold important implications for skill development policy, but so does the full survey conducted among professionals working within the creative industries to empirically test the relation among various 21 st-century digital skills (see Chapter 5 ). The survey results provide useful insights into the other skills that are needed to perform well on a specific skill (RQ4). In addition to the factors that influence differences in workers' skil levels (see Chapter 7), the results highlight another barrier to skill development as the skills build on each other sequentially. This means that a person who lacks one type of skill is also likely to lack another. The sequence of the model begins with information and communication digital skills followed by collaboration, critical-thinking and creative digital skills. An important finding is that except for critical-thinking digital skills, all skills directly lead to problem-solving digital skills. The exposure of how various types of skills relate to each other is important for designing interventions that result in skill improvements. For example, directly focusing on the improvement of collaboration digital skills wil be less effective compared to programs that first focus on repairing insufficient information and communication digital skills, which are required for performing well on collaboration digital skills. A thorough understanding of how 21stcentury digital skills interrelate is necessary for improved policy initiatives.

\subsection{THEORETICAL AND METHODOLOGICAL IMPLICATIONS}

The outcomes of the studies have several theoretical and methodological implications. To begin, the primary contribution to the theory is the identification of the digital aspect of 21st-century skills. Various terms exist to describe the skills related to the use of ICT or digital technology (Ilomäki et al., 2016; Litt, 2013). The conceptual confusion in the literature is addressed by elaborating on the existing concepts and skill dimensions. The broadness of the dimensions related to 21 st-century skills illustrates the complexity of the term and the multiple contexts in which it may appear. On the one hand, it could be seen as a temporary and popular term. On the other hand, if you look at the literature the term is widely supported in the academic and practitioner outlets. However the meaning of 21st-century skills often remains implicit or vague and, therefore, it is difficult to accumulate knowledge in the long-term and build toward comparative research. This dissertation specifies 21st-century skills through the addition of digital technology. Another contribution to the theory is that the relations between the technical and content-related aspects of each skill are determined. Traditionally, a great deal of focus has been directed toward the technology itself and the skills that are needed to operate computers and software (Erstad, 2011). By synthesizing the literature, theoretical support is provided for a broader definition beyond mere technical skills. Content-related skills with a strong digital component component - such as communication, creativity, and problem solving - are considered to be essential for the flexibility required by future workplace demands (Van Deursen \& Helsper, 2018). Our 21 st-century digital skills framework demonstrates the relations between the technical and content-related aspects of each skill. A final conceptual contribution is that the sequence of 21 st-century digital skills is determined. In most conceptualizations of 21 st-century skills and digital skills, the relevant skills are considered and analyzed separately, as if they were independent of each other.

Nevertheless, one could raise the question of whether our academic definition of 21st-century digital skills is as complete and fundamental as we 
seem to suggest. Although we have specified 21st-century digital skills through survey questions and performance test tasks, we do acknowledge that our academic conceptualization of 21st-century digital skills could be specified for organizations. The skills found in the literature have received substantial scientific effort, and we attempt to make them applicable to the workforce. In line with a lack of theoretical and empirical research on digital skills of the workforce (Murawski \& Bick, 2017), it is necessary to establish a research stream that tries to understand the consequences and requirements of digitization in terms of individual workers' skills (Hirsch-Kreinsen, 2016). The analysis of working professionals' skills, including various occupations or industries, is a neglected field of study. From our point of view, focusing on the workforce, in our case the sector creative industries, is necessary to respond to the growing demand for highly digitally skilled workers who meet the requirements and expectations of the current workplace (Lanvin \& Kralik, 2009). They represent a technological and knowledge-intensive sector and might exemplify the skills that other industries can acquire to improve their innovation capabilities (Bakhshi, Cunningham, \& Mateos-Garcia, 2015). In addition, the strong presence of creative professionals across many parts of the economy outside of the creative industries makes the sector worthy of focus. An implication for the theory is that, based on our conceptualization and corresponding operationalization, one could specify the 21 st-century digital skills for a branch of the creative industries. This contribution has shown that working professionals' skills play an important role in future industry changes (Kamprath \& Mietzner, 2015). To date, the creative industries have received relatively little attention from business and management researchers (Chaston \& SadlerSmith, 2012) while they could provide input for innovation into the production processes of businesses in other sectors.

In addition, we demonstrate how our broader organizing framework may be applied in structuring the empirical investigation of 21 st-century digital skills. This contribution also adds to the literature with the development and validation of the 21 st-century digital skills instrument, which is unique in the sense that it provides researchers and practitioners with a reliable measure to separately quantify the level of a broad range of skills among working professionals. This instrument explicitly incorporates the full range of digital skills, from information management to problems-solving skills. There is an urgent need for the development of measures across the range of 21st-century digital skills. Although it is expected that the instrument applies to a broad range of occupations, a recommendation for the theory is to test whether the scales are consistent in their characteristics when compared across different professional groups. Continuing the research on 21st-century digital skills could also benefit from more clearly explicating the rationale for inclusion of the given underlying components that underscore the operationalization of each skill (Reynolds, 2016). The research needs to recognize the multidimensional nature of the digital skills required to engage with online content (Helsper \& Van Deursen, 2015). Overall, there is a growing need to reflect on the concept of 21 st-century digital skills, their construction and underlying components to build toward more organized ongoing research efforts.

Furthermore, while there are challenges in separately measuring various skills, the added value of working with separate skills is high because it allows for a more nuanced understanding of skill development practices. This contribution demonstrates the importance of separately operationalizing skills as it allows researchers to investigate in which sequence the skills must be learned and to investigate the impact of a determinant on a range of skills. Thus, it is recommended that survey measures be developed that clearly operationalize separate skills. Another contribution to the theory is the explanation of the differences in the levels of skills by relating a variety of psychological and sociological factors to a broad set of 21st-century digital skills. Most of the research in this area has primarily focused on the impact of demographics such as gender, age and education (Ghobadi \& Ghobadi, 2015). It is necessary to consider other variables besides demographics that may help us understand the nature of skill differences (Gallardo-Echenique, Marqués-Molías, Bullen, \& Strijbos, 2015). Therefore, the challenge is to focus on the determinants that can be controlled. It is insufficient to expect that every working professional naturally possess 21 st-century digital skills or that they will develop them by chance while undertaking work activities.

Moreover, this contribution responds to the need for a performance test to derive people's actual skill levels (Siddiq, Hatlevik, Olsen, Throndsen, \& Scherer, 2016). By performing an activity on the Internet, it is evident that performancebased assessments have the potential to deliver more valid measures of skills. Our performance test responds to the call to conduct a qualitative analysis to provide more details about the specific skills indices (Van Deursen \& Van Dijk, 2011b). Although our performance-based test is hindered by its relatively small sample size, the results are an important step forward in the analysis of performance-based rather than self-perceived skill levels (Aesaert, Van Nijlen, 
Vanderlinde, Tondeur, Devlieger, \& Van Braak, 2015). Other researchers are encouraged to use a performance-based approach.

In conclusion, the theoretical contribution of this dissertation is an interdisciplinary conceptual and operational elaboration of various 21st-century digital skills and their potential causes at the level of the individual worker and to demonstrate their significance by applying a multimethod research approach.

\subsection{PRACTICAL IMPLICATIONS}

Thera are a number of practical implications for educators, organizations and individual workers involved in the creative industries that can be derived from our findings.

1) Awareness initiatives: A general debate about 21 st-century digital skills is needed to ensure that the concept is more widely accepted and supported in practice. The fact that managers working within the creative industries do not seem to recognize 21st-century digital skills raises the need for a discussion on how the 21st-century digital skills of working professionals at various positions and levels of an organization should be interpreted. On the one hand, in the minds of managers, digital skills are mostly related to technical or mediumrelated skills. Although they touch upon some broader aspects or applications of 21st-century digital skills, managers often do not recognize it as such. The content-related aspects of digital skills are widely acknowledged in the academic literature (e.g., Helsper \& Van Deursen, 2015; Kaarakainen, Kaarakainen, \& Kivinen, 2018). On the other hand, our framework of 21st-century digital skills seems to imply that all workers need some degree of proficiency in each skill; however, it is unclear if they are critical to the successful execution of every job function. Although we do acknowledge that not all workers need the same level of 21st-century digital skills, information about which skills are needed in particular job categories is lacking. Working professionals may differ in their ability to perform specific tasks because their human capital is occupationspecific (Kambourov \& Manovskii, 2009; Koch, 2016; Sullivan, 2010). Academics and industry experts could learn from each other to bring the concept of $21 \mathrm{st}-$ century digital skills forward. Involving practitioners in the research and drawing on their expertise when developing future projects or policy initiatives might be a first step toward their commitment to them (Ananiadou \& Claro, 2009) This approach could potentially optimize the valorization of the research results by giving the opportunity, for instance, to present the results in a conference or symposium devoted to the creative industries. In this way, an open and informed discussion about the meaning of 21st-century digital could be held.

2) Skills monitoring: Organizations could do more to evaluate and monitor skill levels by setting clear time frames and deliverables for review. Additionally, little evidence is provided that the organizations involved in our research systematically assess 21 st-century digital skills. In other words, it is likely that digital skills are defined with little distinction between them or understanding of the operational components covered by each skill. Our 21st-century digital skills framework can be used as a guideline to describe the skill needs per occupational group. An overview of the required 21st-century digital skills per job position makes it possible to identify skill gaps, which can ultimately be used as a measurement guideline. The skill levels can be monitored against the job profiles as well as against specific indicators and performance features. This approach could bring skills assessment more into focus. As above point shows, thorough assessment methods cannot be developed without clear operationalizations of the 21st-century digital skills in question. That said, skills assessment is important to identify areas that require a change in policy strategy within an organization. Overall, the findings might contribute to the debate on appropriate evaluation methods and show practitioners the need to undertake regular evaluation in the area of 21 st-century digital skills.

3) Strengthening the connection between education and industry: Although managers acknowledge that pursuing a perfect skills match is not realistic because content is rapidly outdated, a closer alignment between education and industry is necessary. A possible source of the mismatch is that employers and educators have different understandings of the types of skills that are valued in the labor market (Cunningham \& Villaseñor, 2016). With regard to technical skills mismatch, incoming employees who have just graduated from school generally have sufficient basic medium-related digital skills but lack the more advanced or specialized ones. An implication for education is to use up-to-date software that is compliant with work requirements. An implication for industry is to use, maybe even more than it already does, work placements as an opportunity to provide necessary targeted development opportunities for emergent advanced digital skills. Education and industry both have an important role to play in addressing the skills mismatch. Strengthening the connection between education and the labor market remains one of the notable challenges (Cobo, 2011). Education requires change to meet the demanding needs of the labor market but at the same time requires input from industry with 
regard to the proper direction in which to move. On the one hand, educational institutions, in many instances, have difficulties with aligning curricula with the requirements of industry. Educational programs could invite industry experts to participate in lectures and the development of curriculums more often. On the other hand, educational institutions cannot change that which they do not know exists. Therefore, industry must support educational institutions to reflect on their digital practices and to further develop their strategies. Rather than attempting to meet all technical skill requirements, it may be just as valuable for educational institutions and organizations to prepare students to take personal responsibility for their own skill development in an ongoing way (Bridgstock, 2011). In addition, it is unlikely that students can be prepared for all of the employment scenarios they will encounter. The vision in which all individuals must continuously update and expand their skills should be embraced in education and working life. Providing students with the opportunity to learn from multiple disciplines might widen their perspective and increase their ability to handle new situations.

4) Collective professionalism: The debate about how to effectively deal with advanced medium-related skills should be continued, and more attention should be given to the development of the 21st-century digital skills that are required for employability. With regard to the skills mismatch, several managers state the importance of developing soft skills; however, most of them do not mention 21st-century skills as defined in our framework. They discuss soft skills in terms of leadership and project management skills and seem to have no policy with respect to the development of 21 st-century skills or 21 st-century digital skills. Even after the confrontation with 21 st-century digital skill levels, skills such as communication and critical thinking in digital contexts are usually assumed to develop spontaneously or organically while they also must be learned and trained. It is imperative to consider how training should be developed to support the development of 21 st-century digital skills. Managers could review our developed survey questions and performance tasks and link them to their own profession and organizational settings. They could collectively, in a team of working professionals, discuss how they approach these skills. Together, professionals can evaluate how they, for instance, analyze a problem or use and select information sources in digital contexts. Especially because a community of professionals exists in almost all sectors of the creative industries (Bettiol \& Sedita, 2011; Parmentier \& Mangematin, 2014). Learning from each other is essential to impart 21 st-century digital skills.
5) Lifelong learning imperative: The responsibility is on individual workers to position themselves in such a way that they continue to add value to the labor market. From the perspective of the individual worker, among other actions, it is valuable to take the initiative, ask for help and participate in training. Perhaps behind those factors lies the deeper motivation to strengthen one's own value within the organization. Individuals are expected to possess a strong learning orientation and to actively seek valuable new knowledge or experiment with new digital technologies. A substantial concern associated with technological advances is that certain technical skills suddenly become less valuable or even obsolete. Rapid technological change implies that there may be a greater need for ongoing skill development than in other sectors of the economy. The policy implications from these conclusions indicate the importance of lifelong learning in ICTs for achieving those skills that will increase one's employment opportunities. Professionals working within the creative industries need to constantly reinvent themselves and apply new and valuable knowledge that will result in unique, distinctive and original products and services (Cabrita, Machado, \& Cabrita, 2013). As such, they should invest in their own skill development as well as express to employers their demand for formal or informal training. One should not underestimate the role of individual workers; they must seek for opportunities to increase their skill levels. At the same time, there is also a need to identify how organizations can stimulate continuous professional development to ensure that workers' skills are updated in line with technological changes.

6) E-learning: With the use of digital tools, learning can happen trough both individual learning and social interaction. Skill development should not be seen as a solely individual activity but as a joint effort. The availability of digital learning resources enables the self-directed learning of 21 st-century digital skills while connectivity to other people provides formal and/or informal support when needed (Baruch \& Erstad, 2018; Punie \& Ala-Mutka, 2007). A potential policy strategy to discuss with organizations to strengthen 21 st-century digital skills is to implement digital tools. First, implementing digital tools in the work process can encourage working professionals, for instance, to create and share resources or to develop multiple solutions to problems. If digital tools are introduced to workers with the need to use them for a specific purpose, it is more likely that they will seek out, explore and use them (Ng, 2012). Second, digital tools can foster the discussion about what 21 st-century digital skills should encompass or how the design of such tooling can be improved. 
E-learning can be seen as a platform where knowledge can be shared and discussed among colleagues (Louw, 2014). Again, from a policy point of view, our recommendations can only be put into practice if organizations regard them as valuable and relevant to their work. Practice will show how and when digital tools can best be used to support 21st-century digital skills.

In conclusion, it is preferable to first raise awareness before attempting to reshape practice. Overall, our findings show that the goal of policy should be the creation of a broader digitally skilled workforce. The three perspectives present in our practical implications show the importance of the interconnectedness among education, industry and individual workers. They all have their responsibility and must take the call to action to fulfill the demand for a digitally skilled workforce.

\subsection{LIMITATIONS AND FUTURE RESEARCH DIRECTIONS}

Aside from the limitations per study as discussed in the chapters, the research reported in this dissertation presents some overall limitations that should be addressed.

First, it is important to note that the efforts to define measurable skill dimensions do not consist in simply translating offline skills to an online context. Although many of the skill activities we undertake have a digital component, analyzing skills related to the digital context requires a thorough understanding of the underlying aspects (Ferrari, Punie, \& Redecker, 2012). In an effort to operationalize 21st-century digital skills, several separate aspects and categories of it have been formulated. This was a challenging process because the digital component is often not embedded within 21st-century skills (Voogt \& Pareja Roblin, 2012). As such, more work is needed to continue strengthening the operationalization. In addition, our survey instrument can be improved by validating these measures through performance tests as a comparison.

Second, the survey research was limited by focusing solely on the factors at the level of the individual worker to explain differences in skill levels. In the organizational context, other factors might hinder or support the development of 21 st-century digital skills. For example, organizational factors such as job autonomy, professional learning and development opportunities, and organizational culture could be included (e.g., Martínez-Cerdá, Torrent-Sellens, \& González-González, 2018; Van Deursen, Verlage, \& Van Laar, 2019). Future research could also investigate the interplay between how individual factors interact with the organizational setting. The extent to which workers apply or further develop their skills is often integral to the organizational dynamic at work, which either limits or facilitates the workplace environment as a learning space (Evans \& Kersh, 2014; Wang, Vogel, \& Ran, 2011). The alignment of individual and organizational learning needs is not considered. To expand our findings, future research may also consider other individual factors. The included factors explain a relatively modest percentage of variance within skill levels; therefore, it is important to take into account the other factors at the individual level that potentially influence 21 st-century digital skills. This research was only able to include a few individual factors identified from the systematic literature review. For example, individual factors such as learning motivation and learning styles might play a pivotal role (Jiménez-Cortés, Vico-Bosch, \& Rebollo-Catalán, 2017; Youssef, Dahmani, \& Omrani, 2015).

Third, because the execution of performance-based tasks is a timeconsuming process, the number of skills selected for measurement was limited. For example, the skills to communicate or collaborate with clients or colleagues in a digital environment have been neglected. Because the tasks impose a high cognitive load on the participants, the inclusion of other skills would have made the performance test too demanding. In addition, it is difficult to measure such social skills in performance tests as interaction will be required (Van Deursen \& Helsper, 2018). However, online communication and collaboration skills are valuable skills and must receive more research attention. An avenue for future research might be to explore the optimal test design to include multiple skills in one test. Although this research attempts to measure skills in a direct way by assessing the individual performance on distinct tasks, it is problematic to use our approach on a large scale. The costs and labor associated with performance testing makes them extremely difficult to replicate on larger samples (Hargittai \& Hsieh, 2012). Another proxy for performance tests that could be applied at a larger scale are scenario-based performance tasks. In such tasks, the participants must solve information problems using simulated software (Katz, Haras, \& Blaszczynski, 2010). Future research may further consider how to combine direct and indirect skills measurement instruments in their research designs that can be deployed in large-scale settings.

Lastly, although the research was conducted in an emerging, knowledgeintensive sector of the economy, specifically, the creative industries, the samples included in this contribution have some overall limitations. The creative industries refer to a highly diverse and fragmented industry and include a variety 
of job activities and organizations (Hennekam \& Bennett, 2017). The samples of professionals and managers working within the creative industries were spread out across subsectors (from architecture to gaming) and in terms of organization size (from small to large) and job function (from business owners to designers) Although this contribution aimed for a diverse sample of working professionals and managers from various sectors and professional backgrounds, this may limit the generalizability of the findings for all sectors within the creative industries. In addition, the data were collected in a single country, the Netherlands, which also limits generalizability. Future research could test whether the results of the current research apply to specific subsectors of the creative industries and other countries. Empirical data are needed on which specific skills are needed and which skills are lacking for which groups of individuals and sectors (Van Deursen \& Helsper, 2018). Our research area is the creative industries, implying that we strictly do not know whether the same results would be found in other sectors. However, we do expect that our results say something about the need for 21st-century digital skills in sectors where knowledge workers play an increasingly important role. This dissertation demonstrates that there is an increasing need for knowledge workers who possess 21st-century digital skills in times of advanced automation and robotization. These skills are not only essential for the professionals working within the creative industries but also for other knowledge-intensive professions. 


\section{REFERENCES}

Aesaert, K., \& Van Braak, J. (2015). Gender and socioeconomic related differences in performance based ICT competences. Computers \& Education, 84, 8-25. doi:10.1016/j.compedu.2014.12.017.

Aesaert, K., Van Nijlen, D., Vanderlinde, R., Tondeur, J., Devlieger, I., \& Van Braak, J. (2015). The contribution of pupil, classroom and school level characteristics to primary school pupils' ICT competences: A performance-based approach Computers \& Education, 87, 55-69. doi:10.1016/j.compedu.2015.03.014.

Aesaert, K., Van Nijlen, D., Vanderlinde, R., \& Van Braak, J. (2014). Direct measures of digital information processing and communication skills in primary education: Using item response theory for the development and validation of an ICT competence scale. Computers \& Education, 76, 168-181. doi:10.1016/j.compedu.2014.03.013.

Ahmad, M., Karim, A. A., Din, R., \& Albakri, I. S. M. A. (2013). Assessing ICT competencies among postgraduate students based on the 21st century ICT competency model. Asian Social Science, 9(16), 32-39. doi:10.5539/ass.v9n16p32.

Ahonen, A. K., \& Kinnunen, P. (2015). How do students value the importance of twentyfirst century skills? Scandinavian Journal of Educational Research, 59(4), 1-18. doi:10.1080/00313831.2014.904423.

Ala-Mutka, K. (2011). Mapping digital competence: Towards a conceptual understanding. Sevilla, Spain: Joint Research Centre, Institute for Prospective Technological Studies.

Amabile, T. M. (1988). A model of creativity and innovation in organizations. Research in Organizational Behavior, 10(1), 123-167.

Amabile, T. M., Conti, R., Coon, H., Lazenby, J., \& Herron, M. (1996). Assessing the work environment for creativity. Academy of Management Journal, 39(5), 1154-1184. doi:10.2307/256995.

Amabile, T. M., \& Pillemer, J. (2012). Perspectives on the social psychology of creativity. The Journal of Creative Behavior, 46(1), 3-15. doi:10.1002/jocb.001.

Ananiadou, K., \& Claro, M. (2009). 21st Century skills and competences for new millennium learners in OECD countries. OECD Education Working Papers, No. 41. Paris, France: OECD Publishing. doi:10.1787/218525261154.

Anderson, R. (2008). Implications of the information and knowledge society for education. In J. M. Voogt \& G. Knezek (Eds.), International handbook of information technology in primary and secondary education (pp. 5-22). New York, NY: Springer.

Annink, A., Den Dulk, L., \& Steijn, B. (2016). Work-family conflict among employees and the self-employed across Europe. Social Indicators Research, 126(2), 571-593. doi:10.1007/s11205-015-0899-4.

Archibald, D., Trumpower, D., \& MacDonald, C. J. (2014). Validation of the Interprofessional Collaborative Competency Attainment Survey (ICCAS). Journal of Interprofessional Care, 28(6), 553-558. doi:10.3109/13561820.2014.917407. 
Arntz, M., Gregory, T., \& Zierahn, U. (2016). The risk of automation for jobs in OECD countries. OECD Social, Employment and Migration Working Papers, No. 189. Paris, France: OECD Publishing. doi:10.1787/5jlz9h56dvq7-en.

Assessment and Teaching of 21st Century Skills (2012). What are 21st century skills? Retrieved from: http://atc21s.org/.

Autor, D. H. (2015). Why are there still so many jobs? The history and future of workplace automation. The Journal of Economic Perspectives, 29(3), 3-30. doi:10.1257/ jep.29.3.3.

Autor, D. H., Levy, F., \& Murnane, R. J. (2003). The skill content of recent technologica change: An empirical exploration. The Quarterly Journal of Economics, 118(4), 12791333. doi:10.1162/003355303322552801.

Bakhshi, H., Cunningham, S., \& Mateos-Garcia, J. (2015). Public policy for the creative industries. In C. Jones, M. Lorenzen \& J. Sapsed (Eds.), The Oxford handbook of creative industries (pp. 465-479). Oxford, UK: Oxford University Press.

Bakhshi, H., Freeman, A., \& Higgs, P. (2012). A dynamic mapping of the UK's creative economy. London, UK: NESTA.

Bakke, E. (2010). A model and measure of mobile communication competence. Human Communication Research, 36(3), 348-371. doi:10.1111/j.1468-2958.2010.01379.x.

Bălău, N., \& Utz, S. (2017). Information sharing as strategic behaviour: The role of information display, social motivation and time pressure. Behaviour \& Information Technology, 36(6), 589-605. doi:10.1080/0144929X.2016.1267263.

Bandalos, D. L., \& Finney, S. J. (2001). Item parceling issues in structural equation modeling. In G. A. Marcoulides \& R. E. Schmacker (Eds.), New developments and techniques in structural equation modeling (pp. 269-296). Mahwah, NJ: Lawrence Erlbaum Associate.

Barak, M. (2018). Are digital natives open to change? Examining flexible thinking and resistance to change. Computers \& Education, 121, 115-123. doi:10.1016/j. compedu.2018.01.016.

Baruch, A. F., \& Erstad, O. (2018). Upbringing in a digital world: Opportunities and possibilities. Technology, Knowledge and Learning, 23(3), 377-390. doi:10.1007/ s10758-018-9386-8.

Bawden, D. (2008). Origins and concepts of digital literacy. In C. Lankshear \& M. Knobel (Eds.), Digital literacies: Concepts, policies and practices (pp. 17-32). New-York, NY: Peter Lang Publishing.

Benedek, M., Nordtvedt, N., Jauk, E., Koschmieder, C., Pretsch, J., Krammer, G., \& Neubauer, A. C. (2016). Assessment of creativity evaluation skills: A psychometric investigation in prospective teachers. Thinking Skills and Creativity, 21, 75-84. doi:10.1016/j.tsc.2016.05.007

Berger, T., \& Frey, C. B. (2015). Bridging the skills gap. In T. Dolphin (Ed.), Technology, globalisationand the future of work in Europe: Essays on employment in a digitised economy (pp. 75-79). London, UK: Institute for Public Policy Research.
Bettiol, M., \& Sedita, S. R. (2011). The role of community of practice in developing creative industry projects. International Journal of Project Management, 29(4), 468479. doi:10.1016/j.ijproman.2011.01.007.

Bilton, C., \& Leary, R. (2002). What can managers do for creativity? Brokering creativity in the creative industries. International Journal of Cultural Policy, 8(1), 49-64. doi:10.1080/10286630290032431.

Binkley, M., Erstad, O., Herman, J., Raizen, S., Ripley, M., Miller-Ricci, M., \& Rumble, M. (2012). Defining twenty-first century skills. In P. Griffin \& E. Care (Eds.), Assessment and teaching of 21st century skills: Methods and approach (pp. 17-66). Dordrecht, the Netherlands: Springer.

Binnewies, C., Ohly, S., \& Sonnentag, S. (2007). Taking personal initiative and communicating about ideas: What is important for the creative process and for idea creativity? European Journal of Work and Organizational Psychology, 16(4), 432-455. doi:10.1080/13594320701514728.

Bloom, B. S., Engelhart, M. D., Furst, E. J., Hill, W. H., \& Krathwohl, D. R. (1956) Taxonomy of educational objectives: The classification of educational goals. New York, NY: David McKay.

Boeren, E., Nicaise, I., \& Baert, H. (2010). Theoretical models of participation in adult education: The need for an integrated model. International Journal of Lifelong Education, 29(1), 45-61. doi:10.1080/02601370903471270."

Bontje, M., Musterd, S., Kovács, Z., \& Murie, A. (2011). Pathways toward European creative-knowledge city-regions. Urban Geography, 32(1), 80-104. doi:10.2747/02723638.32.1.80.

Bosch-Sijtsema, P. M., Ruohomäki, V., \& Vartiainen, M. (2009). Knowledge work productivity in distributed teams. Journal of Knowledge Management, 13, 533 546. doi:10.1108/13673270910997178.

Bosch-Sijtsema, P. M., Fruchter, R., Vartiainen, M., \& Ruohomäki, V. (2011). A framework to analyze knowledge work in distributed teams. Group \& Organization Management 36(3), 275-307. doi:10.1177/1059601111403625.

Boyd, D. M., \& Ellison, N. B. (2007). Social network sites: Definition, history, and scholarship. Journal of Computer-Mediated Communication, 13(1), 210-230. doi:10.1111/j.1083-6101.2007.00393.x.

Brake, D. R. (2014). Are we all online content creators now? Web 2.0 and digital divides. Journal of Computer-Mediated Communication, 19(3), 591-609. doi:10.1111/ jcc4.12042.

Brandtweiner, R., Donat, E., \& Kerschbaum, J. (2010). How to become a sophisticated user: A two-dimensional approach to e-literacy. New Media \& Society, 12(5), 813833. doi:10.1177/1461444809349577.

Brandtzæg, P. B., Lüders, M., \& Skjetne, J. H. (2010). Too many Facebook "friends"? Content sharing and sociability versus the need for privacy in social network sites. International Journal of Human-Computer Interaction, 26(11-12), 1006-1030. doi:10.1080/10447318.2010.516719. 
Braun, V., \& Clarke, V. (2006). Using thematic analysis in psychology. Qualitative Research in Psychology, 3(2), 77-101. doi:10.1191/1478088706qp063oa.

Bridgstock, R. (2011). Skills for creative industries graduate success. Education + Training, 53(1), 9-26. doi:10.1108/00400911111102333.

Bronstein, L. R. (2003). A model for interdisciplinary collaboration. Social Work, 48(3), 297-306. doi:10.1093/sw/48.3.297.

Buckingham, D (2007). Digital media literacies: Rethinking media education in the age of the Internet research. Comparative and International Education, 2(1), 43-55. doi:10.2304/rcie.2007.2.1.43

Bunz, U., Curry, C., \& Voon, W. (2007). Perceived versus actual computer-emailweb fluency. Computers in Human Behavior, 23(5), 2321-2344. doi:10.1016/j. chb.2006.03.008.

Burleson, B. R., \& Samter, W. (1990). Effects of cognitive complexity on the perceived importance of communication skills in friends. Communication Research, 17(2), 165182. doi:10.1177/009365090017002002.

Burton, L. J., \& Mazerolle, S. M. (2011). Survey instrument validity part I: Principles of survey instrument development and validation in athletic training education research. Athletic Training Education Journal, 6(1), 27-35.

Byrne, B. M. (2010). Structural equation modeling with Amos: Basic concepts, applications and programming (2nd edition). New York, NY: Taylor \& Francis Group.

Cabrita, M. R. M., Machado, V. A. C., \& Cabrita, C. (2013). Managing creative industries in the context of knowledge-based urban development. International Journal of Knowledge-Based Development, 4(4), 318-337. doi:10.1504/IJKBD.2013.058524.

Campbell, D. T., \& Fiske, D. W. (1959). Convergent and discriminant validation by the multitrait-multimethod matrix. Psychological Bulletin, 56(2), 81-105. doi:10.1037/ h0046016.

Campbell, T. A. (2018). A phenomenological study of business graduates' employment experiences in the changing economy. Journal for Labour Market Research, 52(4), 1-10. doi:10.1186/s12651-018-0238-8.

Carey, C., \& Naudin, A. (2006). Enterprise curriculum for creative industries students: An exploration of current attitudes and issues. Education + Training, 48(7), 518-531. doi:10.1108/00400910610705908.

Carleton, K. (2011). How to motivate and retain knowledge workers in organizations: A review of the literature. International Journal of Management, 28(2), 459-468.

Carmeli, A., \& Schaubroeck, J. (2007). The influence of leaders' and other referents' normative expectations on individual involvement in creative work. The Leadership Quarterly, 18(1), 35-48. doi:10.1016/j.leaqu.2006.11.001.

Carnevale, A. P., \& Smith, N. (2013). Workplace basics: The skills employees need and employers want. Human Resource Development International, 16(5), 491-501. doi:10.1080/13678868.2013.821267.
Carr, M., McChesney, J Cowie, B, Miles-Kingston, R, \& Sands, L. (2010). Dispositions, disciplines, and marble runs: A case study of resourcefulness. In S. R. Goldman, J. Pellegrino, K. Gomez, L. Lyons \& J. Radinsky (Eds.), Proceedings of International Conference of the Learning Sciences Conference 2010 (pp. 215-221). Chicago, IL: International Society of the Learning Sciences.

Castells, M. (1996). The rise of the network society. Oxford, UK: Blackwell Publishers.

Catts, R., \& Lau, J. (2008). Towards information literacy indicators. Paris, France: UNESCO Publishing.

Caves, R. (2000). Creative industries: Contracts between art and commerce. Cambridge MA: Harvard University Press.

Çevik, Y. D. (2015). Assessor or assessee? Investigating the differential effects of online peer assessment roles in the development of students' problem-solving skills. Computers in Human Behavior, 52, 250-258. doi:10.1016/j.chb.2015.05.056.

Chaston, I., \& Sadler-Smith, E. (2012). Entrepreneurial cognition, entrepreneurial orientation and firm capability in the creative industries. British Journal of Management, 23(3), 415-432. doi:10.1111/j.1467-8551.2011.00752.x.

Chen, C. H. (2010). Promoting college students' knowledge acquisition and ill-structured problem solving: Web-based integration and procedure prompts. Computers \& Education, 55(1), 292-303. doi:10.1016/j.compedu.2010.01.015.

Chen, C. J., Shih, H. A., \& Yeh, Y. C. (2011). Individual initiative, skill variety, and creativity: The moderating role of knowledge specificity and creative resources. The International Journal of Human Resource Management, 22(17)، 3447-3461. doi:10.1080/09585192.2011.599940.

Chen, M. H., Chang, Y. Y., \& Lo, Y. H. (2015). Creativity cognitive style, conflict, and career success for creative entrepreneurs. Journal of Business Research, 68(4), 906 910. doi:10.1016/j.jbusres.2014.11.050.

Chiocchio, F., Grenier, S., O’Neill, T. A., Savaria, K. \& Willms, J. D. (2012). The effects of collaboration on performance: A multilevel validation in project teams. International Journal of Project Organisation and Management, 4(1), 1-37. doi:10.1504/ IJPOM.2012.045362.

Chiu, C. M., Hsu, M. H., \& Wang, E. T. (2006). Understanding knowledge sharing in virtual communities: An integration of social capital and social cognitive theories. Decision Support Systems, 42(3), 1872-1888. doi:10.1016/j.dss.2006.04.001.

Chou, S. W. (2010). Why do members contribute knowledge to online communities? Online Information Review, 34(6), 829-854. doi:10.1108/14684521011099360.

Choy, D., Deng, F., Chai, C. S., Koh, H. L. J., \& Tsai, P. S. (2016). Singapore primary and secondary students' motivated approaches for learning: A validation study. Learning and Individual Differences, 45, 282-290. doi:10.1016/j.lindif.2015.11.019.

Choy, S. C., \& Cheah, P. K. (2009). Teacher perceptions of critical thinking among students and its influence on higher education. International Journal of Teaching and Learning in Higher Education, 20(2), 198-206. 
Chung, S., Lee, K. Y., \& Choi, J. (2015). Exploring digital creativity in the workspace: The role of enterprise mobile applications on perceived job performance and creativity. Computers in Human Behavior, 42, 93-109. doi:10.1016/j.chb.2014.03.055.

Claro, M., Preiss, D. D., San Martín, E., Jara, I., Hinostroza, J. E., Valenzuela, S., Cortes, F., \& Nussbaum, M. (2012). Assessment of 21st century ICT skills in Chile: Test design and results from high school level students. Computers \& Education, 59(3), 1042 1053. doi:10.1016/j.compedu.2012.04.004.

Cobo, C. (2013). Mechanisms to identify and study the demand for innovation skills in world-renowned organizations. On the Horizon, 21(2), 96-106. doi:10.1108/10748121311322996.

Çoklar, A. N., Yaman, N. D., \& Yurdakul, I. K. (2017). Information literacy and digital nativity as determinants of online information search strategies. Computers in Human Behavior, 70, 1-9. doi:10.1016/j.chb.2016.12.050

Coll, R. K., Eames, C., Paku, L., Lay, M., Hodges, D., Bhat, R., Ram, S., Ayling, D. Flemming, D., Ferkins, L., Wiersma, C., \& Martin, A. (2009). An exploration of pedagogies employed to integrate knowledge in work-integrated learning. Journal of Cooperative Education and Internships, 43(1), 14-35.

Correa, T. (2010). The participation divide among "online experts": Experience, skills and psychological factors as predictors of college students' web content creation. Journal of Computer-Mediated Communication, 16(1), 71-92. doi:10.1111/j.10836101.2010.01532.x

Costello, A. B., \& Osborne, J. W. (2005). Best practices in exploratory factor analysis: Four recommendations for getting the most from your analysis. Practical Assessment, Research and Evaluation, 10(7), 1-9.

Cunningham, W., \& Villaseñor, P. (2016). Employer voices, employer demands, and implications for public skills development policy connecting the labor and education sectors. Working paper, No. 7682. Washington, DC: World Bank Group.

Daniel, R., \& Daniel, L. (2015). Success in the creative industries: The push for enterprising and entrepreneurial skills. Journal of Australian Studies, 39(3), 411-424. doi:10.108 0/14443058.2015.1046896.

David, P. A., \& Foray, D. (2002). An introduction to the economy of the knowledge society. International Social Science Journal, 54(171), 9-23. doi:10.1111/14682451.00355.

Davies, E. M., Hanley, K., Jenkins, A. K., \& Chan, C. (2017). Learning and training for older workers. In M. Flynn, Y. Li \& A. Chiva (Eds.), Managing the ageing workforce in the East and the West (pp. 185-206). Bingley, UK: Emerald Publishing Limited.

Davis, F. D. (1989). Perceived usefulness, perceived ease of use, and user acceptance of information technology. MIS Quarterly, 13(3), 319-339.

De Haan, J. (2004). A multifaceted dynamic model of the digital divide. IT and Society, $1(7), 66-88$.

De Haan, J., \& Sonck, N. (2012). Digital skills in perspective: A critical reflection on research and policy. Medijske Studije, 3(6), 125-137.
De Wit, K., Heerwegh, D., \& Verhoeven, J. C. (2014). Can openness to ICT and scientific research predict the ICT skills and ICT use of bachelor's students? Computers \& Education, 78, 397-413. doi:10.1016/j.compedu.2014.07.003.

Dede, C. (2010). Comparing frameworks for 21st century skills. In J. Bellanca \& R. Brandt (Eds.), 21st Century skills (pp. 51-76). Bloomington, IN: Solution Tree Press.

Den Hartog, D., \& Belschak, F. (2007). Personal initiative, commitment and affect at work. Journal of Occupational and Organizational Psychology, 80, 601-622. doi:10.1348/096317906X171442.

Desimone, L. M. \& Le Floch, K. C. (2004). Are we asking the right questions? Using cognitive interviews to improve surveys in education research. Educational Evaluation and Policy Analysis, 26(1), 1-22. doi:10.3102/01623737026001001.

DiLiello, T. C., \& Houghton, J. D. (2008). Creative potential and practiced creativity: Identifying untapped creativity in organizations. Creativity and Innovation Management, 17(1), 37-46. doi:10.1111/j.1467-8691.2007.00464.x.

DiMaggio, P., Hargittai, E., Celeste, C., \& Shafer, S. (2004). From unequal access to differentiated use: A literature review and agenda for research on digital inequality. In K. Neckerman (Ed.), Social inequality (pp. 355-400). New York, NY: Russell Sage Foundation.

Dong, Y., Bartol, K. M., Zhang, Z. X., \& Li, C. (2017). Enhancing employee creativity via individual skill development and team knowledge sharing: Influences of dualfocused transformational leadership. Journal of Organizational Behavior, 38(3), 439 458. doi:10.1002/job.2134

Drucker, P. F. (1969). The age of discontinuity: Guidelines to our changing society. New York, NY: Harper \& Row.

Drucker, P. F. (1993). The rise of the knowledge society. Wilson Quarterly, 17(2), 52-71.

Dumas, D., Schmidt, L. C., \& Alexander, P. A. (2016). Predicting creative problem solving in engineering design. Thinking Skills and Creativity, 21, 50-66. doi:10.1016/j. tsc.2016.05.002.

Dunning, D., Johnson, K., Ehrlinger, J., \& Kruger, J. (2003). Why people fail to recognize their own incompetence. Current Directions in Psychological Science, 12(3), 83-87. doi:10.1111/1467-8721.01235

Dutton, W., Helsper, E. J., \& Gerber, M. (2011). The Internet in Britain in 2011. Oxford, UK: Oxford Internet Institute.

Eastin, M. S., \& LaRose, R. (2000). Internet self-efficacy and the psychology of the digital divide. Journal of Computer-Mediated Communication, 6(1). doi:10.1111/j.1083-6101.2000.tb00110.x.

Eastman, C. M., \& Jansen, B. J. (2003). Coverage, relevance, and ranking: The impact of queryoperators on web search engine results. ACM Transactions on Information Systems, 21(4), 383-411. doi:10.1145/944012.944015.

Edmunds, R., Thorpe, M., \& Conole, G. (2012). Student attitudes towards and use of ICT in course study, work and social activity: A technology acceptance mode approach. British Journal of Educational Technology, 43(1), 71-84. doi:10.1111/j.14678535.2010.01142.x 
Eggers, F., Lovelace, K. J., \& Kraft, F. (2017). Fostering creativity through critical thinking: The case of business start-up simulations. Creativity and Innovation Management 26(3), 266-276. doi:10.1111/caim.12225

Ennis, R. H. (1991). Critical thinking: A streamlined conception. Teaching Philosophy, 14(1), 5-24. doi:10.5840/teachphil19911412

Ennis, R. H. (1993). Critical thinking assessment. Theory into Practice, 32(3), 179-186.

Erozkan, A. (2013). The effect of communication skills and interpersonal problem-solving skills on social self-efficacy. Educational Sciences: Theory \& Practice, 13(2), 739-745.

Erstad, O. (2011). Weaving the context of digital literacy. In S. Ludvigsen, A. Lund, I. Rasmussen \& R. Säljö (Eds.), Learning across sites: New tools, infrastructures and practices (pp. 295-310). Abingdon, UK: Routledge.

Eshet-Alkalai, Y. (2004). Digital literacy: A conceptual framework for survival skills in the digital era. Journal of Educational Multimedia \& Hypermedia, 13(1), 93-107.

Eshet-Alkalai, Y., \& Amichai-Hamburger, Y. (2004). Experiments in digital literacy. CyberPsychology \& Behavior, 7(4), 421-429. doi:10.1089/cpb.2004.7.421.

Eshet-Alkalai, Y., \& Chajut, E. (2009). Changes over time in digital literacy. CyberPsychology \& Behavior, 12(6), 713-715. doi:10.1089/cpb.2008.0264.

Evangelista, R., Guerrieri, P., \& Meliciani, V. (2014). The economic impact of digital technologies in Europe. Economics of Innovation and New Technology, 23(8), 802 824. doi:10.1080/10438599.2014.918438.

Evans, K., \& Guile, D. (2012). Putting different forms of knowledge to work in practice. In J. Higgs, R. Barnett, S. Billett, M. Hutchings \& F. Trede (Eds.), Practice-based education: Perspectives and strategies (pp. 113-130). Rotterdam, the Netherlands: Sense Publishers.

Evans K., \& Kersh N. (2014). Training and workplace learning. In K. Kraiger, J. Passmore, N. R. Santos \& S. Malvezzi (Eds.), The Wiley-Blackwell handbook of the psychology of training, development and performance improvement. Chichester, UK: WileyBlackwell.

Falk, M., \& Biagi, F. (2017). Relative demand for highly skilled workers and use of different ICT technologies. Applied Economics, 49(9), 903-914. doi:10.1080/00036846.201 6.1208357.

Ferrari, A. (2012). Digital competence in practice: An analysis of frameworks. Seville Spain: Joint Research Centre, Institute for Prospective Technological Studies. doi:10.2791/82116

Ferrari, A. (2013). DIGCOMP: A framework for developing and understanding digital competence in Europe. Seville, Spain: Joint Research Centre, Institute for Prospective Technological Studies. doi:10.2788/52966.

Ferrari, A. Punie, Y., \& Redecker, C. (2012). Understanding digital competence in the 21st century: An analysis of current frameworks. In A. Ravenscroft, S. Lindstaedt, C. D. Kloos \& D. Hernández-Leo (Eds.), 21st Century learning for 21st century skills (pp. 79-92). Berlin Heidelberg, Germany: Springer. doi:10.1007/978-3-642-33263-0 7.
Fishbein M., \& Ajzen, I. (1975). Belief, attitude, intention, and behavior: An introduction to theory and research. Reading, MA: Addison-Wesley.

Flew, T. \& Cunningham, S. (2010). Creative industries after the first decade of debate. Thelnformation Society, 26(2), 113-123. doi:10.1080/01972240903562753.

Florida, R. (2002). The rise of the creative class: And how it's transforming work, leisure, community, and everyday life. New York, NY: Basic Books.

Florida, R., \& Goodnight, J. (2005). Managing for creativity. Harvard Business Review, $3(7), 124-131$.

Fonseca, C. (2010). The digital divide and the cognitive divide: Reflections on the challenge of human development in the digital age. Information Technologies and International Development, 6, 25-30.

Fornell, C., \& Larcker, D. F. (1981). Evaluating structural equation models with unobservable variables and measurement error. Journal of Marketing Research 18(1), 39-50. doi:10.1177/002224378101800104.

Fraillon, J., Ainley, J., Schulz, W., Friedman, T., \& Gebhardt, E. (2014). Preparing for life in a digital age - The IEA international computer and information literacy study international report. Dordrecht, the Netherlands: Springer.

Fraser, K., \& Hvolby, H. (2010). Effective teamworking: Can functional flexibility act as an enhancing factor? An Australian case study. Team Performance Management: An International Journal, 16(1-2), 74-94. doi:10.1108/13527591011028933.

Frese, M. (1995). Entrepreneurship in East Europe: A general model and empirical findings. In C. L. Cooper \& D. M. Rousseau (Eds.), Trends in organizational behavior (pp. 65-83). Chichester, UK: John Wiley \& Sons.

Frese, M., Fay, D., Hilburger, T., Leng, K., \& Tag, A. (1997). The concept of personal initiative: Operationalization, reliability and validity in two German samples. Journal of Occupational and Organizational Psychology, 70(2), 139-161. doi:10.1111/j.2044-8325.1997.tb00639.x.

Frey, C. B., \& Berger, T. (2014). Work in the digital age. RSA Journal, 56(3), 16-19

Frey, C. B., \& Osborne, M. A. (2017). The future of employment: How susceptible are jobs to computerisation? Technological Forecasting and Social Change, 114, 254 280. doi:10.1016/j.techfore.2016.08.019.

Friese, S. (2014). Qualitative data analysis with ATLAS.ti. London, UK: Sage Publications.

Fuchs, C. (2009). The role of income inequality in a multivariate cross-national analysis of the digital divide. Social Science Computer Review, 27(1), 41-58. doi:10.1177/0894439308321628.

Fuchs, C. (2010). Grounding critical communication studies: An inquiry into the communication theory of Karl Marx. Journal of Communication Inquiry, 34(1), 15-41. doi:10.1177/0196859909338409.

Füller, J., Hutter, K., \& Faullant, R. (2011). Why co-creation experience matters? Creative experience and its impact on the quantity and quality of creative contributions. R\&D Management, 41(3), 259-273. doi:10.1111/j.1467-9310.2011.00640.x. 
Funke, J., Fischer, A., \& Holt, D. V. (2018). Competencies for complexity: Problem solving in the 21st century. In E. Care, P. Griffin \& M. Wilson (Eds.), Assessment and teaching of 21st century skills: Research and applications (pp. 41-53). Dordrecht, the Netherlands: Springer.

Gagné, R. M. (1985). The conditions of learning and theory of instruction (4th edition). New York, NY: Holt, Rinehart \& Winston.

Gallardo-Echenique, E. E., De Oliveira, M. J., Marqués-Molias, L., \& Esteve-Mon, F. (2015). Digital competence in the knowledge society. Journal of Online Learning and Teaching, 11(1), 1-16.

Gallardo-Echenique, E. E., Marqués-Molías, L., Bullen, M., \& Strijbos, J. W. (2015). Let's talk about digital learners in the digital era. The International Review of Research in Open and Distributed Learning, 16(3), 156-187. doi:10.19173/irrodl.v16i3.2196.

Garrido, M., Sullivan, J., \& Gordon, A. (2012). Understanding the links between ICT skills training and employability: An analytical framework. Information Technologies \& International Development, 8(2), 17-32.Gaskin, J. (2011). Validity during CFA made easy. Retrieved from: https://www.youtube.com/watch?v=yk6DVC7Wg7g.

Ghobadi, S., \& Ghobadi, Z. (2015). How access gaps interact and shape digital divide: A cognitive investigation. Behaviour \& Information Technology, 34(4), 330-340. doi:10.1080/0144929X.2013.833650

Gilster, P. (1997). Digital literacy. New York, NY: Wiley Computer Publishing.

Goldkind, L., \& Wolf, L. (2014). A digital environment approach: Four technologies that will disrupt social work practice. Social Work, 60(1), 85-87. doi:10.1093/sw/swu045.

Gómez, N., Tobarra, M. A., \& López, L. A. (2014). Employment opportunities in Spain: Gender differences by education and ICT usage. Regional and Sectoral Economic Studies, 14(3), 105-130.

Gonçalves, G., Oliveira, T., \& Cruz-Jesus, F. (2018). Understanding individual-level digital divide: Evidence of an African country. Computers in Human Behavior, 87, 276-291. doi:10.1016/j.chb.2018.05.039.

Goundar, S. (2014). The distraction of technology in the classroom. Journal of Education and Human Development, 3(1), 211-229.

Green, F., Ashton, D., \& Felstead, A. (2001). Estimating the determinants of supply of computing, problem-solving, communication, social, and teamworking skills. Oxford Economic Papers, 53(3), 406-433. doi:10.1093/oep/53.3.406.

Greene, S. L. (2002). Characteristics of applications that support creativity. Communications of the ACM, 45(10), 100-104.

Greiff, S., \& Funke, J. (2017). Interactive problem solving: Exploring the potential of minimal complex systems. In B. Csapó \& J. Funke (Eds.), The nature of problem solving: Using research to inspire 21st century learning (pp. 93-105). Paris, France: OECD Publishing.

Greiff, S., Kretzschmar, A., Müller, J. C., Spinath, B., \& Martin, R. (2014). The computerbased assessment of complex problem solving and how it is influenced by students' information and communication technology literacy. Journal of Educational Psychology, 106(3), 666-680. doi:10.1037/a0035426.
Greiff, S., Niepel, C., \& Wüstenberg, S. (2015). 21st Century skills: International advancements and recent developments. Thinking Skills and Creativity, 18, 1-3. doi:10.1016/j.tsc.2015.04.007

Greiff, S., Wüstenberg, S., \& Funke, J. (2012). Dynamic problem solving: A new assessment perspective. Applied Psychological Measurement, 36(3), 189-213. doi:10.1177/0146621612439620

Gretter, S., \& Yadav, A. (2016). Computational thinking and media \& information literacy: An integrated approach to teaching twenty-first century skills. TechTrends, 60(5), 510-516. doi:10.1007/s11528-016-0098-4.

Griffin, P., \& Care, E. (2012). Assessment and teaching of 21st century skills: Methods and approach. Dordrecht, the Netherlands: Springer.

Grugulis, I., \& Stoyanova D. (2012). Social capital and networks in film and TV: Jobs for the boys? Organization Studies, 33(10), 1311-1331. doi:10.1177/0170840612453525.

Grundke, R., Marcolin, L., Nguyen, T. L. B., \& Squicciarini, M. (2018). Which skills for the digital era? A return to skills analysis. OECD Science, Technology and Industry Working Papers, No. 2018/09. Paris, France: OECD Publishing. doi:10.1787/9a9479b5en.

Guest, G., Bunce, A., \& Johnson, L. (2006). How many interviews are enough? An experiment with data saturation and variability. Field Methods, 18(1), 59-82. doi:10.1177/1525822X05279903.

Gui, M., \& Argentin, G. (2011). Digital skills of Internet natives: Different forms of digital literacy in a random sample of northern Italian high school students. New Media \& Society, 13(6), 963-980. doi:10.1177/1461444810389751.

Guilford, J. P. (1967). The nature of human intelligence. New York, NY: McGraw-Hill Education.

Gut, D. M. (2011). Integrating 21st century skills into the curriculum. In G. Wan \& D. M. Gut (Eds.), Bringing schools into the 21st century (pp. 137-157). Dordrecht, the Netherlands: Springer.

Hager, P., \& Hodkinson, P. (2009). Moving beyond the metaphor of transfer of learning British Educational Research Journal, 35(4), 619-638. doi:10.1080/01411920802642371.

Hair, J. F., Anderson, R., Tatham, R., \& Black, W. (1998). Multivariate data analysis (5th edition). Upper Saddle River, NJ: Prentice Hall.

Hair, J. F., Black, W. C., Babin, B. J., Anderson, R. E., \& Tatham, R. L. (2006). Multivariate data analysis (6th edition). Upper Saddle River, NJ: Pearson Prentice Hall.

Hargittai, E. (2002). Beyond logs and surveys: In-depth measures of people's web use skills. Journal of the American Society for Information Science and Technology, 53(14), 1239-1244. doi:10.1002/asi.10166

Hargittai, E. (2005). Survey measures of web-oriented digital literacy. Social Science Computer Review, 23(3), 371-379. doi:10.1177/0894439305275911.

Hargittai, E. (2010). Digital na (t) ives? Variation in Internet skills and uses among members of the "net generation". Sociological Inquiry, 80(1), 92-113. doi:10.1111/ j.1475-682X.2009.00317.x 
Hargittai, E., \& Hsieh, Y. P. (2012). Succinct survey measures of web-use skills. Socia Science Computer Review, 30(1), 95-107. doi:10.1177/0894439310397146.

Hargittai, E., \& Shafer, S. (2006). Differences in actual and perceived online skills: The role of gender. Social Science Quarterly, 87(2), 432-448. doi:10.1111/j.15406237.2006.00389.x

Hartley, J. (2015). Urban semiosis: Creative industries and the clash of systems. International Journal of Cultural Studies, 18(1), 79-101. doi:10.1177/1367877914528120.

Hatlevik, I. K., \& Hatlevik, O. E. (2018). Students' evaluation of digital information: The role teachers play and factors that influence variability in teacher behaviour. Computers in Human Behavior, 83, 56-63. doi:10.1016/j.chb.2018.01.022.

Hatlevik, O. E., \& Christophersen, K. A. (2013). Digital competence at the beginning of upper secondary school: Identifying factors explaining digital inclusion. Computers \& Education, 63, 240-247. doi:10.1016/j.compedu.2012.11.015.

Hatlevik, O. E., Ottestad, G., \& Throndsen, I. (2015). Predictors of digital competence in 7th grade: A multilevel analysis. Journal of Computer Assisted Learning, 31(3) 220-231. doi:10.1111/jcal.12065

Haukka, S. (2011). Education-to-work transitions of aspiring creatives. Cultural Trends, 20(1), 41-64. doi:10.1080/09548963.2011.540813.

Head, A. J., Van Hoeck, M., \& Garson, D. S. (2015). Lifelong learning in the digital age: A content analysis of recent research on participation. First Monday, 20(2). doi:10.5210/fm.v20i2.5857.

Heale, R., \& Twycross, A. (2015). Validity and reliability in quantitative studies. EvidenceBased Nursing, 18(3), 66-67. doi:10.1136/eb-2015-102129.

Heerwegh, D., De Wit, K., \& Verhoeven, J. C. (2016). Exploring the self-reported ICT skill levels of undergraduate science students. Journal of Information Technology Education, 15(1), 19-47.

Helsper, E. J., \& Eynon, R. (2013). Distinct skill pathways to digital engagement. European Journal of Communication, 28(6), 696-713. doi:10.1177/0267323113499113.

Helsper E. J., \& Van Deursen A. J. A. M. (2015). Digital skills in Europe: Research and policy. In K. Andreasson K (Ed.), Digital divides: The new challenges and opportunities of e-inclusion (pp. 125-148). Boca Raton, FL: CRC Press.

Helsper, E. J., Van Deursen, A. J. A. M., \& Eynon, R. (2015). Tangible outcomes of Internet use: From digital skills to tangible outcomes project report. Oxford, UK: Oxford Internet Institute.

Hennekam, S., \& Bennett, D. (2017). Creative industries work across multiple contexts: Common themes and challenges. Personnel Review, 46(1), 68-85. doi:10.1108/PR082015-0220

Henriksen, D., Mishra, P., \& Fisser, P. (2016). Infusing creativity and technology in 21st century education: A systemic view for change. Journal of Educational Technology \& Society, 19(3), 27-37.
Heppner, P. P., \& Petersen, C. H. (1982). The development and implications of a personal problem-solving inventory. Journal of Counseling Psychology, 29(1), 66-75. doi:10.1037/0022-0167.29.1.66

Heppner, P. P., Walther, D. J., \& Good, G. E. (1995). The differential role of instrumentality, expressivity, and social support in predicting problem-solving appraisal in men and women. Sex Roles, 32(1-2), 91-108. doi:10.1007/BF01544759.Hesmondhalgh D. (2002). The cultural industries. London, UK: Sage Publications.

Hetzner, S., Heid, H., \& Gruber, H. (2012). Change at work and professional learning: How readiness to change, self-determination and personal initiative affect individual learning through reflection. European Journal of Psychology of Education, 27(4) 539-555. doi:10.1007/s10212-011-0094-1.

Higgins, S. (2014). Critical thinking for 21st-century education: A cyber-tooth curriculum? Prospects, 44(4), 559-574. doi:10.1007/s11125-014-9323-0.

Hirsch-Kreinsen, H. (2016). Digitization of industrial work: Development paths and prospects. Journal for Labour Market Research, 49(1), 1-14. doi:10.1007/s12651 016-0200-6

Hoffmann, J., Ivcevic, Z., \& Brackett, M. (2016). Creativity in the age of technology: Measuring the digital creativity of millennials. Creativity Research Journal, 28(2) 149-153. doi:10.1080/10400419.2016.1162515.

Hong, Y. C., \& Choi, I. (2015). Assessing reflective thinking in solving design problems The development of a questionnaire. British Journal of Educational Technology, 46(4), 848-863. doi:10.1111/bjet.12181.

Hotho, S., \& Champion, K. (2011). Small businesses in the new creative industries: Innovation as a people management challenge. Management Decision, 49(1), 29-54 doi:10.1108/00251741111094428.

Huang, Y. M. (2016). Networking behavior: From goal orientation to promotability Personnel Review, 45(5), 907-927. doi:10.1108/PR-03-2014-0062.

Hwang, Y. (2011). Is communication competence still good for interpersonal media? Mobile phone and instant messenger. Computers in Human Behavior, 27(2), 924 934. doi:10.1016/j.chb.2010.11.018.

Hwang, Y., Kettinger, W. J., \& Yi, M. Y. (2015). Personal information management effectiveness of knowledge workers: Conceptual development and empirical validation. European Journal of Information Systems, 24(6), 588-606. doi:10.1057/ ejis.2014.24

Hwang, G. J., Tsai, P. S., Tsai, C. C., \& Tseng, J. C. (2008). A novel approach for assisting teachers in analyzing student web-searching behaviors. Computers \& Education 51(2), 926-938. doi:10.1016/j.compedu.2007.09.011.

Hyytinen, H., Holma, K., Toom, A., Shavelson, R. J., \& Lindblom-Ylänne, S. (2014). The complex relationship between students' critical thinking and epistemological beliefs in the context of problem solving. Frontline Learning Research, 2(5), 1-25. doi:10.14786/flr.v2i4.124. 
Hyytinen, H., Toom, A., \& Postareff, L. (2018). Unraveling the complex relationship in critical thinking, approaches to learning and self-efficacy beliefs among first-year educational science students. Learning and Individual Differences, 67, 132-142. doi:10.1016/j.lindif.2018.08.004

Ifenthaler, D. (2012). Determining the effectiveness of prompts for self-regulated learning in problem-solving scenarios. Journal of Educational Technology \& Society, 15(1), 38-52.

Illeris, K. (2006). Lifelong learning and the low-skilled. International Journal of Lifelong Education, 25(1), 15-28. doi:10.1080/02601370500309451.

Ilomäki, L., Kantosalo, A., \& Lakkala, M. (2011). What is digital competence? Brussels, Belgium:European Schoolnet (EUN). Retrieved from: https://core.ac.uk/download/ pdf/33734457.pdf.

Ilomäki, L., Paavola, S., Lakkala, M., \& Kantosalo, A. (2016). Digital competence - An emergent boundary concept for policy and educational research. Education and Information Technologies, 21(3), 655-679. doi:10.1007/s10639-014-9346-4.

Janssen, J., Stoyanov, S., Ferrari, A., Punie, Y., Pannekeet, K., \& Sloep, P. (2013). Experts' viewson digital competence: Commonalities and differences. Computers \& Education, 68, 473-481. doi:10.1016/j.compedu.2013.06.008.

Janssen, O. (2000). Job demands, perceptions of effort-reward fairness and innovative workbehaviour. Journal of Occupational and Organizational Psychology, 73(3), 287 302. doi:10.1348/096317900167038.

Jara, I., Claro, M., Hinostroza, J. E., San Martín, E., Rodríguez, P., Cabello, T., Ibieta, A., Labbé, C. (2015). Understanding factors related to Chilean students' digital skills: A mixed methods analysis. Computers \& Education, 88, 387-398. doi:10.1016/j. compedu.2015.07.016.

Jeffcutt, P., \& Pratt, A. C. (2002). Managing creativity in the cultural industries. Creativity and Innovation Management, 11(4), 225-233. doi:10.1111/1467-8691.00254.

Jenkins, H., Clinton, K., Purushotma, R., Robison, A. J., \& Weigel, M. (2006). Confronting the challenges of participatory culture: Media education for the 21st century. Chicago, IL: MacArthur Foundation. Retrieved from: https://www.macfound.org/ media/article_pdfs/jenkins_white_paper.pdf.

Jenkins, H., Purushotma, R., Weigel, M., Clinton, K., \& Robison, A. J. (2009). Confronting the challenges of participatory culture: Media education for the 21st century - Digital learning. Cambridge, MA: MIT Press.

Jeong, A. C. (2003). The sequential analysis of group interaction and critical thinking in online. The American Journal of Distance Education, 17(1), 25-43. doi:10.1207/ S15389286AJDE1701_3.

Jesson, J., Matheson, L., \& Lacey, F. M. (2011). Doing your literature review: Traditional andsystematic techniques. London, UK: Sage Publications.

Jiménez-Cortés, R., Vico-Bosch, A., \& Rebollo-Catalán, A. (2017). Female university student's ICT learning strategies and their influence on digital competence. International Journal of Educational Technology in Higher Education, 14(10), 1-12. doi:10.1186/s41239-017-0040-7.
Johanson, G. A., \& Brooks, G. P. (2010). Initial scale development: Sample size for pilot studies. Educational and Psychological Measurement, 70(3), 394-400. doi:10.1177/0013164409355692.

Jolliffe, I. T. (1972). Discarding variables in a principal component analysis I: Artificial data. Applied Statistics, 21(2), 160-173. doi:10.2307/2346488.

Joo, B. K., Yang, B., \& McLean, G. N. (2014). Employee creativity: The effects of perceived learning culture, leader-member exchange quality, job autonomy, and proactivity. Human Resource Development International, 17(3), 297-317. doi:10.10 80/13678868.2014.896126.

Kaarakainen, M. T., Kaarakainen, S. S., \& Kivinen, A. (2018). Seeking adequate competencies for the future. Nordic Journal of Science and Technology Studies, 6(1), 4-20. doi:10.5324/njsts.v6i1.2520.

Kambourov, G., \& Manovskii, I. (2009). Occupational specificity of human capital. International Economic Review, 50(1), 63-115. doi:10.1111/j.1468-2354.2008.00524.x.

Kamprath, M., \& Mietzner, D. (2015). The impact of sectoral changes on individual competences: A reflective scenario-based approach in the creative industries. Technological Forecasting and Social Change, 95, 252-275. doi:10.1016/j. techfore.2015.01.011.

Kanbay, Y., \& Okanlı, A. (2017). The effect of critical thinking education on nursing students' problem-solving skills. Contemporary Nurse, 53(3), 313-321. doi:10.1080 /10376178.2017.1339567.

Kang, Y. J., Lee, J. Y., \& Kim, H. W. (2017). A psychological empowerment approach to online knowledge sharing. Computers in Human Behavior, 74, 175-187. doi:10.1016/j. chb.2017.04.039.

Karakaya, A. F., \& Demirkan, H. (2015). Collaborative digital environments to enhance the creativity of designers. Computers in Human Behavior, 42, 176-186. doi:10.1016/j chb.2014.03.029.

Katz, I. R. (2007). Testing information literacy in digital environments: ETS's iSkills assessment.Information Technology and Libraries, 26(3), 3-12. doi:10.6017/ital. v26i3.3271.

Katz, I. R., Haras, C., \& Blaszczynski, C. (2010). Does business writing require information literacy?Business Communication Quarterly, 73(2), 135-149. doi:10.1177/1080569910365892.

Kauffman, D. F., Ge, X., Xie, K., \& Chen, C. H. (2008). Prompting in web-based environments: Supporting self-monitoring and problem-solving skills in college students. Journal of Educational Computing Research, 38(2), 115-137. doi:10.2190/ EC.38.2.a.

Kaufman, K. J. (2013). 21 ways to 21 st century skills: Why students need them and ideas for practical implementation. Kappa Delta Pi Record, 49(2), 78-83. doi:10.1080/00 228958.2013.786594.

Kaur, J., \& Beri, A. (2016). Coping as a life skill for lifelong learning. Man in India, 96(5), 1365-1376. 
Keane, T., Keane, W. F., \& Blicblau, A. S. (2016). Beyond traditional literacy: Learning and transformative practices using ICT. Education and Information Technologies, 21(4), 769-781. doi:10.1007/s10639-014-9353-5.

Kefela, G. T. (2010). Knowledge-based economy and society has become a vital commodity to countries. International NGO Journal, 5(7), 160-166.

Kereluik, K., Mishra, P., Fahnoe, C., \& Terry, L. (2013). What knowledge is of most worth: Teacher knowledge for 21st century learning. Journal of Digital Learning in Teacher Education, 29(4), 127-140. doi:10.1080/21532974.2013.10784716.

Kersh, N. (2015). Rethinking the learning space at work and beyond: The achievement of agency across the boundaries of work-related spaces and environments. International Review of Education, 61(6), 835-851. doi:10.1007/s11159-015-9529-2.

Keshavarz, H. (2014). How credible is information on the web: Reflections on misinformation and disinformation. Infopreneurship Journal, 1(2), 1-17.

Keupp, M. M., Palmié, M., \& Gassmann, O. (2012). The strategic management of innovation: A systematic review and paths for future research. International Journal of Management Reviews, 14(4), 367-390. doi:10.1111/j.1468-2370.2011.00321.x.

Khan, M. L., Wohn, D. Y., \& Ellison, N. B. (2014). Actual friends matter: An Internet skills perspective on teens' informal academic collaboration on Facebook. Computers \& Education, 79, 138-147. doi:10.1016/j.compedu.2014.08.001.

Kiliç-Çakmak, E. (2010). Learning strategies and motivational factors predicting information literacy self-efficacy of e-learners. Australasian Journal of Educational Technology, 26(2), 192-208. doi:10.14742/ajet.1090.

Kim, S., \& Lee, H. (2010). Factors affecting employee knowledge acquisition and application capabilities. Asia-Pacific Journal of Business Administration, 2(2), 133 152. doi:10.1108/17574321011078184.

Knafl, K., Deatrick, J., Gallo, A., Holcombe, G., Bakitas, M., Dixon, J., \& Grey, M. (2007). The analysis and interpretation of cognitive interviews for instrument development. Research in Nursing \& Health, 30(2), 224-234. doi:10.1002/nur.20195.

Koch, M. (2016). Skills, tasks and the scarcity of talent in a global economy. Review of International Economics, 24(3), 536-563. doi:10.1111/roie.12222.

Kohn, K., \& Wewel, S. A. (2018). Skills, scope and success: An empirical look at the start-up process in creative industries in Germany. Creativity and Innovation Management, 27(3), 295-318. doi:10.1111/caim.12279.

Kohnke, O. (2017). It's not just about technology: The people side of digitization. In G. Oswald \& M. Kleinemeier (Eds.), Shaping the digital enterprise (pp. 69-91). Cham Switzerland: Springer International Publishing.

Koltay, T. (2011). The media and the literacies: Media literacy, information literacy, digita literacy. Media, Culture \& Society, 33(2), 211-221. doi:10.1177/0163443710393382.

Kotter J. P. (2014). Accelerate: Building strategic agility for a faster-moving world. Boston, MA: Harvard Business Review Press.
Kuhlemeier, H., \& Hemker, B. (2007). The impact of computer use at home on students' Internet skills. Computers \& Education, 49(2), 460-480. doi:10.1016/j. compedu.2005.10.004.

Kuo, F.-R., \& Hwang, G. J. (2014). A five-phase learning cycle approach to improving the web-based problem-solving performance of students. Journal of Educational Technology \& Society, 17(1), 169-184.

Kurbanoglu, S. S., Akkoyunlu, B., \& Umay, A. (2006). Developing the information literacy self-efficacy scale. Journal of Documentation, 62(6), 730-743. doi:10.1108/00220410610714949.

Kyndt, E., Govaerts, N., Dochy, F., \& Baert, H. (2011). The learning intention of lowqualified employees: A key for participation in lifelong learning and continuous training. Vocations and Learning, 4(3), 211. doi:10.1007/s12186-011-9058-5.

Kyndt, E., Govaerts, N., Keunen, L., \& Dochy, F. (2013). Examining the learning intentions of low-qualified employees: A mixed method study. Journal of Workplace Learning 25(3), 178-197. doi:10.1108/13665621311306556.

Lai, C. Y., \& Yang, H. L. (2014). The reasons why people continue editing Wikipedia content-task value confirmation perspective. Behaviour \& Information Technology 33(12), 1371-1382. doi:10.1080/0144929X.2014.929744.

Lanvin, B., \& Kralik, M. (2009). E-skills: Who made that big dent in my flat world? Information Technologies \& International Development, 5(2), 81-84.

Lanvin, B., \& Passman, P. (2008). Building e-skills for the information age. In A. LópezClaros, I. Mia \& S. Dutta (Eds.), The global information technology report 2007-2008: Fostering innovation through networked readiness (pp. 77-90). Basingstoke, UK: Palgrave Macmillan.

Laxman, K. (2010). A conceptual framework mapping the application of information search strategies to well and ill-structured problem solving. Computers \& Education, 55(2), 513-526. doi:10.1016/j.compedu.2010.02.014

Leahy, D., \& Dolan, D. (2010). Digital literacy: A vital competence for 2010? In N Reynolds \& M. Turcsányi-Szabó (Eds.), Key competencies in the knowledge society (pp. 210-221). Berlin Heidelberg, Germany: Springer.

LeBlanc, M., Léger, M. T., Godin, J., Freiman, V., Robichaud, X., Larose, F., Chukalovskyy, R., \& Bourgeois, Y. (2015). A strategic partnership to understand the ecosystem adaptability and transfer of digital skills: A focus on the educational system. In D. Rutledge \& D. Slykhuis (Eds.), Proceedings of Society for Information Technology \& Teacher Education International Conference 2015 (pp. 968-973). Las Vegas, NV: AACE International.

Lee, H., Park, N., \& Hwang, Y. (2015). A new dimension of the digital divide: Exploring the relationship between broadband connection, smartphone use and communication competence. Telematics and Informatics, 32(1), 45-56. doi:10.1016/j.tele.2014.02.001.

Lee, K. S., \& Chen, W. (2017). A long shadow: Cultural capital, techno-capital and networking skills of college students. Computers in Human Behavior, 70, 67-73. doi:10.1016/j.chb.2016.12.030. 
Lee, M. R., \& Chen, T. T. (2015). Digital creativity: Research themes and framework. Computers in Human Behavior, 42, 12-19. doi:10.1016/j.chb.2014.04.001.

Lemke, C. (2002). enGauge 21st century skills: Digital literacies for a digital age. Naperville, IL: North Central Regional Educational Laboratory (NCREL).

Lessig, L. (2008). Remix: Making art and commerce thrive in the hybrid economy. New York, NY: Penguin Press

Levy, F., \& Murnane, R. J. (2004). The new division of labor: How computers are creating the next job market. Princetown, NJ: Princetown University Press.

Lewin, C., \& McNicol, S. (2015). Supporting the development of 21st century skills through ICT. In T. Brinda, N. Reynolds, R. Romeike \& A. Schwill (Eds.), KEYCI 2014: Key competencies in informatics and ICT (pp. 181-198). Potsdam, Germany: Universitätsverlag Potsdam.

Li, C., Shi, X., \& Dang, J. (2014). Online communication and subjective well-being in Chinese college students: The mediating role of shyness and social self-efficacy. Computers in Human Behavior, 34, 89-95. doi:10.1016/j.chb.2014.01.032.

Liang, T. P., Ho, Y. T., Li, Y. W., \& Turban, E. (2011). What drives social commerce: The role of social support and relationship quality. International Journal of Electronic Commerce, 16(2), 69-90. doi:10.2753/JEC1086-4415160204.

Liberati, A., Altman, D. G., Tetzlaff, J., Mulrow, C., Gøtzsche, P. C., loannidis, J. P. A. Clarke, M., Devereaux, P. J., Kleijnen, J., \& Moher, D. (2009). The PRISMA statement for reporting systematic reviews and meta-analysis of studies that evaluate health care interventions: Explanation and elaboration. PLoS Medicine, 6(7), doi:10.1371/ journal.pmed.1000100.

Lin, C. P. (2010). Learning task effectiveness and social interdependence through the mediating mechanisms of sharing and helping: A survey of online knowledge workers. Group \& Organization Management, 35(3), 299-328. doi:10.1177/1059601110369730.

Lin, L., Mills, L. A., \& Ifenthaler, D. (2016). Collaboration, multi-tasking and problem solving performance in shared virtual spaces. Journal of Computing in Higher Education, 28(3), 344-357. doi:10.1007/s12528-016-9117-x.

Literat, I. (2012). The work of art in the age of mediated participation: Crowdsourced art and collective creativity. International Journal of Communication, 6, 2962-2984.

Literat, I., \& Glaveanu, V. P. (2018). Distributed creativity on the Internet: A theoretical foundation for online creative participation. International Journal of Communication 12, 893-908.

Litt, E. (2013). Measuring users' Internet skills: A review of past assessments and a look toward the future. New Media \& Society, 15(4), 612-630. doi:10.1177/ 1461444813475424

Littlejohn, A., Beetham, H., \& McGill, L. (2012). Learning at the digital frontier: A review of digital literacies in theory and practice. Journal of Computer Assisted Learning 28(6), 547-556. doi:10.1111/j.1365-2729.2011.00474.x.

Liu, Y., Wang, S., \& Yao, X. (2017). Individual goal orientations, team empowerment, and employee creative performance: A case of cross-level interactions. The Journal of Creative Behavior, 1-14. doi:10.1002/jocb.220.
Livingstone, S. (2004). Media literacy and the challenge of new information and communication technologies. The Communication Review, 7(1), 3-14 doi:10.1080/10714420490280152.

Longhurst, R. (2010). Semi-structured interviews and focus groups. In N. Clifford, S. French \& G. Valentine (Eds.), Key methods in geography (pp. 103-115). London, UK: Sage Publications.

Louw, W. (2014). Designing learning experiences to prepare lifelong learners for the complexities of the workplace. In M. Coetzee (Ed.), Psycho-social caree metacapacities: Dynamics of contemporary career development (pp. 307-320). Cham, Switzerland: Springer International Publishing.

Loveless, A. (2003). Creating spaces in the primary curriculum: ICT in creative subjects. Curriculum Journal, 14(1), 5-21. doi:10.1080/0958517032000055965.

Loveless, A. (2007). Creativity, new technologies and learning: A review of recent literature (an update). Bristol, UK: Futurelab.

u, H. P., \& Lee, M. R. (2012). Experience differences and continuance intention of blog sharing. Behaviour \& Information Technology, 31(11), 1081-1095. doi:10.1080/0144 929X.2011.611822.

MacKenzie, D., \& Wajcman, J. (1985). The Social Shaping of Technology. Buckingham UK: Open University Press.

Magrabi, S. A. R., Pasha, M. I., \& Pasha, M. Y. (2018). Classroom teaching to enhance critical thinking and problem-solving skills for developing IOT applications. Journal of Engineering Education Transformations، 31(3), 152-157. doi:10.16920/jeet/2018/ v31i3/120785.

Mainert, J., Niepel, C., Murphy, K. R., \& Greiff, S. (2018). The incremental contribution of complex problem-solving skills to the prediction of job level, job complexity, and salary. Journal of Business and Psychology, 1-21, doi:10.1007/s10869-018-9561-x.

Majid, S., San, M. M., Tun, S. T. N., \& Zar, T. (2010). Using Internet services for personal information management. 2nd international symposium on information management in a changing world, September 2010. Ankara, Turkey.

Manalo, E., Kusumi, T., Koyasu, M., Michita, Y., \& Tanaka, Y. (2013). To what extent do culture-related factors influence university students' critical thinking use? Thinking Skills and Creativity, 10, 121-132. doi:10.1016/j.tsc.2013.08.003.

Mangematin, V., Sapsed J., \& Schüßler E. (2014). Disassembly and reassembly: An introduction to the special issue on digital technology and creative industries. Technological Forecasting and Social Change, 83, 1-9. doi:10.1016/j. techfore.2014.01.002.

Manuti, A., Pastore, S., Scardigno, A. F., Giancaspro, M. L., \& Morciano, D. (2015). Formal and informal learning in the workplace: A research review. International Journal of Training and Development, 19(1), 1-17. doi:10.1111/ijtd.12044.

Marchionini, G., \& White, R. (2007). Find what you need, understand what you find. International Journal of Human-Computer Interaction, 23(3), 205-237. doi:10.1080/10447310701702352 
Margaryan, A., Littlejohn, A., \& Vojt, G. (2011). Are digital natives a myth or reality? University students' use of digital technologies. Computers \& Education, 56(2), 429-440. doi:10.1016/j.compedu.2010.09.004.

Martin, A. (2008). Digital literacy and the 'digital society'. In C. Lankshear \& M. Knobe (Eds.), Digital literacies: Concepts, policies and practices (pp. 151-176). New York, NY: Peter Lang Publishing.

Martínez-Cerdá, J. F., Torrent-Sellens, J., \& González-González, I. (2018). Socio-technical e-learning innovation and ways of learning in the ICT-space-time continuum to improve the employability skills of adults. Computers in Human Behavior, in press, doi:10.1016/j.chb.2018.10.019.

Mason, L., Scrimin, S., Tornatora, M. C., Suitner, C., \& Moè, A. (2018). Internet source evaluation: The role of implicit associations and psychophysiological self-regulation. Computers \& Education, 119, 59-75. doi:10.1016/j.compedu.2017.12.009

Matzat, U., \& Sadowski, B. (2012). Does the "do-it-yourself approach" reduce digital inequality? Evidence of self-learning of digital skills. The Information Society, 28(1) 1-12. doi:10.1080/01972243.2011.629023.

McGregor, J., Tweed, D., \& Pech, R. (2004). Human capital in the new economy: Devil's bargain? Journal of Intellectual Capital, 5(1), 153-164. doi:10.1108/14691930410512978.

Merritt, K., Smith, D., \& Renzo, J. C. D. (2005). An investigation of self-reported computer literacy: Is it reliable. Issues in Information Systems, 6(1), 289-295.

Metiri Group (2003). enGauge 21st century skills for 21st century learners. Retrieved from: https://www.cwasd.k12.wi.us/highschl/newsfile1062_1.pdf.

Metzger, M. J. (2007). Making sense of credibility on the web: Models for evaluating online information and recommendations for future research. Journal of the American Society for Information Science and Technology, 58(13), 2078-2091. doi:10.1002/asi.20672

Metzger, M. J., Flanagin, A. J., \& Medders, R. B. (2010). Social and heuristic approaches to credibility evaluation online. Journal of Communication, 60(3), 413-439. doi:10.1111/j.1460-2466.2010.01488.x.

Midtsundstad, T. (2019). A review of the research literature on adult learning and employability. European Journal of Education, 54(1), 13-29. doi:10.1111/ejed.12321.

Mietzner, D., \& Kamprath, M. (2013). A competence portfolio for professionals in the creative industries. Creativity and Innovation Management, 22(3), 280-294. doi:10.1111/caim.12026.

Mishra, P., \& Kereluik, K. (2011). What 21st century learning? A review and a synthesis. In C. D. Maddux, M. J. Koehler, P. Mishra \& C. Owens (Eds.), Proceedings of Society for Information Technology \& Teacher Education International Conference 2011 (pp. 3301-3312). Chesapeake, VA: AACE International.

Mitchell, G. W., Skinner, L. B., \& White, B. J. (2010). Essential soft skills for success in the twenty-first century workforce as perceived by business educators. Delta Pi Epsilon Journal, 52(1), 43-53
Mitrovic, Z. (2010). Positioning e-skills within an organisation: An information systems management viewpoint. South African Journal of Information Management, 12(1) 1-7. doi:10.4102/sajim.v12i1.427.

Moeller, M.,Cutler, K., Fiedler, D., \& Weier, L. (2013). Visual strategies: Creative and critical thinking. Phi Delta Kappan, 95(3), 56-60. doi:10.1177/003172171309500312.

Moher, D., Liberati, A., Tetzlaff, J., \& Altman, D. G. (2009). Preferred reporting items for systematic reviews and meta-analyses: The PRISMA statement. Annals of Internal Medicine, 151(4), 264-269. doi:10.7326/0003-4819-151-4-200908180-00135.

Moher, D., Shamseer, L., Clarke, M., Ghersi, D., Liberati, A., Petticrew, M., Shekelle, P. Stewart, L. A. (2015). Preferred reporting items for systematic review and metaanalysis protocols (PRISMA-P) 2015 statement. Systematic Reviews, 4(1), 1-9. doi:10.1186/2046-4053-4-1.

Moore, B., \& Parker, R. (2007). Critical thinking. New York, NY: McGraw-Hill Education.

More, E. (1999). The role of communication in current debates on knowledge management. Journal of Communication Management, 3(4), 353-361. doi:10.1108/ eb023498.

Mossberger, K., Tolbert, C. J., \& Stansbury, M. (2003). Virtual inequality: Beyond the digital divide. Washington, DC: Georgetown University Press.

Müller, K., Rammer, C., \& Trüby, J. (2009). The role of creative industries in industrial innovation. Innovation: Management, Policy \& Practice, 11(2), 148-168. doi:10.5172/ impp.11.2.148.

Mulnix, J. W. (2012). Thinking critically about critical thinking. Educational Philosophy and Theory, 44(5), 464-479. doi:10.1111/j.1469-5812.2010.00673.x.

Murawski, M., \& Bick, M. (2017). Digital competences of the workforce - A research topic? Business Process Management Journal, 23(3), 721-734. doi:10.1108/BPMJ 06-2016-0126

Musterd, S., Bontje, M., Chapain, C., Kovacs, Z., \& Murie, A. (2007). Accommodating creative knowledge: $A$ literature review from a European perspective, ACRE Report 1. Amsterdam, the Netherlands: University of Amsterdam.

Neubert, J. C., Mainert, J., Kretzschmar, A., \& Greiff, S. (2015). The assessment of 21 st century skills in industrial and organizational psychology: Complex and collaborative problem solving. Industrial and Organizational Psychology, 8(2), 238268. doi:10.1017/iop.2015.14

Newman, D. R., Webb, B., \& Cochrane, C. (1995). A content analysis method to measure critical thinking in face-to-face and computer supported group learning. Interpersonal Computing and Technology, 3(2), 56-77.

Ng, W. (2012). Can we teach digital natives digital literacy? Computers \& Education 59(3), 1065-1078. doi:10.1016/j.compedu.2012.04.016.

Norman, C., \& Jerrard, R. (2015). Design managers, their organisations and workbased learning. Higher Education, Skills and Work-Based Learning, 5(3), 271-284. doi:10.1108/HESWBL-07-2014-0028. 
Nunnally, J. C., \& Bernstein, I. H. (1967). Psychometric theory. New York, NY: McGrawHill Education.

Nussbaum, E. M., \& Schraw, G. (2007). Promoting argument-counterargument integration in students' writing. The Journal of Experimental Education, 76(1), 59-92. doi:10.3200/JEXE.76.1.59-92.

Oldham, G. R., \& Cummings, A. (1996). Employee creativity: Personal and contextual factors at work. Academy of Management Journal, 39(3), 607-634. doi:10.2307/256657.

Oldham, G. R., \& Da Silva, N. (2015). The impact of digital technology on the generation and implementation of creative ideas in the workplace. Computers in Human Behavior, 42, 5-11. doi:10.1016/j.chb.2013.10.041.

Organisation for Economic Co-operation and Development (2017). Future of work and skills. 2nd meeting of the G20 employment working group, February 2017. Hamburg, Germany

Park, S. (2012). Dimensions of digital media literacy and the relationship with social exclusion. Media International Australia, 142(1), 87-100. doi:10.1177/1329878X1214200111.

Parmentier, G., \& Mangematin, V. (2014). Orchestrating innovation with user communities in the creative industries. Technological Forecasting and Social Change, 83(1), 40-53. doi:10.1016/j.techfore.2013.03.007.

Parry, R., Eikhof, R., Barnes, S., \& Kispeter, E. (2018). Mapping the museum digital skills ecosystem: Phase one report. Leicester, UK: University of Leicester. Retrieved from: https://Ira.le.ac.uk/bitstream/2381/41572/2/One\%20by\%20One_Phase1_Report.pdf.

Partnership for 21st Century Skills (2007). Framework for 21st century learning. Retrieved from: http://www.p21.org/documents/P21_ Framework_Definitions.pdf.

Partnership for 21st Century skills (2008). 21st Century skills, education \& competitiveness: A resource and policy guide. Tucson, AZ: Author.

Pásztor, A., Molnár, G., \& Csapó, B. (2015). Technology-based assessment of creativity in educational context: The case of divergent thinking and its relation to mathematical achievement. Thinking Skills and Creativity, 18, 32-42. doi:10.1016/j.tsc.2015.05.004.

Paul, R., \& Elder, L. (2004). The nature and functions of critical and creative thinking Dillon Beach, CA: The Foundation for Critical Thinking.

Paul, R., \& Elder, L. (2006). Critical thinking: The nature of critical and creative thought. Journal of Developmental Education, 30(2), 34-35.

Pennacchia, J., Jones, E., \& Aldridge, F. (2018). Barriers to learning for disadvantaged groups: Report of qualitative findings. Manchester, UK: Department for Education. Retrieved from: https://www.learningandwork.org.uk/wp-content/uploads/2018/08/ Barriers-to-learning-for-disadvantaged-groups.pdf.

Perry-Smith, J. E., \& Shalley, C. E. (2003). The social side of creativity: A static and dynamic social network perspective. Academy of Management Review, 28(1), 89106. doi:10.5465/AMR.2003.8925236.
Petersen, S. M. (2008). Loser generated content: From participation to exploitation. First Monday, 13(3). doi:10.5210/fm.v13i3.2141.

Petrucco, C., \& Ferranti, C. (2017). Developing critical thinking in online search. Journa of E-Learning and Knowledge Society, 13(3), 35-45. doi:10.20368/1971-8829/1390.

Picatoste, J., Pérez-Ortiz, L., \& Ruesga-Benito, S. M. (2018). A new educational pattern in response to new technologies and sustainable development: Enlightening ICT skills for youth employability in the European Union. Telematics and Informatics, 35(4), 1031-1038. doi:10.1016/j.tele.2017.09.014

Piergiovanni, R., Carree, M. A. \& Santarelli, E. (2012). Creative industries, new business formation, and regional economic growth. Small Business Economics, 39(3), 539560. doi:10.1007/s11187-011-9329-4

Pina, K., \& Tether, B. S. (2016). Towards understanding variety in knowledge intensive business services by distinguishing their knowledge bases. Research Policy, 45 401-413. doi:10.1016/j.respol.2015.10.005.

Pintrich, P. R. (2000). Multiple goals, multiple pathways: The role of goal orientation in learning and achievement. Journal of Educational Psychology, 92(3), 544-555. doi:10.1037/0022-0663.92.3.544.

Plomp, J., Tims, M., Akkermans, J., Khapova, S. N., Jansen, P. G., \& Bakker, A. B. (2016). Career competencies and job crafting: How proactive employees influence their well-being. Career Development International, 21(6), 587-602. doi:10.1108/CDI-082016-0145.

Plomp, T. (2013). Preparing education for the information society: The need for new knowledge and skills. International Journal of Social Media and Interactive Learning Environments, 1(1), 3-18. doi:10.1504/IJSMILE.2013.051651.

Potts, J., Cunningham, S., Hartley, J., \& Ormerod, P. (2008). Social network markets: A new definition of the creative industries. Journal of Cultural Economics, 32(3), 167 185. doi:10.1007/s10824-008-9066-y.

Preston, P., Kerr, A., \& Cawley, A. (2009). Innovation and knowledge in the digital media sector: An information economy approach. Information, Communication \& Society, 12(7), 994-1014. doi:10.1080/13691180802578150.

Punie, Y. (2007). Learning Spaces: An ICT-enabled model of future learning in the knowledge-based society. European Journal of Education, 42(2), 185-199. doi:10.1111/j.1465-3435.2007.00302.x.

Punie, Y., \& Ala-Mutka, K. (2007). Future learning spaces: New ways of learning and new digital skills to learn. Nordic Journal of Digital Literacy, 2(4), 210-225.

Raes, S. E. P., \& Hofstede, B. P. (2005). Creativiteit in kaart gebracht - Mapping document creatieve bedrijvigheid in Nederland. Gezamenlijke uitgave van het ministerie van Economische Zaken en het ministerie van Onderwijs, Cultuur en Wetenschap. 's Gravenzande: Van Deventer.

Rausch, A., \& Wuttke, E. (2016). Development of a multi-faceted model of domainspecific problem-solving competence and its acceptance by different stakeholders in the business domain. Unterrichtswissenschaft, 44(2), 164-189. 
Redecker, C., \& Johannessen, Ø. (2013). Changing assessment - Towards a new assessment paradigm using ICT. European Journal of Education, 48(1), 79-96. doi:10.1111/ejed.12018.

Reich, R. (1992). The work of nations: Preparing ourselves for the 21st-century capitalism New York, NY: Vintage Books.

Rentsch, J. R., Mello, A. L. \& Delise, L. A. (2010). Collaboration and meaning analysis process in intense problem-solving teams. Theoretical Issues in Ergonomics Science, 11(4), 287-303. doi:10.1080/14639221003729151.

Reynolds, R. (2016). Defining, designing for, and measuring "social constructivist digita literacy" development in learners: A proposed framework. Educational Technology Research and Development, 64(4), 735-762. doi:10.1007/s11423-015-9423-4.

Riessman, C. K. (2008). Narrative methods for the human sciences. London, UK: Sage Publications.Robles, M. M. (2012). Executive perceptions of the top 10 soft skills needed in today's workplace. Business Communication Quarterly, 75(4), 453-465. doi:10.1177/1080569912460400.

Rode, H. (2016). To share or not to share: The effects of extrinsic and intrinsic motivations on knowledge-sharing in enterprise social media platforms. Journal of Information Technology, 31(2), 152-165. doi:10.1057/jit.2016.8.

Ross, M., Perkins, H., \& Bodey, K. (2016). Academic motivation and information literacy self-efficacy: The importance of a simple desire to know. Library \& Information Science Research, 38(1), 2-9. doi:10.1016/j.lisr.2016.01.002.

Rousseau, D. M. (2012). Envisioning evidence-based management. In D. M. Rousseau (Ed.), Oxford handbook of evidence-based management (pp. 3-24). Oxford, UK: Oxford University Press.

Runco, M. A. (1993). Cognitive and psychometric issues in creativity research. In S. G. Isaksen, M. C. Murdock, R. L. Firestien \& D. J. Treffinger (Eds.), Understanding and recognizing creativity: The emergence of a discipline (pp. 331-368). Norwood, NJ: Ablex Publishing Corporation.

Runco, M. A., Noble, E. P., Reiter-Palmon, R., Acar, S., Ritchie, T., \& Yurkovich, J. M. (2011). The genetic basis of creativity and ideational fluency. Creativity Research Journal, 23(4), 376-380. doi:10.1080/10400419.2011.621859.

Russell-Rose, T., Chamberlain, J., \& Azzopardi, L. (2018). Information retrieval in the workplace: A comparison of professional search practices. Information Processing \& Management, 54(6), 1042-1057. doi:10.1016/j.ipm.2018.07.003.

Saadé, R. G., Morin, D., \& Thomas, J. D. (2012). Critical thinking in e-learning environments. Computers in Human Behavior, 28(5), 1608-1617. doi:10.1016/j. chb.2012.03.025.

Santos-Rodrigues, H., Dorrego, P. F., \& Jardon, C. F. (2010). The influence of human capital on the innovativeness of firms. The International Business \& Economics Research Journal, 9(9), 53-64. doi:10.19030/iber.v9i9.625.

Sawyer, R. K., \& DeZutter, S. (2009). Distributed creativity: How collective creations emerge from collaboration. Psychology of Aesthetics, Creativity, and The Arts, 3(2), 81-92. doi:10.1037/a0013282.
Scarbrough, H., Swan, J., Laurent, S., Bresnen, M., Edelman, L., \& Newell, S. (2004). Project-based learning and the role of learning boundaries. Organization Studies, 25(9), 1579-1600. doi:10.1177/0170840604048001.

Scheerder, A. J., Van Deursen, A. J. A. M., \& Van Dijk, J. A. G. M. (2017). Determinants of Internet skills, uses and outcomes. A systematic review of the second-and thirdlevel digital divide. Telematics and Informatics, 34(8), 1607-1624. doi:10.1016/j. tele.2017.07.007

Schulze, J., Schultze, M., West, S. G., \& Krumm, S. (2017). The knowledge, skills, abilities and other characteristics required for face-to-face versus computer-mediated communication: Similar or distinct constructs? Journal of Business and Psychology, 32(3), 283-300. doi:10.1007/s10869-016-9465-6.

Scott, S. G., \& Bruce, R. A. (1994). Determinants of innovative behavior: A path mode of individual innovation in the workplace. Academy of Management Journal, 37(3) 580-607. doi:10.2307/256701.

Selwyn, N. (2004). Reconsidering political and popular understandings of the digital divide. New Media \& Society, 6(3), 341-362. doi:10.1177/1461444804042519.

Selwyn, N. (2015). The discursive construction of education in the digital age. In R. H. Jones, A. Chik \& C. A. Hafner (Eds.), Discourse and digital practices: Doing discourse analysis in the digital age (pp. 226-240). New York, NY: Routledge.

Selwyn, N., Gorard, S., \& Furlong, J. (2006). Adult learning in the digital age: Information technology and the learning society. London, UK: Routledge.

Şendağ, S., \& Odabaşı, H. F. (2009). Effects of an online problem-based learning course on content knowledge acquisition and critical thinking skills. Computers \& Education, 53(1), 132-141. doi:10.1016/j.compedu.2009.01.008.

Senkbeil, M., \& Ihme, J. M. (2017). Motivational factors predicting ICT literacy: First evidence on the structure of an ICT motivation inventory. Computers \& Education 108, 145-158. doi:10.1016/j.compedu.2017.02.003

Shalley, C. E., Gilson, L. L., \& Blum, T. C. (2000). Matching creativity requirements and the work environment: Effects on satisfaction and intentions to leave. Academy of Management Journal, 43(2), 215-223. doi:10.5465/1556378.

Shamseer, L., Moher, D., Clarke, M., Ghersi, D., Liberati, A., Petticrew, M., Shekelle, P. Stewart, L. A. (2015). Preferred reporting items for systematic review and metaanalysis protocols (PRISMA-P) 2015: Elaboration and explanation. BMJ 2015, 349:g7647. doi:10.1136/bmj.g7647.

Siddiq, F., Gochyyev, P., \& Wilson, M. (2017). Learning in digital networks - ICT literacy: A novel assessment of students' 21st century skills. Computers \& Education, 109, 11-37. doi:10.1016/j.compedu.2017.01.014.

Siddiq, F., Hatlevik, O. E., Olsen, R. V., Throndsen, I., \& Scherer, R. (2016). Taking a future perspective by learning from the past: A systematic review of assessment instruments that aim to measure primary and secondary school students' IC literacy. Educational Research Review, 19, 58-84. doi:10.1016/j.edurev.2016.05.002. 
Siddiq, F., Scherer, R., \& Tondeur, J. (2016). Teachers' emphasis on developing students' digital information and communication skills (TEDDICS): A new construct in 21st century education. Computers \& Education, 92, 1-14. doi:10.1016/j. compedu.2015.10.006.

Sigala, M., \& Chalkiti, K. (2015). Knowledge management, social media and employee creativity. International Journal of Hospitality Management, 45, 44-58. doi:10.1016/j. ijhm.2014.11.003.

Silva, E. (2009). Measuring skills for 21st-century learning. The Phi Delta Kappan, 90(9), 630-634.

Silverman, D. (2001). Interpreting qualitative data: Methods for analysing talk, text and interaction. London, UK: Sage Publications.

Singh, S. (2012). Developing e-skills for competitiveness, growth and employment in the 21st century: The European perspective. International Journal of Development Issues, 11(1), 37-59. doi:10.1108/14468951211213859.

Slof, B., Erkens, G., Kirschner, P. A., \& Helms-Lorenz, M. (2013). The effects of inspecting and constructing part-task-specific visualizations on team and individual learning. Computers \& Education, 60(1), 221-233. doi:10.1016/j.compedu.2012.07.019.

Slof, B., Erkens, G., Kirschner, P. A., Jaspers, J. G., \& Janssen, J. (2010). Guiding students' online complex learning-task behavior through representational scripting. Computers in Human Behavior, 26(5), 927-939. doi:10.1016/j.chb.2010.02.007.

Song, G., \& Ling, C. (2011). Users' attitude and strategies in information management with multiple computers. International Journal of Human-Computer Interaction 27(8), 762-792. doi:10.1080/10447318.2011.555307.

Sosu, E. M. (2013). The development and psychometric validation of a critical thinking disposition scale. Thinking Skills and Creativity, 9, 107-119. doi:10.1016/j. tsc. 2012.09.002.

Soulé, H., \& Warrick, T. (2015). Defining 21st century readiness for all students: What we know and how to get there. Psychology of Aesthetics Creativity, and the Arts, 9(2), 178-186. doi:10.1037/aca0000017.

Starkey, L. (2011). Evaluating learning in the 21st century: A digital age learning matrix. Technology, Pedagogy and Education, 20(1), 19-39. doi:10.1080/147593 9X.2011.554021.

Stevens, J. P. (2012). Applied multivariate statistics for the social sciences (5th edition) New York, NY: Taylor \& Francis Group.

Strawn, G. (2017). IT and 21st century employment. IT Professional, 19(6), 71-73. doi:10.1109/MITP.2017.4241470.

Sullivan, P. (2010). Empirical evidence on occupation and industry specific human capital. Labour Economics, 17(3), 567-580. doi:10.1016/j.labeco.2009.11.003.

Suto, I. (2013). 21st Century skills: Ancient, ubiquitous, enigmatic. Research Matters: Cambridge Assessment, 15, 2-8.
Talja, S. (2005). The social and discursive construction of computing skills. Journal of the American Society for Information Science and Technology, 56(1), 13-22. doi:10.1002/asi.20091.

Thoman, E., \& Jolls, T. (2004). Media literacy - A national priority for a changing world. American Behavioral Scientist, 48(1), 18-29. doi:10.1177/0002764204267246.

Tondeur, J., Sinnaeve, I., Van Houtte, M., \& Van Braak, J. (2011). ICT as cultural capital: The relationship between socioeconomic status and the computer-use profile of young people. New Media \& Society, 13(1), 151-168. doi:10.1177/1461444810369245.

Torrance, E. P. (1968). Examples and rationales of test tasks for assessing creative abilities, The Journal of Creative Behavior, 2(3), 165-178. doi:10.1002/j.2162-6057.1968. tb00099.x.

Torrance, E. P. (1972). Predictive validity of the Torrance tests of creative thinking. The Journal of Creative Behavior, 6(4), 236-262. doi:10.1002/j.2162-6057.1972.tb00936.x.

Trip, J. J., \& Romein, A. (2014). Creative city policy and the gap with theory. European Planning Studies, 22(12), 2490-2509. doi:10.1080/09654313.2013.790592.

Van Audenhove, L., Vanwynsberghe, H., \& Mariën, I. (2018). Media literacy policy in Flanders-Belgium: From parliamentary discussions to public policy. Journal of Media Literacy Education, 10(1), 59-81.

Van Damme, M., De Haan, J., Kraan K., T. Kwakkelstein, T., De Leede, J., Steijn, B., \& Tijdens, K.(2005). Verzonken Technologie: ICT en arbeidsmarkt. Den Haag: Sociaal Cultureel Planbureau (SCP).

Van de Oudeweetering, K., \& Voogt, J. M. (2018). Teachers' conceptualization and enactment of twenty-first century competences: Exploring dimensions for new curricula. The Curriculum Journal, 29(1), 116-133. doi:10.1080/09585176.2017.1369136.

Van Deursen, A. J. A. M., Courtois, C., \& Van Dijk, J. A. G. M. (2014). Internet skills, sources of support, and benefiting from Internet use. International Journal of Human-Computer Interaction, 30(4), 278-290. doi:10.1080/10447318.2013.858458.

Van Deursen, A. J. A. M., \& Helsper, E. J. (2018). ICT skills for the future. In M. Gibson (Ed.), Measuring the Information Society Report Volume 1. Geneva, Switzerland: International Telecommunication Union (ITU).

Van Deursen, A. J. A. M., Helsper, E. J., \& Eynon, R. (2016). Development and validation of the Internet Skills Scale (ISS). Information, Communication \& Society, 19(6), 804 823. doi:10.1080/1369118X.2015.1078834.

Van Deursen, A. J. A. M., Helsper, E. J., Eynon, R., \& Van Dijk, J. A. G. M. (2017). The compoundness and sequentiality of digital inequality. International Journal of Communication, 11, 452-473.

Van Deursen, A. J. A. M., \& Van Diepen, S. (2013). Information and strategic Internet skills of secondary students: A performance test. Computers \& Education, 63, 218226. doi:10.1016/j.compedu.2012.12.007.

Van Deursen, A. J. A. M., \& Van Dijk, J. A. G. M. (2008). Digitale vaardigheden van Nederlandse burgers: Een prestatiemeting van operationele, formele, informatie en strategische vaardigheden bij het gebruik van overheidswebsites. Enschede, the Netherlands: University of Twente. 
Van Deursen, A. J. A. M., \& Van Dijk, J. A. G. M. (2009). Using the Internet: Skill related problems in users' online behavior. Interacting with Computers, 21(5-6), 393-402. doi:10.1016/j.intcom.2009.06.005

Van Deursen, A. J. A. M., \& Van Dijk, J. A. G. M. (2010). Measuring Internet skills. International Journal of Human-Computer Interaction, 26(10), 891-916. doi:10.108 0/10447318.2010.496338.

Van Deursen, A. J. A. M., \& Van Dijk, J. A. G. M. (2011a). Internet skills and the digital divide. New Media \& Society, 13(6), 893-911. doi:10.1177/1461444810386774.

Van Deursen, A. J. A. M., \& Van Dijk, J. A. G. M. (2011b). Internet skills performance tests: Are people ready for eHealth? Journal of Medical Internet Research, 13(2). doi:10.2196/jmir.1581.

Van Deursen, A. J. A. M., \& Van Dijk, J. A. G. M. (2014). Loss of labor time due to malfunctioning ICTs and ICT skill insufficiencies. International Journal of Manpower, 35(5), 703-719. doi:10.1108/IJM-07-2012-0102.

Van Deursen, A. J. A. M., \& Van Dijk, J. A. G. M. (2015a). Internet skill levels increase but gaps widen: A longitudinal cross-sectional analysis (2010-2013) among the Dutch population. Information, Communication \& Society, 18(7), 782-797. doi:10.1080/13 69118X.2014.994544.

Van Deursen, A. J. A. M., \& Van Dijk, J. A. G. M. (2015b). Towards a multifaceted model of Internet access to understand digital divides: An empirical investigation. The Information Society, 31(5), 379-391. doi:10.1080/01972243.2015.1069770.

Van Deursen, A. J. A. M., \& Van Dijk, J. A. G. M. (2016). Modeling traditional literacy, Internet skills and Internet usage: An empirical study. Interacting with Computers, 28(1), 13-26. doi:10.1093/iwc/iwu027.

Van Deursen, A. J. A. M., Van Dijk, J. A. G. M., \& Peters, O. (2011). Rethinking Internet skills: The contribution of gender, age, education, Internet experience, and hours online to medium- and content-related Internet skills. Poetics, 39(2), 125-144. doi:10.1016/j.poetic.2011.02.001.

Van Deursen, A. J. A. M., Van Dijk, J. A. G. M., \& Peters, O. (2012). Proposing a survey instrument for measuring operational, formal, information and strategic Internet skills. International Journal of Human-Computer Interaction, 28(12), 827-837. doi:10.1080/10447318.2012.670086

Van Deursen, A. J. A. M., Verlage, C., \& Van Laar, E. (2019). Social network site skills for communication professionals: Conceptualization, operationalization, and an empirical investigation. IEEE Transactions on Professional Communication, 62(1), 43-54. doi:10.1109/TPC.2018.2867168.

VandeWalle, D. (1997). Development and validation of a work domain goal orientation instrument. Educational and Psychological Measurement, 57(6), 995-1015. doi:10.1 177/0013164497057006009.

Van Dijk, J. A. G. M. (2004). Divides in succession: Possession, skills, and use of new media for societal participation. In J. N. Newhagen \& E. Bucy (Eds.), Media access: Social and psychological dimensions of new technology use (pp. 233-254). Mahwah, NJ: Lawrence Erlbaum Associates.
Van Dijk, J. A. G. M. (2005). The deepening divide: Inequality in the information society. London, UK: Sage Publications.

Van Dijk, J. A. G. M. (2013). A theory of the digital divide. In M. Ragnedda \& G. W. Muschert (Eds.), The digital divide: The Internet and social inequality in international perspective (pp. 29-51). Abingdon, UK: Routledge.

Van Dijk, J. A. G. M. (2019). The digital divide. Cambridge UK, Malden MA: Polity Press.

Van Dijk, J. A. G. M., \& Van Deursen, A. J. A. M. (2014). Digital skills: Unlocking the information society. New York, NY: Palgrave Macmillan.

Vassallo, S. (2014). The entanglement of thinking and learning skills in neolibera discourse. In T. Corcoran (Ed.), Psychology in education (pp. 145-165). Dordrecht, the Netherlands: Sense Publishers.

Verhoeven, J. C., Heerwegh, D., \& De Wit, K. (2016). ICT learning experience and research orientation as predictors of ICT skills and the ICT use of university students. Education and Information Technologies, 21(1), 71-103. doi:10.1007/s10639-0149310-3

Volman, M., \& Ten Dam, G. (2015). Critical thinking for educated citizenship. In M. Davies \& R. Barnett (Eds.), The Palgrave handbook for critical thinking in higher education (pp. 593-603). London, UK: Palgrave MacMillan.

Voogt, J. M., Erstad, O., Dede, C., \& Mishra, P. (2013). Challenges to learning and schooling in the digital networked world of the 21st century. Journal of Computer Assisted Learning, 29(5), 403-413. doi:10.1111/jcal.12029.

Voogt, J. M., \& Pareja Roblin, N. P. (2012). A comparative analysis of international frameworks for 21st century competences: Implications for national curriculum policies. Journal of Curriculum Studies, 44(3)، 299-321. doi:10.1080/00220272.20 12.668938 .

Voskoglou, M. G., Buckley, S. (2012). Problem solving and computational thinking in a learning environment. Egyptian Computer Science Journal, 36(4), 28-46.

Wagner, T. (2008). The global achievement gap: Why even our best schools don't teach the new survival skills our children need - and what we can do about it. New York, NY: Basic Books.

Walraven, A., Brand-Gruwel, S., \& Boshuizen, H. P. (2008). Information-problem solving: A review of problems students encounter and instructional solutions. Computers in Human Behavior, 24(3), 623-648. doi:10.1016/j.chb.2007.01.030.

Wang, M., Vogel, D., \& Ran, W. (2011). Creating a performance-oriented e-learning environment: A design science approach. Information and Management, 48(7) 260-269.

Wang, Q. (2010). Using online shared workspaces to support group collaborative learning. Computers \& Education, 55(3), 1270-1276. doi:10.1016/j.compedu.2010.05.023.

Wang, S., \& Noe, R. A. (2010). Knowledge sharing: A review and directions for future research. Human Resource Management Review, 20(2), 115-131. doi:10.1016/j. hrmr.2009.10.001. doi:10.1016/j.im.2011.06.003. 
Wang, W., Hsieh, J. P. A., \& Song, B. (2012). Understanding user satisfaction with instant messaging: An empirical survey study. International Journal of Human-Computer Interaction, 28(3), 153-162. doi:10.1080/10447318.2011.568893.

Warschauer, M. (2003). Technology and social inclusion: Rethinking the digital divide. Cambridge, MA: MIT Press.

Wasserstein, R. L., \& Lazar, N. A. (2016). The ASA's statement on p-values: Context, process and purpose. The American Statistician, 70(2), 129-133. doi:10.1080/0003 1305.2016.1154108

Wechsler, S. M., Saiz, C., Rivas, S. F., Vendramini, C. M. M., Almeida, L. S., Mundim, M. C. \& Franco, A. (2018). Creative and critical thinking: Independent or overlapping components? Thinking Skills and Creativity, 27, 114-122. doi:10.1016/j.tsc.2017.12.003.

Weiner, J. M. (2011). Is there a difference between critical thinking and information literacy? Journal of Information Literacy, 5(2), 81-92. doi:10.11645/5.2.1600.

West, R. F., Toplak, M. E., \& Stanovich, K. E. (2008). Heuristics and biases as measures of critical thinking: Associations with cognitive ability and thinking dispositions. Journal of Educational Psychology, 100(4), 930-941. doi:10.1037/a0012842.

Whitten, D., \& Brahmasrene, T. (2011). Predictors of critical thinking skills of incoming business students. Academy of Educational Leadership Journal, 15(1), 1-13.

Willingham, D. T. (2008). Critical thinking: Why is it so hard to teach? Arts Education Policy Review, 109(4), 21-32. doi:10.3200/AEPR.109.4.21-32.

Willoughby, T., Anderson, S. A., Wood, E., Mueller, J., \& Ross, C. (2009). Fast searching for information on the Internet to use in a learning context: The impact of domain knowledge. Computers \& Education, 52(3), 640-648. doi:10.1016/j. compedu.2008.11.009.

Wilson, M., Scalise, K., \& Gochyyev, P. (2015). Rethinking ICT literacy: From computer skills to social network settings. Thinking Skills and Creativity, 18, 65-80. doi:10.1016/j. tsc.2015.05.001.

Wolff, H. G., \& Moser, K. (2010). Do specific types of networking predict specific mobility outcomes? A two-year prospective study. Journal of Vocational Behavior, 77(2) 238-245. doi:10.1016/j.jvb.2010.03.001.

Wolters, C. A. (2010). Self-regulated learning and the 21st century competencies. Menlo Park, CA: The William and Flora Hewlett Foundation. Retrieved from: http://www. hewlett.org/library/grantee-publication/self-regulated-learning-and-21st-centurycompetencies.

Woodman, R. W., Sawyer, J. E., \& Griffin, R. W. (1993). Toward a theory of organizational creativity. Academy of Management Review, 18(2), 293-321. doi:10.5465/ amr.1993.3997517.

Wrench, J. S. (2004). Face-to-face vs. online friendships: An examination of friendship intimacy, interpersonal communication satisfaction and interpersonal communication motives. National Communication Association's Convention, November 2004. Chicago, IL.
Yang, Y. T. C. (2012). Building virtual cities, inspiring intelligent citizens: Digital games for developing students' problem solving and learning motivation. Computers \& Education, 59(2), 365-377. doi:10.1016/j.compedu.2012.01.012.

Yang, Y. T. C. (2015). Virtual CEOs: A blended approach to digital gaming for enhancing higher order thinking and academic achievement among vocational high schoo students. Computers \& Education, 81, 281-295. doi:10.1016/j.compedu.2014.10.004.

Yi, M. Y., \& Hwang, Y. (2003). Predicting the use of web-based information systems: Self-efficacy, enjoyment, learning goal orientation, and the technology acceptance model. International Journal of Human-Computer Studies, 59(4), 431-449. doi:10.1016/S1071-5819(03)00114-9.

Yilmaz, F. G. K. (2016). The relationship between metacognitive awareness and online information searching strategies. Pegem Journal of Education and Instruction, 6(4), 447-468. doi:10.14527/pegegog.2016.022.

Youssef, A. B., Dahmani, M., \& Omrani, N. (2015). Information technologies, students' e-skills and diversity of learning process. Education and Information Technologies, 20(1), 141-159. doi:10.1007/s10639-013-9272-x.

Yu, A. Y., Tian, S. W., Vogel, D., \& Kwok, R. C. W. (2010). Can learning be virtually boosted? An investigation of online social networking impacts. Computers \& Education, 55(4), 1494-1503. doi:10.1016/j.compedu.2010.06.015.

Zampetakis, L. A., Bouranta, N., \& Moustakis, V. S. (2010). On the relationship between individual creativity and time management. Thinking Skills and Creativity, 5(1), 23-32. doi:10.1016/j.tsc.2009.12.001

Zhang, X., Majid, S., \& Foo, S. (2010). Environmental scanning: An application of information literacy skills at the workplace. Journal of Information Science, 36(6), 719-732. doi:10.1177/0165551510385644.

Zhong, Z. J. (2011). From access to usage: The divide of self-reported digital skills among adolescents. Computers \& Education, 56(3), 736-746. doi:10.1016/j. compedu.2010.10.016.

Zhou, J., \& George, J. M. (2001). When job dissatisfaction leads to creativity: Encouraging the expression of voice. Academy of Management Journal, 44(4), 682 696. doi:10.2307/3069410

Zhou, J., \& George, J. M. (2003). Awakening employee creativity: The role of leade emotional intelligence. The Leadership Quarterly, 14(4-5), 545-568. doi:10.1016/ S1048-9843(03)00051-1.

Zikmund, W. G., Babin, B. J., Carr, J. C., \& Griffin, M. (2010). Business research methods (8th edition). Mason, OH: South Western Cengage Learning.

Zimmerman, B. J. (2000). Attaining self-regulation: A social cognitive perspective. In M. Boekaerts, P. R. Pintrich \& M. Zeidner (Eds.), Handbook of self-regulation (pp. 13-39). New York, NY: Academic Press.

Zimmerman, B. J. (2002). Achieving self-regulation: The trial and triumph of adolescence. In F. Pajares \& T. Urdan (Eds.), Academic motivation of adolescents (pp. 1-27) Greenwich, CT: Information Age Publishing. 


\section{SUMMARY}

The rapid integration of ICTs results in continuously evolving digital skills that are necessary for employment. As global competition is becoming increasingly knowledge-centric, the requisite digital skills include not only technical skills such as the ability to perform basic practical tasks online but also a more generic set of skills related to the ability to communicate across cultural and institutional boundaries, to work in remote teams, to create and share knowledge in digital environments (Lanvin \& Passman, 2008) and to adapt to changing requirements on the job (Carnevale \& Smith, 2013). The industrial economy based on manufacturing has shifted to a service economy driven by information, knowledge and creativity. As a result, work environments are increasingly knowledge-driven and technology-rich, work problems are becoming more complex, and people often work in multidisciplinary teams (Griffin \& Care, 2012; Littlejohn, Beetham, \& McGill, 2012). These are just a few examples of developments in the labor markets that have been changing the skill demands of many jobs.

The skills that are needed for education and the workplace in contemporary society are often labeled as 21 st-century skills. The concept of '21st-century skills' covers a broad spectrum of content-related skills besides more ICT or digital related skill aspects. However, only a few approaches provide an integration of digital and 21 st-century skills. Therefore, we introduce the term 21st-century digital skills to understand the consequences of digitization in terms of individual workers' skills. The essence is what workers can do with ICTs to support a broad spectrum of 21st-century skills and in turn take full advantage of ICTs. A main contribution is made to the concept of 21 st-century digital skills by clarifying, operationalizing and testing its value within the creative industries. The Dutch government defines the creative industries as one of the nine top sectors in the Netherlands. The creative sector represents a knowledge-intensive industry characterized by rapid technological changes (Musterd, Bontje, Chapain, Kovacs, \& Murie, 2007); it is a sector where new and complex knowledge is continuously being created and demanded and where underlying competences are needed to strengthen one's skills permanently (Kamprath \& Mietzner, 2015). As such, the creative industries in the Netherlands are used as a case study. Before conducting multiple quantitative and qualitative studies within the creative industries, this dissertation begins with clarifying the conceptual indistinctions by conducting a systematic literature review. 
Chapter 2 describes a systematic review of the literature to synthesize the relevant academic literature between 2000 and 2016 addressing 21st-century skills, digital skills, and closely related terms. Key 21 st-century skill and digital skill dimensions are identified by evaluating articles that aim to define or measure them in reference to the labor market. First, the results provide insights into the relation between '21st-century skills' and 'digital skills' definitions. On the one hand, 21st-century skills literature emphasizes a broad spectrum of skills, yet do not explicitly integrate digital aspects. Instead, digital skills are considered to be a separate skill within the range of 21st-century skills, for instance, under the label of ICT skills. The digital skills literature, on the other hand, often does not cover the broad spectrum of skills posed by 21 st-century skills studies. Second, the review resulted in the formation of a comprehensive 21st-century digital skills framework. The framework presents seven core skills supported by the use of ICT: technical, information management, communication, collaboration, creativity, critical thinking, and problem solving. The following five contextual skills that play a role when using ICT are also presented: ethical awareness, cultural awareness, flexibility, self-direction, and lifelong learning.

Chapter 3 describes a qualitative study with managers and senior executives working within the creative industries. The interview approach expands on the findings from Chapter 2 by showing the previously identified 21st-century digital skills to determine if they are applicable to the creative industries. An in-depth study of industry experts' perspectives on the 21st-century digital skills that are necessary for the workforce is provided. In the beginning of the interview, the digital aspect is excluded to allow participants to disclose their own views on the use of ICTs with regard to each skill. Before presenting our framework, they mentioned comparable skills as relevant, which can be understood as a validation of the skills found in the literature. In particular, the core skills are viewed as essential. In addition, the results show that while 21 st-century skills are considered relevant for selection procedures, when someone is already employed, attention to skill levels is limited. Although the participants subscribe the importance of 21 st-century skills, they often do not recognize the digital aspect within these skills. Most participants seem to view digital skills as selfexplanatory and do not deviate from describing technical skills. In general, the interview study is a first attempt to investigate the 21st-century digital skills framework within the labor market. Additional cues to further operationalize each skill are provided by the participants.
Chapter 4 presents a carefully constructed 21st-century digital skills survey instrument that has been tested via cognitive interviews, a survey-pilot and a ful survey among professionals working within the creative industries. Based on the findings of the systematic literature review (Chapter 2) and interviews (Chapter 3 ), the following core 21 st-century digital skills are further operationalized: information management, information evaluation, communication expressiveness, communication contact-building, communication networking, communication content-sharing, collaboration, critical thinking, creativity, and problem solving. The developed survey instrument measures the frequency of various skill-related actions (at work, how often do you...?). This instrument avoids common response formats such as self-evaluation (how good are you at...?) or agreement (how much do you agree?) scales. The result is an instrument that can measure a broad range of 21st-century digital skills supported by empirical data to validate the structure and content of each skill.

In Chapter 5, the survey instrument, as developed in Chapter 4, is used to empirically test the relation among various 21 st-century digital skills. Insights into what other skills are needed to perform well on a specific skill are provided. The results show that 21 st-century digital skills build on each other. Our empirically tested model begins from information to communication digital skills and it ends with problem-solving digital skills. The intermediaries are collaboration, critical-thinking and creative digital skills. An important finding is that except for critical-thinking digital skills, all skills directly lead to problemsolving digital skills. The results underscore that the 21 st-century digital skills under investigation show gradients of difficulty, which can be used to justify initiatives targeting skill improvement. Once the level of information digital skills is sufficient, it is, for instance, useful to focus on the development of communication digital skills.

Chapter 6 presents a systematic literature review on determinants of 21 st-century skills and digital skills at the level of the individual worker. The various skill concepts and dimensions, as identified in Chapter 2, guided the literature search. An overview of empirical studies on determinants relevant to each skill is provided and categorized. The results demonstrate which skills and determinants warrant future research attention. In general, research on determinants of communication and collaboration skills is lacking. More specifically, for 21 st-century skills studies, creativity and critical thinking are the most investigated skills. In the case of digital skills studies, technical and information skills are the most investigated skills. Furthermore, 21st-century 
skills studies are largely limited to psychological factors such as personality traits and intelligence. Although digital skills studies show more variety, they mostly cover demographics (e.g., age and gender), socioeconomic (e.g., education) and mental or motivational (e.g., training) factors. Factors such as gender, age and personality are more permanent and difficult to account for in skill policies.

In Chapter 7, the survey instrument, as developed in Chapter 4, is used to measure the level of 21 st-century digital skills. The survey also measures various mental (ICT attitude, perceived ease of use, ICT self-regulation, selfdirected learning, goal orientations, ICT training), personal (individual initiative) and social (support sources) factors. The systematic literature review, as described in Chapter 6, is used to select potential skill determinants that can be influenced and accounted for in skill policies. With regard to the skill levels, the respondents report fairly high levels of 21st-century digital skills. Except for the communication dimensions content-sharing and contact-building, the skill levels are above average. Prominent factors contributing to various skills are perceived ease of use, performance goal orientation and support from Internet contacts online. In addition, personal initiative is of particular importance for employed professionals whereas self-directed learning is of particular importance for selfemployed professionals. Overall, the level of each 21st-century digital skill is explained by a different set of determinants.

Chapter 8 is about measuring information, critical-thinking, creativity and problem-solving digital skills by means of a performance test. A key issue with respect to the previous chapters is the reliance on self-reported survey data instead of directly demonstrated performance. Performance tests are more labor-intensive and difficult to conduct on large samples; however, they do rely on the completion of tasks to demonstrate skills. This approach leads to the development of an authentic performance test using detailed indices per skill to assess task performance. A key observation is that participants seem to have most difficulty with information and problem-solving digital skills. They, for instance, rarely check their answer on another website or provide multiple solutions with an explanation. With regard to critical-thinking and creative digital skills, the observations are more promising. They, for instance, give arguments for multiple perspectives provided with proof or examples and are able to produce a large number of useful ideas. Overall, the observations expose detailed skill indices to provide a deeper analysis of working professionals' levels of digital skills.
Chapter 9 considers how organizations within the creative industries support skill development. Through in-depth interviews with top-level managers, this study offers a deeper analysis of skill levels and the roles of both the individual worker and the organization in the development of 21 st-century digital skills. The results show that managers often do not seem to account for the 21 stcentury digital skills posed in this dissertation. Managers seem to believe that workers' technical skill levels are naturally high, while in fact, digital skills might require attention when content-related skills are considered. The first priority in this case should be to raise awareness of 21 st-century digital skills within an organization's management. Thereafter, intentional and structural efforts on the part of individual workers and organizations are needed to improve learning and skill development practices in the workplace.

In conclusion, this dissertation provides an interdisciplinary conceptual and operational elaboration of various 21 st-century digital skills and their potential causes at the level of the individual worker. The significance of 21 st-century digital skills is demonstrated by applying a multimethod research approach. To further strengthen 21st-century digital skills, it is preferable to first raise awareness before attempting to reshape practice. This dissertation shows that the overarching goal of skill policy should be the creation of a broader digitally skilled workforce. The involved stakeholders (e.g., education, industry, and individual workers) all have their responsibility and must take the call to action to fulfill the demands of the labor market. 


\section{SAMENVATTING (SUMMARY IN DUTCH)}

De snelle integratie van informatie- en communicatietechnologieën (ICT) resulteert in continue veranderende digitale vaardigheden die nodig zijn voor werk. Gezien in de wereldwijde competitie de beheersing van kennis centraal staat, bevatten de benodigde digitale vaardigheden niet alleen technische vaardigheden zoals het uitvoeren van praktische online taken, maar ook een set generieke vaardigheden gerelateerd aan het communiceren over culturele grenzen heen, het samenwerken met teams op afstand, het creëren en delen van kennis in digitale omgevingen (Lanvin \& Passman, 2008) en het aanpassen aan veranderende eisen op het werk (Carnevale \& Smith, 2013). De industriële economie gebaseerd op produceren is getransformeerd naar een serviceeconomie die wordt gedreven door informatie, kennis en creativiteit. Als gevolg hiervan worden werkomgevingen in toenemende mate kennisgestuurd en technologierijk, worden werkproblemen steeds complexer en werken mensen vaker in multidisciplinaire teams (Griffin \& Care, 2012; Littlejohn, Beetham, \& McGill, 2012). Dit zijn slechts enkele voorbeelden van ontwikkelingen op de arbeidsmarkt die de vaardigheidseisen voor banen hebben veranderd.

De vaardigheden die nodig zijn voor het onderwijs en de werkplek in de hedendaagse samenleving worden vaak aangeduid als 21 e-eeuwse vaardigheden. Het concept van '21e-eeuwse vaardigheden' omvat een breed spectrum van inhoudelijke vaardigheden naast meer ICT- of digitaal gerelateerde vaardigheden. Echter, slechts enkele benaderingen integreren digitale en $21 \mathrm{e}$-eeuwse vaardigheden. Om de gevolgen van digitalisering in termen van de vaardigheden van individuele werknemers te begrijpen, introduceren we de term 21e-eeuwse digitale vaardigheden. De essentie is wat werknemers met ICT kunnen doen om een breed spectrum van 21e-eeuwse vaardigheden te ondersteunen, om daaropvolgend ten volle van ICT te kunnen profiteren. Een belangrijke bijdrage wordt geleverd aan het concept van 21e-eeuwse digitale vaardigheden door deze te verduidelijken, te operationaliseren en te testen binnen de creatieve industrie. De Nederlandse overheid definieert de creatieve industrie als één van de negen topsectoren in Nederland. De creatieve sector vertegenwoordigt een kennisintensieve industrie die wordt gekenmerkt door snelle technologische veranderingen (Musterd, Bontje, Chapain, Kovacs, \& Murie, 2007); het is een sector waar voortdurend nieuwe en complexe kennis wordt gecreëerd en gevraagd en waar onderliggende competenties nodig zijn om iemands vaardigheden continue te versterken (Kamprath \& Mietzner, 
2015). De creatieve industrie wordt daarom als een casestudie gebruikt. Voordat meerdere kwantitatieve en kwalitatieve studies binnen de creatieve industrie worden uitgevoerd, begint dit proefschrift met het verduidelijken van het concept door een systematisch literatuuronderzoek uit te voeren.

Hoofdstuk 2 beschrijft een systematische evaluatie van de literatuur om de relevante academische literatuur tussen 2000 en 2016 samen te brengen over 21 -eeuwse vaardigheden, digitale vaardigheden en verwante termen. Belangrijke 21e-eeuwse en digitale vaardigheidsdimensies worden geïdentificeerd door artikelen te evalueren die tot doel hebben deze te definiëren of te meten met betrekking tot de arbeidsmarkt. Ten eerste bieden de resultaten inzicht in de relatie tussen de definities van '21e-eeuwse vaardigheden' en 'digitale vaardigheden'. Enerzijds wordt in de literatuur over 21e-eeuwse vaardigheden de nadruk gelegd op een breed spectrum van vaardigheden, maar digitale aspecten worden vaak niet expliciet geïntegreerd. In plaats daarvan worden digitale vaardigheden beschouwd als een afzonderlijke vaardigheid binnen $21 \mathrm{e}$-eeuwse vaardigheden zoals onder het label ICTvaardigheden. Anderzijds bevat de literatuur over digitale vaardigheden vaak niet het brede spectrum aan vaardigheden die worden voorgesteld in 21 -eeuwse vaardighedenstudies. Ten tweede resulteerde de review in de vorming van een uitgebreid raamwerk van 21 e-eeuwse digitale vaardigheden. Het raamwerk presenteert zeven kernvaardigheden die worden ondersteund door het gebruik van ICT: technisch, informatiemanagement, communicatie, samenwerken, creativiteit, kritisch denken en probleemoplossend vermogen. De volgende vijf contextuele vaardigheden die een rol spelen bij het gebruik van ICT worden ook gepresenteerd: ethisch bewustzijn, cultureel bewustzijn, flexibiliteit, zelfsturend vermogen en levenslang leren.

Hoofdstuk 3 beschrijft een kwalitatief onderzoek met managers en senior leidinggevenden die werkzaam zijn binnen de creatieve industrie. De interviewbenadering bouwt voort op de bevindingen uit hoofdstuk 2 door de geïdentificeerde 21e-eeuwse digitale vaardigheden te laten zien om te kijken of deze van toepassing zijn op de creatieve industrie. Er wordt diepgaand onderzoek gedaan naar de perspectieven van industrie-experts op de 21e-eeuwse digitale vaardigheden die nodig zijn voor werknemers In het begin van het interview is het digitale aspect uitgesloten, zodat de deelnemers hun eigen mening kunnen geven over het gebruik van ICT met betrekking tot elke vaardigheid. Voordat we ons raamwerk presenteerden, noemden ze vergelijkbare vaardigheden als relevant. Dit kan gezien worden als een validatie voor de vaardigheden die gevonden zijn in de literatuur. In het bijzonder worden de kernvaardigheden als essentieel beschouwd. Bovendien laten de resultaten zien dat hoewel 21 -eeuwse vaardigheden relevant worden geacht voor selectieprocedures, de aandacht voor vaardigheidsniveaus beperkt is wanneer iemand al in dienst is. Hoewel de deelnemers het belang van 21 -eeuwse vaardigheden onderschrijven, herkennen ze het digitale aspect binnen deze vaardigheden vaak niet. De meeste deelnemers lijken digitale vaardigheden als vanzelfsprekend te beschouwen en wijken niet af van het beschrijven van technische vaardigheden. In het algemeen is de interviewstudie een eerste poging om het 21 se-eeuwse digitale vaardigheden raamwerk op de arbeidsmarkt te onderzoeken. Aanvullende aanwijzingen om elke vaardigheid verder te operationaliseren, worden door de deelnemers gegeven.

Hoofdstuk 4 presenteert een zorgvuldig samengestelde vragenlijst voor het meten van 21 e-eeuwse digitale vaardigheden, welke is getest via cognitieve interviews, een vragenlijst pilot en een volledig vragenlijstonderzoek onder professionals die werkzaam zijn binnen de creatieve industrie. Op basis van de bevindingen van het systematisch literatuuronderzoek (hoofdstuk 2) en de interviews (hoofdstuk 3), worden de volgende 21e-eeuwse digitale vaardigheden verder geoperationaliseerd: informatiemanagement, informatie evaluatie, communicatie expressiviteit, communicatie contacten opbouwen, communicatie netwerken, communicatie inhoud delen, samenwerken, kritisch denken, creativiteit en probleemoplossend vermogen. De ontwikkelde vragenlijst meet de frequentie van verschillende vaardigheidsgerelateerde acties (op het werk, hoe vaak...?). Dit instrument vermijdt veelgebruikte antwoordschalen zoals zelfevaluatie (hoe goed bent $u$ in ...?) of overeenstemming (in hoeverre bent $u$ het eens met?). Het resultaat is een meetinstrument dat een breed scala aan 21e-eeuwse digitale vaardigheden kan meten ondersteund door empirische data om de samenstelling en inhoud van elke vaardigheid te valideren.

In hoofdstuk 5 wordt het meetinstrument, zoals ontwikkeld in hoofdstuk 4, gebruikt om de relatie tussen verschillende 21 e-eeuwse digitale vaardigheden empirisch te testen. Er wordt inzicht gegeven in welke andere vaardigheden nodig zijn om goed te presteren op een specifieke vaardigheid. De resultaten laten zien dat de 21e-eeuwse digitale vaardigheden op elkaar voortbouwen. Ons empirisch geteste model loopt van digitale informatievaardigheden naar digitale communicatievaardigheden en eindigt bij digitaal probleemoplossend vermogen. De tussenliggende digitale vaardigheden zijn samenwerken, kritisch denken en creativiteit. Een belangrijke bevinding is dat, behalve digitaal kritisch 
denken, alle vaardigheden direct leiden naar digitaal probleemoplossend vermogen. De resultaten benadrukken dat de onderzochte 21e-eeuwse digitale vaardigheden moeilijkheidsgraden vertonen. Dit gegeven kan worden gebruikt om initiatieven gericht op de verbetering van vaardigheden te rechtvaardigen. Zodra het niveau van digitale informatievaardigheden voldoende is, is het bijvoorbeeld nuttig om te focussen op de ontwikkeling van digitale communicatievaardigheden.

Hoofdstuk 6 presenteert een systematisch literatuuronderzoek over determinanten van 21e-eeuwse vaardigheden en digitale vaardigheden op het niveau van de individuele werknemer. De verschillende vaardigheidsconcepten en dimensies, zoals geïdentificeerd in hoofdstuk 2, waren de leidraad voor deze literatuurstudie. Er wordt een overzicht van empirische studies naar determinanten relevant voor elke vaardigheid gegeven en gecategoriseerd. De resultaten laten zien welke vaardigheden en determinanten toekomstige aandacht van onderzoek verdienen. In het algemeen ontbreekt onderzoek naar determinanten van communicatie- en samenwerkingsvaardigheden Meer specifiek zijn voor de 21e-eeuwse vaardighedenstudies creativiteit en kritisch denken de meest onderzochte vaardigheden. In het geval van digitale vaardighedenstudies zijn technische en informatievaardigheden de meest onderzochte vaardigheden. Bovendien zijn de $21 \mathrm{e}$-eeuwse vaardighedenstudies grotendeels beperkt tot psychologische factoren zoals persoonlijkheidskenmerken en intelligentie. Hoewel digitale vaardighedenstudies meer variatie laten zien, hebben ze vooral betrekking op demografische (bv. leeftijd en geslacht), sociaaleconomische (bv. opleiding) en mentale of motiverende (bv. training) factoren. Factoren zoals geslacht, leeftijd en persoonlijkheid zijn meer permanent en moeilijk om rekening mee te houden in vaardighedenbeleid.

In hoofdstuk 7 wordt het meetinstrument, zoals ontwikkeld in hoofdstuk 4, gebruikt om het niveau van 21 e-eeuwse digitale vaardigheden te meten. De vragenlijst meet ook verschillende mentale (ICT-attitude, waargenomen gebruiksgemak, ICT-zelfregulatie, zelfsturend leren, doeloriëntaties, ICTtraining), persoonlijke (initiatiefrijkheid) en sociale (hulpbronnen) factoren. Het systematisch literatuuronderzoek, zoals beschreven in hoofdstuk 6, wordt gebruikt om potentiële vaardigheidsdeterminanten te selecteren die kunnen worden beïnvloed en verantwoord in vaardighedenbeleid. Wat de vaardigheidsniveaus betreft, rapporteren de respondenten vrij hoge niveaus van 21 -eeuwse digitale vaardigheden. Behalve de communicatiedimensies inhoud delen en contacten opbouwen, zijn de vaardigheidsniveaus boven gemiddeld. Prominente factoren die bijdragen aan verschillende vaardigheden zijn waargenomen gebruiksgemak, prestatiedoelgerichtheid en hulp van online internetcontacten. Bovendien is initiatiefrijkheid in het bijzonder van belang voor werknemers in loondienst, terwijl zelfsturend leren in het bijzonder van belang is voor zelfstandigen. In het algemeen wordt het niveau van elke 21 -eeuwse digitale vaardigheid verklaard door een andere set determinanten.

Hoofdstuk 8 gaat over het meten van informatie, kritisch denken, creativiteit en probleemoplossende digitale vaardigheden door middel van een prestatiemeting. Een belangrijk punt met betrekking tot de vorige hoofdstukken is de afhankelijkheid van zelfgerapporteerde onderzoeksgegevens in plaats van direct gemeten prestaties. Prestatiemetingen zijn arbeidsintensiever en moeilijker uit te voeren onder grote aantallen respondenten, maar ze vertrouwen echter wel op de voltooiing van taken om vaardigheden aan te tonen. Deze aanpak leidt tot de ontwikkeling van een authentieke prestatiemeting met gedetailleerde indicatoren per vaardigheid om de taakprestaties te beoordelen. Een belangrijke observatie is dat deelnemers de meeste moeite lijken te hebben met informatie en probleemoplossende digitale vaardigheden. Ze controleren bijvoorbeeld zelden hun antwoord op een andere website of geven meerdere oplossingen met een toelichting. Met betrekking tot kritisch denken en creatieve digitale vaardigheden zijn de observaties veelbelovender. Ze geven bijvoorbeeld argumenten voor meerdere perspectieven voorzien van bewijs of voorbeelden en zijn in staat om een groot aantal bruikbare ideeën te genereren. In het algemeen leggen de observaties gedetailleerde vaardigheidsindicatoren bloot om een diepere analyse te bieden van de digitale vaardigheidsniveaus van werkende professionals.

Hoofdstuk 9 gaat in op hoe organisaties binnen de creatieve industrie de ontwikkeling van vaardigheden ondersteunen. Door middel van diepteinterviews met managers uit de top van organisaties biedt deze studie een diepere analyse van vaardigheidsniveaus en de rollen van zowel de individuele werknemer als de organisatie bij de ontwikkeling van 21e-eeuwse digitale vaardigheden. De resultaten laten zien dat managers vaak geen rekening lijken te houden met de 21e-eeuwse digitale vaardigheden zoals voorgesteld in dit proefschrift. Managers lijken te geloven dat de technische vaardigheidsniveaus van werknemers vanzelfsprekend hoog zijn, terwijl digitale vaardigheden misschien wel aandacht behoeven wanneer inhoudelijke vaardigheden in overweging worden genomen. In dit geval moet de eerste prioriteit zijn om het 
bewustzijn van de 21e-eeuwse digitale vaardigheden binnen het management van een organisatie te vergroten. Daarna zijn bewuste en structurele inspanningen van individuele werknemers en organisaties nodig om het leren en ontwikkelen van vaardigheden op de werkplek te verbeteren.

Concluderend biedt dit proefschrift een interdisciplinaire conceptuele en operationele uitwerking van verschillende $21 \mathrm{e}$-eeuwse digitale vaardigheden en de mogelijke oorzaken op het niveau van de individuele werknemer. De betekenis van 21e-eeuwse digitale vaardigheden wordt aangetoond door meerdere onderzoeksmethodes toe te passen. Om 21e-eeuwse digitale vaardigheden verder te versterken, verdient het de voorkeur om eerst het bewustzijn te vergroten voordat wordt geprobeerd de praktijk te hervormen. Dit proefschrift laat zien dat het overkoepelende doel van vaardighedenbeleid moet zijn om een breed digitaal geschoold personeelsbestand te creëren. De betrokken belanghebbenden (bv. onderwijs, industrie en individuele werknemers) hebben allemaal hun verantwoordelijkheid en moeten de oproep tot actie aangaan om aan de eisen van de arbeidsmarkt te voldoen. 


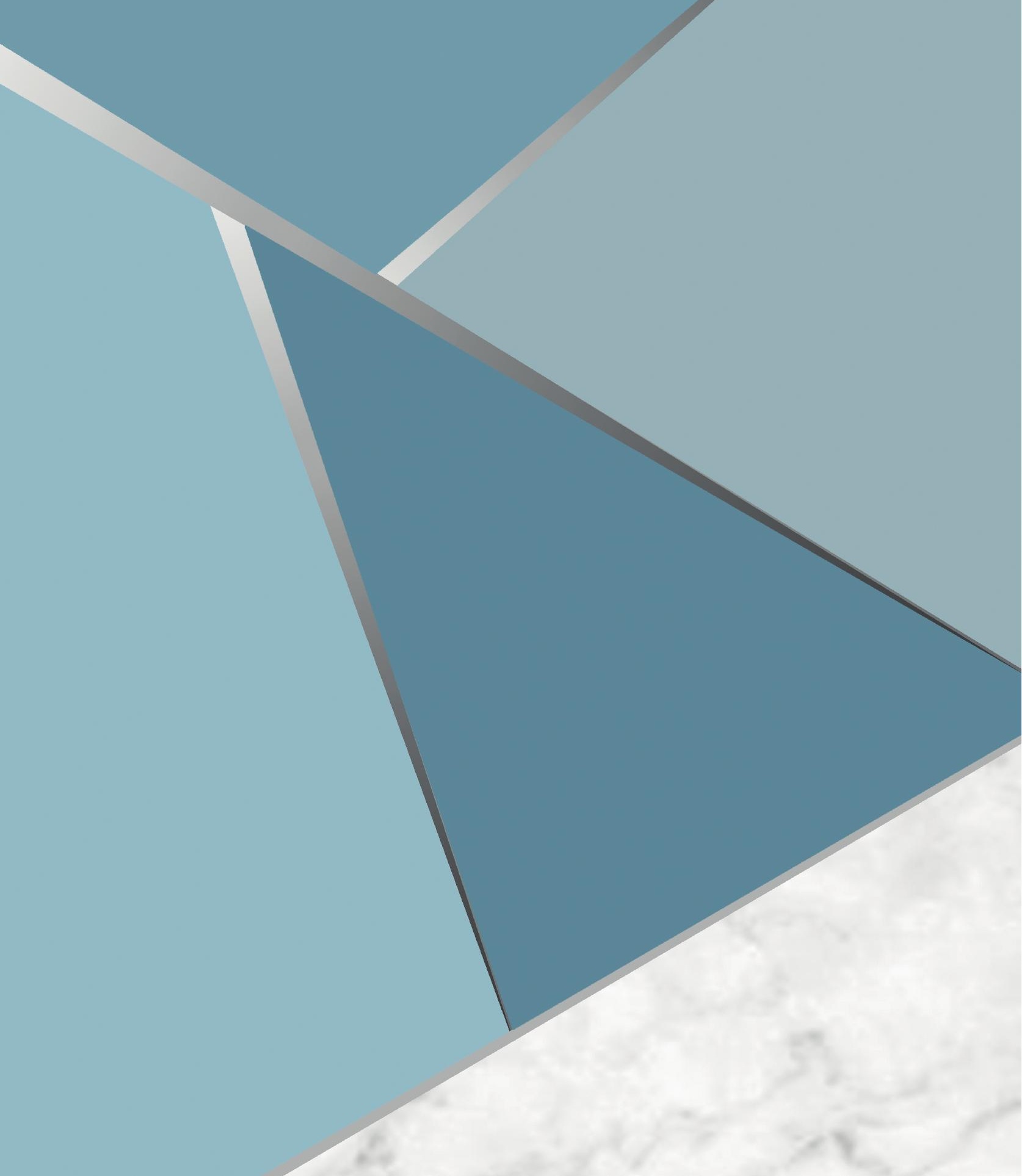

